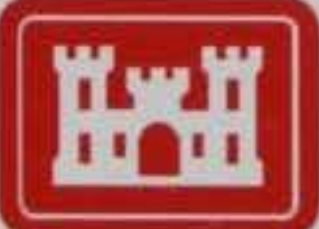

US Army Corps of Engineers 。 Engineer Research and Development Center

\title{
An Environmental Distress Prediction Model for Flexible Army Airfield Pavements
}

William Patrick Grogan

August 2000

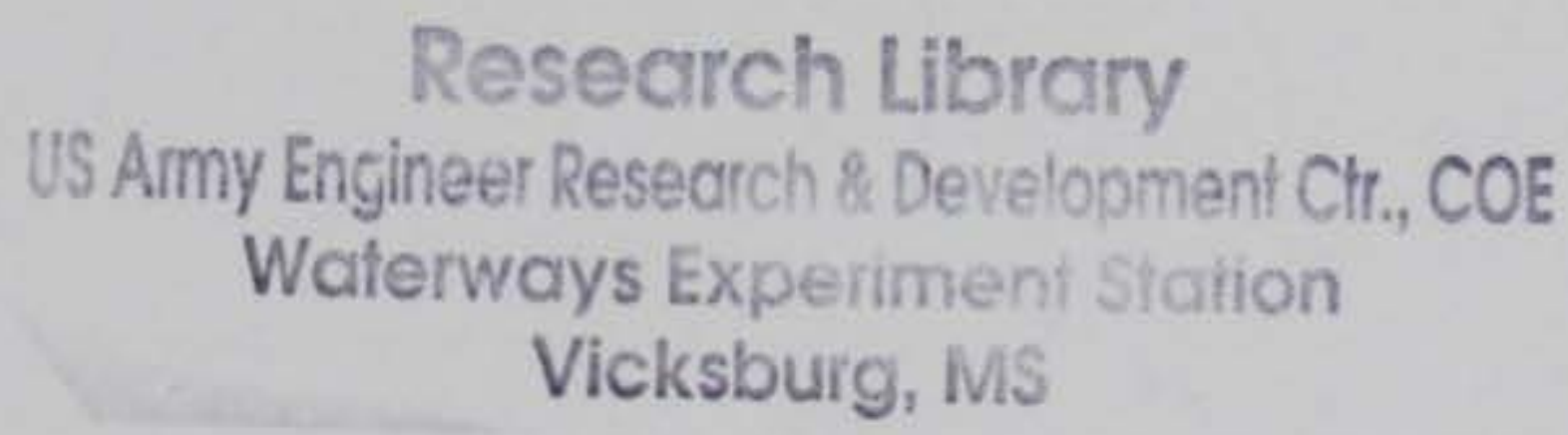

Approved for public release; distribution is unlimited. 


\section{An Environmental Distress Prediction Model for Flexible Army Airfield Pavements}

by William Patrick Grogan

Geotechnical Laboratory

U.S. Army Engineer Research and Development Center

3909 Halls Ferry Road

Vicksburg, MS 39180-6199

Final report

Approved for public release; distribution is limited

Prepared for

U.S. Army Corps of Engineers

Research, Development, Testing, and Evaluation Program 


\section{Engineer Research and Development Center Cataloging-in-Publication Data}

\section{Grogan, William P.}

An environmental distress prediction model for flexible army airfield pavements / by William Patrick Grogan ; prepared for U.S. Army Corps of Engineers.

283 p. : ill. ; $28 \mathrm{~cm}$. -- (ERDC/GL ; TR-00-6)

Includes bibliographic references.

1. Runways (Aeronautics) -- Performance -- Evaluation. 2. Runways (Aeronautics) -- Maintenance and repair. 3. Pavements, Flexible -- Evaluation. 4. Strains and stresses. I. United States. Army. Corps of Engineers. II. U.S. Army Engineer Research and Development Center. III. Geotechnical Laboratory (U.S.) IV.Title. V. Series: ERDC/GL TR ; 00-6.

TA7 E8 no.ERDC/GL TR-00-6 


\section{PREFACE}

The research reported herein was sponsored by the U.S. Army Corps of Engineers through the Research, Development, Testing, and Evaluation (RDT\&E) Program. This research was conducted by the U.S. Army Engineer Research and Development Center (ERDC), Geotechnical Laboratory (GL), Airfields and Pavements Division (APD), Vicksburg, MS.

The study was conducted under the general supervision of Dr. Michael J. O'Connor, Director, GL, Dr. W. F. Marcuson III, former Director, GL, and Dr. David W. Pittman, Chief, APD. Technical Direction was provided by Dr. Roger E. Smith, Associate Professor, Texas A\&M University. Dr. Robert L. Lytton, Professor, Texas A\&M University, provided much insight and technical guidance in the analysis and explanation of data trends. Dr. Reed B. Freeman, APD, provided support and technical guidance on the reduction and interpretation of data. Dr. William P. Grogan was the project principal investigator and author of this report. This report was submitted by Dr. Grogan to and accepted by the Graduate School, Texas A\&M University, in partial fulfillment of the requirements for the degree of Doctor of Philosophy.

At the time of publication of this report, Director of ERDC was Dr. James R. Houston, and Commander was COL James S. Weller, EN.

The contents of this report are not to be used for advertising, publication, or promotional purposes. Citation of trade names does not constitute an official endorsement of the use of such commercial products. 
TABLE OF CONTENTS

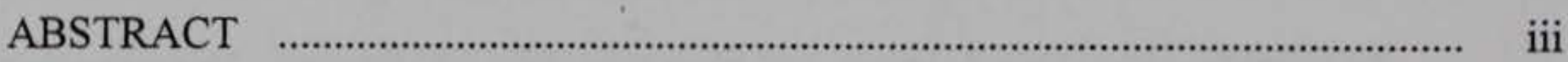

TABLE OF CONTENTS ................................................................................. iv

LIST OF FIGURES ...................................................................................... vii

LIST OF TABLES …….............................................................................. viii

\section{CHAPTER}

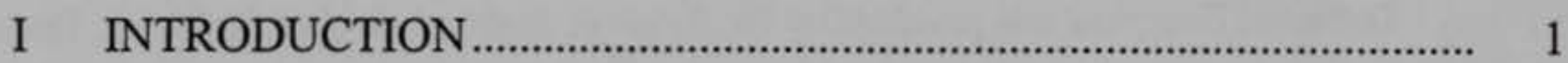

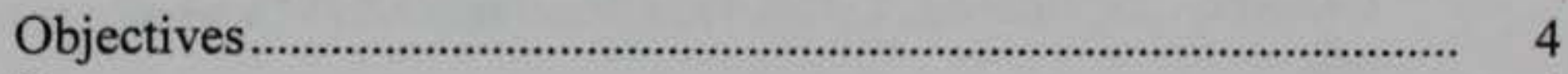

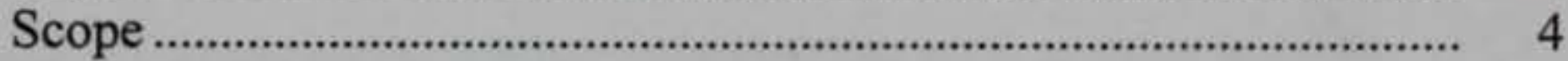

Dissertation Format ................................................................... 6

II LITERATURE REVIEW ..................................................................... 8

Literature Review ....................................................................... 11

Pavement Evaluation Concepts ................................................... 11

Pavement Performance Models................................................. 16

PCI Prediction Techniques...................................................... 16

Minnesota Prediction Model ................................................. 19

Texas Method of Determining Remaining Life ...................... 21

AASHTO Model …….......................................................... 21

Thermal Cracking Models................................................... 22

Discussion of Performance Models.................................................. 26

Block Cracking................................................................................. 29

III CORPS OF ENGINEERS PAVEMENT

EVALUATION PROCEDURE …....................................................... 34

Structural Evaluation Procedure ....................................................... 35

Surface Condition Evaluation Procedure ........................................ 38

IV DATA PRESENTATION AND ANALYSIS .......................................... 41

Evaluation Data Summary............................................................... $\quad 45$

Condition Survey Data ........................................................... 45 
CHAPTER

Construction Survey Data ......................................................... 48

Climatic Survey Data ................................................................ 48

Evaluation of Survey Data .......................................................... 51

Condition Survey Data Analysis ............................................... 54

Discussion of Data Analysis.............................................................. 59

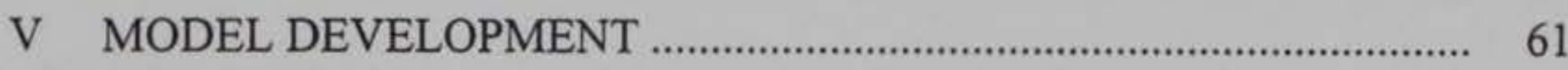

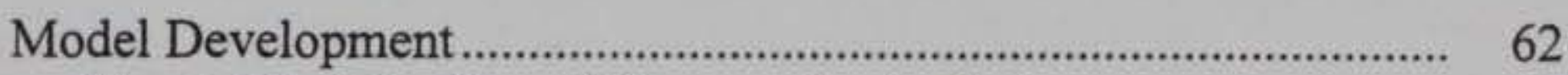

Step 1: Identification of Element for Analysis............................. 63

Step 2: Identification of Prediction Variables ................................ 63

Step 3: Identification of Performance Variable............................ 64

Step 4: Relate Independent and Dependent Variables ................. 72

Regression Analysis for Block Cracking ............................. 84

Regression Analysis for Longitudinal/Transverse Cracking... 92

Regression Analysis for Raveling/Weathering ...................... 97

Step 5: Compare Actual versus Predicted Performance ............. 100

Step 6: Calibrate Model with Field Performance......................... 106

Step 7: Establish Model Reliability............................................ 108

Time to Critical Distress Density .................................................... 114

VI SUMMARY, CONCLUSIONS AND RECOMMENDATIONS ............ 116

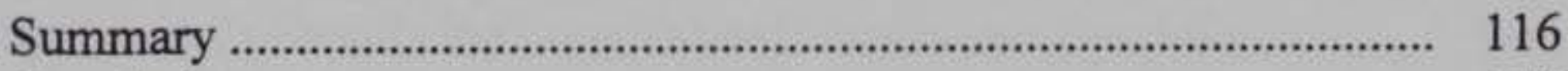

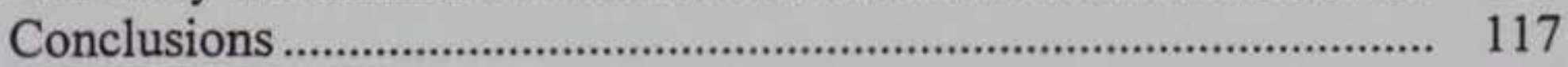

Recommendations ....................................................................... 118

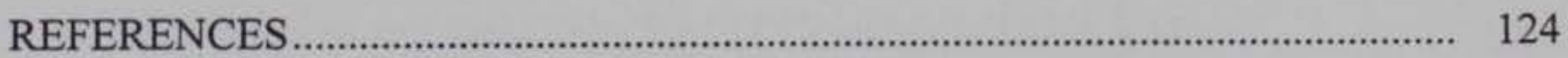

APPENDIX A: PAVEMENT CONDITION INDEX DATA …............................... 137

APPENDIX B: WEIGHTED PCI DETERMINATIONS ....................................... 175

APPENDIX C: CONSTRUCTION DATA ………............................................ 202

APPENDIX D: DISTRESS DENSITY VERSUS DEDUCT VALUE CURVES.... 218

APPENDIX E: WEIBULL DISTRIBUTION ANALYSIS ....................................... 227 
APPENDIX F: CURVE FITTING PROCEDURE.

APPENDIX G: GUMBEL PARAMETERS REGRESSION DATA …................... 256 APPENDIX H: FIELD DATA VERSUS MODEL CURVES 265 VITA 


\section{LIST OF FIGURES}

FIGURE

1 Schematic Representation of Pavement Performance.

2 Numerical PCI Value Versus Pavement Condition Rating.......................... 14

3 Deflection Response Versus Time/Performance........................................... 15

4 PCI Trend with Time........................................................................... 17

5 Performance History with Maintenance..................................................... 17

6 Location of Army Airfields and SHRP Climatic Zones............................. 44

7 Examples of Gumbel CDF Curves ( $\rho=10 ; \beta=0.5,2$, and 10 as shown)....... 72

8 Example of Field Data Plotted on Model Curves........................................ 73

9 Sensitivity Analysis Based on the Extremes of Precipitation ...................... 88

10 Sensitivity Analysis Based on the Extremes of Wind Speed ....................... 89

11 Sensitivity Analysis Based on the Extremes of Sky Cover......................... 90

12 Sensitivity Analysis Results for Longitudinal/Transverse Cracking ........... 96

13 Model Curve and Field Data for Block Cracking at Cairns AAF ................ 101

14 Model Curve and Field Data for L/T Cracking at Hood AAF ..................... 102 


\section{LIST OF TABLES}

\section{TABLE}

1 MWHGL Study PCI Results of Failed Pavement Items

2 AC Distress Types and Associated Mechanisms …..................................... 40

3 Army Airfields Evaluated .................................................................... 43

4 Summary of Weighted PCI and Weighted Distress Mechanism ................ 47

5 NOAA Weather Data ........................................................................... 50

6 Design of Experiment............................................................................ 53

7 Summary of General Linear Statistical Model Results ................................. 55

8 Summary of Significant Distress Types.................................................... 57

9 Summary of Conversion of Low and High Distress Densities to Medium Severity Level ...................................................................... 66

10 Sample of Converted PCI to Actual PCI................................................... 68

11 Results of Gumbel CDF Parameter Determinations for Block Cracking ..... 74

12 Results of Gumbel CDF Parameter Determinations for Longitudinal/Transverse Cracking

13 Results of Gumbel CDF Parameter Determinations for Raveling/Weathering ........................................................................ 76

14 Summary of Features Available for Model Development ............................. 78

15 Correlation Analysis for Block Cracking Gumbel Parameters and Independent Variables

16 Correlation Analysis for Longitudinal/Tansverse Cracking Gumbel Parameters and Independent Variables

17 Correlation Analysis for Raveling/Weathering Gumbel Parameters and Independent Variables 
TABLE

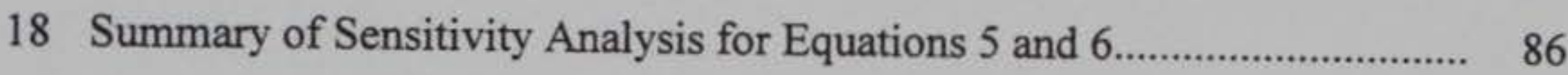

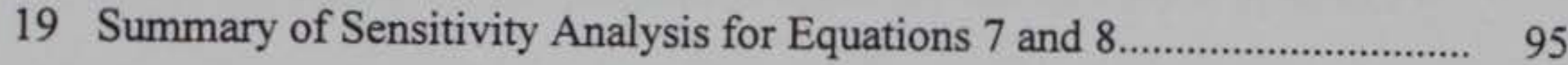

20 Comparison of Field and Model Block Cracking Distress Density Data..... 103

21 Comparison of Field and Model L/T Cracking Distress Density Data ......... 104

22 Summary of Monte Carlo Simulation .................................................... 113 


\section{CHAPTER I}

\section{INTRODUCTION}

Since the 1940's, the Department of the Army has sponsored programs to evaluate the condition of Army airfields. The most recent program was initiated in 1982. In the early to mid 1980 's, the advancement of nondestructive test (NDT) procedures for pavements (Green and Hall 1975, O'Brien et al 1983, Bush 1986), coupled with the development of the pavement condition index (PCI) procedure (Shahin and Kohn 1977), provided a means for evaluating airfield pavements relatively quickly and consistently. The procedures used for evaluating pavements have been continually improved through research and the application of new technology.

Airfield pavement evaluations performed by the Corps of Engineers involve one main objective (TM 5-826-2, 1990) ${ }^{1}$ : the determination of the load carrying capacity of the pavement expressed in terms of pass/load relationships. In addition, a visual survey is conducted to rate the surface condition of the pavements (TM 5-827-1, 1981).

Nondestructive testing methods are used to evaluate the structural capacity of pavements, and the $\mathrm{PCI}$ is used to rate the surface condition of pavements. The pavement evaluation

This dissertation follows the style and format of the Journal of Transportation Engineering of the American Society of Civil Engineers.

${ }^{1}$ Technical Manuals (TMs), Army Regulations (ARs) and Engineer Instructions (EIs) cited in the text are entered in the reference section under Headquarters, Department of the Army, Headquarters, Departments of the Army and Air Force or Headquarters, U.S. Army Corps of Engineers, as appropriate. 
procedure makes a separate determination of the structural evaluation and the surface condition. It has been determined that the structural capacity and PCI cannot be correlated and that both are necessary to address pavement performance (Hall 1987). Pavements with low PCI ratings may have adequate structural capacity for imposed loads; conversely, pavements with excellent surface conditions may not have adequate structural capacity for the anticipated loads.

The current Corps of Engineers method of structurally evaluating flexible pavements uses NDT equipment to obtain load-deflection data for each pavement feature (EI $02 \mathrm{C} 036$ 1997). A feature is an area of pavement of like cross section subjected to similar loads. The load-deflection data coupled with layer material properties are used to backcalculate layer moduli. The pavement system is modeled as a layered-elastic system with loads applied to the surface. The strains caused by the loading are calculated at critical points. The values of these strains are compared to empirical criteria, and a ratio of calculated to allowable values, termed the damage value, is calculated (EI $02 \mathrm{C} 036$ 1997). If the damage value exceeds one, indicating the calculated strains are greater than the allowable values, an overlay thickness is determined that will reduce the calculated strains so that the damage value will be less than or equal to one. Although inherent in the criteria is the consideration that the pavement will be able to withstand the calculated strains for a certain number of cycles, no fatigue or reduction in life is assessed to account for previous loadings of existing pavements when estimating expected performance. 
The Corps of Engineers uses the PCI procedure for visually assessing the condition of Army airfield pavement surfaces. The PCI procedure involves the inspection of portions of a pavement feature to determine the presence, severity level and quantity of surface distresses. The PCI survey results are entered into Micro PAVER, a computer program used for managing pavement information data. The results of the structural evaluation can also be entered and stored in Micro PAVER. The Micro PAVER program calculates a numerical PCI value for each feature. Micro PAVER provides a means of projecting PCI performance through the use of family performance curves (Micro PAVER ver 3.21). Currently, the airfield pavement evaluation procedure used by the Corps of Engineers does not use the PCI projection capability of Micro PAVER, nor any other condition prediction procedure. The airfield pavement evaluations report the history of pavement performance in terms of the results of the most recent past condition survey compared to the current survey.

The Corps of Engineers evaluation procedure recommends maintenance and repair procedures based on the current PCI level and the types of distresses present on individual pavement features (AR 420-70). The extent and severity of particular distress types are analyzed to determine appropriate maintenance and repair alternatives for particular pavement features. A procedure that would predict the growth of particular pavement distress types based on measurable input parameters would allow the prediction of when work might be needed if none were currently needed and provide an estimate of future work requirements and funds needed. 


\section{OBJECTIVES}

The objectives of this study are to determine the predominant distress types observed on flexible Army airfield pavements, develop a procedure for predicting the growth of individual distress types on flexible Army airfield pavements, and recommending future research areas for improving the distress growth prediction procedure developed.

\section{SCOPE}

For many years Army airfields have been periodically evaluated for structural and surface condition. The evaluation of these Army airfields in the United States and around the world has included the collection of NDT and PCI data. The large number of Army airfield evaluations should provide adequate data for developing performance curves for individual distress types. The research reported herein consists of the tasks discussed in the following paragraphs:

TASK I: Data from Army airfield evaluations and other pertinent sources were collected and organized. The Army airfield evaluation reports were studied to determine what information was available and appropriate. In addition, environmental data from the National Oceanic and Atmospheric Administration were collected to supplement the data contained in the evaluation reports. The collected data were compiled and formatted for accessibility and use in the remaining part of this study. 
Task II: The Army airfield pavement evaluation data were analyzed to determine the predominant types of distresses found on flexible Army airfield pavements. The purpose of this task was to determine the predominant distress mechanisms for investigation into causative factors. The predominant types of distress influenced the selection of predictive performance equations and appropriate independent variables.

Task III: A literature review was conducted to determine the types and applicability of existing pavement performance models. In addition, the causative factors for the most predominant distress type on Army airfield pavements were reviewed.

Task IV: An appropriate form for the performance prediction equation was selected. The performance of pavements, in terms of distress development, generally follows a similar pattern, and this was exploited. The selected equation was taken from probability, which is also appropriate for defining pavement performance. The selected form of the distress development equation was used to determine performance curves for distress types on individual pavement features based on observed performance. The coefficients used to shape and scale the performance curves to fit the field data were analyzed for correlation to appropriate independent variables such as environmental data. A procedure was 
developed for determining the time to the critical level of distress density at specific levels of reliability. The critical level of distress density is defined as that level which corresponds to the minimum allowable PCI according to Army Regulation 420-70.

TASK V: Areas of future research for improving the prediction technique developed were recommended.

\section{DISSERTATION FORMAT}

The findings and results of this investigation are presented in the following manner:

Chapter II: The introduction to Chapter II presents a discussion of the initial objective of this study and why it had to be redirected. In addition, a review of pavement evaluation concepts, structural and condition evaluation procedures used by others, the condition prediction method used in Micro PAVER, thermal cracking models, and the causative factors for block cracking are presented.

Chapter III: This chapter reviews the current Corps of Engineers procedure for conducting Army airfield pavement evaluations. Included is a detailed 
discussion of the PCI survey and data analysis procedure and the nondestructive pavement testing and data analysis procedure.

Chapter IV: This chapter presents a summary of data obtained from the Army airfield pavement evaluation program. The data includes $\mathrm{PCI}$ results, physical property data, and climatic data from 16 Army airfields. In addition, an analysis is presented of the survey data in terms of defining predominant distress types. A discussion of the data analysis provides the reasoning for the prediction technique developed in Chapter V.

Chapter V: This chapter presents the model development for predicting the growth of individual distress types. The model development includes a presentation of the selected form of equation for describing the growth of individual distress type densities, the determination of associated shape and scale parameters, the correlation of the parameters to appropriate prediction variables, such as environmental data, and the application of a reliability analysis.

Chapter VI: This chapter contains the summary, conclusions, and recommendations for future research. 


\section{CHAPTER II}

\section{LITERATURE REVIEW}

The initial direction of this research effort was aimed at developing a technique for better predicting the structural performance of flexible Army airfield pavements. Based on the initial analysis of the data available and the structural performance of flexible Army airfield pavements, it became evident that this goal would not be attainable. Flexible Army airfield pavements rarely fail structurally as found in the Army airfield evaluation reports reviewed. In order to verify this, a review of photographs from the report detailing the test sections used to establish the structural criteria were used to estimate PCI values at time of failure. The results revealed that the PCIs of most sections at structural failure would have been, on a scale from 0 to 100 , in the single digit range (Burns et al 1971). Table 1 provides a summary of the test section PCIs based on a review of the photographs from the multiple-wheel heavy gear load (MWHGL) pavement tests (Burns et al 1971). Two of the test sections (item 1 lane 2 and item 2 lane 2) had a PCI of 33, but this was because rutting could not be verified due to the lack of a straight edge in the photographs. It is believed that these sections did have rutting, and if so, their PCIs would have also been in the single digits. 
TABLE 1. MWHGL Study PCI Results of Failed Pavement Items

\begin{tabular}{c|c|c}
\hline $\begin{array}{c}\text { Item } \\
(1)\end{array}$ & $\begin{array}{c}\text { Lane } \\
(2)\end{array}$ & $\begin{array}{c}\mathrm{PCl} \\
(3)\end{array}$ \\
\hline 1 & 1 & 2 \\
1 & 2 & 33 \\
2 & 2 & 33 \\
1 & $2 \mathrm{~A}$ & 8 \\
2 & $2 \mathrm{~A}$ & 0 \\
3 & $3 \mathrm{~B}$ & 0 \\
4 & $3 \mathrm{~B}$ & 6 \\
5 & $3 \mathrm{~B}$ & 0 \\
2 & 1 & 3 \\
\hline
\end{tabular}

The Army requires that all active airfield pavements be maintained at or above a minimum PCI level (65-75 for runways and primary taxiways and 40-55 for secondary taxiways and aprons)(AR 420-70). This policy precludes most pavements from reaching a state of structural failure according to the established failure criteria. Most flexible military airfield pavements have been maintained at or above the minimum PCI level required as found in the Army airfield reports reviewed. In fact, no pavements in active use were found to have a PCI at as low a level as the structurally failed pavement items observed in the MWHGL report. 
Additional problems frustrating the attempt to develop a structural performance model involved the construction history records and traffic data records. Both of these items were suspect in terms of their accuracy for most of the airfields reviewed. The construction history records did not coincide with measured pavement thicknesses. The traffic records obtained from the airfield operations office generally indicated levels of operations well in excess of the levels observed by the evaluation crews. Traffic data and construction history are essential for determining the fatigue life and structural capacity of a pavement.

In addition to the previously stated difficulties with developing a structural performance model, the majority of the distress types observed on the Army airfield pavements were attributed to environmental causes. Not only had few pavements failed structurally, the distress types observed were not structural in nature. The predominant distress type observed on the majority of the airfields reviewed was block cracking, which is considered an environmental distress commonly attributed to a type of thermal cracking (Shahin and Kohn 1981). A summary of the distress data is presented in Appendix A.

Since the data obtained through the Army airfield pavement evaluation program would not support the development of a structural performance model, and the need for a structural performance model was determined to be minimal, the research was redirected toward developing a surface condition prediction technique. Currently, the Corps of 
Engineers pavement evaluation procedure uses no technique for predicting the future performance or fund needs of airfield pavements. The pavement evaluation report either identifies the pavement as needing work or not needing work; it does not say when work will be required in the future. A surface condition prediction procedure could be used to estimate when the PCI would be expected to reach a level requiring the expenditure of funds. The level of PCI that would require the expenditure of funds is generally the minimum level of PCI at which airfield pavements must be maintained which is established by the Army (AR 420-70). This condition prediction tool could be used by installations to justify funding requests to insure funds would be available when the pavement condition reaches the minimum established level.

\section{LITERATURE REVIEW}

The remaining portion of this chapter briefly reviews some pavement evaluation concepts, pavement performance prediction techniques, thermal cracking models, and block cracking causes.

\section{Pavement Evaluation Concepts}

Figure 1 schematically illustrates the serviceability of a pavement as a function of time (Ullidtz 1987). Serviceability is a point-in-time measurement of how well a pavement is serving its intended function. Performance can be defined as the time history of serviceability and is represented by the curve in Figure 1 (Ullidtz 1987). 


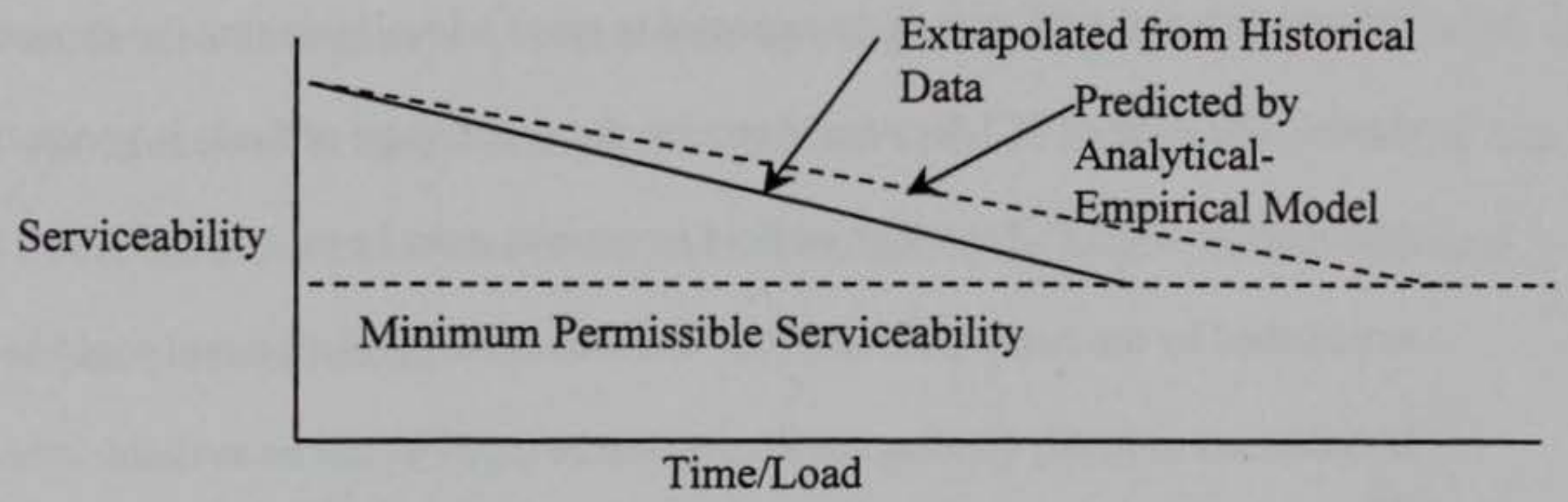

FIG 1. Schematic Representation of Pavement Performance

(Note: The curve above is represented by a straight line, however many models use a sigmoidal or " $\mathrm{s}$ " shaped curve for modeling performance (Smith 1993).)

The AASHTO pavement design guide uses the concept of present serviceability index (PSI) as the performance variable upon which the design is based (AASHTO 1993). The concept of serviceability was developed at the AASHO road test. The PSI is determined by measurements of roughness and distress. The PSI ranges in value from zero to five. The guide is concerned with functional and structural performance. Functional performance is a measure of how well the pavement is serving the user, and structural performance relates to the physical condition of the pavement (AASHTO 1993). 
An adequately designed new pavement should begin with a high level of serviceability and should give satisfactory performance for the design life as long as routine maintenance is provided. The level of serviceability will decrease as traffic and environmental effects cause distresses to develop with usage and exposure to the environment.

The pavement condition index $(\mathrm{PCI})$ survey procedure was developed by the Corps of Engineers to assess the surface condition of a pavement with a numerical rating (Shahin and Kohn 1979). The PCI survey is a visual inspection of the airfield pavements to determine the present surface condition (TM 5-826-6 1989). The condition survey procedure requires the inspection of portions of the surface of a pavement feature. The survey team records distress types, severity levels, and quantities. The PCI of a feature is based on the survey results. The PCI is a numerical indicator based on a scale from 100 to 0 . Pavement condition ratings (from excellent to failed) are assigned to different levels of PCI values. These ratings and their respective $\mathrm{PCI}$ value definitions are shown in Figure 2.

Pavement deflection response under loads has been related to performance (Joseph 1971, Hveem 1955), and deflection measurements with the falling weight deflectometer (FWD) are routinely used to evaluate pavement structural capacity (TM 5826-5 1993). However, the elastic (rebound) deflection is nearly constant for much of the pavement life (except for seasonal effects of moisture and temperature variations) as 
indicated by Figure 3 (Moore et al 1978). Figure 3 implies that the deflection assessment of structural capacity alone cannot differentiate the pavement age or amount of structural life that has been depleted.

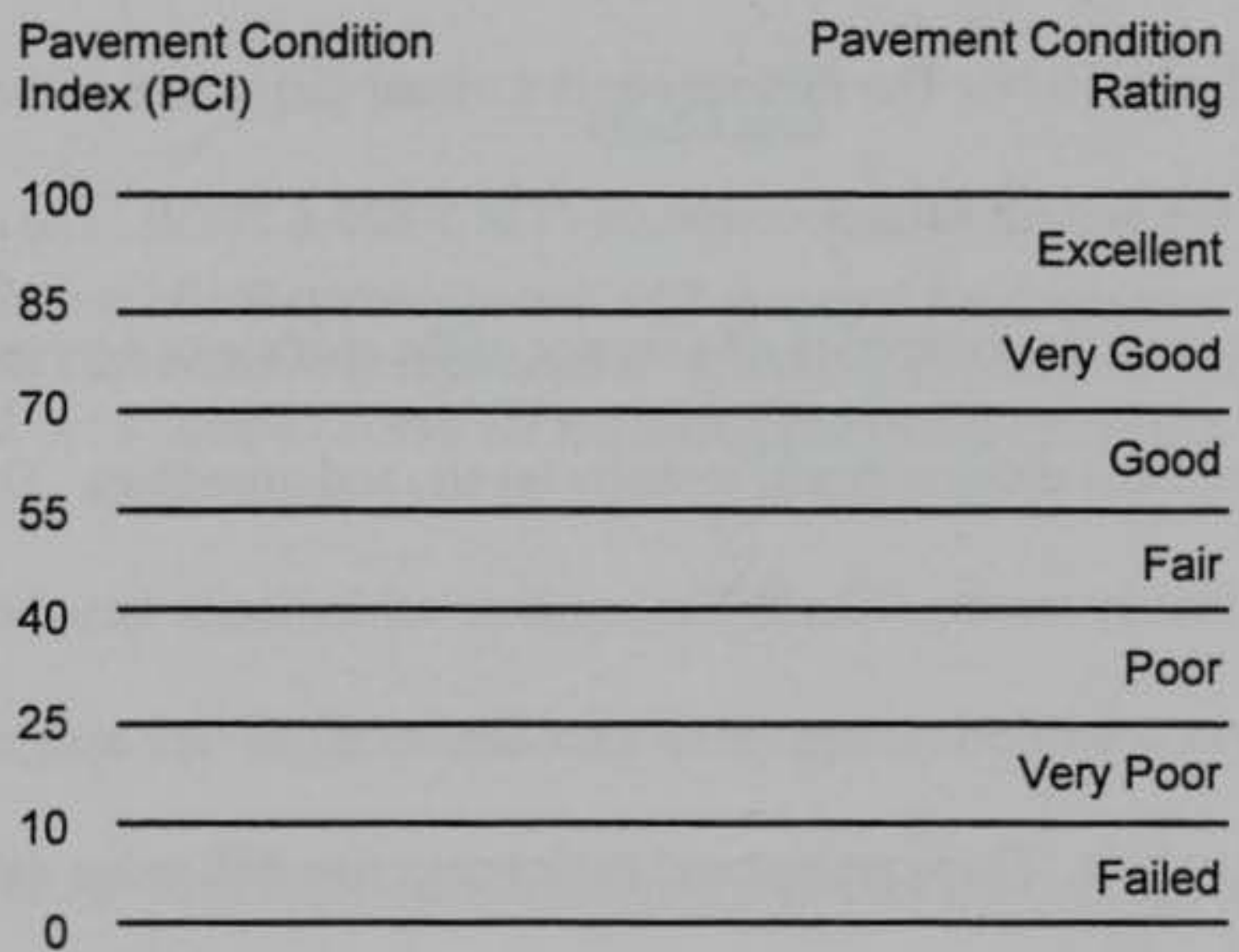

FIG 2. Numerical PCI Values Versus Pavement Condition Rating 


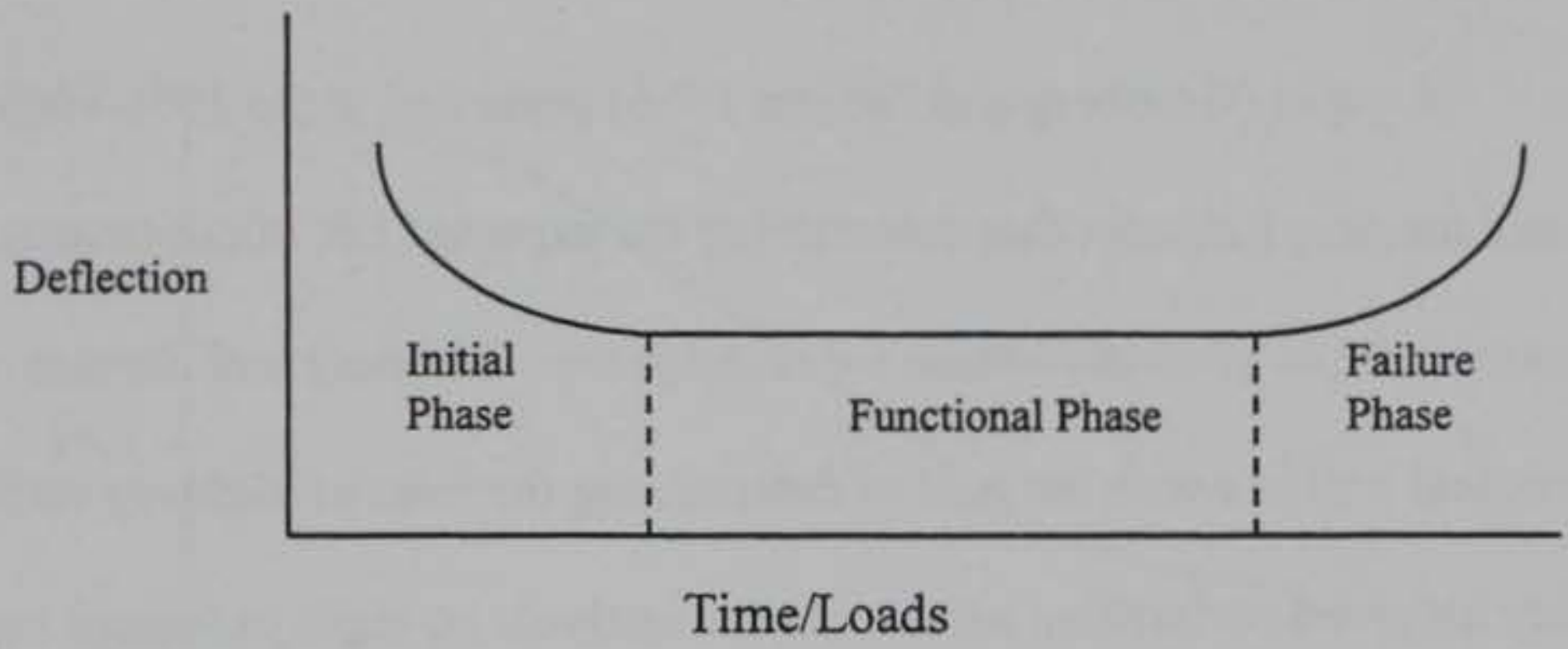

FIG 3. Deflection Response Versus Time/Performance

Pavement evaluation concepts are used as tools to measure the performance of pavements. The evaluation concepts are used in pavement performance models that predict the future condition of pavements. Knowledge of the future condition provides the owning agency with information for estimating the type of work that will be required and the funds that will be needed to maintain their pavements at a level deemed appropriate over some selected analysis period. Pavement performance prediction models can provide information at both the network level and project level for pavement management. Network level models are less detailed than project level models.

Network level models are used for the selection of treatment strategies; size, weight and cost allocation studies; and trade-off analyses between costs, maintenance and damage (Lytton 1987). Project level models are used for pavement design and analysis, and lifecycle cost analyses of alternative designs (Lytton 1987). 


\section{Pavement Performance Models}

A paper (Gronberg and Blosser 1956) presented at the 1956 Highway Research Board meeting indicates that determining the expected life of pavements has been an important topic of consideration for many years. Gronberg and Blosser performed a statistical analysis with the goal of determining the lives of highway surfaces. Their study involved performing survivor curve analyses on eight pavement surface types. The survivor curve analyses calculated the average pavement life of each pavement type using a definition of average service life as the time after construction that the surface remained in service prior to being replaced, resurfaced, reconstructed, or otherwise taken out of service. From this study, remaining service life was predicted in terms of years, based on the age of the pavement and the projected life of the pavement type.

PCI Prediction Techniques

A great deal of research has been conducted in projecting pavement performance as defined in terms of the PCI (Shahin and Becker 1985, Shahin 1982, Shahin and Rozanski 1977). The performance history of PCI over the life of a pavement generally follows a trend as represented by a sigmoidal shaped curve shown in Figure 4 (Smith et al 1987). If maintenance or repair is performed on the pavement over its life, there is generally an increase in PCI. Following the increase in PCI, the performance history continues along a new curve which is often similar to the initial curve as shown in Figure 5 (Smith et al 1987). 


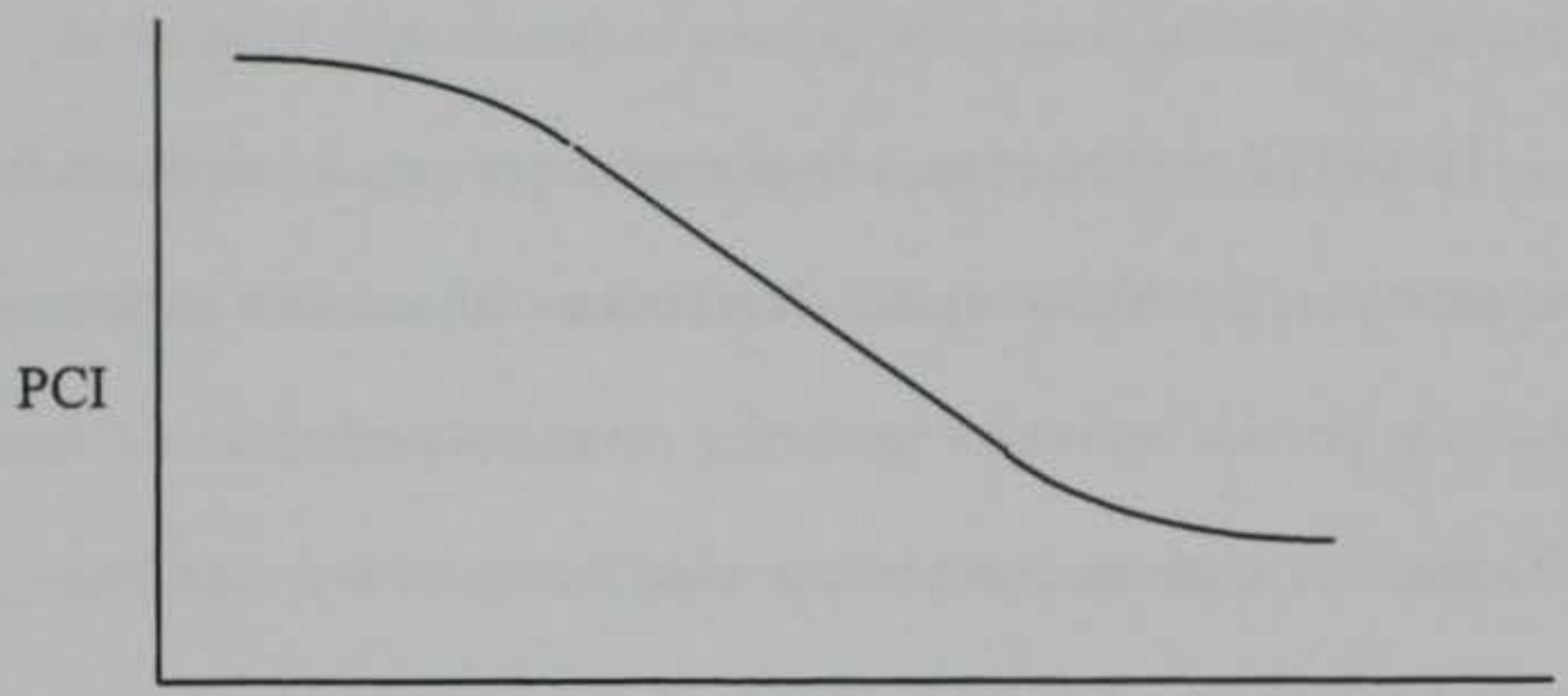

Time/Loads

FIG 4. PCI Trend with Time

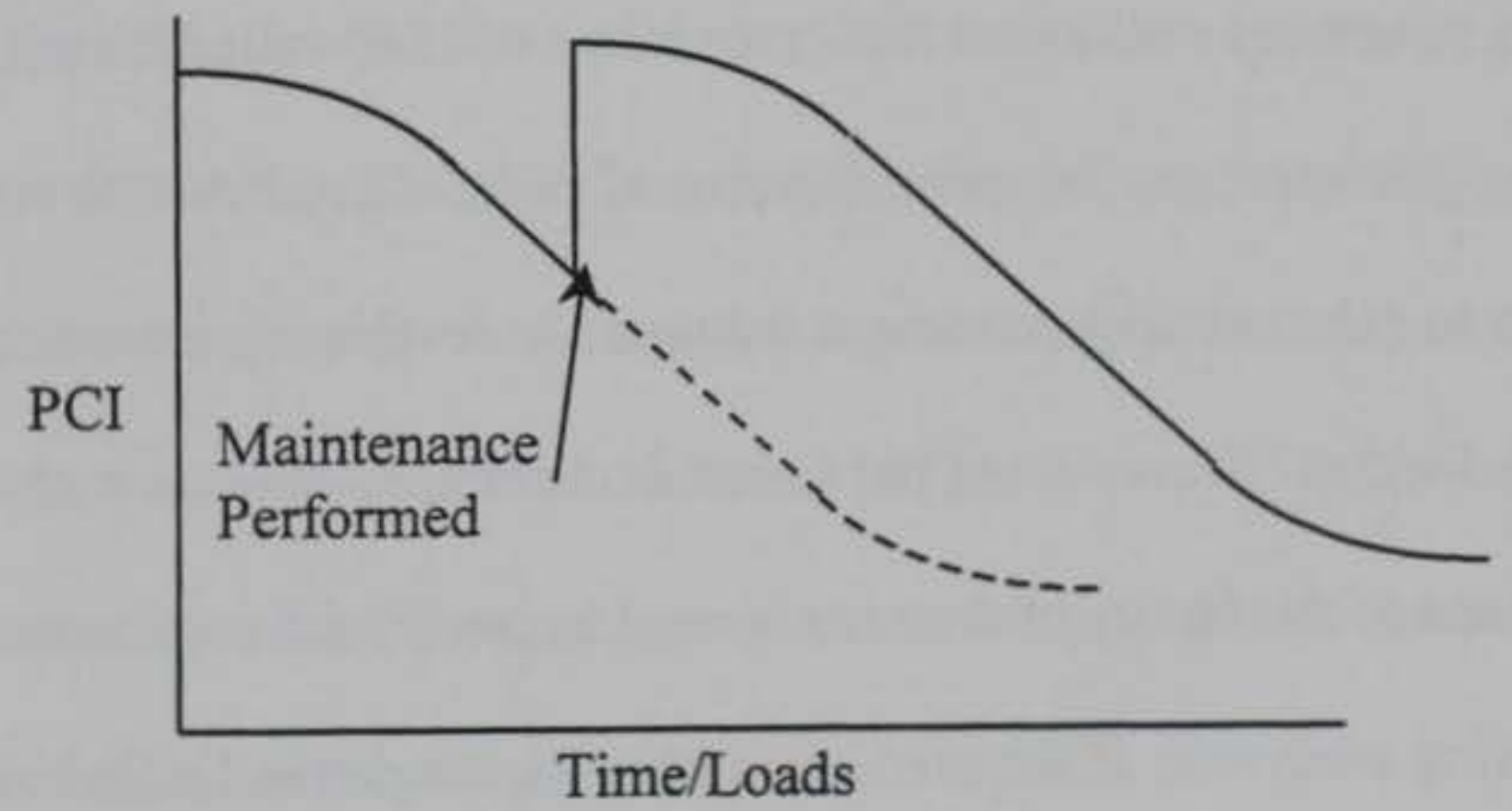

FIG 5. Performance History with Maintenance 
Initial PCI prediction models grouped large quantities of data for different pavement types (flexible, or rigid). Regression analyses were performed on the large databases to provide curves for predicting pavement performance (Nunez and Shahin 1986). More sophisticated procedures using family curves, data filtering, and curve fitting techniques have also been developed and applied to predicting pavement performance (Shahin et al 1987). The underlying basis for many PCI prediction models are regression equations developed from the analysis of large databases containing information on the past performance of similar pavement types.

Micro PAVER, the pavement database manager used by the Army for storing and analyzing pavement evaluation data, provides a method called "family curves" for predicting pavement performance in terms of $\mathrm{PCI}$. Micro PAVER provides the user the capability to select similar pavement features for developing a prediction curve for a particular feature. The selected pavement features are considered a "family," and the performance of the family of features is used to predict the performance of the particular feature being analyzed. If the prediction time for the particular feature is beyond the data existing in the family curve, the family curve is extrapolated as a straight line with a slope equivalent to the last part of the existing curve (Micro PAVER ver 3.21). 
Minnesota Prediction Model

Many state departments of transportation have studied the performance of their pavements with the goal of predicting pavement performance. As an example, Minnesota has done much research in the area of projecting pavement performance.

In 1980, the Minnesota Department of Transportation (MinnDOT) published a report (Lukanen 1980) that calibrated and modified the AASHTO design equation for flexible pavements to the conditions that exist in Minnesota. The study resulted in a new pavement design procedure for Minnesota. The primary modification to the design equation was the incorporation of a relationship between the maximum spring time Benkleman beam deflection and the number of accumulated standard axle loads that deteriorated the pavement to a residual present serviceability rating (PSR) of 2.5. The PSR ranges from 5 to 0 . The residual PSR is the value expected at the end of the design life of the pavement. Mechanics are involved in this equation through the relationship of deflection to serviceability. Although pavement deflection has been related to pavement performance in the past (Joseph and Hall 1971, Hveem 1955), the relationship between deflection and percent life used is not clear as evidenced by an additional report for MinnDOT (Skok and Lukanen 1982).

The 1982 MinnDOT report (Skok and Lukanen 1982) states that there is no statistically significant change in deflection over time, based on a study measuring pavement deflections over a 14 year period. The purpose of the 1982 report was to 
determine the requirements needed for designing an overlay. The report found that the measured deflection of the pavement does not increase with time or increase with a rise in functionality reducing distresses, but rather increases when the section begins to fail structurally.

A further report for MinnDOT (Lukanen 1986) developed pavement life prediction models for various pavement types based on data collected on pavements from 1967 to 1984 . The study found that there were large variations in the PSR, surface rating and individual distress types; however, the study stated that the database was large enough to develop performance prediction models. Those pavements that exhibited very little decrease in PSR with time were omitted from the model development. The report also determined that the 95 percent confidence limits for the intercept, or initial PSR, of the regression equation developed for asphalt surfaced pavements was 2.75 to 4.20 . Layer thicknesses and material types were not used in the model. The pavements, for each pavement type studied, were categorized into one of nine groups. Three traffic levels (low, medium, and high) were defined and combined with three subgrade strengths (low, medium, and high) for a total of nine pavement groups. Regression analyses were run on each of the nine groups to determine the relationship between time and the parameter under consideration (PSR, surface rating, or individual distress types). 
Texas Method of Determining Remaining Life

The Texas Transportation Institute and Texas A\&M University developed a procedure for the Texas Department of Transportation to use in estimating the remaining structural life for flexible pavements (Michalak and Scullion 1995). The procedure outlined in the "Modulus 5.0: User's Manual" (Michalak and Scullion 1995) uses shape factors determined from the FWD measured deflection basin and the deflection at the seventh sensor (farthest from the loading plate) to determine strength parameters for the surface, base and subgrade of the pavement. Based on these parameters, estimates of tensile strain in the asphalt and vertical strain in the subgrade are made. These estimates are coupled with the projected traffic and existing cracking and rutting to categorize the estimated life into periods of $0-2,2-5,5-10$, or $10+$ years.

\section{AASHTO Model}

Performance models, such as the American Association of State Highway and Transportation Officials (AASHTO) Design Method (AASHTO Guide 1993), are used for projecting the functional condition of pavements. In the AASHTO design guide the desired or allowable change in the present serviceability index (PSI) is required in the design equation. The result of the AASHTO design guide is a pavement section that will experience a change in PSI only of the magnitude desired over the design life of the pavement. The AASHTO design equation is intended to consider pavement performance, traffic, roadbed soil, materials of construction, environment, drainage, reliability, life-cycle costs, and shoulder design. The guide also states that the major factors 
influencing the loss of serviceability are traffic, age, and environment. Age is indirectly incorporated in the design equation. Traffic is directly incorporated in the design equation through 18-kip equivalent-single-axle load applications. The environment is indirectly handled through the drainage coefficient incorporated in the structural number determination.

Thermal Cracking Models

Because block cracking was found to be the most predominant distress observed on Army airfield pavements, and because block cracking is generally considered a form of thermal cracking, a review of some thermal cracking models was considered appropriate.

The first thermal cracking model reviewed was developed by Shahin (Shahin 1972). This model actually consists of four models that are described as follows:

Model I - Simulation of bituminous pavement temperatures

Model II - (i) Estimation of asphalt concrete stiffness as a function of temperature and loading time

(ii) Prediction of in-service aging of asphalt

(iii) Estimation of thermal stresses

Model III - Prediction of low temperature cracking

Model IV - Prediction of thermal-fatigue cracking (Shahin 1972) 
The first distress type addressed by the model is low temperature cracking, which occurs when the tensile strength of the asphalt is exceeded by the thermally induced tensile stress. A low temperature spike or a rapid decrease in temperature may cause this type of crack. The crack is due to a one-time event. However, the asphalt concrete strength and thermally induced stresses are described in terms of a probability distribution, which results in the development of observed cracking over time (Shahin 1972).

The second distress type addressed by the model is thermal fatigue cracking which is described as being the result of daily fluctuations in temperature. The daily temperature cycling induces stresses below the ultimate tensile strength of the asphalt concrete. The damage values for each cycle are additive, and eventually the fatigue limit of the asphalt concrete is reached, causing the asphalt concrete to crack. Thermal fatigue cracking is not due to a single event; rather, it is due to a compilation of events, and the cracks develop over time (Shahin 1972).

Shahin's Model I involves an environmental model which predicts the temperature of the asphalt concrete based on material and weather data inputs. The material properties used include unit weight, thermal conductivity, specific heat and surface absorptivity. The weather data includes mean air temperature, air temperature range, mean wind velocity and solar radiation. Based on these input data, a sinusoidal model is used to predict the pavement temperature cycles through a day (Shahin 1972). 
The second model (Model II) predicts the asphalt binder stiffness, asphalt concrete stiffness, and the subsequent thermally induced stresses. The stiffness of the asphalt used in the model is determined using Van der Poel's theory (Shahin 1972). Van der Poel developed a nomograph based on experimental data and the concept that the asphalt stiffness is a function of the tensile stress divided by the total strain. In addition to the asphalt stiffness prediction using Van der Poel's nomograph, an increase in stiffness is predicted based on, and limited to: time, 1-100 months; original ring and ball temperature, $99-125^{\circ} \mathrm{F}$; and thin film oven test, $30-70$ percent. The asphalt stiffness and the environmental model are used to predict the stiffness of the asphalt concrete. Based on these stiffness properties, thermal stresses are determined. The determination of the stresses involves the development of a method for estimating the thermal loading time (since the stress is considered a function of the stiffness of the asphalt concrete and the time of loading).

In the final models (Models III and IV) a stochastic approach is used for comparing the estimated tensile strength and the thermal stress induced in the asphalt concrete. As stated previously, the low temperature cracking is attributed to a one-time event; however, the distribution in strength and induced stress is considered for describing the development of the cracking. The fatigue cracking is addressed by considering a damage concept whereby the damage is accumulated over several time periods based on the temperature cycling and the stiffness of the asphalt concrete. The 
stiffness of the asphalt increases with time, and the damage is added for each time period until it reaches a critical value and the asphalt concrete cracks. Similarly to the lowtemperature cracking, stochastic considerations are used to describe the variations in stiffness, induced strength and stress, and the resulting development of fatigue cracking over time.

A more recent thermal cracking model, which is still undergoing some development, is the SHRP thermal cracking pavement performance model (Lytton et al 1993). The SHRP model consists of two primary parts: 1) a mechanics-based model that calculates the progression of a crack at one site with average material properties, and 2) a probabilistic model that predicts the global amount of visible thermal cracking (Lytton et al 1993).

The SHRP model, similar to Shahin's model, requires the input of material and environmental data. The material inputs include data concerning the pavement structure and the pavement material properties. Material properties include creep compliance and tensile strength of the asphalt concrete (Janoo 1998). The environmental data includes temperature data, latitude of the site, wind velocity data, and sunshine data.

The SHRP environmental model is used to predict the temperature distribution in the asphalt layer. A pavement response model predicts the stress at various nodes through the pavement depth. The stress distribution is used to provide input to the 
pavement distress model. The pavement distress model uses a fracture mechanics approach to predict crack development based on the average material properties. A stochastic approach is then applied to predict the amount of cracking that will be observed, based on the average crack depth and the assumed distribution of crack depths within the asphalt concrete surface layer (Lytton et al 1993).

\section{DISCUSSION OF PERFORMANCE MODELS}

Although the prediction models presented were developed for road and highway pavements, they were reviewed to determine if the procedures used could be applied to Army airfields.

The 1950's studies for projecting pavement life were appropriate for determining what types of pavements were performing well and the life expectancy for each pavement type studied. Gronberg and Blosser provided an approximate method for estimating pavement life based on the results of thousands of miles of in-service roads. The results of these studies had limited applicability to project-level work for determining the remaining life of a particular pavement.

The PCI rating is appropriate for quantifying the overall current condition of a pavement. The PCI prediction models available in Micro PAVER are based on the performance of like pavement types. Although these models are based on the performance of like pavements, they do not consider the types of distresses nor the 
contributing factors to particular distress type development for individual pavement features. In particular, the environmental and structural loading conditions are not considered in these performance prediction models. Thus, the family curve PCI models, which do not consider any contributing factors to distress development, are severely limited in their ability to predict the performance of particular pavement features. The ability to predict the performance of individual features provides the owning agency with information on the work effort and funds required to maintain their pavements at a level deemed appropriate.

The design procedure developed for MinnDOT is a modification of the AASHTO design procedure with a calibration for the experiences in Minnesota. The intercept or initial condition of the pavements, with a 95 percent confidence level, is modeled to be between a PSR of 2.75 and 4.2. The residual PSR as defined by the design procedure is 2.5. This indicates that there is an extremely wide range for the expected initial PSR. This wide range in initial PSR indicates that some of the pavements are close to failure when constructed. Since the design equation is based solely on a regression analysis, the results are more appropriate for network level analysis. It is worth noting that those pavements that were performing well, as defined by very little decrease in PSR, were omitted from the study. If these pavements had been included in the analysis, they probably would have had an impact on the performance equations. 
The Texas evaluation procedure seems to have promise and may have provided an avenue for further study had this study not been directed away from a structural performance model. However, the concept of categorizing pavements in terms of expected performance in years (i.e. $0-2,2-5,5-10$, and 10+) is considered very appropriate for the type of predictions that would be beneficial to local Army installations.

The AASHTO design equation is the result of a regression analysis based on the AASHO road test, modified due to experience and knowledge gained since the AASHO road test. Because the design procedure is empirically based, it is not prudent to try to extend the prediction capabilities beyond the conditions that existed at the time of the road test or the conditions that have been incorporated since. As evidence of the design equation limitations, the guide instructs the designer to use local proven experience where it differs from the results of the design guide (AASHTO 1993). In addition, the AASHTO procedure was developed for highways and would be difficult to apply to airfields.

The thermal cracking models in general, and the SHRP thermal cracking model in particular, may have some promise for use in better predicting pavement performance in terms of the development of block cracking. The SHRP thermal cracking model is based in mechanics, which allows for it to be extended beyond those conditions that existed at the time of development. In addition, since the loads dealt with in the thermal 
cracking model are environmental, airfields and highways would be expected to have similar experiences. Currently, the Corps of Engineers does not collect the input parameters required for using these models. The material properties required for input to the SHRP model include at a minimum the creep compliance and tensile strength of the asphalt concrete (Janoo 1998). During airfield evaluations, the Corps of Engineers does not usually collect material samples for laboratory testing. The distress prediction model developed herein (see Chapter V) could possibly be extended to include components of the SHRP thermal cracking model if and when appropriate data are collected.

\section{BLOCK CRACKING}

The following description of block cracking was taken from the technical manual (TM 5-826-6 1989), which is used by the Corps of Engineers for conducting PCI surveys. It is appropriate to begin the discussion of block cracking by including this definition, because this is the definition used by the field crews for identifying the distress type of block cracking.

Block cracks are interconnected cracks that divide the pavement into approximately rectangular pieces. The blocks may range in size from approximately 1 by 1 foot to 10 by 10 feet. When the blocks are larger than 10 by 10 feet, they are classified as longitudinal or transverse cracking. Block cracking is caused mainly by shrinkage of the asphalt concrete and daily temperature cycling (which results in daily stress/strain cycling). It is not loadassociated. Block cracking usually indicates that the asphalt has hardened significantly. Block cracking normally occurs over a large portion of pavement area, but sometimes will occur only in nontraffic areas. This type of distress differs from alligator cracking in that alligator cracks form smaller, many sided 
pieces with sharp angles. Also, unlike block cracks, alligator cracks are caused by repeated traffic loadings, and are therefore only found in traffic areas (i.e. wheel paths). (TM 5-826-6 1989).

From the preceding definition of block cracking, it is apparent that the primary causes of block cracking are considered to be environmental and material factors. The important points to notice from the preceding definition are the effects of daily temperature cycles and the observation that the asphalt has hardened significantly. It is also important to note that block cracking is observed to occur in non-traffic areas, indicating that it is not caused by vehicular loads.

The daily temperature cycling reference in the definition of block cracking would indicate that block cracking is primarily due to thermal fatigue cracking as opposed to low temperature cracking. The fact that block cracking does not usually occur for many years, sometimes as many as ten to twenty years after construction, would support the inference that it could be considered a thermal fatigue-related problem.

The observation that the asphalt has hardened can be attributed to two phenomena, oxidative aging and molecular structuring. Because asphalt in pavements occurs as a film exposed to atmospheric oxygen, it oxidizes, resulting in the formation of polar, strongly interacting, oxygen-containing chemical functional groups. The formation of these oxygen-containing functional groups changes the viscosity of the 
asphalt, making it more brittle and leading to pavement failure in the form of cracking (Petersen 1984). Thixotropic or steric hardening are terms often used to describe the molecular structuring phenomenon found in asphalt cement. This molecular structuring behavior is one of the least understood effects because of the difficulty in measuring it. The steric hardening process is reversible through heating or continued mechanical working. In addition, the molecular structuring resulting in the structural hardening is lost during the solvent recovery of asphalt from aged pavements. The majority of the work studying this phenomenon was performed in the 1930's with some additional work being conducted in the 1950 's. One of the results from this early work indicated that structural hardening and oxidative aging may be synergistic (Petersen 1984).

The synergy of oxidative aging and molecular structuring would result in the asphalt becoming more brittle than would be expected as a result of the additive effect of each cause. This may cause the asphalt to become more susceptible to both low temperature and thermal fatigue cracking. The observation that block cracking is observed in non-traffic areas supports the idea that the molecular structuring portion of the stiffening may be significant. Because the asphalt is not mechanically worked in the non-traffic areas, the molecular structuring is allowed to develop.

In addition to the definition for block cracking, the definition for reflective cracking is given. 
This distress occurs only on pavements having an asphalt or tar surface over a portland cement concrete slab. This category does not include reflection cracking from any other type of base (i.e., cement stabilized or lime stabilized). Such cracks are listed as longitudinal and transverse cracks. Joint reflection cracking is caused mainly by movement of the PCC slab beneath the AC surface because of thermal and moisture changes. It is not load-related. However, traffic loading may cause a break down of the AC near the crack, resulting in spalling and FOD potential. If the pavement is fragmented along the crack, the crack is spalled. A knowledge of slab dimensions beneath the AC surface will help to identify these cracks. (TM 5-826-6 1989).

The definition of reflective cracking indicates that it is only found where a PCC pavement underlies the $\mathrm{AC}$ surface. However, if an $\mathrm{AC}$ surface has been placed over an old AC pavement that had block cracking, the conditions that cause reflective cracking exist. In the case of a new AC surface over an old block-cracked AC pavement, the AC overlay pavement would be expected to exhibit block cracking at a much faster rate than it would had it been a placed on a non-block-cracked pavement. Unfortunately in the model development presented in Chapter V, data did not exist describing the condition of existing pavements before overlays were applied. Therefore, those pavements that may have experienced block cracking due to underlying block-cracked pavements can not be differentiated from other pavements.

Because many of the pavements that suffer from block cracking do not receive significant usage, some agencies may not believe they need to evaluate the impact of this distress type on future performance capability. This may be a mistake for the Army 
because the Army has many pavements that receive little regular use, but would be required in case of a major deployment. The Army pavements are designed and built with consideration for deployment-level usage. Normal day-to-day operations on most Army airfields are relatively light in terms of the number of operations and load levels when compared to deployment operations. Because block cracking develops while waiting for a deployment, Army airfield pavements with block cracking may not be able to adequately support a deployment if subjected to one. The current structural evaluation procedure tests the center of blocks; the effects of the cracking are not considered. Therefore it is not known if block cracked pavements will perform adequately during a deployment. However, it can be assumed that unsealed block cracking will permit water to enter a pavement structure, and this could lead to structural weakening. The Army is expending large sums to build pavements intended to support an emergency, and block cracked pavements may not be capable of supporting a critical mission when required. 


\section{CHAPTER III}

\section{CORPS OF ENGINEERS PAVEMENT EVALUATION PROCEDURE}

The main objective of Army airfield pavement evaluations is to determine the load carrying capacity of the pavements (TM 5-826-2 1990). However, Army airfield pavement evaluation reports document both structural capacity and surface condition. Reports include allowable aircraft loads (structural capacity) and the identification of maintenance, repair and structural improvement needs for each airfield pavement feature based on the structural evaluation and the surface condition of the pavements (EI 02C036 1997, AR 420-70). The results of evaluations are used to (McCaffrey 1994):

a.) provide preliminary engineering data for pavement design,

b.) assist in identifying and forecasting maintenance and repair work, the preparation of long range work plans, and programming funds for the various work classification categories,

c.) determine type and gross weights of aircraft that can operate on a given airfield feature without causing structural damage or shortening the life of the pavement structure,

d.) determine aircraft operational constraints as a function of pavement strength and surface condition,

e.) determine the need for structural improvements to sustain current level of aircraft operations,

f.) determine the need for structural improvements to accommodate increased use of the airfield (e.g., to accommodate mobilization out loading or new aircraft mission). 
The Corps of Engineers evaluation procedure considers the structural evaluation and pavement surface condition determinations separately (Hall 1987). When determining maintenance repair and construction strategies, the Corps of Engineers procedure only uses the current PCI data unless the structural evaluation indicates a deficiency. If the structural evaluation indicates a deficiency, maintenance and repair alternatives are only suggested that will bring the pavement up to the minimum PCI value required for the pavement as defined in AR 420-72. It is expected that construction will be accomplished as soon as practical to resolve the structural deficiency problem. If the $\mathrm{PCI}$ is above the minimum value, the Corps of Engineers evaluation procedure does not attempt to predict a time to reach the critical PCI level. The critical PCI level is defined as the minimum level allowed by the Army, which is $65-75$ for runways and primary taxiways and 40 - 55 for secondary taxiways and aprons (AR 42072).

\section{STRUCTURAL EVALUATION PROCEDURE}

The Corps of Engineers structural evaluation procedure is essentially the reverse of the design procedure. In the design procedure the results obtained are the required thicknesses of the pavement layers based on aircraft load and pass level requirements (Barker and Brabston 1975). In the evaluation procedure the results are the allowable passes or the allowable load of the design aircraft based on the existing structure (EI 02C036 1997). Both the design and the evaluation procedures require the input of material properties. The design procedure assumes these material properties will be 
obtained during construction. The evaluation procedure uses inferred modulus values for the pavements layers based on nondestructive test results and environmental data. The design procedure requires the design aircraft load and pass level, which are used in conjunction with design material properties to determine a pavement thickness. A similar procedure is followed in the evaluation procedure. A design aircraft pass and load level are determined, coupled with the layer modulus values to determine a required pavement thickness. If the required thickness is less than or equal to the actual pavement thickness, the pavement is considered adequate. If the calculated thickness is greater than the actual thickness, the load and or pass level is reduced until the calculated and actual thicknesses are equal. The difference between the calculated thickness for the full load and pass level and the actual thickness for deficient pavements is reported as the overlay thickness requirement. The Corps of Engineers bases a pavement design on traffic loads estimated over a 20-year design life (EI $02 \mathrm{C} 036$ 1997).

The first step involved in conducting a nondestructive structural evaluation is to test the pavement with a device such as a falling weight deflectometer (EI $02 \mathrm{C} 036$ 1997). Currently the airfield evaluations conducted for the Army by the Corps of Engineers use either a Dynatest model 8000 falling weight deflectometer (FWD) or a Dynatest heavy falling weight deflectometer (HWD). Both the HWD and FWD operate similarly; however, the HWD is capable of applying a maximum force of approximately $224 \mathrm{kN}$ ( $50,000 \mathrm{lbs})$ while the FWD is capable of applying a maximum force of approximately $112 \mathrm{kN}(25,000 \mathrm{lbs})$. With these trailer mounted devices, a dynamic force is applied to 
the pavement surface by dropping a weight onto a set of rubber cushions. This results in an impulse loading with a 25-50 millisecond duration on an underlying circular plate 300 $\mathrm{mm}(11.8 \mathrm{in}$.) in diameter, which is in contact with the pavement. The applied force and the pavement deflections are respectively measured with load cells and velocity transducers. The drop height of the weights can be varied to produce a range of force levels. The systems are controlled with a computer that also records the output data. The recorded output data includes peak deflections computed from velocity transducers measured at the center of the load plate (D1) and at standard distances of 300 (12), 610 (24), 910 (36), 1,220 (48), 1,520 (60), and 1,830 mm (72-in.) (D2-D7) from the center of the load plate.

The NDT data are analyzed to obtain modulus values for the various layers of the pavement systems in accordance with the method described in EI $02 \mathrm{C} 036$ (EI $02 \mathrm{C} 036$ 1997). The calculation procedure involves the input of the measured deflections, layer thicknesses and material types into a layered elastic multi-layered backcalculation computer program (WESDEF) to determine the surface, base(s) and subgrade modulus values. The program determines a set of modulus values that provide the best fit between the measured (NDT) deflections and the computed (theoretical) deflections.

Once the modulus of each layer is determined, modeled loads and the layered elastic system model are used to calculate strains at critical locations. These calculated strains are compared to criteria to determine the capacity of the pavement system (EI 
02C036 1997). As stated previously, if the pavement system is deemed capable of supporting the design loads for the design life, the pavement is reported as being structurally sound and is considered capable of sustaining the design traffic for a 20 -year design life. If the pavement is determined to be deficient, an overlay thickness is calculated that will lower the calculated strains to within criteria guidelines. If this overlay is constructed, the pavement is considered capable of supporting the design traffic for the 20-year design life.

\section{SURFACE CONDITION EVALUATION PROCEDURE}

The pavement condition survey is a visual inspection of the airfield pavements to determine the present surface condition (TM 5-826-6 1989). In an airfield evaluation, the PCI and estimated distress quantities are determined for each feature (Shahin 1982) by inspecting a selected number of sample units. Sample units are subdivisions of a feature used exclusively to facilitate the inspection process by reducing the effort needed to determine distress quantities and the PCI. The sample units for AC pavement features are approximately 465 square meters. A statistical sampling technique is used to determine the number and spacing of sample units to be inspected to provide a 95 percent confidence level in the determination of the $\mathrm{PCI}$ for the entire feature. Sample units are chosen along the centerline of runways and taxiways. Aprons are divided into a grid pattern, the sample units are numbered and the statistical sampling plan indicates which samples should be surveyed. After the sample units are inspected, the mean PCI of all sample units within a feature are calculated, and the feature is rated 
as to its condition: excellent, very good, good, fair, poor, very poor, and failed. The distress information collected during an Army airfield pavement condition survey is entered in to the Micro PAVER computer program. Micro PAVER is a pavement data management tool that estimates the quantities of distress types for each feature after the field data is entered. The Micro PAVER program can be used to calculate the PCI, determine condition rating, and identify distress mechanism (load, climate, or other) causing each type of distress observed. The distress mechanism is tied to the distress type. Table 2 lists the distress mechanism associated with each distress type as defined by Micro PAVER. The mechanism termed "other" is used for distress types for which a cause is not readily apparent. Possible causes for distresses associated with the mechanism of "other" include load, climate, construction problems, or combinations of all three.

As discussed previously, Micro PAVER can be used to predict the future PCI rating of a pavement feature through the use of a family curve model. This option is not exercised in the Army airfield evaluation procedure. The family curve prediction procedure does not provide the capability to predict changes in individual distress quantities nor severities. 
TABLE 2. AC Distress Types and Associated Mechanisms

\begin{tabular}{r|r|l}
\hline \multicolumn{1}{r|}{ Distress Type } & $\begin{array}{r}\text { Numerical } \\
\text { Designation } \\
\text { (1) }\end{array}$ & Mechanism \\
Alligator Cracking & 41 & Load \\
Bleeding & 42 & Other \\
Block Cracking & 43 & Climate \\
Corrugation & 44 & Other \\
Depression & 45 & Other \\
Jet Blast & 46 & Other \\
Joint Reflection Cracking & 47 & Climate \\
Longitudinal/Transverse Cracking & 48 & Climate \\
Oil Spillage & 49 & Other \\
Patching & 50 & Other \\
Polished Aggregate & 51 & Other \\
Weathering/Raveling & 52 & Climate \\
Rutting & 53 & Load \\
Shoving & 54 & Other \\
Slippage Cracking & 55 & Other \\
Swelling & 56 & Other \\
& & \\
\hline
\end{tabular}




\section{CHAPTER IV}

\section{DATA PRESENTATION AND ANALYSIS}

The U.S. Army Engineer Waterways Experiment Station (WES) has been conducting Army airfield evaluations since the 1940's. The most recent program was initiated in 1982 under Project Operation and Maintenance, Army (O\&M, A), "Army Airfield Evaluation," to determine the physical properties, the load-carrying capacity for various aircraft, and the general condition of the pavements at major U.S. Army airfields. The results of these Army airfield evaluations are contained in Miscellaneous Paper reports published by the WES. The WES has performed 159 Army airfield evaluations during the fiscal years 1982 through 1997. Many Army airfields have been evaluated two or three times. A full evaluation includes both a visual survey and a structural survey; some evaluations involve only a visual survey. In either case, a visual survey (PCI) is always performed. During the 1982 through 1997 fiscal years (inclusive), the Army expended an average of $\$ 375,000$ per year for a total of approximately 6 million dollars to evaluate airfield pavements. In 1985, the Army spent approximately 10 million dollars on surfaced airfield pavement maintenance (Department of the Army 1985). In 1996, the total funds expended, by the Army on surfaced airfield pavement maintenance was approximately 13 million dollars (Department of the Army 1996). The average amount spent on evaluations has been approximately 3.25 percent of the annual funds expended on maintenance of military airfield pavements. 
Since 1982, Army airfields have been evaluated using the PCI procedure and the PAVER (the predecessor of Micro PAVER) or Micro PAVER data management system. The use of the PCI procedure and Micro PAVER data management system has provided for consistent collection and systematic storage of data pertaining to the surface condition of Army airfields. This facilitates the analysis of pavement performance over time. Data from these Army airfield evaluations were used for this study.

The first step in selecting a group of airfields to be included in this study was to divide the continental United States into climatic zones. The Strategic Highway Research Program (SHRP) divided the United States and Canada into four climatic zones, wet freeze, wet-no freeze, dry freeze and dry-no freeze (Simpson et al 1994). The same climatic zones were used for selecting a group of airfields for this study. Originally five airfields were selected from each of the climatic zones based on location, size and number of evaluations performed. During the reduction of data, one airfield in two of the zones and two airfields in one of the zones were determined unsuitable. Table 3 lists the airfields included in this study, the SHRP climatic zone in which they are located, their location, and the dates of their evaluations. A list of the Army airfield evaluation reports from which data were obtained for use in this study is provided in the references. Figure 6 shows the location of the airfields on a map of the continental United States, with the SHRP climatic zones delineated. 
TABLE 3. Army Airfields Evaluated

\begin{tabular}{|c|c|c|c|}
\hline \multirow{2}{*}{$\begin{array}{c}\text { SHRP } \\
\text { Climatic Zone }\end{array}$} & \multicolumn{3}{|c|}{ Army Airfield } \\
\hline & $\begin{array}{l}\text { Airfield Name } \\
\text { (2) }\end{array}$ & $\begin{array}{l}\text { Installation Name and } \\
\text { Location } \\
\text { (3) }\end{array}$ & $\begin{array}{c}\text { Dates of } \\
\text { Evaluation* } \\
(4)\end{array}$ \\
\hline \multirow{5}{*}{ Wet Freeze } & Forney & Ft. Leonard Wood, MO & $\begin{array}{c}\text { May- } 86, \text { May-92 } \\
\text { May-96C }\end{array}$ \\
\hline & McCoy & Ft. McCoy, WI & Aug- 85 , May- 93 \\
\hline & Muir & Ft. Indian Town Gap, PA & Apr-87, Nov-93 \\
\hline & Phillips & Aberdeen PG, MD & Jul-86, Oct-93 \\
\hline & Wheeler-Sack & Ft. Drum, NY & Aug- 85 , Oct-93 \\
\hline \multirow{4}{*}{$\begin{array}{l}\text { Wet-No } \\
\text { Freeze }\end{array}$} & Cairns & Ft. Rucker, AL & Jun-85, Sep-89C, Mar-92 \\
\hline & Hunter & Ft. Stewart, GA & Jul-82, Jul-86C, Nov-93 \\
\hline & Redstone & Redstone Arsenal, AL & Apr-87, Nov-93 \\
\hline & Simmons & Ft. Bragg, NC & Jun-85, Sep-89C, Nov-93 \\
\hline \multirow{3}{*}{ Dry Freeze } & Butts & Ft. Carson, CO & Apr-84, Apr-89C, May-93 \\
\hline & Marshall & Ft. Riley, KS & Sep-83, Sep-87C, Mar-94 \\
\hline & Selah & Yakima TC, WA & Oct-85, Apr-94 \\
\hline \multirow{4}{*}{$\begin{array}{l}\text { Dry-No } \\
\text { Freeze }\end{array}$} & Biggs & Ft. Bliss, TX & Mar-84, Aug-89C, Mar-92 \\
\hline & Hood & Ft. Hood, Tx & Mar-84, Jun-88C, Dec-93 \\
\hline & Libby & Ft. Huachuca, AZ & Mar-87, Mar-95 \\
\hline & Los Alamitos & Los Alamitos, CA & Feb-85, Jun-90, Feb-93 \\
\hline
\end{tabular}

"Note: Those dates followed by a " $\mathrm{C}$ " indicate that only a visual condition survey was performed; no structural evaluation was performed for that evaluation. 


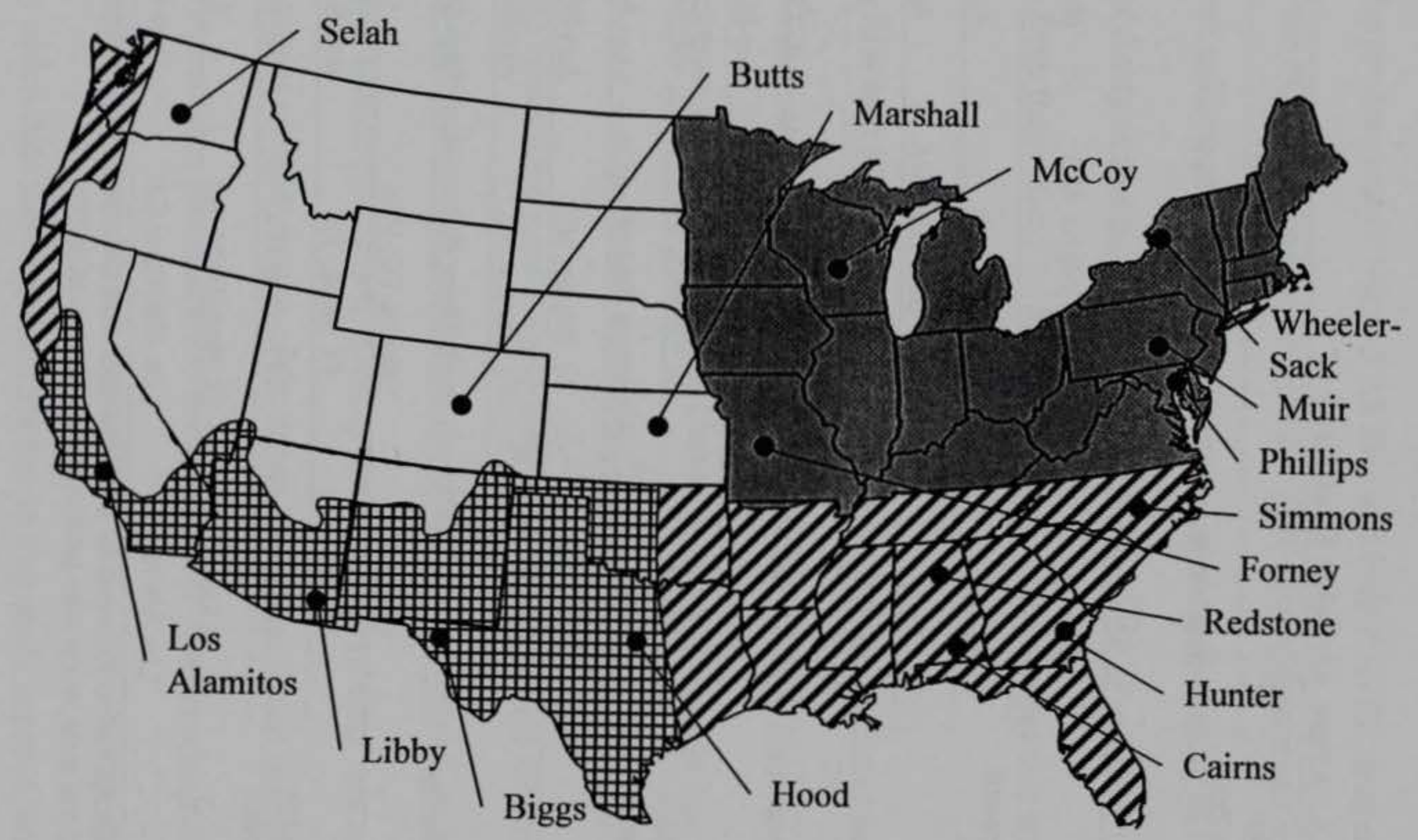

D- Wet No Freeze $\square$ - Wet Freeze 妌- Dry No Freeze $\square$ - Dry Freeze

FIG 6. Location of Army Airfields and SHRP Climatic Zones 


\section{EVALUATION DATA SUMMARY}

The following paragraphs present a summary of the data contained in the evaluation reports that were included in this study.

\section{Condition Survey Data}

The data from the condition surveys for all the asphalt concrete (AC) pavement features at each airfield were compiled in spreadsheet format for data analysis purposes. Appendix A contains tables listing the distress data for each feature at all airfields included in this study. In order to summarize the data, a weighted PCI for each airfield was determined. The weighted PCI required that each feature PCI be adjusted by multiplying the $\mathrm{PCI}$ of the feature by a ratio of the area of that feature to the total area of AC pavements surveyed at the airfield. The weighted PCI for an airfield was then calculated as the sum of all adjusted feature PCIs (see Equation 1).

$$
\text { Weighted Airfield PCI }=\sum_{\mathrm{AF}}\left[\mathrm{PCI}_{\mathrm{F}}\left(\text { Area }_{\mathrm{F}} / \sum_{\mathrm{A}} \text { Area }_{\mathrm{F}}\right)\right]
$$

Where:

$\Sigma_{\mathrm{AF}}=$ Sum of the individual feature PCI weights for the entire airfield

$\mathrm{PCI}_{\mathrm{F}}=$ The $\mathrm{PCI}$ for a particular feature

Area $_{\mathrm{F}}=$ The area of a particular feature

$\Sigma_{\mathrm{A}}$ Area $_{\mathrm{F}}=$ The sum of areas of all the features for an airfield 
A weighted PCI was used so that a small feature would not influence the overall PCI to the same degree as a large feature, which would be the case if a simple average of the PCI values of all the features of an airfield were determined. Appendix B contains tables with the PCI and weighted PCI for every feature and airfield, respectively, for each evaluation included in this study. Similarly, weighted distress type mechanisms were determined for each airfield to give an overall percentage of distress attributable to the three distress mechanism types. Instead of using $\mathrm{PCI}_{\mathrm{F}}$ in equation 1 , the percentage of distress type mechanism was used, resulting in a weighted percentage of distress type mechanism for an airfield. The three distress mechanisms are as defined in Micro PAVER (climate, load, and other) and shown in Table 2. For some of the airfields, the sum total of percentage of distress type mechanism does not equal 100. This is because if a feature had a PCI of 100 , it had no distress mechanism, but it was included in the weighted PCI average and the weighted distress mechanism type determination. The percent distress mechanisms for the distress types observed on each feature are presented in the tables in Appendix A. Table 4 lists the average weighted $\mathrm{PCI}$ and distress mechanism type for each airfield included in this study. 
TABLE 4. Summary of Weighted PCI and Weighted Distress Mechanism Airfield Survey Date Weighted PCl

Distress Mechanism

\begin{tabular}{|c|c|c|c|c|c|}
\hline (1) & (2) & (3) & $\begin{array}{l}\text { Load } \\
\text { (4) }\end{array}$ & $\begin{array}{c}\text { Climate } \\
(5)\end{array}$ & $\begin{array}{l}\text { Other } \\
(6)\end{array}$ \\
\hline \multirow[t]{3}{*}{ Biggs } & 1992 & 30 & 0 & 100 & 0 \\
\hline & 1989 & 31 & 0 & 100 & 0 \\
\hline & 1984 & 50 & 3 & 93 & 4 \\
\hline \multirow[t]{3}{*}{ Butts } & 1993 & 36 & 12 & 88 & 0 \\
\hline & 1989 & 40 & 3 & 97 & 0 \\
\hline & 1984 & 80 & 10 & 90 & 0 \\
\hline \multirow[t]{3}{*}{ Cairns } & 1992 & 65 & 1 & 96 & 3 \\
\hline & 1989 & 59 & 6 & 85 & 9 \\
\hline & 1985 & 81 & 7 & 84 & 5 \\
\hline \multirow[t]{3}{*}{ Forney } & 1996 & 33 & 34 & 64 & 2 \\
\hline & 1992 & 64 & 0 & 100 & 0 \\
\hline & 1986 & 66 & 5 & 95 & 0 \\
\hline \multirow[t]{3}{*}{ Hood } & 1993 & 73 & 7 & 89 & 1 \\
\hline & 1988 & 79 & 2 & 87 & 1 \\
\hline & 1984 & 84 & 0 & 60 & 3 \\
\hline \multirow[t]{3}{*}{ Hunter } & 1993 & 75 & 2 & 95 & 3 \\
\hline & 1986 & 88 & 2 & 89 & 4 \\
\hline & 1982 & 74 & 0 & 90 & 5 \\
\hline \multirow[t]{2}{*}{ Libby } & 1995 & 62 & 10 & 83 & 7 \\
\hline & 1987 & 68 & 5 & 62 & 7 \\
\hline \multirow[t]{3}{*}{ Los Alamitos } & 1993 & 75 & 12 & 27 & 11 \\
\hline & 1990 & 56 & 30 & 52 & 13 \\
\hline & 1985 & 54 & 10 & 79 & 11 \\
\hline \multirow[t]{3}{*}{ Marshall } & 1994 & 33 & 0 & 69 & 31 \\
\hline & 1987 & 41 & 0 & 65 & 35 \\
\hline & 1983 & 43 & 0 & 88 & 12 \\
\hline \multirow[t]{2}{*}{ McCoy } & 1993 & 91 & 8 & 87 & 5 \\
\hline & 1985 & 75 & 6 & 87 & 7 \\
\hline \multirow[t]{2}{*}{ Muir } & 1993 & 56 & 13 & 69 & 19 \\
\hline & 1987 & 66 & 14 & 67 & 19 \\
\hline \multirow[t]{2}{*}{ Phillips } & 1993 & 63 & 6 & 86 & 8 \\
\hline & 1986 & 72 & 0 & 86 & 4 \\
\hline \multirow[t]{2}{*}{ Redstone } & 1993 & 91 & 18 & 71 & 11 \\
\hline & 1987 & 42 & 0 & 63 & 37 \\
\hline \multirow[t]{2}{*}{ Selah } & 1994 & 51 & 17 & 82 & 1 \\
\hline & 1985 & 69 & 26 & 72 & 2 \\
\hline \multirow[t]{3}{*}{ Simmons } & 1993 & 95 & 10 & 37 & 18 \\
\hline & 1989 & 61 & 1 & 77 & 0 \\
\hline & 1985 & 78 & 0 & 97 & 3 \\
\hline \multirow[t]{2}{*}{ Wheeler-Sack } & 1993 & 90 & 10 & 21 & 1 \\
\hline & 1985 & 63 & 5 & 83 & 12 \\
\hline
\end{tabular}




\section{Construction Survey Data}

Similarly to the condition survey data, the construction data from all of the airfields evaluated were compiled in spreadsheet format. Appendix $\mathrm{C}$ contains tables listing the construction data from all the airfields surveyed. The construction data compiled consists of layer thicknesses, material types, and construction dates.

The backcalculated asphalt concrete layer moduli data are not presented in Appendix $\mathrm{C}$ because the values listed in the reports are not backcalculated values. The Army airfield evaluation procedure requires the backcalculation of moduli values for all the layers in the pavement system, but then uses assumed $\mathrm{AC}$ modulus value based on temperature data. The evaluation procedure uses temperature data from the hottest and coldest months at the airfield being evaluated to determine modulus values (EI $02 \mathrm{C} 036$ 1997). This reason for assuming modulus values is to evaluate the pavement at the critical conditions when considering $\mathrm{AC}$ rutting and low temperature cracking. The $\mathrm{AC}$ modulus value determined for the hottest month is intended to consider the potential for rutting of the asphalt, and the $\mathrm{AC}$ modulus value determined based on the coldest month is intended to consider the potential for low temperature cracking.

\section{Climatic Survey Data}

The airfields were selected based on location according to the zoning established for the SHRP program. The purpose of considering the SHRP climatic zones was to 
insure that a range of climatic conditions were represented. Actual environmental data were used for any analyses performed that considered climatic data.

Climatic data are collected and included in most of the evaluation reports. However, the consistency and types of data collected varied tremendously. In order to provide the same quality of data at each site for analysis purposes, data were collected from the nearest National Oceanic and Atmospheric Administration (NOAA) weather station site. Table 5 presents the NOAA data, which was used for all analyses that used climatic data (NOAA 1998, NSRDB 1998).

The weather data shown in Table 5 are 30 -year averages. The solar radiation data is reported in watt-hours per square meter. The sky cover data indicates the average daily percent of sky cover determined during daylight hours. The precipitation data is the average monthly precipitable water in centimeters. The heating degree days and cooling degree days are computed from each days mean temperature (the maximum temperature plus the minimum temperature divided by two). Each degree that a day's mean temperature is below or above 18 degrees $\mathrm{C}$ is counted as one heating or cooling degree day, respectively. The average wind speed is presented in meters per second regardless of the direction of the wind. 
TABLE 5. NOAA Weather Data

\begin{tabular}{|c|c|c|c|c|c|c|}
\hline Airfield & $\begin{array}{c}\text { Solar } \\
\text { Radiation } \\
\text { SR } \\
\left(\mathrm{Wh} / \mathrm{m}^{2}\right) \\
(2)\end{array}$ & $\begin{array}{l}\text { Sky Cover } \\
\text { SC }\end{array}$ & $\begin{array}{c}\text { Precipitation } \\
\text { H2O }\end{array}$ & $\begin{array}{c}\text { Heating } \\
\text { Degree } \\
\text { Days } \\
\text { HDD } \\
\text { (deg C) } \\
\text { (5) }\end{array}$ & $\begin{array}{l}\text { Cooling } \\
\text { Degree } \\
\text { Days } \\
\text { CDD } \\
\text { (deg C) } \\
\text { (6) }\end{array}$ & $\begin{array}{l}\text { Wind } \\
\text { Speed } \\
\text { WS } \\
(\mathrm{m} / \mathrm{s}) \\
(7)\end{array}$ \\
\hline Biggs & 5732 & 3.8 & 1.37 & 1475 & 1180 & 3.4 \\
\hline Butts & 4690 & 5.3 & 1.04 & 3524 & 270 & 4.4 \\
\hline Cairns & 4620 & 5.7 & 2.52 & 1241 & 1273 & 2.9 \\
\hline Forney & 4364 & 5.7 & 1.89 & 2570 & 787 & 4.4 \\
\hline Hood & 4870 & 5.3 & 2.18 & 1193 & 1618 & 5 \\
\hline Hunter & 4612 & 5.9 & 2.64 & 1038 & 1391 & 3.4 \\
\hline Libby & 5700 & 3.8 & 1.54 & 908 & 1646 & 3.9 \\
\hline Los Alamitos & 4946 & 4.6 & 1.74 & 734 & 388 & 3.5 \\
\hline Marshall & 4300 & 5.8 & 1.88 & 2918 & 775 & 4.3 \\
\hline McCoy & 3872 & 6.3 & 1.59 & 4151 & 447 & 3.8 \\
\hline Muir & 3938 & 6.3 & 1.76 & 2971 & 566 & 3.4 \\
\hline Phillips & 4048 & 5.9 & 1.87 & 2617 & 696 & 3.9 \\
\hline Redstone & 4368 & 6.4 & 2.21 & 1824 & 946 & 3.6 \\
\hline Selah & 4097 & 5.9 & 1.13 & 3286 & 270 & 3.3 \\
\hline Simmons & 4395 & 5.8 & 2.13 & 1974 & 839 & 3.5 \\
\hline Wheeler-Sack & 3721 & 7.1 & 1.59 & 3786 & 308 & 4.2 \\
\hline Mean & 4570.13 & 5.50 & 1.83 & 2161.60 & 872.80 & 3.78 \\
\hline Std Dev & 563.58 & 0.82 & 0.46 & 1067.64 & 460.44 & 0.55 \\
\hline
\end{tabular}




\section{EVALUATION OF SURVEY DATA}

The following paragraphs present analyses of the summarized data. The results of these analyses provided direction for the remaining part of the study. However, before any statistical analyses were performed, a matrix-type experimental design was studied to determine if any treatment blocks were deficient. A significant deficiency in any blocking factor could skew analyses performed on the data.

The parameters considered in the experimental design included the following: all of the environmental parameters, the pavement class (primary or secondary), pavement age, asphalt concrete thickness, and subgrade type (fine or coarse grained). The environmental parameters were considered by taking the average of each parameter and classifying an airfield as high or low for that parameter depending on whether it had a greater or lesser value compared to the mean. All of the features at a particular airfield were classified in the same category for each environmental parameter. The abbreviations for the environmental parameters are defined in Table 5. The pavement class is defined by the Army (AR 420-70) and is based on the usage of the pavement feature. Generally, all runways and important taxiways are primary pavements and all aprons and auxiliary taxiways are secondary pavements. In the tables in Appendix B, all of the runway pavements, designated by an " $R$ " are considered primary; all of the aprons, designated by an " $\mathrm{A}$ " are considered secondary. For the taxiway pavements, all of them should be considered secondary unless denoted by a "-P" in the feature identification in the tables in Appendix B, in which case they were considered primary pavements. The 
pavement age was classified as new, for those pavements constructed in 1980 or after, or old, for those pavements constructed prior to 1980 . The asphalt thickness was divided into groups of thin (100 mm or less in thickness), or thick (greater than $100 \mathrm{~mm}$ ). Silt or clay subgrades were classified as fine. Sand or gravel subgrades were classified as coarse.

Table 6 presents a summary of the experimental design matrix. The values in each block correspond to the number of features that met the criteria of that block. For example, the block meeting the criteria of Lo HDD (indicating the heating degree days were less than the average for all the sites) and Hi SC (indicating the percent of sky cover was greater than the average for all the sites) has a value of 68 . This means that 68 of the total number of features included in this study met the criteria of Lo HDD and Hi SC. There were a total of 281 features included in this study. From inspection of Table 6 ,it appears that there are not any significant deficiencies that may skew the data analyses when all the available data are used. 


\section{TABLE 6. Design of Experiment}

\begin{tabular}{|c|c|c|c|c|c|c|c|c|c|c|c|c|c|c|c|c|c|c|c|c|}
\hline $\begin{array}{l}\text { Factor } \\
\text { (1) }\end{array}$ & $\begin{array}{l}\mathrm{Hi} \\
\mathrm{SR} \\
(2)\end{array}$ & $\begin{array}{l}\text { Lo } \\
\text { SR } \\
\text { (3) }\end{array}$ & $\begin{array}{l}\mathrm{Hi} \\
\mathrm{SC} \\
(4)\end{array}$ & $\begin{array}{l}\text { Lo } \\
\text { SC } \\
\text { (5) }\end{array}$ & $\begin{array}{c}\mathrm{Hi} \\
\mathrm{H} 2 \mathrm{O} \\
(6)\end{array}$ & $\begin{array}{l}\text { Lo } \\
\mathrm{H} 20 \\
(7)\end{array}$ & $\begin{array}{c}\mathrm{Hi} \\
\mathrm{HDD} \\
(8)\end{array}$ & $\begin{array}{l}\text { Lo } \\
\text { HDD } \\
(9)\end{array}$ & $\begin{array}{c}\mathrm{Hi} \\
\mathrm{CDD} \\
(10)\end{array}$ & $\begin{array}{l}\text { Lo } \\
\text { CDD } \\
\text { (11) }\end{array}$ & $\begin{array}{l}\mathrm{Hi} \\
\text { WS } \\
(12)\end{array}$ & $\begin{array}{l}\text { Lo } \\
\text { WS } \\
\text { (13) }\end{array}$ & $\begin{array}{l}\text { Prim } \\
\text { (14) }\end{array}$ & $\begin{array}{l}\text { Sec } \\
(15)\end{array}$ & $\begin{array}{l}\text { New } \\
\text { (16) }\end{array}$ & $\begin{array}{l}\text { Old } \\
\text { (17) }\end{array}$ & $\begin{array}{l}\text { Thick } \\
\text { (18) }\end{array}$ & Thin & $\begin{array}{l}\text { Fine } \\
\text { (20) }\end{array}$ & $\begin{array}{c}\text { Coarse } \\
(21) \\
\end{array}$ \\
\hline $\begin{array}{l}\mathrm{Hi} \\
\text { SR }\end{array}$ & 167 & & & & & & & & & & & & & & & & & & & \\
\hline $\begin{array}{l}\text { Lo } \\
\text { SR }\end{array}$ & NA & 114 & & & & & & & & & & & & & & & & & & \\
\hline $\begin{array}{l}\mathrm{Hi} \\
\mathrm{SC}\end{array}$ & 54 & 114 & 168 & & & & & & & & & & & & & & & & & \\
\hline $\begin{array}{l}\text { Lo } \\
\text { SC }\end{array}$ & 113 & 0 & NA & 113 & & & & & & & & & & & & & & & & \\
\hline $\begin{array}{l}\mathrm{Hi} \\
\mathrm{H} 2 \mathrm{O}\end{array}$ & 99 & 64 & 118 & 45 & 163 & & & & & & & & & & & & & & & \\
\hline $\begin{array}{l}\text { Lo } \\
\text { H2O }\end{array}$ & 66 & 50 & 50 & 68 & NA & 118 & & & & & & & & & & & & & & \\
\hline $\begin{array}{l}\mathrm{Hi} \\
\mathrm{HDD}\end{array}$ & 17 & 100 & 100 & 17 & 54 & 63 & 117 & & & & & & & & & & & & & \\
\hline $\begin{array}{l}\text { Lo } \\
\text { HDD }\end{array}$ & 150 & 14 & 68 & 96 & 96 & 68 & NA & 164 & & & & & & & & & & & & \\
\hline $\begin{array}{l}\mathrm{Hi} \\
\mathrm{CDD}\end{array}$ & 124 & 14 & 68 & 70 & 96 & 42 & 30 & 108 & 138 & & & & & & & & & & & \\
\hline $\begin{array}{l}\text { Lo } \\
\text { CDD }\end{array}$ & 43 & 100 & 100 & 43 & 54 & 89 & 117 & 26 & NA & 143 & & & & & & & & & & \\
\hline $\begin{array}{l}\text { Hi } \\
\text { WS }\end{array}$ & 58 & 50 & 42 & 66 & 82 & 26 & 59 & 49 & 49 & 59 & 108 & & & & & & & & & \\
\hline $\begin{array}{l}\text { Lo } \\
\text { WS }\end{array}$ & 109 & 64 & 126 & 47 & 68 & 105 & 58 & 115 & 89 & 84 & NA & 173 & & & & & & & & \\
\hline Prim & 72 & 72 & 92 & 52 & 68 & 76 & 73 & 71 & 53 & 91 & 74 & 70 & 144 & & & & & & & \\
\hline $\mathrm{Sec}$ & 95 & 42 & 76 & 61 & 72 & 65 & 37 & 100 & 92 & 45 & 57 & 80 & NA & 137 & & & & & & \\
\hline New & 74 & 48 & 77 & 45 & 86 & 36 & 34 & 88 & 88 & 34 & 72 & 50 & 64 & 58 & 122 & & & & & \\
\hline Old & 93 & 66 & 91 & 68 & 54 & 105 & 76 & 83 & 57 & 102 & 59 & 100 & 80 & 79 & NA & 159 & & & & \\
\hline Thick & 50 & 50 & 79 & 21 & 67 & 33 & 44 & 56 & 51 & 49 & 50 & 50 & 65 & 35 & 54 & 46 & 100 & & & \\
\hline Thin & 124 & 57 & 89 & 92 & 73 & 108 & 66 & 115 & 94 & 87 & 81 & 100 & 79 & 102 & 68 & 113 & NA & 181 & & \\
\hline Fine & 43 & 59 & 59 & 43 & 44 & 58 & 69 & 33 & 7 & 95 & 54 & 48 & 68 & 34 & 27 & 75 & 38 & 64 & 102 & \\
\hline Coarse & 124 & 55 & 109 & 70 & 96 & 83 & 41 & 138 & 138 & 41 & 77 & 102 & 76 & 103 & 95 & 84 & 62 & 117 & NA & 179 \\
\hline
\end{tabular}

Note: NA in a cell indicates it is not applicable for this presentation; the combination is not possible. 


\section{Condition Survey Data Analysis}

The survey data were evaluated by considering the results of fitting a general linear statistical model for the survey data (dependent variables), with evaluation period and climatic zone as the grouping factors. These analyses were performed to determine if there were significant differences between evaluation periods and climatic zones. The data analyzed included PCI and distress mechanisms (climate, load, and other). The data for all features of all airfields and all evaluations were included in these analyses. Table 7 provides a summary of the results from fitting general linear statistical models. The Pvalues shown in Table 7 indicate the probability of incorrectly rejecting the null hypotheses. The null hypothesis considers the means of groups of data analyzed not significantly different. In those cases where the null hypothesis was accepted, either the interactions between grouping factors were not considered significant or the means for treatment within a grouping factor were not considered significantly different. The analyses were performed separately for primary and secondary pavements because the Army has different condition requirements for primary and secondary pavements. 
TABLE 7. Summary of General Linear Statistical Model Results

\begin{tabular}{|c|c|c|c|c|c|c|}
\hline \multirow[b]{2}{*}{$\begin{array}{l}\text { Aspect } \\
\text { (1) }\end{array}$} & \multicolumn{2}{|c|}{ Interaction } & \multicolumn{2}{|c|}{ Evaluation Period } & \multicolumn{2}{|c|}{ Climatic Zone } \\
\hline & $\begin{array}{c}\text { P-Value } \\
\text { (2) }\end{array}$ & $\begin{array}{l}\text { Accept } H_{0} \\
\text { (3) }\end{array}$ & $\begin{array}{c}\text { P-Value } \\
\text { (4) }\end{array}$ & $\begin{array}{l}\text { Accept } \mathrm{H}_{0} \\
\text { (5) }\end{array}$ & $\begin{array}{l}\text { P-Value } \\
\text { (6) }\end{array}$ & $\begin{array}{l}\text { Accept } \mathrm{H}_{0} \\
\text { (7) }\end{array}$ \\
\hline PCl-P & 0.06 & $x$ & 0.00 & & 0.00 & \\
\hline PCl-S & 0.32 & $x$ & 0.20 & $x$ & 0.00 & \\
\hline Climate-P & 0.09 & $\mathrm{x}$ & 0.01 & & 0.00 & \\
\hline Climate-S & 0.18 & $x$ & 0.70 & $x$ & 0.80 & $x$ \\
\hline Load-P & 0.65 & $\mathrm{x}$ & 0.02 & & 0.01 & \\
\hline Load-S & 0.45 & $x$ & 0.81 & X & 0.77 & $x$ \\
\hline Other-P & 0.65 & X & 0.48 & $x$ & 0.00 & \\
\hline Other-S & 0.10 & $x$ & 0.68 & $x$ & 0.08 & $x$ \\
\hline
\end{tabular}

Notes: $\mathrm{H}_{0}=$ null hypothesis $=$ grouping factor means are equal or grouping factors have no interaction. $\mathrm{P}$-Value $=$ probability of incorrectly rejecting $\mathrm{H}_{0}$.

From Table 7 it can be seen that interactions between evaluation period and climatic zone were not significant at the 95 percent confidence level for any of the aspects analyzed. Therefore, the results for main effects (the evaluation period and the climatic zone) can be considered. If the interactions had been significant, it would have been necessary to analyze the data separately for each evaluation period and climatic zone.

Examining the results of evaluation period shown in Table 7 indicates that in only three of eight aspects, time had a significant affect on the evaluation results.

Climate was significant in five out of eight of the aspects examined. For all aspects a 95 percent confidence level was considered. The fact that time did not have a significant influence for many aspects would indicate that the airfields are being maintained at a 
fairly constant level over time. This is not particularly unexpected since the Army has a minimum standard for maintaining their airfields. The fact that climate was a significant factor for most of the aspects evaluated could be caused by many things. Airfields in some climates may be more susceptible to particular distresses. Some climates may have more important airfields, from a strategic viewpoint, resulting in greater funding and a subsequent better overall condition of those airfields. The important point is that climate is playing a roll in the condition of the airfields and thus should be a factor considered in any performance prediction procedure developed.

Reviewing Table 4 reinforces the observation that climate should be significant. From Table 4 it is apparent that most of the distresses observed on the Army airfield pavements are attributable to climate related mechanisms. The next logical step was to determine the most prevalent distress types observed on Army airfield pavements. Table 8 lists the distress types, severity levels, and densities for the most prevalent distresses observed. The density of distress is the percent of all the flexible airfield pavement area at an installation that exhibited that distress at that severity level. Only those distresses found with a density of 5 percent or greater are listed in Table 8. The only distress types found consistently at a density of 5 percent or more were block cracking (43), longitudinal and transverse cracking (48), and raveling and weathering (52). 
TABLE 8. Summary of Significant Distress Types

\section{Airfield Survey Year}

(1)

Biggs

(2)

1984

\begin{tabular}{|c|c|c|c|c|}
\hline & \multirow{3}{*}{1989} & \multirow[b]{2}{*}{ Block Cracking } & \multirow{3}{*}{$M$} & \multirow{3}{*}{$\frac{60}{29}$} \\
\hline & & & & \\
\hline & & Block Cracking & & \\
\hline & & Block Cracking & $\mathrm{H}$ & 66 \\
\hline & 1994 & Block Cracking & $M$ & 36 \\
\hline & & Block Cracking & $\mathrm{H}$ & 64 \\
\hline \multirow[t]{7}{*}{ Butts } & 1989 & Block Cracking & $L$ & 10 \\
\hline & & LT Cracking & $\mathrm{L}$ & 6 \\
\hline & & Ravel/Weather & $\mathrm{H}$ & 65 \\
\hline & 1993 & Block Cracking & $\mathrm{L}$ & 33 \\
\hline & & Block Cracking & $M$ & 16 \\
\hline & & Block Cracking & $\mathrm{H}$ & 14 \\
\hline & & Ravel/Weather & $\mathrm{H}$ & 65 \\
\hline \multirow[t]{8}{*}{ Cairns } & 1985 & Block Cracking & $\mathrm{L}$ & 30 \\
\hline & 1989 & Block Cracking & $\mathrm{L}$ & 25 \\
\hline & & Block Cracking & $M$ & 9 \\
\hline & & Ravel/Weather & $\mathrm{L}$ & 50 \\
\hline & 1992 & Block Cracking & $\mathrm{L}$ & 30 \\
\hline & & Block Cracking & $M$ & 10 \\
\hline & & Ravel/Weather & $L$ & 48 \\
\hline & & Ravel/Weather & $M$ & 9 \\
\hline \multirow[t]{5}{*}{ Forney } & 1986 & LT Cracking & $L$ & 5 \\
\hline & 1992 & Block Cracking & $L$ & 100 \\
\hline & 1996 & Block Cracking & $\mathrm{L}$ & 52 \\
\hline & & Block Cracking & $\mathrm{M}$ & 12 \\
\hline & & Ravel/Weather & $\mathrm{L}$ & 70 \\
\hline \multirow[t]{2}{*}{ Hood } & 1988 & Ravel/Weather & $\mathrm{L}$ & 44 \\
\hline & 1993 & Ravel/Weather & $\mathrm{L}$ & 56 \\
\hline \multirow[t]{3}{*}{ Hunter } & 1982 & Block Cracking & $\mathrm{L}$ & 24 \\
\hline & & Block Cracking & M & 24 \\
\hline & 1992 & Block Cracking & L & 38 \\
\hline \multirow[t]{5}{*}{ Libby } & 1987 & Block Cracking & $M$ & 30 \\
\hline & & Ravel/Weather & $\mathrm{L}$ & 9 \\
\hline & & Ravel/Weather & $M$ & 24 \\
\hline & 1995 & Block Cracking & $\mathrm{L}$ & 13 \\
\hline & & Ravel/Weather & $\mathrm{L}$ & 22 \\
\hline \multirow[t]{7}{*}{ Los Alamitos } & 1985 & Block Cracking & $L$ & 18 \\
\hline & & Block Cracking & M & 27 \\
\hline & 1990 & Alligator Crack & $M$ & 7 \\
\hline & & Block Cracking & $\mathrm{M}$ & 29 \\
\hline & & Ravel/Weather & $\mathrm{L}$ & 27 \\
\hline & 1993 & Block Cracking & M & 9 \\
\hline & & Ravel/Weather & $\mathrm{L}$ & 11 \\
\hline \multirow[t]{4}{*}{ Marshall } & 1983 & Block Cracking & M & 99 \\
\hline & 1987 & Block Cracking & $\mathrm{M}$ & 100 \\
\hline & 1994 & Block Cracking & $M$ & 86 \\
\hline & & Block Cracking & $\mathrm{H}$ & 10 \\
\hline
\end{tabular}

\section{Distress}

Severity Level Density (\%)
(4)

(5)

(3)

Block Cracking

Block Cracking

Cracking LT Cracking

Block Cracking

Block Cracking

RavelWeather

Block Cracking

Block Cracking

Block Cracking

Block Cracking

relWeather

LT Cracking

Block Cracking

Block Cracking

Block Cracking

Ravel/Weathe

Ravel/Weathe

Block Cracking

Block Cracking

Ravel/Weathe

Block Cracking

/Weather

Block Cracking

Alligator Crack

Block Cracking

Block Cracking

Ravel/Weathe

Block Cracking

Block Cracking

$\mathrm{H}$ 
TABLE 8. Continued

Airfield Survey Year Distress

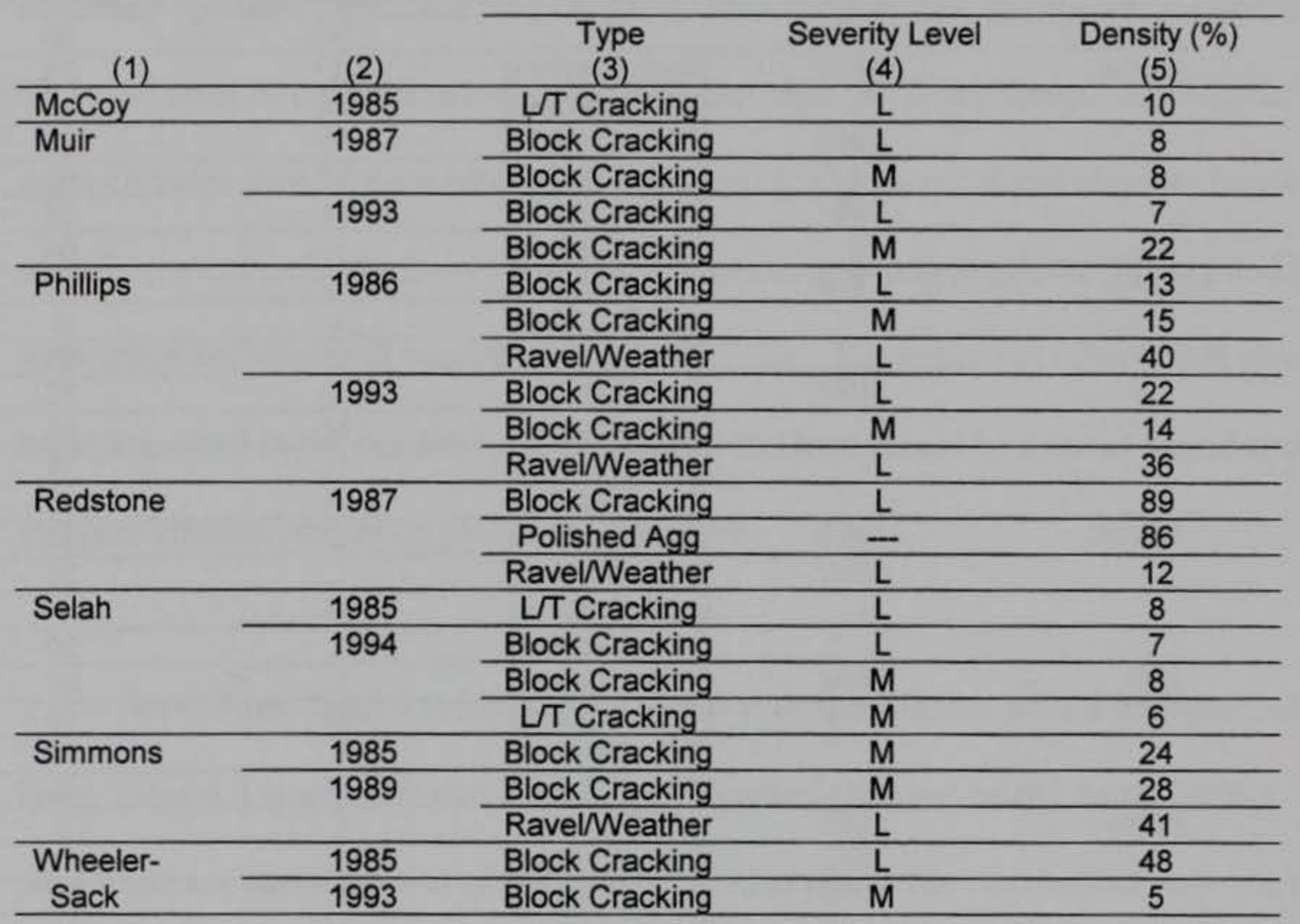

The distress types of block cracking (43), longitudinal/transverse cracking (48) and raveling/weathering (52) are associated with environmental causes as shown in Table 2. A discussion was presented on the causes of block cracking in Chapter II. Raveling/weathering could result from many of the factors that cause block cracking; aging of the asphalt cement in particular. In addition, raveling/weathering may be related to construction or aggregate problems. The longitudinal/transverse cracking are also 
normally due to environmental influences and may be the initial stages of block cracking; on occasion they may be structural in nature in the very early stages. Because there were few data showing structural problems as discussed previously, it would not be unreasonable to assume that most of the longitudinal/transverse cracking is caused by environmental factors as well.

\section{DISCUSSION OF DATA ANALYSIS}

The results of the data analysis indicated that the primary distress types were due to climate related mechanisms. Because Army airfield pavements are generally designed to support deployment aircraft loadings, but the pavements are seldom subjected to that level of loading, it is not surprising that structural distresses are not predominant. As discussed previously, day-to-day operations on most Army airfields are light in terms of number of operations and load levels when compared to the expected number of operations and load levels considered for deployment operations.

A method to predict when individual distress types will reach critical levels for individual airfield pavement features would provide Army installations with a useful tool. This tool could be used for projecting when funds would be needed and the types of maintenance and repair that would be required to maintain their airfield pavements within the criteria established by the Army (AR420-70). Although the Army only requires that the airfield pavements be maintained at established PCI levels, projecting $\mathrm{PCI}$ alone can not provide the Army installation with information on the types and 
severity level of distresses that would be expected in the future. By providing information on expected types and severity level of distresses, installations can more accurately plan the work effort that will be required and the funds necessary to maintain their airfield pavements at the required levels.

The current method for projecting PCI, which is not used, could be used at Headquarters level for determining overall expected funding requirements. Local installations need guidance on when and what types of work will be required to maintain their airfield pavements at the levels established by the Army. A method should be developed for predicting individual distress type growth rather then just the PCI to provide the local installations with a tool that can be used to predict future work requirements. 


\section{CHAPTER V}

\section{MODEL DEVELOPMENT}

After summarizing the current evaluation procedure used by the Corps of Engineers and presenting a summary and analysis of the performance data, it seems apparent that Army installations would benefit from an individual distress type development prediction method for flexible Army airfield pavements. A distress prediction model would provide local installations with information on when pavement maintenance, repair, and construction would be required, and when the funds would be needed. Although many models exist for predicting various aspects of pavement performance, the development of improved performance models is a necessary and worthwhile task (Lytton 1987). A quote from a paper presented at the $2^{\text {nd }}$ North American Conference on Managing Pavements provides support for the concept of developing a distress prediction model for flexible Army airfield pavements:

Finally, the development of performance prediction models should be a continuing task, aimed at continual improvement and better use of the available data. (Lytton 1987) 
Currently, the distress data collected through the Army airfield evaluation program are not used in any manner for predicting pavement performance. The development of a distress prediction model will exploit this pavement performance data in a manner that benefits the Army.

\section{MODEL DEVELOPMENT}

Moody (Moody 1997) describes a general framework for pavement performance model development using the long term pavement performance (LTPP) database from SHRP. The following steps listed for developing an empirical model are based on the LTPP model framework:

Step 1: Identify elements for analysis

Step 2: Identify independent (prediction) variable(s)

Step 3: Identify dependent (response) variable(s) (performance variables)

Step 4: Relate independent and dependent variables

Step 5: Compare actual versus predicted performance

Step 6: Calibrate model with field performance

Step 7: Establish model reliability

The procedure presented by Moody offers a logical stepwise model development procedure that will be used in the remaining portion of this study. The remaining part of this chapter will focus on the model development steps outlined above. 


\section{Step 1: Identification of Element for Analysis}

The first step in developing the model requires that the elements for analysis be identified. The ultimate goal of this model is a prediction, in terms of years, of when a particular distress type will reach the critical distress density level for a particular feature. The critical distress density level is related to the deduct value that results in a PCI that reaches the preset limits established by the Army. Therefore, the elements for analysis will be the individual distress types for individual pavement features. The development or growth of each distress type will be predicted independently.

\section{Step 2: Identification of Prediction Variables}

The second step of the model development procedure requires that the independent variables be established. To achieve the goal of predicting distress density growth versus time, it is necessary to develop a relationship in terms of an equation that will predict the expected performance or growth of individual distress types. The performance curve should be a function of those parameters that affect the development of particular distress types. Therefore, those distresses related to environmental mechanisms will require a relationship with environmental prediction variables. Those distress types that are the result of load mechanisms will require a relationship with load variables. Those distress types classified as "other" may require relationships with variables related to load, environment, or other factors that can not be easily identified. An example of these "other" factors that are not easily identifiable would be construction procedures. 
The three distress types investigated in the remainder of this study include block cracking, longitudinal/transverse cracking and raveling/weathering. All three of these distress types are considered to be due to climatic mechanisms. Therefore, for all three of these distress types, all of the available environmental data will be considered for use as prediction or independent variables. In addition, for all three distress types, the following list of available independent variables will be considered because they could have an impact on the development of these distress types: construction dates, asphalt thickness, whether the subgrade is fine or coarse grained, and whether the base course is stabilized. Finally for the distress type of longitudinal/transverse cracking, the load and pass levels used for evaluation will be considered since longitudinal cracking may be load related.

\section{STEP 3: Identification of Performance Variable}

The third step in the model development requires the selection of the dependent or response variable. As stated previously, the ultimate goal of the model is to predict, in terms of years, when a particular distress type will reach the critical distress density level for a particular feature. Therefore the performance parameter being sought is the distress density of individual distress types on individual features.

The PCI procedure for asphalt concrete airfield pavements uses 16 distress types, as listed in Table 2. Most of these distress types are defined at three discrete severity levels: low, medium, and high. The discrete severity levels are a convenience to aid in 
the collection of the performance data. In general, the severity levels are a function of crack width or some other measurable attribute of the distress. Over time, as the density of a distress at a particular severity level increases the corresponding deduct value increases. Appendix D presents the deduct values versus distress density curves for each distress type. While monitoring distress growth, the discrete classification of the severity level may change. As an example, as cracks grow and become wider, their severity level classification increases from low to medium and then ultimately to high. However, all of the cracks on a pavement feature will not necessarily deteriorate at the same rate. This results in fluctuating amounts of individual distress type densities at various severity levels. The fluctuating quantities, as opposed to a continuous increase in distress density, makes it difficult to model the development of a distress at individual severity levels.

In reality, total distress quantity increases continuously; although, the rate may vary by season or severity of climate over time. Therefore, a continuous function will be proposed for predicting the growth rate of individual distress types. In order to fit the field data to the form of the proposed equation, relationships were developed for "collapsing" the three severity levels of deduct values versus distress density curves for each distress type into one curve. The medium severity level curve was selected as most appropriate, and the high and low severity level curves were converted to medium severity level. The data used for collapsing the high and low severity curves to the 
medium severity level curve were the actual tabulated deduct values versus distress

density curve values used in Micro PAVER. Table 9 presents a summary of the regression equations developed and the $\mathrm{R}^{2}$ achieved.

TABLE 9. Summary of Conversion of Low and High Distress Densities to Medium Severity Level

\begin{tabular}{cccc}
\hline $\begin{array}{c}\text { Distress Type } \\
(1)\end{array}$ & $\begin{array}{c}\text { Conversion from to } \\
(2)\end{array}$ & $\begin{array}{c}\text { Regression Equation } \\
(3)\end{array}$ & $\begin{array}{c}\mathrm{R}^{2}(\%) \\
(4)\end{array}$ \\
\hline Alligator Crack & Low to Medium & $.0001 \mathrm{DD}^{2}+.2866 \mathrm{DD}$ & 99 \\
Alligator Crack & High to Medium & $.1949 \mathrm{DD}^{2}+.8275 \mathrm{DD}$ & 99 \\
Block Crack & Low to Medium & $.0003 \mathrm{DD}^{2}+.3306 \mathrm{DD}$ & 99 \\
Block Crack & High to Medium & $-.0899 \mathrm{DD}^{2}+6.2481 \mathrm{DD}$ & 99 \\
Corrugation & Low to Medium & $.0008 \mathrm{DD}^{2}+.2452 \mathrm{DD}$ & 99 \\
Corrugation & High to Medium & $-.0174 \mathrm{DD}^{2}+2.8687 \mathrm{DD}$ & 99 \\
Depression & Low to Medium & $.0004 \mathrm{DD}^{2}+.3433 \mathrm{DD}$ & 99 \\
Depression & High to Medium & $-.0079 \mathrm{DD}^{2}+2.1137 \mathrm{DD}$ & 99 \\
Joint Refl Crack & Low to Medium & $.0008 \mathrm{DD}^{2}+.1586 \mathrm{DD}$ & 99 \\
Joint Refl Crack & High to Medium & $.4735 \mathrm{DD}^{2}-.1873 \mathrm{DD}$ & 99 \\
LT Crack & Low to Medium & $-.0027 \mathrm{DD}^{2}+.4692 \mathrm{DD}$ & 99 \\
LT Crack & High to Medium & $.1137 \mathrm{DD}^{2}+1.5009 \mathrm{DD}$ & 99 \\
Patching & Low to Medium & $-.0007 \mathrm{DD}^{2}+.2667 \mathrm{DD}$ & 99 \\
Patching & High to Medium & $.0067 \mathrm{DD}^{2}+2.5509 \mathrm{DD}$ & 99 \\
Ravel/Meather & Low to Medium & $.0006 \mathrm{DD}^{2}+.1697 \mathrm{DD}$ & 99 \\
Ravel/Weather & High to Medium & $-.1835 \mathrm{DD}^{2}+9.7211 \mathrm{DD}$ & 99 \\
Rutting & Low to Medium & $.0006 \mathrm{DD}^{2}+.1736 \mathrm{DD}$ & 99 \\
Rutting & High to Medium & $-.0084 \mathrm{DD}^{2}+4.1155 \mathrm{DD}$ & 99 \\
Shoving & Low to Medium & $-.0002 \mathrm{DD}^{2}+.1789 \mathrm{DD}$ & 99 \\
Shoving & High to Medium & $-.0097 \mathrm{DD}^{2}+4.2917 \mathrm{DD}$ & 99 \\
Swell & Low to Medium & $-.00001 \mathrm{DD}^{2}+.2272 \mathrm{DD}$ & 99 \\
Swell & High to Medium & $-.042 \mathrm{DD}^{2}+4.7773 \mathrm{DD}$ & 98 \\
\hline
\end{tabular}

Note: The DD value in each equation is the distress density being converted from. The result of applying each regression equation is the converted medium severity level distress density for that particular distress type. 
The values of the PCI based on the converted distress densities were compared to the original PCI values for many features. Features with single and multiple distress types were included. For those features with multiple distresses with deduct values greater than 5 percent, the standard PCI deduct correction procedure was followed (TM 5-826 1989). The results of some features evaluated are shown in Table 10. Although Table 10 is just a sample, it is apparent that in general the $\mathrm{PCI}$ resulting from the converted data agrees reasonably well with the actual PCI. Only one of the converted PCI values shown was greater than 5 PCI points from the originally calculated PCI. Of 28 total features reviewed the mean of the absolute difference between original PCI and converted PCI was 2.5 with a standard deviation of 1.5 , on a scale of 100 . The range of absolute differences was 0 to 7 .

Based on the acceptable agreement between converted PCI and actual PCI values, the converted-to-medium severity distress density level for each distress type will be used as the performance variable for the model being developed. 
TABLE 10. Sample of Converted PCI to Actual PCI

\begin{tabular}{lcccccc}
\hline \multicolumn{1}{c}{ Airfield } & Survey Year & Feature & PCl & $\begin{array}{c}\text { Number of } \\
\text { Distress Types }\end{array}$ & Conv PCl & Conv PCl-PCl \\
\hline (1) & $(2)$ & $(3)$ & $(4)$ & $(5)$ & $(6)$ & $(7)$ \\
\hline Biggs & 1989 & T6E & 64 & 1 & 64 & 0 \\
Butts & 1984 & R11E & 94 & 1 & 91 & -3 \\
Butts & 1984 & R3E & 90 & 1 & 87 & -3 \\
Hood & 1984 & R6E & 87 & 1 & 85 & -2 \\
Hood & 1988 & A12E & 98 & 1 & 98 & 0 \\
Redstone & 1988 & T5E & 78 & 1 & 78 & 0 \\
Simmons & 1994 & R2E & 94 & 1 & 92 & -2 \\
Butts & 1993 & T13E & 79 & 1 & 74 & -5 \\
Butts & 1984 & T1E & 61 & 2 & 63 & 2 \\
Cairns & 1993 & R3E & 69 & 2 & 74 & 5 \\
Cairns & 1985 & T3E & 78 & 3 & 71 & -7 \\
Cairns & 1985 & A9E & 57 & 2 & 62 & 5 \\
Cairns & 1989 & R6I & 68 & 4 & 67 & -1 \\
Forney & 1992 & A10E & 67 & 2 & 66 & -1 \\
Forney & 1986 & R3A & 65 & 2 & 60 & -5 \\
\hline & 1986 & R4A & 72 & 2 & 67 & -5 \\
\hline
\end{tabular}

Following the determination of the independent and dependent variables, an equation for modeling the growth of individual distress densities was selected. The form of the equation should be selected prior to the analysis of the data to ensure that it adheres to the known boundary conditions and expected growth behavior of pavement distresses (Lytton 1987). 
An explanation for the form of equation selected for modeling distress density growth and the attributes of the curve that will be exploited for predicting distress density growth is warranted. Because cracking and other distress development does not occur all at once, it has been represented in mechanics as the result of a stochastic process (Zollinger and McCullough, 1994). Making use of this knowledge indicates that equations used in probability are appropriate for use in describing the performance of pavements in terms of distress development (Lytton 1987, Zollinger and McCullough, 1994). Many forms of probability density could be selected for use in determining the performance relationships such as the normal, log normal, Weibull or Gumbel. For this model, the Weibull and Gumbel density functions were examined and the Gumbel density function was selected for the following reasons (Note: an analysis similar to that presented here for the Gumbel distribution was performed with the Weibull distribution and the results are shown in Appendix E):

1.) The Gumbel distribution has a minimum value of zero, which coincides with the initial boundary conditions (from prior knowledge, it is known there cannot be less than zero percent distress). The form of the Gumbel distribution is the Type II exponential form as classified by Gumbel (Ang and Tang 1990).

2.) The rate of distress development can be negative, positive or constant. The negative case would not be appropriate for modeling pavement distress development. However, the nature of the distribution provides needed flexibility in data fitting.

3.) The cumulative distribution function reaches an asymptote as a final boundary condition, which coincides with the terminal boundary conditions (This agrees with prior knowledge based on observed field 
performance and logic. The amount of distress cannot develop to infinity, there is a limit to the amount that can be observed on a pavement feature).

4.) The results of the regression analyses between the Gumbel parameters and the independent variables provided the best fit.

The Gumbell probability density function (PDF) has the form:

$$
f(t)=\beta(\rho / t)^{(\beta-1)} \exp \left(-(\rho / t)^{\beta}\right), t \geq 0, \rho \geq 0, \beta \geq 0
$$

Where:

$$
\begin{aligned}
& t=\text { time } \\
& \rho=\text { Gumbel scale parameter } \\
& \beta=\text { Gumbel shape parameter }
\end{aligned}
$$

The cumulative distribution function (CDF) is obtained by integrating the PDF and can be expressed as follows:

$$
F(t)=\exp \left(-(\rho / t)^{\beta}\right)
$$


The Gumbel CDF ranges from zero to one. By multiplying the CDF by a factor, it can be made to range from zero to any value required. A multiplying value of 100 is selected for this study because 100 is the maximum percent of distress density achievable. Therefore the distress density at any given time will be a function of the Gumbel CDF as shown in Equation 4.

$$
\mathrm{DD}_{\mathrm{t}}=100\left[\exp \left(-(\rho / t)^{\beta}\right)\right]
$$

Where:

$$
\mathrm{DD}_{\mathrm{t}}=\text { the distress density of a particular distress at some time }
$$

Figure 7 shows representative Gumbel CDF curves. As can be observed in Figure 7, the initial slope and mid-portion slope can fit almost any expected rate of distress development. If the form of the equation is examined, it is noticed that the $\beta$ factor adjusts the slope or shape of the curve at the inflection point, which is at approximately 37 percent. The $\rho$ parameter is referred to as the scale parameter because it adjusts where the inflection point is located along the time axis. A small value of $\rho$ means the inflection point is close to the origin, while a large value of $\rho$ places the inflection point a great distance from the origin. The value of $\rho$ is approximately equivalent to the time in years for the distress density (DD) to reach 37 percent, the inflection point. 


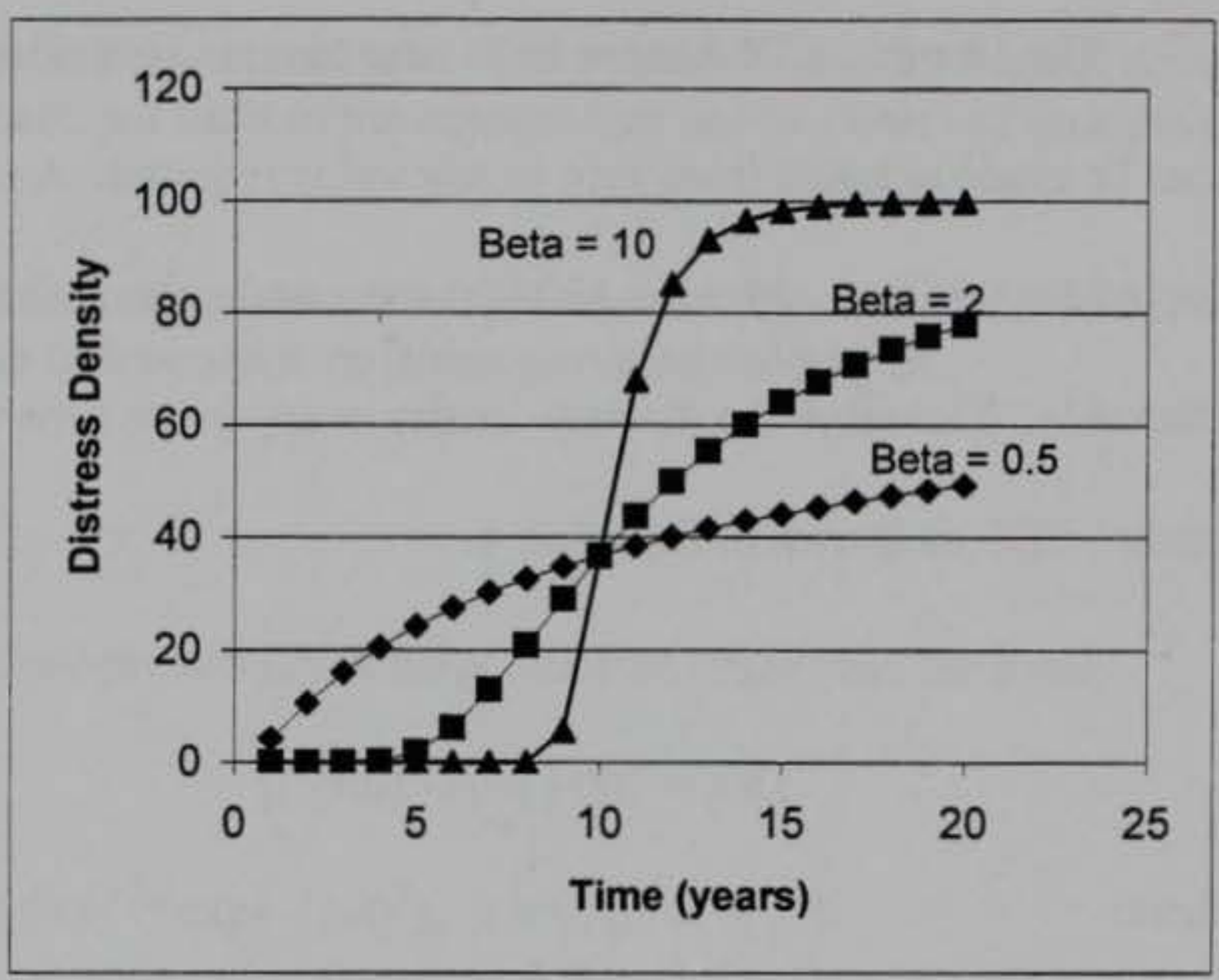

FIG 7. Examples of Gumbell CDF Curves $(\rho=10 ; \beta=0.5,2$, and 10 as shown)

\section{Step 4: Relate Independent and Dependent Variables}

Step 4 of the model development involves fitting field data to the performance equation to determine the appropriate shape and scale parameters. The shape and scale parameters are adjusted until the Gumbel curve matches the field data. Shape and scale parameters were determined for the three primary distress types found; block cracking, longitudinal/transverse cracking; and raveling/weathering. The curve fitting was done by hand; Appendix F provides a detailed explanation of the procedures and method used for determining the shape parameters. Briefly, the shape and scale parameters were adjusted until the CDF curve fit the observed field performance. Figure 8 shows an example of a plot of field data from two features with the fitted CDF curves. 


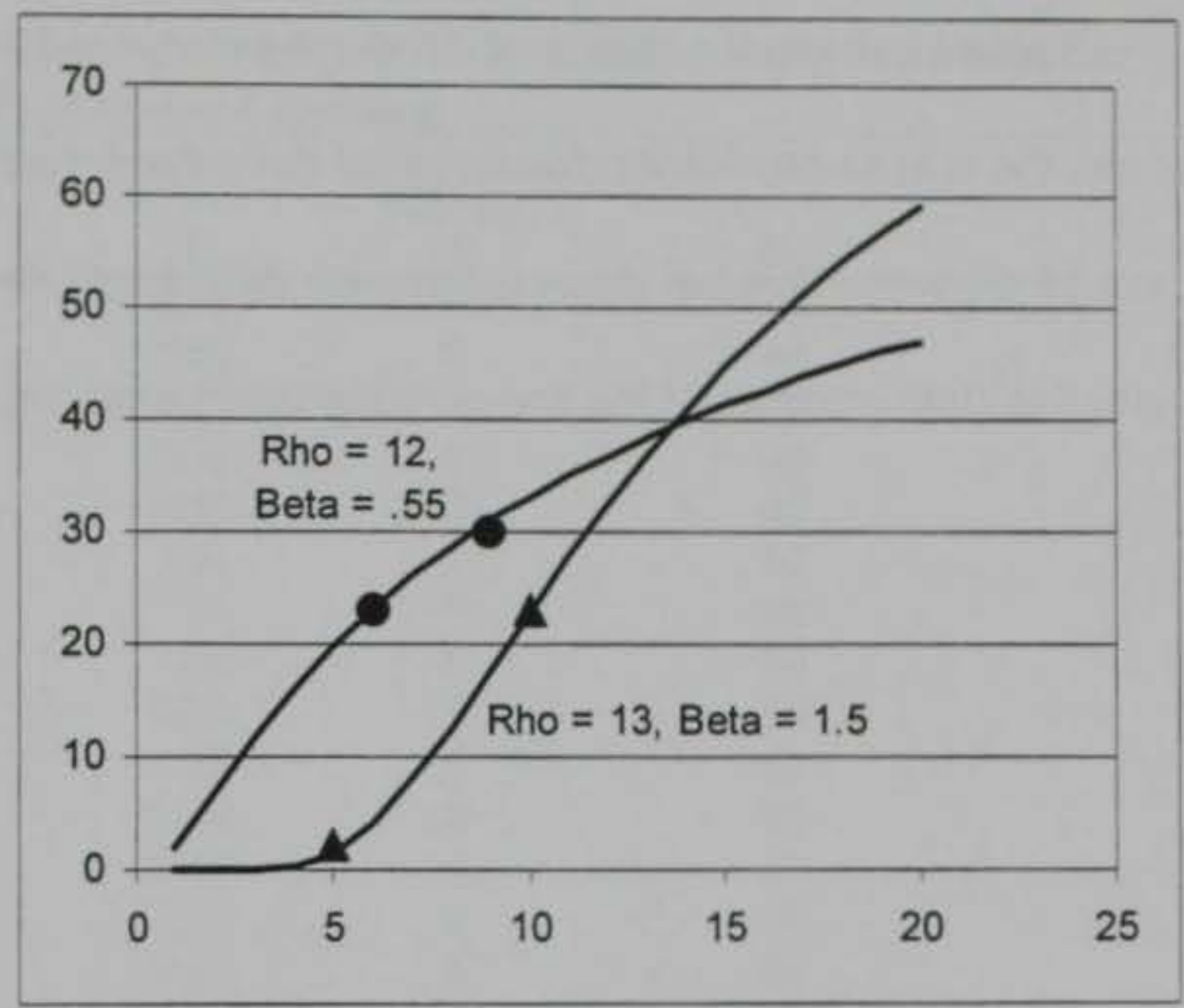

FIG 8. Example of Field Data Plotted on Model Curves

Before the field data for a particular feature could be used for fitting to the form of the equation, there were some criteria that had to be met. The data criteria were: a feature had to have two PCI levels greater than the critical level and there had to be a known construction date for the last overlay or initial construction. Data from features that met the criteria were fitted to the Gumbel CDF curve to determine appropriate shape and scale parameters. 
Table 11 shows the results of the shape parameter determinations for all features that met the criteria previously discussed for the distress type of block cracking. Tables 12 and 13 show the Gumbel shape parameters determined for features with longitudinal/transverse cracking and raveling/weathering, respectively.

TABLE 11. Results of Gumbel CDF Parameter Determinations for Block Cracking Airfield Feature Secondaryl Primary

\begin{tabular}{llllc}
\multicolumn{1}{c}{$(1)$} & $(2)$ & $(3)$ & $(4)$ & $(5)$ \\
\hline Biggs & A9E & S & 6 & 6 \\
Cairns & T8E & S & 25 & 1.2 \\
Cairns & T11E & S & 35 & 1.3 \\
Hunter & R5E & P & 18 & 1.2 \\
Hunter & T1E & P & 20 & 1.2 \\
Hunter & T8E & P & 19 & 0.5 \\
Hunter & T9E & P & 20 & 1.4 \\
Wheeler-Sack & T2E & S & 9 & 6 \\
\hline
\end{tabular}


TABLE 12. Results of Gumbel CDF Parameter Determinations for Longitudinal/Transverse Cracking Airfield

Feature

(1)

Butts

Butts

Butts

Butts

Butts

Cairns

Cairns

Cairns

Cairns

Cairns

Cairns

Cairns

Cairns

Cairns

Cairns

Cairns

Hood

Hood

Hood

Hood

Hunter

Hunter

Hunter

Hunter

Hunter

Hunter

Hunter

Phillips

Phillips

Phillips

Phillips

Phillips

Selah

Selah

Simmons
Secondary/

Primary

R2E

R3E

R4I

R5E

R6E

R6I

T1E

T4E

T8E

T9E

T10E

T12E

A6E

A10E

A11E

A12E

A19E

A21E

A8E

T6E

T9E

A7E

A8E

A19E

A30E

T6E

T10E

R2I

R4I

R5I

T2E

T4E

R8E

A1E

R1E
(3)

$P$

P

$P$

$P$

P

P

$P$

$S$

S

S

$\mathrm{S}$

$\mathrm{S}$

$\mathrm{S}$

$\mathrm{S}$

$\mathrm{S}$

S

S

S

$S$

P

S

S

S

S

S

S

P

P

P

$P$

P

$S$

$P$

$S$

P
(4)

40

40

40

40

40

60

60

80

50

50

50

80

60

50

65

80

60

80

60

60

50

50

90

60

50

60

55

80

50

60

60

80

100

100

100
(5)

.65

65

.65

.65

.63

.77

.77

.82

.73

.82

.82

.83

.76

.72

.73

.77

.74

.78

.74

.71

.74

.72

.71

.73

.74

.76

.75

.72

.74

.76

.74

.75

60

.62

.64 
TABLE 13. Results of Gumbel CDF Parameter Determinations for Raveling/Weathering

Airfield

(1)
Feature

(2)

Cairns

Cairns

Cairns

Cairns

Cairns

Hood

Hood

Hood

T4E
T9E

T10E

T11E

A11E

A19E

T3E

T5E
Secondaryl

Primary

(3)

$\mathrm{P}$

$S$

S

$S$

$S$

S

$\mathrm{S}$

\section{$\rho$}

(4)

15

16

15

14

12

13

28

21 $\beta$

(5)

3

2

3

5

0.55

1.5

0.6

0.5

Figure 8 showed an example of field data plotted against the Gumbel CDF curve. Appendix F contains additional example plots of the field data fitted to the Gumbel CDF curve for each of the distress types analyzed. In addition, Appendix F contains Tables with the converted distress density data that was used to determine the $\rho$ and $\beta$ parameters for all the features listed in Tables 11, 12 and 13.

For block cracking, as observed in Table 11, only 8 features at 4 airfields met the criteria required to determine a $\rho$ and $\beta$ parameter. The features are located at Biggs, Cairns, Hunter, and Wheeler-Sack. Table 12 shows that 35 features at 7 airfields met the criteria for determining $\rho$ and $\beta$ for the distress type of longitudinal/transverse cracking. 
Table 13 shows that 8 features at only 2 airfields met the criteria for determining the $\rho$ and $\beta$ for the distress type of raveling/weathering. Out of 281 features included in this study, the number available for analysis was greatly reduced. There are many reasons few features meet the criteria required to be included in the model development. One reason for this is because some features never exhibited the distress type under consideration for all the evaluation periods. Other features had either no $\mathrm{PCI}$ values or only one PCI value above the critical value. These pavements with consistently low PCI values did not provide any insight into the development of the distress over time. Some of these pavements had 100 percent of the distress type under consideration at each evaluation (a flat performance curve). Finally, many of the pavements had a rise in PCI due to maintenance procedures performed between evaluations. All of these factors reduced the number of useable features to those shown in Tables 11,12 and 13. Table 14 summarizes the total number of features that exhibited each distress type, out of the 281 features included in this study, categorized by why they were rejected from the model development. 
TABLE 14. Summary of Features Available for Model Development

\begin{tabular}{|c|c|c|c|}
\hline \multirow{2}{*}{$\begin{array}{l}\text { Reason for Removel } \\
\text { from Model } \\
\text { Development }\end{array}$} & \multicolumn{3}{|c|}{ Model } \\
\hline & Block Cracking & $\begin{array}{l}\text { Longitudinal/Transverse } \\
\text { Cracking }\end{array}$ & Raveling/Weathering \\
\hline Total available & 84 & 172 & 58 \\
\hline $\begin{array}{l}\text { All } \mathrm{PCl} \text { values < critical } \\
\text { value }\end{array}$ & 25 & 13 & 6 \\
\hline $\begin{array}{l}\text { Less than } 2 \mathrm{PCl} \text { values } \\
\text { above minimum }\end{array}$ & 8 & 39 & 23 \\
\hline $\begin{array}{l}\text { Distress density }=100 \\
\text { through time }\end{array}$ & 14 & 14 & 10 \\
\hline $\begin{array}{l}\text { Maintenance applied } \\
\text { between evaluations }\end{array}$ & 29 & 71 & 11 \\
\hline $\begin{array}{l}\text { Total remaining for } \\
\text { model development }\end{array}$ & 8 & 35 & 8 \\
\hline
\end{tabular}

Because the shape and scale parameters are related to the shape of the curve that was fitted to the field data, they should also be related to factors that control the growth of the distress density. Regression analyses were performed to relate the shape and scale parameters with appropriate independent variables. Before regression analyses commenced, it was helpful to determine if any correlation existed between the 
independent variables and the dependent variables ( $\rho$ and $\beta$ ). Tables 15,16 and 17 provide the results of the correlation analyses for the independent and dependent variables for the distress types of block cracking, longitudinal/transverse cracking and raveling/weathering, respectively. The abbreviations for the climatic independent variables were defined in Table 5. The other independent variables are abbreviated as follows: original construction date, $\mathrm{OC}$; most recent construction date, $\mathrm{RC}$; asphalt concrete thickness, AC; fine or coarse grained subgrade, FC; stabilized or non-stabilized base, SN; evaluation load level, EL; and evaluation pass level, EP. The climatic and construction data are presented in Appendix C, and the load and pass level data are presented in Appendix $\mathrm{G}$ for those features used in the regression analysis. A summary of the regression data for each distress type is shown in Appendix G. Only those independent variables that were appropriate as discussion in step 2 were considered in the regression analyses. Some of the appropriate variables were omitted from the regression analyses for reasons discussed in the following paragraphs. 
TABLE 15. Correlation Analysis for Block Cracking Gumbel Parameters and Independent Variables

\begin{tabular}{|c|c|c|c|c|c|c|c|c|c|c|c|c|c|c|}
\hline $\begin{array}{l}\text { Factor } \\
\text { (1) }\end{array}$ & $\begin{array}{c}\rho \\
(2)\end{array}$ & $\begin{array}{c}\beta \\
(3)\end{array}$ & $\begin{array}{l}\text { SR } \\
\text { (4) }\end{array}$ & $\begin{array}{l}\mathrm{SC} \\
\text { (5) }\end{array}$ & $\begin{array}{c}\mathrm{H} 2 \mathrm{O} \\
(6)\end{array}$ & $\begin{array}{l}\text { HDD } \\
(7)\end{array}$ & $\begin{array}{l}\text { CDD } \\
(8)\end{array}$ & $\begin{array}{l}\text { WS } \\
\text { (9) }\end{array}$ & $\begin{array}{c}\mathrm{OC} \\
(10)\end{array}$ & $\begin{array}{l}\mathrm{RC} \\
(11)\end{array}$ & $\begin{array}{l}A C \\
(12)\end{array}$ & $\begin{array}{l}\text { FC } \\
\text { (13) }\end{array}$ & $\begin{array}{l}\text { SN } \\
(14)\end{array}$ & $\begin{array}{c}\mathrm{EL} \\
(15)\end{array}$ \\
\hline$\rho$ & 1.00 & & & & & & & & & & & & & \\
\hline$\beta$ & -0.76 & 1.00 & & & & & & & & & & & & \\
\hline SR & -0.16 & 0.10 & 1.00 & & & & & & & & & & & \\
\hline SC & 0.19 & -0.20 & -0.99 & 1.00 & & & & & & & & & & \\
\hline $\mathrm{H} 2 \mathrm{O}$ & 0.74 & -0.98 & -0.21 & 0.31 & 1.00 & & & & & & & & & \\
\hline HDD & -0.48 & 0.75 & -0.58 & 0.48 & -0.68 & 1.00 & & & & & & & & \\
\hline CDD & 0.47 & -0.76 & 0.55 & -0.45 & 0.70 & -1.00 & 1.00 & & & & & & & \\
\hline WS & -0.75 & 0.63 & -0.47 & 0.44 & -0.53 & 0.79 & -0.76 & 1.00 & & & & & & \\
\hline$O C$ & 0.03 & -0.60 & -0.06 & 0.19 & 0.65 & -0.51 & 0.55 & 0.07 & 1.00 & & & & & \\
\hline $\mathrm{RC}$ & 0.11 & -0.66 & 0.27 & -0.14 & 0.66 & -0.76 & 0.80 & -0.22 & 0.93 & 1.00 & & & & \\
\hline $\mathrm{AC}$ & 0.15 & -0.43 & 0.67 & -0.59 & 0.39 & -0.84 & 0.84 & -0.55 & 0.46 & 0.70 & 1.00 & & & \\
\hline FC & - & - & - & - & - & - & - & - & - & - & - & 1.00 & & \\
\hline SN & -0.59 & 0.65 & 0.82 & -0.87 & -0.73 & -0.01 & -0.02 & 0.03 & -0.38 & -0.16 & 0.25 & -- & 1.00 & \\
\hline EL & -0.41 & -0.11 & 0.55 & -0.46 & 0.10 & -0.51 & 0.54 & 0.09 & 0.72 & 0.81 & 0.65 & - & 0.37 & 1.00 \\
\hline EP & -0.67 & 0.20 & -0.14 & 0.20 & -0.12 & 0.19 & -0.15 & 0.76 & 0.65 & 0.46 & 0.01 & -- & 0.03 & 0.67 \\
\hline
\end{tabular}


TABLE 16. Correlation Analysis for Longitudinal/Transverse Cracking Gumbel Parameters and Independent

\begin{tabular}{|c|c|c|c|c|c|c|c|c|c|c|c|c|c|c|}
\hline $\begin{array}{l}\text { Factor } \\
\text { (1) }\end{array}$ & $\begin{array}{c}\rho \\
(2)\end{array}$ & $\begin{array}{c}\beta \\
\text { (3) }\end{array}$ & $\begin{array}{l}\text { SR } \\
\text { (4) }\end{array}$ & $\begin{array}{l}\mathrm{SC} \\
\text { (5) }\end{array}$ & $\begin{array}{l}\mathrm{H} 2 \mathrm{O} \\
(6)\end{array}$ & $\begin{array}{l}\text { HDD } \\
(7)\end{array}$ & $\begin{array}{c}\text { CDD } \\
(8)\end{array}$ & $\begin{array}{l}\text { WS } \\
(9)\end{array}$ & $\begin{array}{c}\text { OC } \\
(10)\end{array}$ & $\begin{array}{l}\mathrm{RC} \\
\text { (11) }\end{array}$ & $\begin{array}{l}A C \\
(12)\end{array}$ & $\begin{array}{l}\mathrm{FC} \\
\text { (13) }\end{array}$ & $\begin{array}{l}\text { SN } \\
(14)\end{array}$ & $\begin{array}{c}\text { EL } \\
(15)\end{array}$ \\
\hline$\rho$ & 1.00 & & & & & & & & & & & & & \\
\hline $\begin{array}{l}\beta \\
S R\end{array}$ & -0.04 & 1.00 & & & & & & & & & & & & \\
\hline $\begin{array}{l}\text { SR } \\
\text { SC }\end{array}$ & -0.40 & 0.17 & 1.00 & & & & & & & & & & & \\
\hline $\begin{array}{l}\mathrm{SC} \\
\mathrm{H} 2 \mathrm{O}\end{array}$ & 0.40 & 0.22 & -0.66 & 1.00 & & & & & & & & & & \\
\hline $\begin{array}{l}\mathrm{H} 2 \mathrm{O} \\
\mathrm{HDD}\end{array}$ & 0.09 & 0.76 & 0.27 & 0.44 & 1.00 & & & & & & & & & \\
\hline $\begin{array}{l}\text { HDD } \\
\text { CDD }\end{array}$ & -0.08 & -0.72 & -0.44 & -0.26 & -0.97 & 1.00 & & & & & & & & \\
\hline $\begin{array}{l}\text { CDD } \\
\text { WS }\end{array}$ & 0.04 & 0.70 & 0.51 & 0.11 & 0.91 & -0.98 & 1.00 & & & & & & & \\
\hline $\begin{array}{l}\text { WS } \\
\text { OC }\end{array}$ & -0.21 & -0.37 & 0.20 & -0.67 & -0.53 & 0.39 & -0.19 & 1.00 & & & & & & \\
\hline $\begin{array}{l}\text { OC } \\
\text { RC }\end{array}$ & 0.35 & -0.38 & 0.01 & -0.34 & -0.43 & 0.30 & -0.20 & 0.52 & 1.00 & & & & & \\
\hline $\begin{array}{l}\mathrm{RC} \\
\mathrm{AC}\end{array}$ & -0.57 & -0.23 & 0.28 & -0.37 & -0.22 & 0.21 & -0.11 & 0.61 & 0.11 & 1.00 & & & & \\
\hline $\begin{array}{l}A C \\
F C\end{array}$ & -0.60 & -0.07 & -0.14 & 0.05 & -0.20 & 0.32 & -0.36 & -0.02 & -0.51 & 0.38 & 1.00 & & & \\
\hline $\begin{array}{l}\text { SN } \\
\text { EL }\end{array}$ & 0.13 & 0.14 & 0.44 & -0.47 & 0.14 & -0.31 & 0.45 & 0.43 & 0.45 & 0.13 & -0.62 & 0.25 & 1.00 & \\
\hline $\mathrm{EL}$ & 0.03 & 0.21 & -0.58 & 0.84 & 0.33 & -0.13 & 0.03 & -0.38 & -0.37 & 0.13 & 0.35 & -0.23 & -0.52 & 1.00 \\
\hline EP & 0.38 & -0.54 & -0.14 & -0.21 & -0.53 & 0.37 & -0.27 & 0.50 & 0.63 & -0.17 & -0.42 & 0.29 & 0.30 & -0.39 \\
\hline
\end{tabular}


TABLE 17. Correlation Analysis for Raveling/Weathering Gumbel Parameters and Independent Variables

\begin{tabular}{|c|c|c|c|c|c|c|c|c|c|c|c|c|c|c|}
\hline $\begin{array}{l}\text { Factor } \\
\text { (1) }\end{array}$ & $\begin{array}{c}\rho \\
(2)\end{array}$ & $\begin{array}{c}\beta \\
(3)\end{array}$ & $\begin{array}{l}\text { SR } \\
\text { (4) }\end{array}$ & $\begin{array}{l}\text { SC } \\
\text { (5) }\end{array}$ & $\begin{array}{c}\mathrm{H} 2 \mathrm{O} \\
(6)\end{array}$ & $\begin{array}{l}\text { HDD } \\
\text { (7) }\end{array}$ & $\begin{array}{l}\text { CDD } \\
\text { (8) }\end{array}$ & $\begin{array}{l}\text { WS } \\
\text { (9) }\end{array}$ & $\begin{array}{c}\mathrm{OC} \\
(10)\end{array}$ & $\begin{array}{c}\mathrm{RC} \\
\text { (11) }\end{array}$ & $\begin{array}{c}A C \\
(12)\end{array}$ & $\begin{array}{l}\text { FC } \\
(13)\end{array}$ & $\begin{array}{l}\text { SN } \\
(14)\end{array}$ & $\begin{array}{c}\mathrm{EL} \\
(15)\end{array}$ \\
\hline$\rho$ & 1.00 & & & & & & & & & & & & & \\
\hline$\beta$ & -0.43 & 1.00 & & & & & & & & & & & & \\
\hline SR & 0.61 & -0.60 & 1.00 & & & & & & & & & & & \\
\hline SC & -0.61 & 0.60 & -1.00 & 1.00 & & & & & & & & & . & \\
\hline $\mathrm{H} 2 \mathrm{O}$ & -0.61 & 0.60 & -1.00 & 1.00 & 1.00 & & & & & & & & & \\
\hline HDD & -0.61 & 0.60 & -1.00 & 1.00 & 1.00 & 1.00 & & & & & & & & \\
\hline CDD & 0.61 & -0.60 & 1.00 & -1.00 & -1.00 & -1.00 & 1.00 & & & & & & & \\
\hline WS & 0.61 & -0.60 & 1.00 & -1.00 & -1.00 & -1.00 & 1.00 & 1.00 & & & & & & \\
\hline OC & -0.29 & -0.13 & 0.49 & -0.49 & -0.49 & -0.49 & 0.49 & 0.49 & 1.00 & & & & & \\
\hline RC & -0.35 & -0.52 & 0.36 & -0.36 & -0.36 & -0.36 & 0.36 & 0.36 & 0.48 & 1.00 & & & & \\
\hline AC & -0.02 & 0.66 & -0.72 & 0.72 & 0.72 & 0.72 & -0.72 & -0.72 & -0.57 & -0.91 & 1.00 & & & \\
\hline FC & 0.61 & -0.60 & 1.00 & -1.00 & -1.00 & -1.00 & 1.00 & 1.00 & 0.49 & 0.36 & -0.72 & 1.00 & & \\
\hline SN & 0.35 & -0.83 & 0.77 & -0.77 & -0.77 & -0.77 & 0.77 & 0.77 & 0.38 & 0.67 & -0.85 & 0.77 & 1.00 & \\
\hline EL & -0.61 & 0.60 & -1.00 & 1.00 & 1.00 & 1.00 & -1.00 & -1.00 & -0.49 & -0.36 & 0.72 & -1.00 & -0.77 & 1.00 \\
\hline EP & 0.61 & -0.60 & 1.00 & -1.00 & -1.00 & -1.00 & 1.00 & 1.00 & 0.49 & 0.36 & -0.72 & 1.00 & 0.77 & -1.00 \\
\hline
\end{tabular}


The first observation made from the correlation analyses was that the dependent variables, $\rho$ and $\beta$, were negatively correlated to each other for the distress type of block cracking. The inverse correlation of these parameters indicates that as the value of one variable decreases the other increases. This observation indicates that any independent variable that effects one parameter, should have the opposite effect on the other parameter. Also, any parameter deemed appropriate for inclusion with one variable was used for analysis with both parameters.

Additional observations from the correlation analyses indicate that solar radiation (SR) and sky cover (SC) have a high inverse correlation in all cases. If there is a great deal of sky cover, it is expected that the amount of solar radiation would be low. Likewise, heating degree days (HDD) and cooling degree days (CDD) are highly inversely correlated. Areas that have a large number of heating degree days would not be expected to have a large number of cooling degree days. In order to limit possible difficulties due to covariance, a single parameter from each of these pairs of correlated parameters were selected for regression analyses. From Table 5, sky cover and cooling degree days were shown to have larger values of coefficient of variation than their respective correlated variables. A larger spread in the data should help in any regression analyses. Therefore, solar radiation and heating degree days were eliminated from the regression analyses. Sky cover and cooling degree days were used to capture the effects of these respective independent variables in any regression analyses for which these factors were deemed appropriate. 


\section{Regression Analysis for Block Cracking}

As stated in Chapter II, although there may be differences in performance for newly constructed pavements and pavements that were block cracked and overlayed, data were not available to make this determination. Therefore, all of the pavements that could be included were used in the block cracking regression analyses.

The independent variables that were considered to have an effect on block cracking included all the environmental variables, the asphalt thickness (AC), whether or not the base was stabilized (SN), the subgrade type (FC) (fine or course), and the construction dates (RC and OC). Aircraft load (EL) and pass level (EP) were not used because block cracking is not considered to be load related

Forward stepwise linear regression analyses were performed comparing $\rho$ and $\beta$ to the appropriate independent variables. The independent variables were entered into the forward stepwise regression procedure in order of decreasing correlation. Variables that had a probability value (P-value) greater than 0.1 , indicating they were not significant at the 90 percent level of confidence, were removed as the steps progressed. A summary of the stepwise procedures for relating $\rho$ and $\beta$ to the independent variables are shown in Table G-4 and G-5, respectively (see Appendix G). The final forms of the equations relating the independent variables to the dependent variables are shown in Equations 5 and 6. The $\mathrm{n}, \mathrm{SEE}$ and $\mathrm{R}^{2}$ for Equation 5 are 8, 3.63, and 91 percent, respectively. The n, SEE and $\mathrm{R}^{2}$ for Equation 6 are 8, 0.34 and 99 percent, respectively. 


$$
\begin{aligned}
& \rho=62.98-0.788(\mathrm{H} 2 \mathrm{O})-24.0(\mathrm{WS})+6.79(\mathrm{SC}) \\
& \beta=9.14-4.10(\mathrm{H} 2 \mathrm{O})+0.580(\mathrm{WS})+0.132(\mathrm{SC})
\end{aligned}
$$

Where:

$$
\begin{aligned}
& \mathrm{H} 2 \mathrm{O}=\text { Amount of Precipitation }(\mathrm{mm}) \\
& \mathrm{WS}=\text { Wind Speed }(\mathrm{m} / \mathrm{s}) \\
& \mathrm{SC}=\text { Sky cover (tenths) }
\end{aligned}
$$

Reviewing equations 5 and 6 shows that the wind speed (WS) variable has a different sign for each equation, as would be expected if its influence is opposite for each dependent variable. The reason the signs were the same in both equations for precipitation ( $\mathrm{H} 2 \mathrm{O})$ and sky cover $(\mathrm{SC})$ is that $\mathrm{H} 2 \mathrm{O}$ had a minor effect on the $\rho$ parameter and SC had a minor effect on the $\beta$ parameter. See Tables G-4 and G-5 (Appendix $\mathrm{G}$ ) for their $\mathrm{P}$-values and the increase in $\mathrm{R}^{2}$ attributed to these two parameters in each equation. Although these variables were not important in one equation, they were important in the other equation. As stated previously, those parameters used in one equation would be included in the other equation.

The $\mathrm{R}^{2}$ values for equations 5 and 6 were high. The reason for the relatively high values is the lack of features used to develop the equation. As discussed previously, only 8 features at 4 airfields were used to develop the block cracking regression 
equations for $\rho$ and $\beta$ based on the independent variables (see Table 11). Fortunately, only two airfields were in the same SHRP climatic zone as shown in Figure 6. The other two airfields were in different climatic zones. The fact that three of the four SHRP climatic zones were represented in the regression analyses helps make the equation useful over a broader range of conditions. However, the small total number of features and airfields still limits the ability to broadly use equations 5 and 6 . When using these equations, the input variables should be examined to ensure they are within the values used to develop equations 5 and 6 .

A sensitivity analysis was performed on Equations 5 and 6 to determine the effect of each independent variable. Table 18 summarizes the sensitivity analysis results, which included the following: the means of each variable, the extremes of each variable with the means of the other variables, and the extremes of each variable. The resulting $\rho$ and $\beta$ are presented in the last two columns of Table 18 .

TABLE 18. Summary of Sensitivity Analysis for Equations 5 and 6

\begin{tabular}{ccccc}
\hline $\begin{array}{c}\mathrm{H} 2 \mathrm{O} \\
(1)\end{array}$ & WS & SC & $\rho$ & $\beta$ \\
\hline 2.32 & $(2)$ & $(3)$ & $(4)$ & $(5)$ \\
1.37 & 3.38 & 5.74 & 19.00 & 2.35 \\
2.64 & 3.38 & 5.74 & 19.75 & 6.24 \\
2.32 & 3.38 & 5.74 & 18.75 & 1.04 \\
2.32 & 2.90 & 5.74 & 30.41 & 2.07 \\
2.32 & 4.20 & 5.74 & -0.82 & 2.83 \\
2.32 & 3.38 & 3.80 & 5.85 & 2.09 \\
1.37 & 3.38 & 7.10 & 28.25 & 2.53 \\
2.64 & 2.90 & 3.80 & 18.01 & 5.71 \\
\hline
\end{tabular}


The values obtained for $\rho$ and $\beta$ in the sensitivity analysis are within the ranges of values observed while fitting Gumbel curves to the field data except for one case where $\rho$ is less than zero. In Equation 3, $\rho$ can mathematically be less than zero. However for distress development it does not make sense to let $\rho$ be less than zero because that would indicate a time less than zero. Therefore, it is important that the values calculated for $\rho$ and $\beta$ be examined to make sure they make sense. If any value less than zero is obtained, it is an indication that the model can not handle the data appropriately. Either the conditions at that site are outside the bounds of the data that were used to develop the model, or the model can not realistically account for the combination of conditions present at that site.

Figures 9,10 and 11 show the results of the sensitivity analysis using actual values from Table 18 within the acceptable range, which means no values less than zero were used. Figure 9 shows the performance prediction curves based on values of $\rho$ and $\beta$ from the sensitivity analysis using the extremes for precipitation $(\mathrm{H} 2 \mathrm{O})$ and the means for wind speed (WS) and sky cover (SC). Figure 9 shows that as the amount of precipitation goes up, the initiation of cracking begins earlier. Figure 10 shows the performance prediction curves based on values of $\rho$ and $\beta$ from the sensitivity analysis using the lower extreme and mean of wind speed and the means of precipitation and sky cover. The upper extreme of wind speed resulted in a negative value for $\rho$ and thus could not be used. Figure 10 shows that as wind speed increases, the rate of block cracking increases. Figure 11 shows the performance prediction curves based on values 
of $\rho$ and $\beta$ from the sensitivity analysis using the extremes of sky cover and the means of precipitation and wind speed. Figure 11 shows that as sky cover increases, the rate of block cracking decreases.

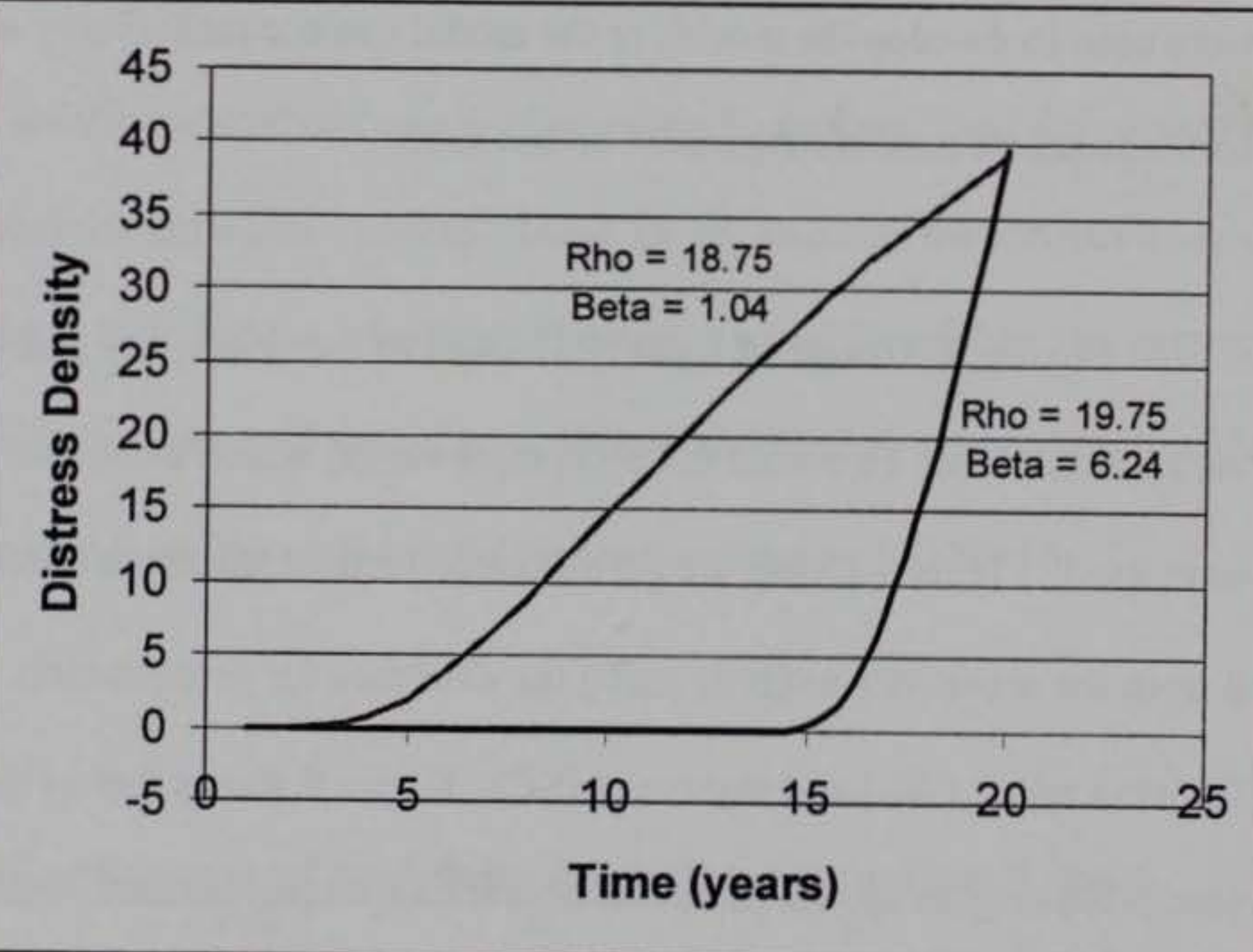

FIG 9. Sensitivity Analysis Based on the Extremes of Precipitation 


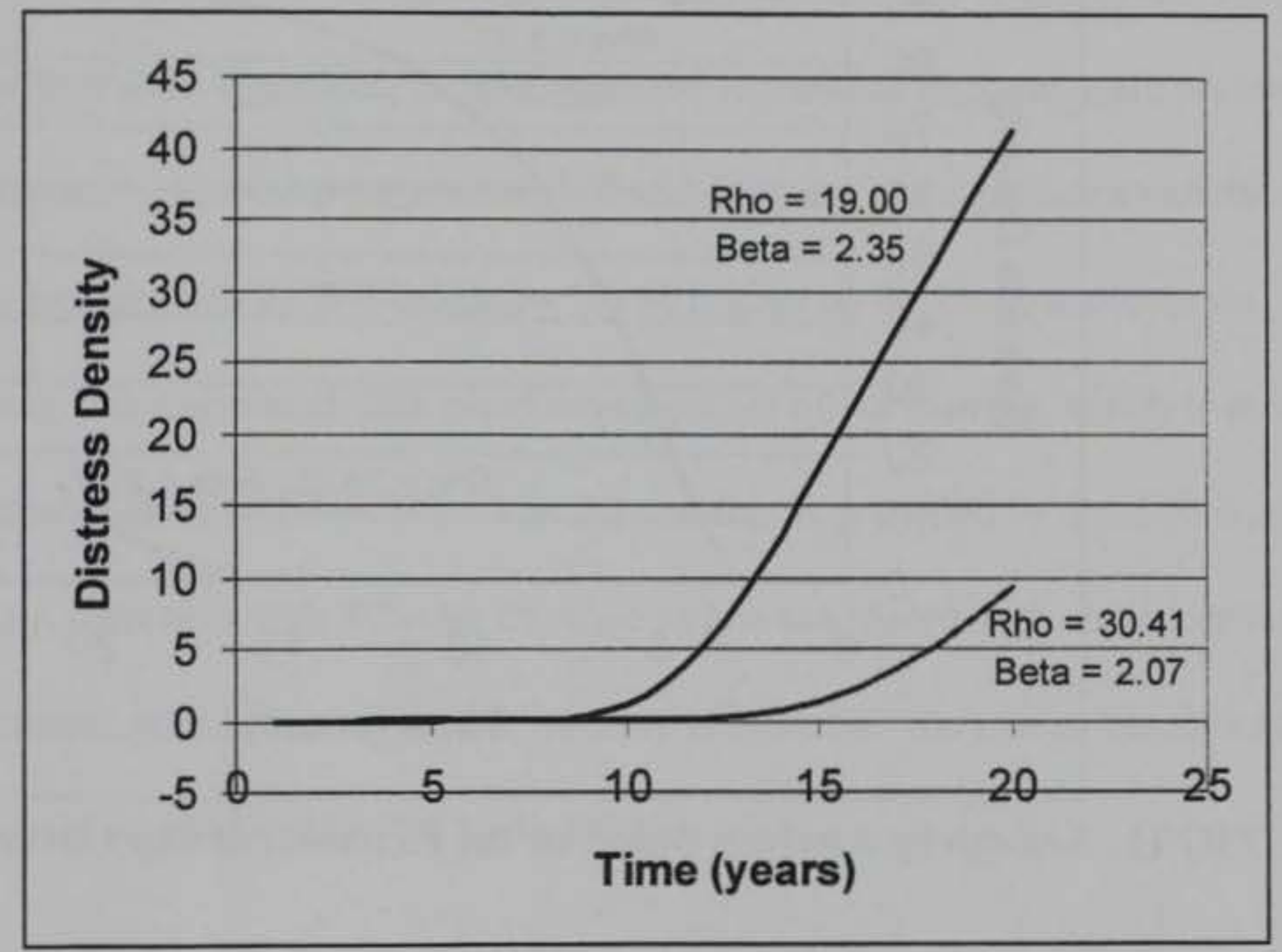

FIG 10. Sensitivity Analysis Based on the Extremes of Wind Speed 


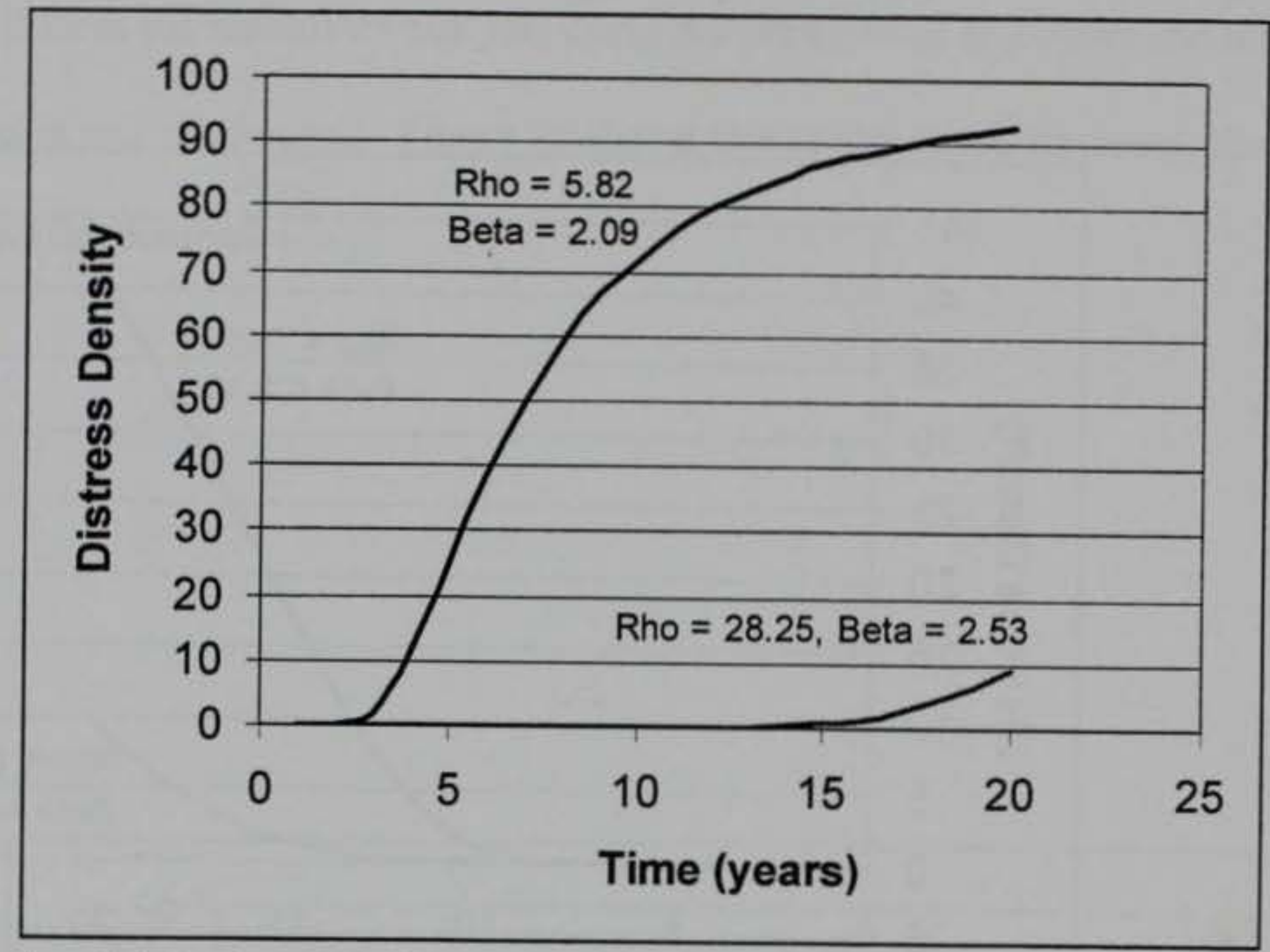

FIG 11. Sensitivity Analysis Based on the Extremes of Sky Cover 
In addition to the sensitivity analysis, the independent variables were examined to ensure that their influence on the Gumbel parameters were appropriate. Only those variables that were significant according to the regression analyses were reviewed for each parameter. For the $\rho$ parameter, WS and SC were the significant variables. The negative sign in front of WS indicates that as it goes up the $\rho$ value decreases. A decrease in $\rho$ is associated with rapid development of the distress, which is as would be expected with an increase in WS. The SC variable is preceded by a positive sign. This indicates $\rho$ increases with SC. An increase in $\rho$ is associated with slower development of the distress, which is as expected. If there is more SC, the rate of block cracking development would be expected to decrease.

The independent variables that were significant for the $\beta$ parameter were $\mathrm{H} 2 \mathrm{O}$ and WS. As the $\mathrm{H} 2 \mathrm{O}$ variable decreased, $\beta$ increased. This is as expected because an increase in $\beta$ indicates a more rapid rate of distress growth. A drier environment, with a shrinking subgrade, would be expected to contribute to a faster growth rate for block cracking. As the WS variable increased, the $\beta$ parameter increased. This is also as expected. An increase in WS would be expected to be associated with an increase in the block cracking growth rate.

The regression equations developed for the $\rho$ and $\beta$ parameters are not ideal, as shown by the sensitivity analysis. One reason for this is that the equations are based on a very limited amount of data. Therefore, the regression relationship between the 
Gumbel parameters and the independent variables should be updated to take advantage of any data that become available. In addition, if and when it can be determined which pavements consisted of an overlay placed on existing block-cracked pavements, these pavement features should be analyzed separately.

Regression Analysis for Longitudinal/Transverse Cracking

The independent variables that were considered to have an effect on longitudinal/transverse cracking included the following: all the environmental variables, the asphalt thickness (AC), whether or not the base was stabilized (SN), the subgrade type (FC) (fine or course), the construction dates (RC and OC), the aircraft load (EL), and the aircraft pass level (EP). Although longitudinal/transverse cracking may be environmentally induced as the initial stages of block cracking, longitudinal cracking may also be related to aircraft loading.

Forward stepwise linear regression procedures were conducted to determine the most suitable equations for predicting the dependent variables ( $\rho$ and $\beta)$. The regression procedures for both $\rho$ and $\beta$ are summarized in Tables G-6 and G-7 (Appendix G). The initial results of the regression analyses included asphalt concrete thickness (AC) as a parameter. When examining the influence of $\mathrm{AC}$ on the Gumbel parameters, an increase in AC (asphalt thickness) caused the rate of longitudinal/transverse cracking to increase. This did not make sense, so the AC parameter was removed. There may be many reasons why the thicker $\mathrm{AC}$ pavements could have been associated with faster rates of 
crack growth; one reason could be that the thicker pavements consisted of overlays placed on existing cracked pavements. The reflective cracking caused by the underlying cracked pavements could progress through the pavement structure at a faster rate than is typical for new pavements. However, this could not be verified with the available data so the $\mathrm{AC}$ parameter was removed from the regression analyses for longitudinal/transverse cracking. Several environmental factors remained in the regression equation, along with one structural factor and a time factor. The regression equations recommended for predicting $\rho$ and $\beta$ are shown in Equations 7 and 8 , respectively. The n, SEE and $\mathrm{R}^{2}$ for Equation 7 are 35, 11.89 and 62 percent, respectively. The n, SEE and $\mathrm{R}^{2}$ for Equation 8 are 35, 0.026 and 83 percent, respectively.

$\rho=-6990+203(\mathrm{SC})+1.98(\mathrm{H} 2 \mathrm{O})-0.406(\mathrm{EL})+9.57(\mathrm{FC})+3.02(\mathrm{RC})$

$\beta=46.9-.432(\mathrm{SC})+.0973(\mathrm{H} 2 \mathrm{O})+.000946(\mathrm{EL})+.0179(\mathrm{FC})-.0223(\mathrm{RC})$

Where:

$$
\begin{aligned}
& \mathrm{SC}=\text { Sky Cover (tenths) } \\
& \mathrm{H} 2 \mathrm{O}=\text { Precipitation (mm) } \\
& \mathrm{EL}=\text { Evaluation Load (kips) } \\
& \mathrm{FC}=\text { Fine or Coarse Grained Subgrade } \\
& \mathrm{RC}=\text { Most Recent Construction Date (Calendar Year) }
\end{aligned}
$$


The $\mathrm{R}^{2}$ values for equations 7 and 8 are not as high as those determined in equations 5 and 6 . This is expected since many more features and airfields were used to develop equations 7 and 8 (see Table 12) than were used for developing equations 5 and 6. There were 35 features from 7 airfields used to develop the relationships found in equations 7 and 8 . The 7 airfields are located in all four SHRP climatic zones as shown in Figure 6. The representation of all the climatic zones helps insure a broader range of applicability for equations 7 and 8 as opposed to the applicability of equations 5 and 6 .

A sensitivity analysis was performed on Equations 7 and 8 as shown in Table 19. The results of the sensitivity analysis were similar to the sensitivity analysis for the block cracking equations in that one case resulted in a negative value for $\rho$. For this distress, the determination of $\rho$ and $\beta$ should again be carefully scrutinized to make sure they make sense and are within the bounds of the model. Figure 12 presents a graphical representation of the results of the sensitivity analysis using actual values from Table 19 within the acceptable range, which means no values less than zero. The area between the two curves shown in Figure 12 represents bounds, within which it would be expected that any prediction curve would fall. As can be seen in Figure 12, the range of possible distress growth rate curves for longitudinal/transverse cracking is relatively narrow. This is not unexpected since most of the longitudinal/transverse cracking rates were relatively low. This also may be because as the longitudinal/transverse cracking rate quantity increases to a higher volume, it converts into block cracking. Therefore, only low amounts of longitudinal/transverse cracking are observed and recorded. 
TABLE 19. Summary of Sensitivity Analysis for Equations 7 and 8

\begin{tabular}{ccccccc}
\hline $\mathrm{SC}$ & $\mathrm{H} 2 \mathrm{O}$ & $\mathrm{EL}$ & $\mathrm{FC}$ & $\mathrm{RC}$ & $\rho$ & $\beta$ \\
$(1)$ & $(2)$ & $(3)$ & $(4)$ & $(5)$ & $\begin{array}{c}\rho \\
(6)\end{array}$ & $(7)$ \\
\hline 5.68 & 2.11 & 204 & 0 & 1982 & 63.89 & 0.74 \\
5.30 & 2.11 & 204 & 0 & 1982 & -13.25 & 0.90 \\
5.90 & 2.11 & 204 & 0 & 1982 & 108.55 & 0.64 \\
5.68 & 1.04 & 204 & 0 & 1982 & 61.77 & 0.63 \\
5.68 & 2.64 & 204 & 0 & 1982 & 64.94 & 0.79 \\
5.68 & 2.11 & 50 & 0 & 1982 & 126.38 & 0.59 \\
5.68 & 2.11 & 325 & 0 & 1982 & 14.79 & 0.85 \\
5.68 & 2.11 & 204 & -1 & 1982 & 54.32 & 0.72 \\
5.68 & 2.11 & 204 & 1 & 1982 & 73.46 & 0.75 \\
5.68 & 2.11 & 204 & 0 & 1976 & 45.79 & 0.87 \\
5.68 & 2.11 & 204 & 0 & 1986 & 75.96 & 0.65 \\
5.30 & 1.04 & 50 & 0 & 1976 & 29.02 & 0.78 \\
5.90 & 2.64 & 325 & 1 & 1986 & 82.14 & 0.74 \\
\hline
\end{tabular}




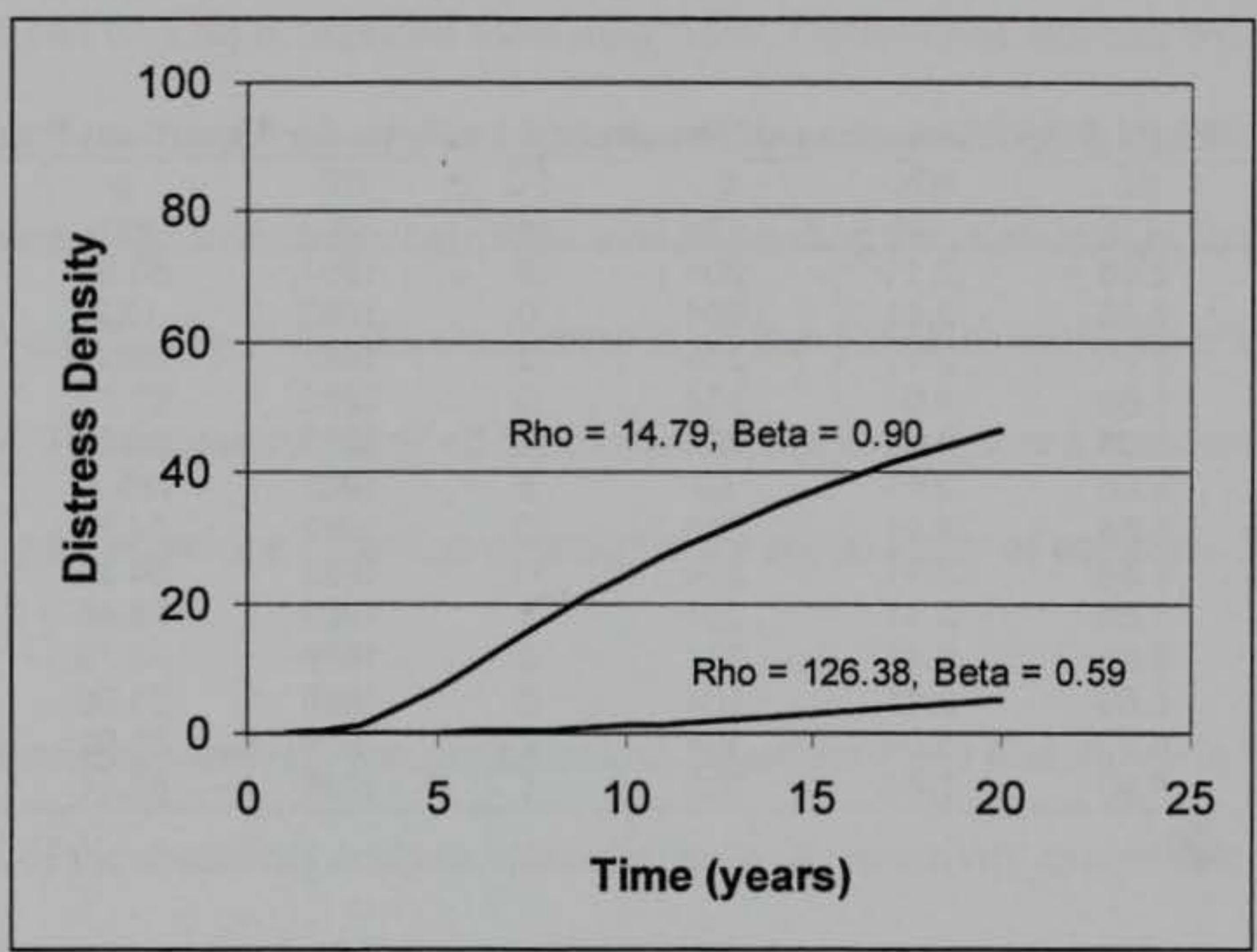

FIG 12. Sensitivity Analysis Results for Longitudinal/Transverse Cracking

Each significant independent variable in Equations 7 and 8 was examined to determine that it was having the proper impact on the calculation of $\rho$ and $\beta$. As stated previously, the $\mathrm{AC}$ variable was removed because it did not have an appropriate impact on both $\rho$ and $\beta$.

The significant factors for $\rho$ were sky cover (SC) and evaluation load level (EL) (see Appendix G, Table G-6 for the results of the regression analyses that identified the significant variables). As the amount of $\mathrm{SC}$ increases, the value of $\rho$ increases and the 
rate of distress progression decreases. This is as expected. More SC indicates less solar radiation, and thus a reduced rate of aging and subsequent cracking. As the evaluation load level increases, the value of $\rho$ decreases and the rate of distress progression increases. This is also as expected. As more loads are applied, it is expected that the rate of cracking would increase.

The significant factors for $\beta$ are precipitation $(\mathrm{H} 2 \mathrm{O})$, fine or coarse grained subgrade (FC), and most recent construction date (RC). As the amount of $\mathrm{H} 2 \mathrm{O}$ decreases, $\beta$ decreases and the rate of distress progression decreases. This is as expected. Less water is associated with shrinking subgrades and more cracking, along with a decrease in the value of $\beta$. The FC variable indicates whether a subgrade is fineor course-grained. The fine-grained subgrade results in an increase in $\beta$. This is as expected because a fine-grained subgrade would be expected to be more susceptible to volume changes and subsequently an increase in cracking rate. The final significant variable for $\beta$ is RC and it is negatively related to $\beta$. This is as expected. In general a newer pavement would be expected to have a slower rate of cracking as opposed to an older pavement.

Regression Analysis for Raveling/Weathering

The independent variables that were considered to have an effect on raveling/weathering included all the environmental variables and the construction dates. Also included was asphalt thickness, which could have an effect on this distress 
progression. As the name implies, weathering should be associated with aging of the asphalt as a direct result of the environment. Raveling is considered a materials or construction problem that may or may not be significantly affected by environmental conditions. If the distress observed is raveling, as opposed to weathering, it may be difficult to associate with any of the independent variables available.

Forward stepwise regression procedures were attempted for both $\rho$ and $\beta$, but these procedures did not result in any predictive equations. All of the analyses for $\rho$ indicated that each independent variable had large $\mathrm{P}$-values. All of the $\mathrm{P}$ values were greater than 0.1 , indicating they were not significant at the 90 percent confidence level. The regression procedure recommends that those independent variables with a $P$ value greater than 0.1 be removed from the model. In addition, the $\mathrm{R}^{2}$ values for the $\rho$ analyses proceeded from 38 percent down to zero. Similarly for the $\beta$ analyses, no variable was found to be significant at the 90 percent level. The $\mathrm{R}^{2}$ values for the analyses with the $\beta$ factor ranged from 36 to 2 percent. Summaries of the results of the forward stepwise regression procedures are shown in Tables G-8 and G-9 (Appendix G).

Reviewing Table 17 shows that the correlation coefficients were extremely high; this is because there were only two sites from which appropriate raveling/weathering data met the criteria for analysis. Examining the NOAA weather data in Table 5 for the two sites used shows that although the two airfields (Cairns and Hood) were in different SHRP climatic zones, their climates are relatively similar. Table 5 shows that for these 
two airfields, all weather data parameters are less than one standard deviation from each other (except wind speed). In fact, most of the weather data parameters are less than one half a standard deviation from each other, when considering the spread of the weather data for all the airfields included in the study. The lack of difference in environmental conditions would make it difficult to determine the contribution of the environment in the development of the distress type under consideration.

The lack of available data confounded the determination of appropriate relationships between the Gumbel parameters and the independent variables. The results of these analyses indicate that either there were not enough data to determine a relationship between the dependent and independent variables or that no relationship exists between the independent and dependent variables. Whichever the case, an appropriate relationship could not be developed based on the information available. 


\section{Step 5: Compare Actual versus Predicted Performance}

The block cracking model equations developed in Step 4 provide only one predictive performance curve for each airfield. This is because the results of the regression analyses included only climatic parameters that are the same for all the features at an airfield. The longitudinal/transverse cracking model retained two environmental variables, the evaluation load level variable, and the variable indicating whether the subgrade was fine or coarse grained; all of which were the same for all of features of each airfield included in the development of the equations predicting $\rho$ and $\beta$. In addition the longitudinal/transverse cracking model contained the independent variable considering the most recent construction date. This variable was the same for most of the features at each airfield; however, a few features at two airfields did have different values for the most recent construction date variable.

Figure 13 shows an example of the model curve plotted against the field data for one of the sites with block cracking. Figure 14 shows a plot of longitudinal/transverse cracking field data plotted against the appropriate model curve. Appendix $\mathrm{H}$ contains figures showing the field data plotted against the model curve for all the sites and conditions included in this study. The field data plotted in the figures in Appendix $\mathrm{H}$ are the same data used to develop the model. Because the available data were limited in terms of quantity, all of the available data were used to develop the model. 


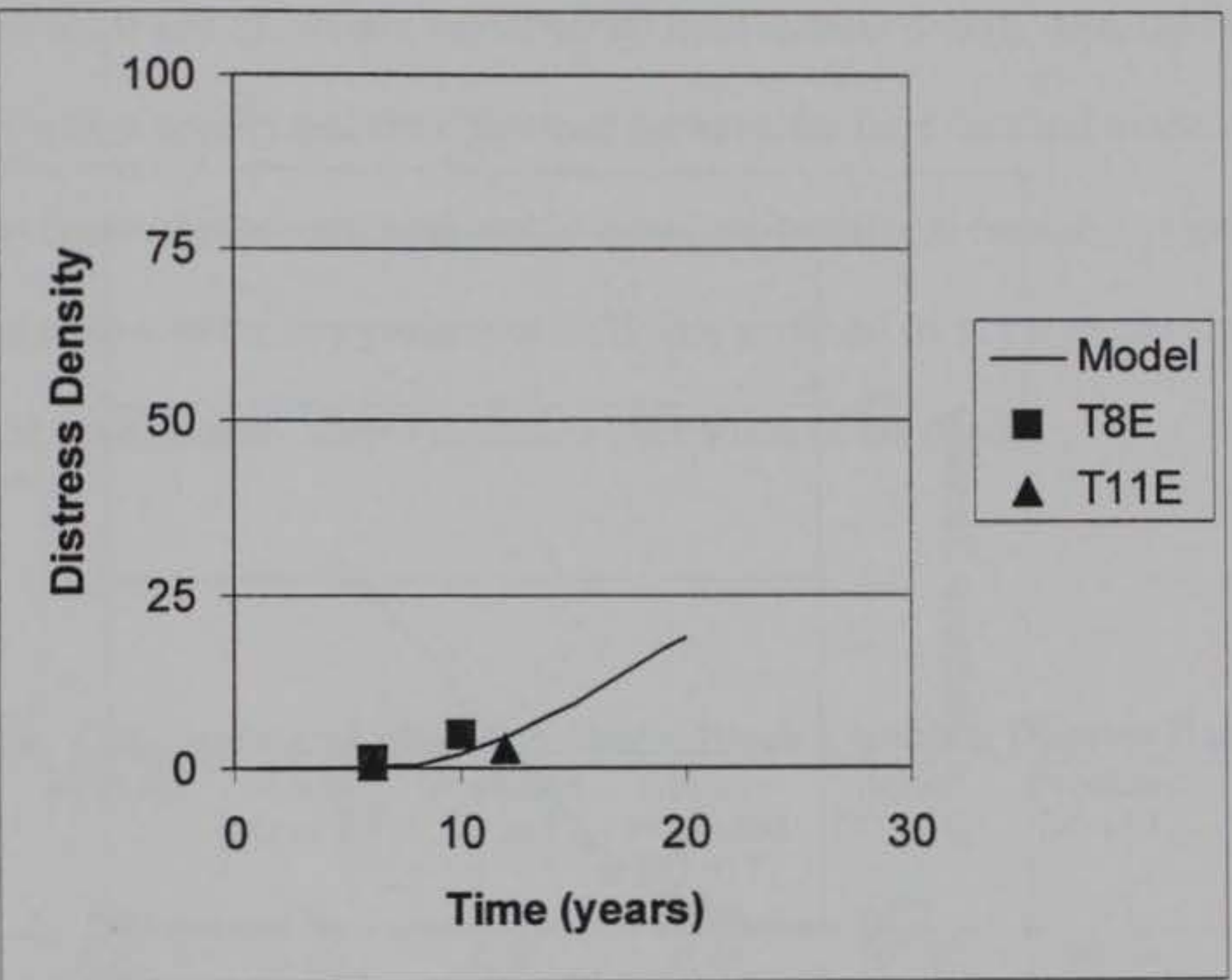

FIG 13. Model Curve and Field Data for Block Cracking at Cairns AAF 


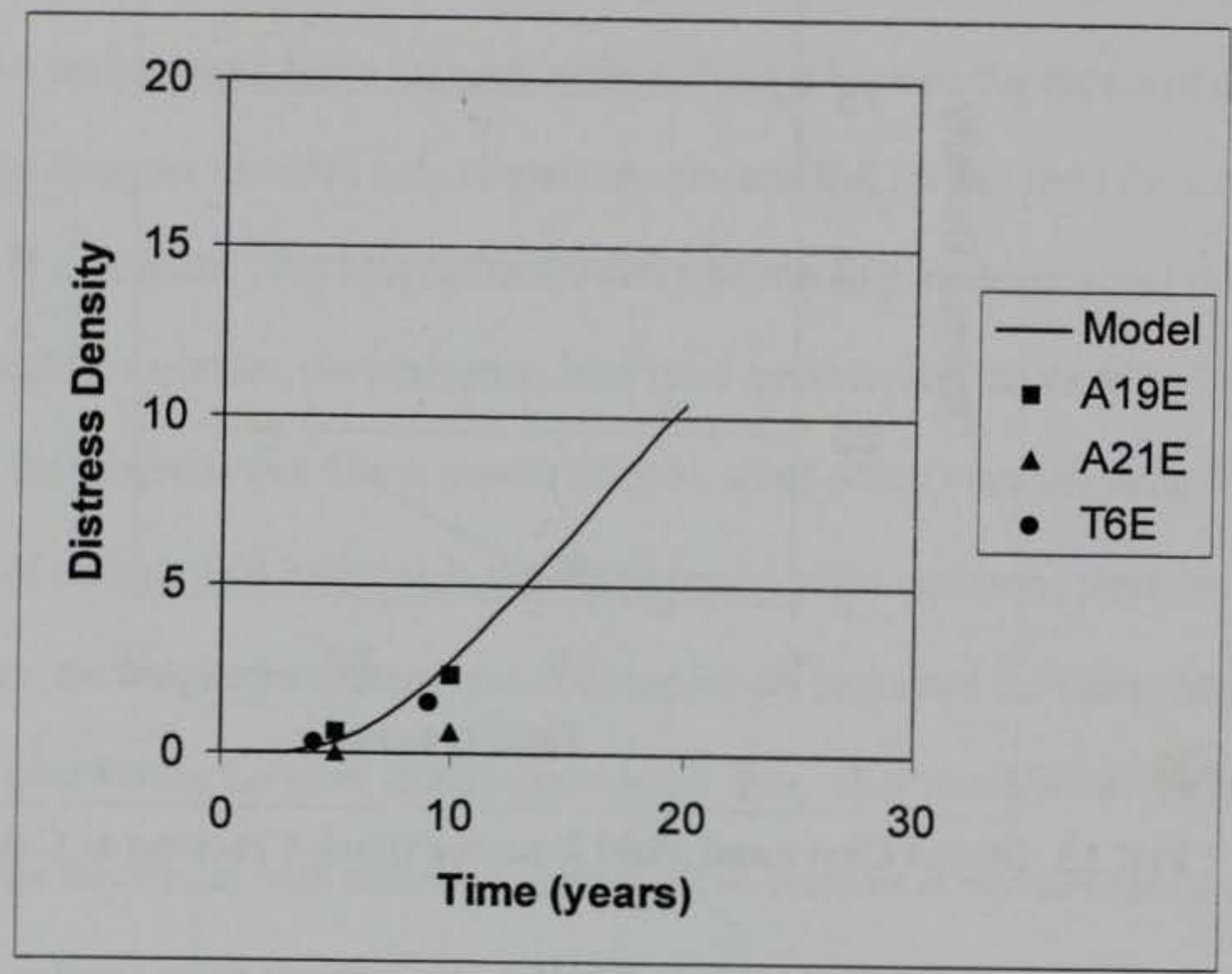

FIG 14. Model Curve and Field Data for L/T Cracking at Hood AAF 
Tables 20 and 21 contain the tabulated field distress density data, the model predicted distress density and the difference between the field data and model values for the distress types of block cracking and longitudinal/transverse cracking, respectively. Based on a review of the comparison of field data to model data, the model should be examined for calibration. Step 6 discusses calibration of the model.

TABLE 20. Comparison of Field and Model Block Cracking Distress Density Data

\begin{tabular}{|c|c|c|c|c|c|c|c|}
\hline Airfield & Feature & $\begin{array}{c}\text { Actual } \\
\text { DD at } T_{1}{ }^{*} \\
\text { (3) }\end{array}$ & $\begin{array}{l}\text { Predicted } \\
\text { DD at } T_{1} \\
\text { (4) }\end{array}$ & $\begin{array}{c}\text { Actual - } \\
\text { Predicted } \\
\text { DD at } T_{1} \\
\text { (5) }\end{array}$ & $\begin{array}{c}\text { Actual } \\
\text { DD at } T_{2}{ }^{*} \\
\text { (6) }\end{array}$ & $\begin{array}{c}\text { Predicted } \\
\text { DD at } T_{2} \\
\text { (7) }\end{array}$ & $\begin{array}{c}\text { Actual - } \\
\text { Predicted } \\
\text { DD at } T_{2} \\
\text { (8) }\end{array}$ \\
\hline Biggs & $\mathrm{A} 9 \mathrm{E}$ & 8.45 & 0.00 & 8.45 & 100.00 & 90.73 & 9.27 \\
\hline Cairns & T8E & $1 .($ & 0. & 1.00 & 4.79 & 1.96 & 2.83 \\
\hline Cairns & T11E & 0.44 & 0.0 & 0.3 & 2. & 4.35 & -1.69 \\
\hline Hunter & R5E & 9. & 10.3 & -1.07 & $\mathrm{~N}$ & NA & NA \\
\hline Hunter & $\mathrm{T} 1$ & 0.3 & & 0.3 & & 10.39 & -2.87 \\
\hline Hunter & T8E & 7.3 & 0.0 & 7.34 & 23.60 & 10.39 & 13.21 \\
\hline Hun & TS & & & & & 10. & -5.36 \\
\hline heeler- & $\mathrm{T} 2 \mathrm{E}$ & 36.60 & 33.48 & 3.12 & 100.00 & 97.61 & 2.39 \\
\hline
\end{tabular}
Sack

*DD = Distress Density, $T_{1}$ refers to the first evaluation, $T_{2}$ refers to the second evaluation 
TABLE 21. Comparison of Field and Model L/T Cracking Distress Density Data

\begin{tabular}{|c|c|c|c|c|c|c|c|c|c|c|}
\hline $\begin{array}{l}\text { Air- } \\
\text { field }\end{array}$ & Feat & $\begin{array}{c}\text { Actual } \\
\text { DD at } \\
T_{1}{ }^{*}\end{array}$ & $\begin{array}{c}\text { Model } \\
\text { DD at } \\
\mathrm{T}_{1}\end{array}$ & $\begin{array}{c}\text { Actual } \\
- \\
\text { Model } \\
\mathrm{DD} \text { at } \\
\mathrm{T}_{1} \\
(5) \\
\end{array}$ & $\begin{array}{c}\text { Actual } \\
\text { DD at } \\
T_{2}{ }^{*}\end{array}$ & $\begin{array}{c}\text { Model } \\
\mathrm{DD} \text { at } \\
\mathrm{T}_{2}\end{array}$ & $\begin{array}{c}\text { Actual } \\
- \\
\text { Model } \\
\text { DD at } \\
\mathrm{T}_{2} \\
(8)\end{array}$ & $\begin{array}{c}\text { Actual } \\
\text { DD at } \\
\mathrm{T}_{3}{ }^{*}\end{array}$ & $\begin{array}{c}\text { Model } \\
\mathrm{DD} \text { at } \\
\mathrm{T}_{3}\end{array}$ & $\begin{array}{c}\text { Actual } \\
- \\
\text { Model } \\
\mathrm{DD} \text { at } \\
\mathrm{T}_{3} \\
(11)\end{array}$ \\
\hline Butts & R2E & 1.54 & 1.02 & 0.52 & 4.17 & 5.71 & -1.54 & $\mathrm{NA}^{\mathrm{a}}$ & NA & NA \\
\hline Butts & R3E & 1.88 & 1.02 & 0.86 & 4.59 & 5.71 & -1.12 & NA & NA & NA \\
\hline Butts & R4I & 1.97 & 1.02 & 0.95 & 4.79 & 5.71 & -0.92 & NA & NA & NA \\
\hline Butts & R5E & 1.85 & 1.02 & 0.83 & 4.27 & 5.71 & -1.44 & NA & NA & NA \\
\hline Butts & R6E & 2.06 & 1.02 & 1.04 & 5.03 & 5.71 & -0.68 & NA & NA & NA \\
\hline Cairns & R6I & 0.46 & 0.43 & 0.03 & 1.92 & 2.19 & -0.27 & NA & NA & NA \\
\hline Cairns & T1E & 0.96 & 0.43 & 0.53 & 1.98 & 2.19 & -0.21 & NA & NA & NA \\
\hline Cairns & T4E & 0.48 & 0.43 & 0.05 & 1.04 & 2.19 & -1.15 & 1.18 & 4.16 & -2.98 \\
\hline Cairns & T8E & 1.08 & 0.43 & 0.65 & 3.94 & 2.19 & 1.75 & NA & NA & NA \\
\hline Cairns & T9E & 1.03 & 0.43 & 0.60 & 3.56 & 2.19 & 1.37 & 4.16 & 4.16 & 0.00 \\
\hline Cairns & T10E & 1.30 & 0.43 & 0.87 & 2.68 & 2.19 & 0.49 & 4.77 & 4.16 & 0.61 \\
\hline Cairns & T12E & 0.27 & 0.43 & -0.16 & 0.46 & 2.19 & -1.73 & 1.10 & 4.16 & -3.06 \\
\hline Cairns & A6E & 1.17 & 0.43 & 0.74 & 1.98 & 2.19 & -0.21 & NA & NA & NA \\
\hline Cairns & $\mathrm{A} 10 \mathrm{E}$ & 0.01 & 0.00 & 0.01 & 3.08 & 1.05 & 2.03 & 4.05 & 2.64 & 1.41 \\
\hline Cairns & A11E & 0.53 & 0.01 & 0.52 & 1.31 & 0.78 & 0.53 & 1.44 & 2.86 & -1.42 \\
\hline Cairns & $\mathrm{A} 12 \mathrm{E}$ & 0.10 & 1.05 & -0.95 & 0.68 & 2.64 & -1.96 & NA & NA & NA \\
\hline Hood & A19E & 0.67 & 0.33 & 0.34 & 2.32 & 2.74 & -0.42 & NA & NA & NA \\
\hline Hood & A21E & 0.04 & 0.33 & -0.29 & 0.64 & 2.74 & -2.10 & NA & NA & NA \\
\hline Hood & A8E & 1.52 & 0.17 & 1.35 & 1.72 & 2.26 & -0.54 & NA & NA & NA \\
\hline Hood & T6E & 0.32 & 0.13 & 0.19 & 1.56 & 2.11 & -0.55 & NA & NA & NA \\
\hline Hunter & T9E & 1.91 & 0.01 & 1.90 & 2.14 & 2.80 & -0.66 & NA & NA & NA \\
\hline Hunter & A7E & 0.01 & 0.01 & 0.00 & 2.33 & 2.80 & -0.47 & NA & NA & NA \\
\hline Hunter & A8E & 0.31 & 0.01 & 0.30 & 0.40 & 2.80 & -2.40 & NA & NA & NA \\
\hline Hunter & A19E & 0.62 & 0.01 & 0.61 & 1.30 & 2.80 & -1.50 & NA & NA & NA \\
\hline Hunter & A30E & 0.37 & 0.01 & 0.36 & 2.81 & 2.80 & 0.01 & NA & NA & NA \\
\hline Hunter & T6E & 0.37 & 0.01 & 0.36 & 1.49 & 2.80 & -1.31 & NA & NA & NA \\
\hline Hunter & T10E & 1.56 & 0.01 & 1.55 & 2.01 & 2.80 & -0.79 & NA & NA & NA \\
\hline Phillips & R2I & 0.15 & 0.04 & 0.11 & 1.11 & 2.63 & -1.52 & NA & NA & NA \\
\hline Phillips & R4! & 0.14 & 0.04 & 0.10 & 3.79 & 2.63 & 1.16 & NA & NA & NA \\
\hline Phillips & R5I & 0.06 & 0.04 & 0.02 & 1.96 & 2.63 & -0.67 & NA & NA & NA \\
\hline Phillips & T2E & 0.05 & 0.04 & 0.01 & 2.36 & 2.63 & -0.27 & NA & NA & NA \\
\hline Phillips & T4E & 0.01 & 0.04 & -0.03 & 0.86 & 2.63 & -1.77 & NA & NA & NA \\
\hline Selah & R8E & 4.23 & 2.64 & 1.59 & 6.02 & 8.01 & -1.99 & NA & NA & NA \\
\hline Selah & A1E & 3.07 & 2.64 & 0.43 & 5.41 & 8.01 & -2.60 & NA & NA & NA \\
\hline $\begin{array}{l}\text { Sim- } \\
\text { mons }\end{array}$ & R1E & 0.16 & 0.38 & -0.22 & 5.00 & 1.87 & 3.13 & NA & NA & NA \\
\hline
\end{tabular}


Regression analyses were performed on the results shown in Tables 20 and 21 comparing the actual data to the field data. The regression analysis on the block cracking data resulted in and $\mathrm{R}^{2}$ of 98 percent, a SEE of 5.09 , with an $\mathrm{n}$ of 15 . The regression analysis performed on the longitudinal/transverse cracking data resulted in an $\mathrm{R}^{2}$ of 1 percent, a SEE of 1.11 , with an $\mathrm{n}$ of 76 . The relatively high $\mathrm{R}^{2}$ for block cracking is probably due to the relatively low $\mathrm{n}$ over a large range of data. The field block cracking distress density data ranged from 0 to 100 percent. The large range in values also contributed to the relatively large SEE value for the block cracking data. The very low $\mathrm{R}^{2}$ for longitudinal/transverse cracking is due to the extremely low distress densities observed and the difficulty in fitting the model to these low values. The field longitudinal/transverse cracking distress density data ranged from 0 to 8 percent with most around or less than 1 percent. Therefore, if the model was in error by only one or two distress density points, although this would not make a meaningful difference in the quality of the prediction, from a statistical analysis the prediction was in error by orders of magnitude. These apparently large discrepancies in predictions result in the very low $\mathrm{R}^{2}$ determined. However, these low values had an opposite effect on the SEE and provided a lower value than that calculated for block cracking. The results of this regression analyses could be used in determining reliability for the model. However, an alternative method is provided in Step 7: Establish Model Reliability. 


\section{Step 6: Calibrate Model with Field Performance}

Ideally there would be a sufficient amount of data available so that some data could have been set aside and used to compare the model predictions to actual performance and used to calibrate the model. The relatively small data sets required that all the available data be used in the development of the models. When and if appropriate additional data become available, the model should be calibrated using these data. When evaluating a particular pavement feature, if it has two or more distress density data points that meet the requirements used for developing the regression equations between the dependent and independent variables, the model should be updated or calibrated with these data.

The following paragraphs discuss procedures for calibrating or adjusting the prediction curve of an individual pavement feature using the results of a $\mathrm{PCI}$ survey. There are two possible ways the prediction curve can be calibrated for a particular feature based on a PCI survey: 1) the shape and slope of the curve can be adjusted to match the field data, or 2) the curve can be shifted to better align with the field. Application of the first method indicates that the model is not predicting the growth rate accurately. Application of the second method indicates that the distress growth rate prediction is accurate, but there is an error in determining an appropriate construction date or date when the distress first begins to develop. 
While reviewing the plots of data in Appendix $\mathrm{H}$, it is apparent that some of the data indicates an adjustment in slope would be appropriate, while others indicate a shift in the curve would be appropriate. If more than one data point exists, the model equation should be fit to the field data. In addition, these data can be used to calibrate the model. The method of fitting the model equation to the field data would be considered adjusting the shape or slope of the curve to match the field performance. For those features with only one data point, it is recommended that the curve be shifted as discussed in the following paragraphs. For new pavements with no distress density data points, the model equation based on the local environment can be used, or no prediction should be made until a PCI survey has been made of the pavement and distresses begin to appear.

The procedure recommended for shifting the performance curve based on the $\mathrm{PCI}$ data of an individual feature is similar to the procedure used for adjusting family curves based on observed data (Smith et al 1987). An example of determining an appropriate estimation to time $t_{\text {crit }}$ by shifting the performance curve for an airfield follows. The term $t_{\text {crit }}$ refers to the projected time in years when it is expected that the distress density will reach a critical level, $\mathrm{DD}_{\text {crit, }}$ resulting in a $\mathrm{PCI}$ at the minimum level established by the Army (AR 420-70). (Note: Step 7 on reliability discusses the determination of $t_{\text {crit }}$ at various confidence levels at selected levels of $\mathrm{DD}_{\text {crit. }}$ ) Consider that the model predicts the time to $t_{\text {crit }}$ for an airfield to be 15 years at a 50 percent confidence level for $\mathrm{a} \mathrm{DD}_{\text {crit }}$ of 66 for block cracking. Also consider that a feature on 
that airfield was surveyed and the distress density of block cracking was found to be 10 percent at 5 years into the life of the pavement. Now consider that the model predicts that the $\mathrm{DD}$ of 10 percent will occur at 7 years, with a confidence level of 50 percent. Considering the field data and the model prediction, the prediction time to $\mathrm{DD}_{\text {crit }}$ should be shifted 2 years. Therefore the prediction to $\mathrm{DD}_{\text {crit }}$ should be adjusted from 15 to 13 years. It would then be expected that the airfield would reach the critical distress density level for block cracking 8 years from the time of the survey.

\section{Step 7: Establish Model Reliability}

Step 7 requires that reliability be established for the model. The ultimate goal of the model is to estimate the time when the critical level of distress density will be reached. The first step in applying a reliability analysis to the model is to establish the expected value and variance for each of $\rho$ and $\beta$. To determine the expected value and variance of $\rho$ and $\beta$, the first order second moment (FOSM) procedure was used (Harr 1987). The model developed to predict the distress density growth of block cracking is used as an example to demonstrate the application of the procedures used to consider reliability. Equations 9 and 10 show the relationships for determining the expected value and variance of $\rho$ for the block cracking model. Similar equations would be used for finding the expected value and variance of $\beta$. It should be noted that the form of Equation 10 assumes that the independent variables are independent of each other and therefore all covariances are zero. Recall that the terms of heating degree days and solar 
radiation were eliminated from the model development because there would have been covariance between these two terms and cooling degree days and sky cover, respectively. If the correlation coefficients are examined in Table 13 for the variables contained in the equations for $\rho$ and $\beta$, the highest correlation coefficient found is between wind speed (WS) and precipitation (H2O). The correlation coefficient between these two variables is -0.53 . This is a relatively low correlation coefficient, and there is no reason to suspect that they would be highly correlated. Therefore the assumption that the covariance is zero is considered appropriate.

$$
\mathrm{E}[\rho(\mathrm{H} 2 \mathrm{O}, \mathrm{WS}, \mathrm{SC})]=\rho(\mathrm{H} 2 \mathrm{O}, \mathrm{WS}, \mathrm{SC})
$$

$$
\operatorname{Var}(\rho)=[\partial \rho / \partial \mathrm{H} 2 \mathrm{O}]^{2} \operatorname{Var}[\mathrm{H} 2 \mathrm{O}]+[\partial \rho / \partial \mathrm{Ws}]^{2} \operatorname{Var}[\mathrm{WS}]+[\partial \rho / \partial \mathrm{SC}]^{2} \operatorname{Var}[\mathrm{SC}]
$$

Where:

$$
\begin{aligned}
& \mathrm{E}[\rho(\mathrm{H} 2 \mathrm{O}, \mathrm{WS}, \mathrm{SC})]=\begin{array}{l}
\text { The expected value of } \rho \\
\text { (a function of } \mathrm{H} 2 \mathrm{O}, \mathrm{WS} \text { and } \mathrm{SC} \text { ) }
\end{array} \\
& \overline{\mathrm{H} 2 \mathrm{O}}=\text { The mean value of } \mathrm{H} 2 \mathrm{O} \\
& \overline{\mathrm{WS}}=\text { The mean value of } \mathrm{WS} \\
& \overline{\mathrm{SC}}=\text { The mean value of SC } \\
& \operatorname{Var}(\rho)=\text { The variance of } \rho
\end{aligned}
$$




$$
\begin{aligned}
& \partial \rho / \partial \mathrm{H}_{2} \mathrm{O}=\text { The partial derivative of } \rho \text { with respect to } \mathrm{H} 2 \mathrm{O} \\
& \operatorname{Var}(\mathrm{H} 2 \mathrm{O})=\text { The variance of } \mathrm{H} 2 \mathrm{O} \\
& \partial \rho / \partial \mathrm{WS}=\text { The partial derivative of } \rho \text { with respect to WS } \\
& \operatorname{Var}(\mathrm{WS})=\text { The variance of WS } \\
& \partial \rho / \partial \mathrm{SC}=\text { The partial derivative of } \rho \text { with respect to SC } \\
& \operatorname{Var}(\mathrm{SC})=\text { The variance of SC }
\end{aligned}
$$

For Equation 10, the partial derivative of $\rho$ with respect to each independent variable is the value of the constant term that is multiplied times that respective independent variable in the original function, as shown in Equation 5. This is because Equation 5 is linear. For example, $\partial \rho / \partial \mathrm{H} 2 \mathrm{O}$ is -0.788 (see Equation 5). For block cracking, the expected value and variance of both $\rho$ and $\beta$ were determined based on Equations 5 and 6, respectively. The expected value and variance of $\rho$ are shown in Equations 11 and 12, respectively.

$$
\begin{aligned}
& E[\rho(H 2 O, W S, S C)]=63.0-0.788(2.32)-24.0(3.38)+6.79(5.74)=19.0 \\
& \operatorname{Var}(\rho)=[-0.788]^{2}[.275]+[-24.0]^{2}[0.162]+[6.79]^{2}[.816]=131
\end{aligned}
$$

Similarly the expected value of $\beta$ was found to be 2.35 and the variance of $\beta$ was found to be 4.68 . 
The next step in determining a solution with reliability considerations is to determine a probability density function for the variable of time. The CDF was rearranged so that the time to the distress density critical level $\left(\mathrm{DD}_{\text {crit }}\right)$ could be calculated with $\rho, \beta$, and $\mathrm{DD}_{\text {crit }}$ as inputs, as shown in Equation 13. The critical distress densities correspond to deduct values of 25 points for primary pavements and 45 points for secondary pavements, on the scale of 100 . The critical level of distress density for block cracking on primary and secondary pavements is 11 and 66 percent, respectively. The critical level of distress density for longitudinal/transverse cracking on primary and secondary pavements is 5 and 16 percent, respectively. The critical level of distress density for raveling and weathering on primary and secondary pavements is 15 and 51 percent, respectively.

$$
t_{\text {crit }}=\rho /\left[\left[-\ln \left(D_{\text {crit }} / 100\right)\right]^{\wedge}(1 / \beta)\right]
$$

To obtain a probability density function for time, a selected value of critical distress density level $\left(\mathrm{DD}_{\text {crit }}\right)$ along with the expected values and variances of $\rho$ and $\beta$ need to be applied to equation 13 . The method selected for finding a probability distribution of time to $t_{\text {crit }}$ is the Monte Carlo simulation technique (Harr 1987). This process involves randomly selecting variables from distributions for each variable in the 
equation and calculating the value of the function. This process is repeated many times until a distribution for the dependent variable can be examined. The number of replicates required depends on the level of confidence desired in the answer. For an equation with two variables, approximately 4,500 replicates are required for a 90 percent level of confidence. For levels of confidence of 95 percent and 99 percent, the respective number of required replicates is approximately 148,000 and $277,000,000$ (Harr 1987).

The Monte Carlo simulation technique requires that a distribution for the input variables be known (Harr 1987). Based on the mean and variance determined for $\rho$ and $\beta$, appropriate distributions can be selected. All values of both $\rho$ and $\beta$ must be greater than or equal to zero. Also, the standard deviations are approximately equal to the means. Therefore, the most appropriate distribution is the exponential distribution (Harr 1987). The exponential distribution has a high positive skew.

A program for performing Monte Carlo simulations was used to determine a probability distribution for $t_{\text {crit }}$ (Sun 1993). The results for two values of $\mathrm{DD}_{\text {crit }}$ are shown in Table 22. The $\mathrm{DD}_{\text {crit }}$ values of 11 and 66 are distress density levels of block cracking associated with PCI levels of 75 and 55. The PCI levels of 75 and 55 are the critical values for primary and secondary pavements, respectively. The number of replicates shown in Table 22 indicates the number of Monte Carlo simulations performed. The value in years associated with a $\mathrm{P}$ level shown in Table 22 indicates the 
level of confidence based on the probability density function for time. For example, a P level of 0.1 indicates a confidence level of 90 percent that the distress will not reach the critical distress density before that time. The $P$ values of $0.2,0.25$, and 0.5 are associated with confidence levels of 80,75 and 50 percent, respectively. The preceding procedure can be used with any level of distress density and any level of confidence can be determined.

\section{TABLE 22. Summary of Monte Carlo Simulation}

\begin{tabular}{lccccc} 
DD ort & $\begin{array}{c}\text { Number of } \\
\text { Replicates }\end{array}$ & \multicolumn{4}{c}{ Time (yrs) to Reach DD ort } \\
\cline { 3 - 6 } & & $\mathrm{P}=0.1$ & $\mathrm{P}=0.2$ & $\mathrm{P}=0.25$ & $\mathrm{P}=0.5$ \\
$(1)$ & $(2)$ & $(3)$ & $(4)$ & $(5)$ & $(6)$ \\
\hline 11 & 500 & .4 & 1.6 & 2.1 & 5.1 \\
& 1,000 & 1.0 & 2.4 & 3.2 & 6.7 \\
& 10,000 & .9 & 2.2 & 2.9 & 6.7 \\
\hline 66 & 500 & 2.1 & 4.9 & 6.2 & 19.8 \\
& 1,000 & 2.3 & 5.2 & 7.0 & 20.0 \\
& 10,000 & 2.4 & 5.2 & 6.8 & 19.4 \\
\hline
\end{tabular}


The results shown in Table 22 show there is a wide range in the predicted time in years for a feature to reach the critical distress density level, depending on the level of confidence considered. This is not too surprising considering the limited data set used to develop the model and the wide range in possible growth curves as shown in Figures 9, 10 and 11 . This wide dispersion in reliability results shows why it is important to shift or adjust the performance prediction curve with field data when available. The shifting or adjusting of the performance curve based on individual feature PCI data should improve the prediction capability of the model.

\section{TIME TO CRITICAL DISTRESS DENSITY}

As discussed previously, the ultimate goal of the distress density prediction model is to determine the time when a pavement feature will reach the critical distress density resulting in a critical PCI level according to criteria established by the Army. Based on the processes used in the Army for requesting funds, and considering the limitations of the proposed model, it is recommended that the time to $\mathrm{DD}_{\text {crit }}$ be reported in categories of years. An appropriate system of categories would be similar to that used in the Texas method for determining remaining pavement life (Michalak and Scullion 1995). The categories are as follows: $0-2,2-5,5-10$, and $10+$ years.

This system of categories should work well for Army installations. Normal funding requests are made annually. Budgets for projected fund requirements for out years, $2-5$ years, are also updated annually. Periodically, every 2 or 3 years, requests are 
made for long term budget projections that include a 5-10 year period. Finally, any pavement projected to have a life greater than 10 years before the critical distress density level will be reached should be surveyed in the interim to provide an update on the performance of those features. 


\section{CHAPTER VI \\ SUMMARY, CONCLUSIONS AND RECOMMENDATIONS}

\section{SUMMARY}

At the beginning of this project it was intended that an improved structural performance prediction model would be developed because the current structural evaluation procedure does not consider fatigue or past structural damage. It became evident, after some investigation, that structural performance was not a significant problem for most Army airfield pavements. Therefore the research was redirected to develop a distress density growth model. Because the Army specifies minimum pavement surface condition levels, it was determined that a procedure for predicting when individual pavement features would reach the critical distress density level would benefit the Army.

The database of airfield evaluations was used as a basis for developing a distress density prediction model. Probability considerations and observed performance characteristics were used to select an appropriate equation form for modeling distress density growth. Reliability concepts were applied to the model to provide predictions in terms of time to the critical distress density level at selected levels of confidence. 


\section{CONCLUSIONS}

There are three major findings that have been discovered through the work documented in this dissertation:

1. Few Army airfield pavements have failed structurally.

2. The majority of the distresses observed on Army airfield pavements are environmentally induced.

3. An environmental distress prediction model is a tool needed by the Army for determining when airfield pavements will reach a critical condition.

The Army should be focusing more research on determining the causes, impact, and developing procedures for mitigating the effects of environmentally induced distresses on their airfield pavements. The model developed in this study provides a tool for predicting environmental distress development on flexible Army airfield pavements. The distress density growth model developed has many limitations as would be expected with any empirical model. However, it does provide an advantage over no prediction procedure. 


\section{RECOMMENDATIONS}

The distress prediction model procedure developed herein should be incorporated and used by the Corps of Engineers in the Army airfield evaluation procedure. The curve fitting technique that was implemented in this study should be used for any feature that has sufficient performance data (i.e. two data points with PCI values less than the critical value and no major rehabilitation or reconstruction during the evaluation period). When data does exist for fitting new Gumbel CDF curves, the resulting $\rho, \beta$ and the associated independent variable data should be used to update the regression equations. The performance prediction equation that predicts the time to a critical distress density should be used, and shifted as appropriate, for features that have only one distress density data point and have similar conditions as those used for developing the $\rho$ and $\beta$ regression equations. For features with no distress density, the prediction curve can be used, or no prediction should be made until distress initiation is observed during a PCI survey.

When the model is used, the values determined for time to $\mathrm{DD}_{\text {crit }}$ should be used for work planning and programming purposes by the local installations and to justify funding requirements. The time to $\mathrm{DD}_{\text {crit }}$ can be determined at any level of confidence desired. It is recommend that the 50 percent confidence level be used for planning and programming purposes. The reasons for recommending the use of time to $\mathrm{DD}_{\text {crit }}$ at a 50 
percent confidence level are as follows: 1) the empirical nature of the model, 2) the frequency of the condition surveys, and 3) the lack of catastrophic failure associated with pavement failures. By lack of catastrophic failure it is meant that loss of life is not expected if the PCI of an airfield pavement drops below 75 for a primary pavement or 55 for a secondary pavement. In addition to using the 50 percent confidence level for reporting the time to $\mathrm{DD}_{\text {crit }}$, it is also recommended that the time to $\mathrm{DD}_{\text {crit }}$ be categorized as follows: $0-2,2-5,5-10$ and $10+$ years. This should provide the local installations with needed input for determining when funds will be required, and this will coincide with the requirements for funding requests that are made by Army installations. Performing the condition surveys on a five-year cycle will ensure that all features are adequately monitored.

Although the model was examined for use in developing prediction capabilities for three distress types, there were only enough data to develop preliminary relationships for two distress types. As more data become available, and if other distress types develop to significant levels, additional relationships should be developed for predicting the development of other distresses. 
It is recommended that a long term, detailed pavement evaluation program for selected sites be initiated. The location of the sites should be evenly spread over climatic zones. All available testing techniques, including nondestructive and destructive, should be performed at these sites on a periodic basis. The purpose for doing this is to provide information on what data are important and should be collected at all the airfields evaluated by the Corps of Engineers. As a researcher, collecting all the data possible at all sites sounds wonderful. Realistically, the cost and time for doing this would likely be prohibitive. Collecting detailed data on an appropriate sample of airfield pavements should be adequate to identify those data that should be collected on all airfield pavements. The results of a detailed long term pavement performance study will provide information for improving the models developed in this study and determining other factors effecting the performance of Army airfield pavements.

Selected material data should be collected at all Army airfields evaluated because one of the most significant limitations to the model developed in this study is the lack of material data. The development of environmental distresses is a function of how the materials react to the environment. Some asphalt cements and asphalt concretes are more susceptible to deterioration due to exposure to environmental conditions. Without appropriate material data, these factors could not be considered. This is evident in the block cracking model which currently only contains environmental parameters. However, the response of the material to the environment would be expected to be a function of the properties of the material. An important factor in the development of 
block cracking is the stiffness of the asphalt cement. The stiffness of the asphalt cement changes over time as the asphalt cement ages due to oxidation, and hardens due to molecular restructuring. Research should be conducted into finding a procedure for determining the stiffness of the asphalt cement due to both the oxidative aging and molecular restructuring. Short of that research and until it can be accomplished, the standard Marshall test performed on cores obtained from the field would provide some indication of the aging of the asphalt, as would viscosity and penetration tests on the recovered binder. In addition, the SHRP low temperature strength and creep compliance tests would provide better indications of the low temperature susceptibility to cracking of the asphalt cement. The results of the SHRP tests could also be used to incorporate the SHRP asphalt cracking model into the performance prediction models developed herein.

More complete FWD data should be collected. Currently, the Corps of Engineers evaluation procedure only requires the collection of the peak load and deflection data; the time histories of these two parameters are not collected. The time histories would allow for a dynamic analysis of the pavement, and in particular the determination of the damping effects of the pavement. It would be expected that as the pavement deteriorates, the damping effect would increase. For example, if micro-cracks develop as block cracking initiates, it would be expected that a corresponding measurable increase in damping would be observed in the deflection time histories. The Corps of Engineers has the capability to collect the time histories of the load and deflection during FWD testing. 
In addition, the FWD should not only be placed in the center of blocks to avoid cracks, but testing should be conducted and noted near cracks so that the impact of the cracks on the backcalculated moduli can be determined. This should better tell whether the block cracking would decrease the life of the pavement if it were subjected to mobilization loadings. It is expected that the base and subbase below the cracks have been weakened due to water infiltration and exposure to the environment. The current Corps of Engineers guidance recommends that that block cracks be sealed. However, unless appropriate FWD testing is conducted to ensure that the pavement structure has not been weakened in the area around the cracks, it is not known whether crack sealing is appropriate or a structural upgrade should be required.

Innovative NDT procedures should be investigated to make sure the Corps of Engineers remains on the cutting edge of pavement evaluation concepts and technologies. Two new procedures being developed include the use of a rolling weight deflectometer and ground penetrating radar. These techniques may yield faster, better and more data for evaluating pavements. The technique of ground penetrating radar may provide information related to asphalt content, moisture conditions, and voids. If this technique is proven to be accurate, a great deal of useful information could be collected relatively quickly and inexpensively during airfield evaluations. 
In summary, the Corps of Engineers should implement the distress density growth prediction technique developed in this study due to the predominance of environmental distresses on Army airfield pavements. In addition, the Corps of Engineers, while conducting Army airfield evaluations, should collect additional data that may provide more insight into the development of these environmentally induced distresses. Finally, innovative data collection and evaluation techniques should be investigated so that the Corps of Engineers can remain in the forefront of pavement evaluation technologies. 


\section{REFERENCES}

American Association of State Highway and Transportation Officials. (1993). AASHTO Guide for the Design of Pavement Structures. Washington, D.C.

Ang, A H-S, and Tang W. H. (1990). Probability Concepts in Engineering Planning and Design. Vol. II. John Wiley and Sons, New York.

Barker, W. R., and Brabston, W. N. (1975). "Development of a Structural Design Procedure for Flexible Airport Pavements." Technical Report S-75-1, U.S. Army Engineer Waterways Experiment Station, Vicksburg, Mississippi.

Burns, C. D., Hutchinson, R. L., Ulery, H. H., Watkins, J. E., and Grau, R. W. (1971). "Multiple-Wheel Heavy Gear Load Tests." Technical Report S-71-17, Vol. II. U.S. Army Engineer Waterways Experiment Station, Vicksburg, Mississippi.

Bush, Albert J., III. (1986). "Performance Prediction of Low Volume Airfield Pavements." Technical Report GL-86-14, U.S. Army Engineer Waterways Experiment Station, Vicksburg, Mississippi.

Department of the Army. (1996). Directory of Public Works Annual Summary of Operations. Vol. III. U.S. Army Center for Public Works, Washington, D.C. . (1985). Facilities Engineering and Housing Annual Summary of Operations. Vol. III. Office of the Assistant Chief of Engineers, Washington, D.C.

Green, J. L. and Hall, J. W. (1975). "Nondestructive Vibratory Testing of Airport Pavements." Technical Report S-75-14. Vol. I. U.S. Army Engineer Waterways Experiment Station, Vicksburg, Mississippi.

Gronberg, Gordon D., and Blosser, Nellie B. (1956). "Lives of Highway Surfaces - Half Century Trends." Highway Research Board, Proceedings of the Thirty-Fifth Annual Meeting, Burggraf, Fred, and Ward, Elmer M., eds., Washington, D.C., 89-101.

Hall, J. W., Jr. (1987). "Pavement Evaluation Concepts Using Nondestructive Structural Evaluation and Pavement Condition Index." Miscellaneous Paper GL87-5, Waterways Experiment Station, Vicksburg, Mississippi.

Harr, M. E. (1987). Reliability-Based Design in Civil Engineering. McGraw Hill Book Company, New York. 
Headquarters, Department of the Army. (1991). "Surfaced Areas, Bridges, Railroad Track and Associated Appurtenances." Army Regulation AR 420-72, Washington, D.C.

Headquarters, Departments of the Army and the Air Force. (1993). "Nondestructive Procedures for Airfield Pavement Evaluation." Technical Manual TM 5-8265/AFM 88-24, Chap.5, Washington, D.C.

. (1990). "Airfield Flexible Pavement Evaluation." Technical Manual TM 5-8262/AFM 88-24, Chap. 2, Washington, D.C.

. (1989). "Procedures for U.S. Army and U.S. Air Force Airfield Pavement Condition Surveys." Technical Manual TM 5-826-6/AFR 93-5, Washington, D.C.

. (1981). "Airfield Pavement Evaluation Concepts." Technical Manual TM 5 827-1/AFM 88-24, Chap. 1, Washington, D.C.

Headquarters, U.S. Army Corps of Engineers. (1997). "Engineering Instructions Airfield Pavement Evaluation." EI 02C036, Joint Departments of the Army, Navy, and the Air Force, Washington, D.C.

Hveem, F. N. (1955). "Pavement Deflections and Fatigue Failures." Highway Research Bulletin No. 114, Washington, D.C.

Janoo, Vincent. (1998). Personal telephone conversation in regards to the use and results of the SHRP thermal fatigue cracking model. U.S. Army Engineer Cold Regions Research Laboratory, Hanover, New Hampshire.

Joseph, A. H. and Hall, J. W., Jr. (1971). "Deflection Coverage Relationship for Flexible Pavements." Miscellaneous Paper S-71-18, U.S. Army Engineer Waterways Experiment Station, Vicksburg, Mississippi.

Lukanen, E.O. (1986). "Development of Pavement Life Prediction Models." MN/RD86/04, Minnesota Department of Transportation, Midwest Pavement Management, St. Paul, Minnesota.

Lukanen, E. O. (1980). "Applications of AASHO Road Test Results to Design of Flexible Pavements in Minnesota." FHWA/MN-80/09, Minnesota Department of Transportation, St. Paul, Minnesota. 
Lytton, R. L. (1987). "Concepts of Pavement Performance Prediction and Modeling." Proc., Second North American Conference on Managing Pavements, Vol. 2. Toronto, Ontario, Canada, 2.4-2.19

Lytton, R. L., Uzan, J., Fernando, E. G., Roque, R., Hiltunen, D., and Stoffels, S. M. (1993). "Development and Validation of Performance Prediction Models and Specification for Asphalt Binder and Paving Mixes." SHRP-A-357, Strategic Highway Research Program, National Research Council, Washington, D.C.

McCaffrey, P. S., Jr. (1994). "Airfield Pavement Evaluation Sparta-Fort McCoy Airport, Wisconsin." Miscellaneous Paper GL-94-11, U.S. Army Engineer Waterways Experiment Station, Vicksburg, Mississippi.

Michalak, C. H., and Scullion, T. (1995). "Modulus 5.0: User's Manual." TX-96/ 1987-1, TTI: 7-1987, Texas Transportation Institute, College Station, Texas.

Micro PAVER, A Pavement Management System, Version 3.21 User's Guide. (1989). Division of Conferences and Institutes, University of Illinois at UrbanaChampaign, Illinois.

Microsoft. (1995). Getting Results with Microsoft Office for Windows 95, Version 7.0, Microsoft Corporation, Redmond, Washington.

Moody, E. D. (1997). "Framework for the Development and Calibration of PCC Performance Models Utilizing the LTPP Database." Doctoral Dissertation, Texas A\&M University, College Station, Texas.

Moore, W. M., Hanson, D. I. and Hall, J. W., Jr. (1978). "An Introduction to Nondestructive Structural Evaluation of Pavements." Transportation Research Circular Number 189, Transportation Research Board, Washington, D.C.

NOAA, National Oceanic and Atmospheric Adminstration. (1998). Comparative Climatic Data. Web site: http://www.ncdc.noaa.gov/.

NSRDB, National Solar Radiation Data Base. (1998). Daily Statistics File. Web site: http://rredc.nrel.gov/solar/old_data/asrdb/dsf/.

Nunez, M. M. and Shahin, M. Y. (1986). "Pavement Condition Data Analysis and Modeling." Transportation Research Record 1070, Transportation Research Board, Washington, D.C., 125-132. 
O'Brien III, Dixon E., Kohn, Starr D., and Shahin, Mohamed Y. (1983). "Prediction of Pavement Performance by Using Nondestructive Test Results." Transportation Research Record 943, Transportation Research Board, Washington, D.C., 13-17.

Petersen, J. C. (1984). "Chemical Composition of Asphalt as Related to Asphalt Durability." Transportation Research Record 999, Transportation Research Board, Washington, D.C., 13-30.

Rauhut, J. B., and Darter, M. I. (1994). "Early Analyses of LTPP General Pavement Studies Data, Executive Summary." SHRP-P-392, Strategic Highway Research Program, National Research Council, Washington, D.C.

Shahin, M. Y. (1972). "Prediction of Low-Temperature and Thermal Fatigue Cracking in Flexible Pavements." Doctoral Dissertation, The University of Texas at Austin, Austin, Texas.

Shahin, M. Y., Darter, M. I., and Kohn, S. D. (1977). "Development of a Pavement Maintenance Management System." CERL-TR-C-76. Vol-1. Construction Engineering Research Laboratory, Champaign, Illinois.

Shahin, M. Y., and Kohn, S. D. (1981). "Pavement Maintenance Management for Roads and Parking Lots." Technical Report M-294, Construction Engineering Research Laboratory, Champaign, Illinois.

Shahin, Mohamed Y. (1982). "Airfield Pavement Distress Measurement and Use in Pavement Management." Transportation Research Record 893, Transportation Research Board, Washington D.C., 59-63.

Shahin, Mohamed Y., and Becker, J. M. (1985). "Development of Performance Prediction Models for Airfield Pavements." Transportation Research Record 985, Transportation Research Board, Washington D.C., 25-33.

Shahin, Mohamed Y., and Kohn, Starr D. (1977). "Development of a Pavement Condition Rating Procedure for Roads, Streets, and Parking Lots." Interim Report M-268, Construction Engineering Research Laboratory, Champaign, Illinois.

Shahin, Mohamed Y., Nunez, Margarita M., Broten, Margaret R., Carpenter, Samuel H., and Sameh, Ahmed. (1987). "New Techniques for Modeling Pavement Deterioration." Transportation Research Record 1123, Transportation Research Board, Washington, D.C., 40-46. 
Shahin, Mohamed Y., and Rozanski, Francine M. (1977). "Automated Pavement Maintenance and Repair Management System." Interim Report C-79, Construction Engineering Research Laboratory, Champaign, Illinois.

Simpson, A. L., Rauhut, J. B., Jordahl, P. R., Owusu-Antwi, E., Darter, M. I., Ahmad, R., Pendelton, O. J., and Lee, Y. (1994). "Sensitivity Analyses for Selected Pavement Distress." SHRP-P-393, Strategic Highway Research Program, National Research Council, Washington, D.C.

Skok, E. L., and Lukanen, E. O. (1982). "Deflection and Serviceability Trends for Predicting Pavement Rehabilitation Needs." Commission No. 82-080, Midwest Pavement Mangement, Inc., Wayzata, Minnesota.

Smith, R. E., Darter, M. I., Carpenter, S. H., and Shahin, M. Y. (1987). "Adjusting Performance Curves for the Influence of Maintenance and Rehabilitation." Proc., Second North American Conference on Managing Pavements, Vol. 2. Toronto, Ontario, Canada, 2.399-2.410

Sun, J. C. (1993). Correlated Random Variables Generator, Version $\alpha$ (computer program). Purdue University, Lafayette, Indiana.

Ullidtz, Per. (1987). Pavement Analysis. Elsevier Science Publishing Company Inc., New York.

Zollinger, D. G., and McCullough, B. F. (1994). "Development of Weibull Reliability Factors and Analysis for Calibration of Pavement Design Models Using Field Data." Transportation Research Record TRR 1449, Transportation Research Board, Washington, D.C., 18-25. 


\section{ARMY AIRFIELD EVALUATION REPORTS USED FOR DATA SOURCE}

\section{(SUPPLEMENTAL SOURCES)}

Bentsen, R. A. (1986). "Airfield Pavement Evaluation Cairns Army Airfield Fort Rucker, Alabama." Miscellaneous Paper GL-86-18, U.S. Army Engineer Waterways Experiment Station, Vicksburg, Mississippi.

Bentsen, R. A. (1986). "Airfield Pavement Evaluation Los Alamitos Army Airfield Los Alamitos, California." Miscellaneous Paper GL-86-13, U.S. Army Engineer Waterways Experiment Station, Vicksburg, Mississippi.

Bentsen, R. A. (1985). "Airfield Pavement Evaluation Biggs Army Airfield, Fort Bliss, Texas." Miscellaneous Paper GL-85-20, U.S. Army Engineer Waterways Experiment Station, Vicksburg, Mississippi.

Bentsen, R. A., and Dorman, C. W. (1985). "Airfield Pavement Evaluation Hood Army Airfield Fort Hood, Texas." Miscellaneous Paper GL-85-18, U.S. Army Engineer Waterways Experiment Station, Vicksburg, Mississippi.

Bentsen, R. A., Grogan, W. P. and Kennedy, M. A. (1987). "Airfield Pavement Evaluation Phillips Army Airfield Aberdeen Proving Ground, Maryland." Miscellaneous Paper GL-87-6, U.S. Army Engineer Waterways Experiment Station, Vicksburg, Mississippi.

Bentsen, R. A., and Mathews, D. D. (1985). "Airfield Pavement Evaluation Marshall Army Airfield Fort Riley, Kansas." Miscellaneous Paper GL-85-10, U.S. Army Engineer Waterways Experiment Station, Vicksburg, Mississippi.

Grau, R. W. (1995). "Airfield Pavement Evaluation, Libby Army Airfield, Fort Huachuca, Arizona." Miscellaneous Paper GL-95-11, U.S. Army Engineer Waterways Experiment Station, Vicksburg, Mississippi.

Grau, R. W. (1984). "Airfield Pavement Evaluation Hunter Army Airfield Savannah, Georgia." Miscellaneous Paper GL-84-1, U.S. Army Engineer Waterways Experiment Station, Vicksburg, Mississippi.

Grogan, W. P. (1994). "Airfield Pavement Evaluation, Redstone Army Airfield, Redstone Arsenal, Huntsville, Alabama." Miscellaneous Paper GL-94-19, U.S. Army Engineer Waterways Experiment Station, Vicksburg, Mississippi. 
Grogan, W. P. (1988). "Airfield Pavement Evaluation Muir Army Airfield Fort Indiantown Gap, Annville, Pennsylvania." Miscellaneous Paper GL-88-18, U.S. Army Engineer Waterways Experiment Station, Vicksburg, Mississippi.

Grogan, W. P. (1988). "Airfield Pavement Evaluation Redstone Army Airfield Redstone Arsenal, Huntsville, Alabama." Miscellaneous Paper GL-88-24, U.S. Army Engineer Waterways Experiment Station, Vicksburg, Mississippi.

Horihan, M. J. (1994). "Airfield Pavement Evaluation Forney Army Airfield Fort Leonard Wood, Missouri." Miscellaneous Paper GL-87-7, U.S. Army Engineer Waterways Experiment Station, Vicksburg, Mississippi.

Horihan, M. J. (1986). "Airfield Pavement Evaluation Selah Creek Airstrip, Yakima Firing Center, Washington ." Miscellaneous Paper GL-86-31, U.S. Army Engineer Waterways Experiment Station, Vicksburg, Mississippi.

Horihan, M. J. (1986). "Airfield Pavement Evaluation Wheeler Sack Army Airfield Fort Drum, New York." Miscellaneous Paper GL-86-32, U.S. Army Engineer Waterways Experiment Station, Vicksburg, Mississippi.

Johnson, W. G. (1994). "Airfield Pavement Evaluation Phillips Army Airfield Aberdeen Proving Ground, Maryland." Miscellaneous Paper GL-94-47, U.S. Army Engineer Waterways Experiment Station, Vicksburg, Mississippi.

Mason, L. W., and McCaffrey, P. S., Jr. (1994). "Airfield Pavement Evaluation, Butts Army Airfield, Fort Carson, Colorado." Miscellaneous Paper GL-94-35, U.S. Army Engineer Waterways Experiment Station, Vicksburg, Mississippi.

Mathews, D. D. (1991). "Condition Survey Los Alamitos Army Airfield Los Alamitos, California." Miscellaneous Paper GL-91-1, U.S. Army Engineer Waterways Experiment Station, Vicksburg, Mississippi.

Mathews, D. D. (1990). "Condition Survey, Biggs Army Airfield Fort Bliss, Texas." Miscellaneous Paper GL-90-8, U.S. Army Engineer Waterways Experiment Station, Vicksburg, Mississippi.

Mathews, D. D. (1989). "Condition Survey, Butts Army Airfield Fort Carson, Colorado." Miscellaneous Paper GL-89-23, U.S. Army Engineer Waterways Experiment Station, Vicksburg, Mississippi.

McCaffrey, P. S., Jr. (1994). "Airfield Pavement Evaluation Sparta-Fort McCoy Airport, Wisconsin." Miscellaneous Paper GL-94-11, U.S. Army Engineer Waterways Experiment Station, Vicksburg, Mississippi. 
McCaffrey, P. S., Jr., and Grau, R. W. (1994). "Airfield Pavement Condition Survey Forney Army Airfield Fort Leonard Wood, Missouri." Miscellaneous Paper GL96-26, U.S. Army Engineer Waterways Experiment Station, Vicksburg, Mississippi.

McCaffrey, P. S., Jr., and Perkins, J. D., Jr. (1986). "Airfield Pavement Evaluation, McCoy Army Airfield Camp McCoy, Wisconsin." Miscellaneous Paper GL-8620, U.S. Army Engineer Waterways Experiment Station, Vicksburg, Mississippi.

Newman, J. K. (1994). "Airfield Pavement Evaluation, Selah Creek Airstrip, Yakima Firing Center, Washington." Miscellaneous Paper GL-94-52, U.S. Army Engineer Waterways Experiment Station, Vicksburg, Mississippi.

Pittman, D. W., and Rosser, T. B., III. (1994). "Airfield Pavement Evaluation, Simmons Army Airfield, Fort Bragg, North Carolina " Miscellaneous Paper GL94-57, U.S. Army Engineer Waterways Experiment Station, Vicksburg, Mississippi.

Rosser, T. B. (1994). "Airfield Pavement Evaluation, Marshall, Army Airfield, Fort Riley, Kansas." Miscellaneous Paper GL-94-40, U.S. Army Engineer Waterways Experiment Station, Vicksburg, Mississippi.

Rosser, T. B. (1986). "Airfield Pavement Evaluation, Simmons Army Airfield Fort Bragg, North Carolina." Miscellaneous Paper GL-86-16, U.S. Army Engineer Waterways Experiment Station, Vicksburg, Mississippi.

Rosser, T. B., III. (1994). "Airfield Pavement Evaluation, Cairns Army Airfield Fort Rucker, Alabama." Miscellaneous Paper GL-94-6, U.S. Army Engineer Waterways Experiment Station, Vicksburg, Mississippi.

Rosser, T. B., III. (1994). "Airfield Pavement Evaluation, Hood Army Airfield, Fort Hood, Texas." Miscellaneous Paper GL-94-31, U.S. Army Engineer Waterways Experiment Station, Vicksburg, Mississippi.

Rosser, T. B., III. (1994). "Airfield Pavement Evaluation, Los Alamitos Army Airfield, Los Alamitos, California." Miscellaneous Paper GL-94-3, U.S. Army Engineer Waterways Experiment Station, Vicksburg, Mississippi.

Rosser, T. B., III (1994). "Airfield Pavement Evaluation, Wheeler-Sack Army Airfield, Fort Drum, New York." Miscellaneous Paper GL-94-17, U.S. Army Engineer Waterways Experiment Station, Vicksburg, Mississippi. 
Rosser, T. B., III. (1993). "Airfield Pavement Evaluation, Biggs Army Airfield, Fort Bliss, Texas." Miscellaneous Paper GL-93-22, U.S. Army Engineer Waterways Experiment Station, Vicksburg, Mississippi.

Rosser, T. B., III. (1990). "Condition Survey, Cairns Army Airfield Fort Rucker, Alabama." Miscellaneous Paper GL-90-20, U.S. Army Engineer Waterways Experiment Station, Vicksburg, Mississippi.

Rosser, T. B., III. (1990). "Condition Survey, Simmons Army Airfield Fort Bragg, North Carolina." Miscellaneous Paper GL-90-11, U.S. Army Engineer Waterways Experiment Station, Vicksburg, Mississippi.

Rosser, T. B., III. (1988). "Airfield Pavement Evaluation, Libby Army Airfield, Fort Huachua (sic), Arizona." Miscellaneous Paper GL-88-9, U.S. Army Engineer Waterways Experiment Station, Vicksburg, Mississippi.

Rosser, T. B., III. (1988). "Condition Survey, Hood Army Airfield Fort Hood, Texas." Miscellaneous Paper GL-88-32, U.S. Army Engineer Waterways Experiment Station, Vicksburg, Mississippi.

Rosser, T. B., III. (1988). "Condition Survey, Hunter Army Airfield Savannah, Georgia." Miscellaneous Paper GL-88-25, U.S. Army Engineer Waterways Experiment Station, Vicksburg, Mississippi.

Rosser, T. B., III. (1988). "Condition Survey, Marshall Army Airfield Fort Riley, Kansas." Miscellaneous Paper GL-88-22, U.S. Army Engineer Waterways Experiment Station, Vicksburg, Mississippi.

Rosser, T. B., III, and Mason, L. W. (1993). "Airfield Pavement Evaluation Forney Army Airfield Fort Leonard Wood, Missouri." Miscellaneous Paper GL-93-8, U.S. Army Engineer Waterways Experiment Station, Vicksburg, Mississippi.

Smith, D. M., and Newman, J. K. (1994). "Airfield Pavement Evaluation, Hunter Army Airfield, Fort Stewart, Georgia." Miscellaneous Paper GL-94-53, U.S. Army Engineer Waterways Experiment Station, Vicksburg, Mississippi.

Weatherford, T. J. (1994). "Airfield Pavement Evaluation, Muir Army Airfield Fort Indiantown Gap, Pennsylvania." Miscellaneous Paper GL-94-38, U.S. Army Engineer Waterways Experiment Station, Vicksburg, Mississippi. 


\section{SUPPLEMENTARY SOURCES CONSULTED}

Artman, David H., Liebman, Judith S., and Darter, Michael I. (TRR 938). "Optimization of Long-Range Major Rehabilitation of Airfield Pavements." Transportation Research Record 938, Transportation Research Board, Washington D.C., 1-11.

Baladi, G. Y., and McKelvey, F. X. (1994). "Mechanistic Evaluation and Calibration of the AASHTO Design Equations and Mechanistic Analysis of the SHARP Asphalt Surfaced Pavement Sections." SHRP-P-678, Strategic Highway Research Program, National Research Council, Washington, D.C.

Berger, Louis, and Greenstein, Jacob. (1983). "Pavement Evaluation and Rehabilitation of Low-Volume Urban Roads." Transportation Research Record 898, Transportation Research Board, Washington, D.C., 189-193.

Butt, Abbas A., Shahin, Mohamed Y., Feighan, Kieran J., and Carpenter, Samuel H. (1987). "Pavement Performance Prediction Model Using the Markov Process." Transportation Research Record 1123, Transportation Research Board, Washington, D.C., 12-19.

Cori, Ivano E., and Houghton, Jewel U. (1971). "Service Lives of Highway Pavements - A Reappraisal." Public Roads, Vol. 36. (No. 9), U.S. Department of Transportation, Federal Highway Administration, Washington, D.C., 92-206.

Darter, Michael I., and Shahin, Mohamed Y. (1980). "Pavement Rehabilitation: Identifying the Need." Journal of Transportation Engineering, Vol. 106. (No. TE1), New York, 1-10.

Freeman, R. B., and Grogan, W. P. (1997). "Statistical Analysis and Variability of Pavement Materials." Technical Report GL-97-12, U.S. Army Engineer Waterways Experiment Station, Vicksburg, Mississippi.

Fwa, Tien F. (1991). "Remaining-Life Consideration in Pavement Overlay Design." Journal of Transportation Engineering, Vol. 117. (No. 6), New York, 585-601.

Grigg, Neil S. (1988). Infrastructure Engineering and Management. John Wiley \& Sons, Inc., New York.

Grogan, W. P. (1991). "Development of a Reliability Based Method for Evaluating a Pavement Feature." M.S. Thesis, Mississippi State University, Mississippi State, Mississippi. 
Haas, Ralph, and Hudson, Ronald W. (1982). Pavement Management Systems. Robert E. Krieger Publishing Company, Malabar, Florida.

Hall, Jim W. Jr. (1987). "Comparative Study of Nondestructive Pavement Testing, MacDill Air Force Base, Florida." Technical Report GL-87-15, U.S. Army Engineer Waterways Experiment Station, Vicksburg, Mississippi.

Headquarters, Department of the Army. (1993). "Nondestructive Procedures for Airfield Pavement Evaluation." Technical Manual TM 5-826-5/AFM 88-24, Chap. 5, Washington, D.C.

. (1991). "Engineering and Design Aircraft Characteristics for Airfield-Heliport Design and Evaluation." Engineering Technical Letter ETL 1110-3-394, U.S. Army Corps of Engineers, Washington, D.C.

. (1988). "Air Traffic Control, Airspace, Airfields, Flight Activities, and Navigational Aids." Army Regulation AR 95-2, Washington, D.C.

. (1988). "Guidance to be Used for the Types of Surfaced Areas." Engineering Technical Letter ETL 1110-3-393, U.S. Army Corps of Engineers, Washington, D.C.

Headquarters, Departments of the Army and the Air Force. (1993). "Standard Practice for Sealing Joints and Cracks in Rigid and Flexible Pavements." Technical Manual TM 5-822-11/AFP 88-6,Chap. 7, Washington, D.C.

. (1990). "Airfield Rigid Pavement Evaluation" Technical Manual TM 5-8263/AFM 88-24, Chap. 3, Washington, D.C.

. (1988). "Airfield Pavement Evaluation Concepts." Technical Manual TM 5826-1/AFM 88-24, Chap. 1, Washington, D.C.

. (1988). "Rigid Pavements for Airfields." Technical Manual TM 5-825-3/AFM 88-6, Chap. 3, Washington, D.C.

Headquarters, Departments of the Army, the Navy, and the Air Force. (1978). "Flexible Pavement Design for Airfields." Technical Manual TM 5-825.2/DM 21.3/AFM 88-6 Chap. 2, Washington, D.C.

Hudson, Ronald W. (1975). "State-of-the-Art in Predicting Pavement Reliability from Input Variability," Contract Report S-75-7, U.S. Army Engineer Waterways Experiment Station, Vicksburg, Mississippi. 
Kirby, Jeffrey G., and Grgas, John M. (1975). "Estimating the Life Expectancy of Facilities." Technical Report P-36, Construction Engineering Research Laboratory, Champaign, Illinois.

Miller, I. and Freud, J. E. (1977). Probability and Statistics for Engineers. Prentice Hall, Inc., Englewood Cliffs, New Jersey.

Richter, Cheryl A., and Irwin, Lynne H. (TRR 1196). "Application of Deflection Testing to Overlay Design: A Case Study." Transportation Research Record 1196, Transportation Research Board, Washington D.C., 193-200.

Roberts, F. L., Kandhal, P. S., Brown, R. E., Lee, D., and Kennedy, T. W. (1991). Hot Mix Asphalt Materials, Mixture Design and Construction. National Asphalt Paving Association Education Foundation, Lanham, Maryland.

Samuels, M. L. (1989). Statistics for the Life Sciences. Dellen Publishing Company, San Francisco.

Schnitter, Otto, Hudson, W. R., and McCollough, B. F. (1985). "Procedure for Design of Overlays for Rigid Pavements for Texas State Department of Highways and Public Transportation." Transportation Research Record 700, Transportation Research Board, Washington D.C., 82-89.

Scullion, Thomas, Mason, John M., and Lytton, Robert L. (1991). "Predicting Reduction in Service Life of Surface-Treated Pavements under Oil Field Traffic." Transportation Research Record 938, Transportation Research Board, Washington D.C., 20-28.

Smith, R. E. (1993). Class Notes for Infrastructure Management. CVEN 624, Texas A\&M University, College Station, Texas.

Taylor, N. H. (1978). "Life Expectancy of Recycled Asphalt Paving." ASTM STP 662, L. E. Wood, Ed., American Society for Testing and Materials, 3-15.

Wadsworth, H. M. (1990). Handbook of Statistical Methods for Engineers and Scientists. McGraw Hill, New York.

Webster, Steve L., Grau, Richard H., Williams, Thomas P. (1992). "Description and Application of Duel Mass Dynamic Cone Penetrometer." Instruction Report GL92-3, U.S. Army Engineer Waterways Experiment Station, Vicksburg, Mississippi. 
Witczak, M. W., and Bell, K. R. (1978). "Remaining Life Analysis of Flexible Pavements." Proceedings-Association of Asphalt Paving Technologists, Technical Sessions, Vol. 47, Minneapolis Minnesota, 229-269. 


\section{APPENDIX A \\ PAVEMENT CONDITION INDEX DATA}

The tables contained in this appendix include the data from individual pavement condition index (PCI) surveys for each of the airfields included in this study. Each table presents the data for a single survey. The tables include the feature name, area of the feature in square meters, the area of individual distress types and severity levels in square meters, and the percent of the distress type mechanism. As an example, in Table A-1, feature A10E had an area of 114,736 sq meters; it had 78,229 sq meters of low severity block cracking ( $43 \mathrm{~L}$ ) and 36,507 sq meters of medium severity block cracking (43M). In addition, 100 percent of the distress observed on feature $\mathrm{A} 10 \mathrm{E}$ was considered to be related to climatic causes. The distress types shown in the tables are listed by their numerical designation. The names associated with the numerical designations are shown in Table 2. Feature designations beginning with an $\mathrm{A}$ (such as $\mathrm{A} 10 \mathrm{E})$ are for aprons; those beginning with an R (such as R10E) are for runways; and those beginning with a $\mathrm{T}$ (such as $\mathrm{T} 12 \mathrm{E}$ ) are for taxiways. 
TABLE A-1. Biggs AAF 1984 PCI

\begin{tabular}{|c|c|c|c|c|c|c|c|c|c|c|c|c|c|c|c|c|c|c|c|}
\hline $\begin{array}{c}\text { Feature } \\
\text { (1) }\end{array}$ & $\begin{array}{c}\text { Area } \\
(2)\end{array}$ & $\begin{array}{l}41 \mathrm{~L} \\
(3)\end{array}$ & $\begin{array}{l}43 \mathrm{~L} \\
(4)\end{array}$ & $\begin{array}{l}43 \mathrm{M} \\
(5)\end{array}$ & $\begin{array}{l}43 \mathrm{H} \\
(6)\end{array}$ & $\begin{array}{l}45 \mathrm{~L} \\
(7)\end{array}$ & $\begin{array}{l}45 \mathrm{M} \\
(8)\end{array}$ & $\begin{array}{l}48 \mathrm{~L} \\
(9)\end{array}$ & $\begin{array}{l}48 \mathrm{M} \\
(10)\end{array}$ & $\begin{array}{l}48 \mathrm{H} \\
(11)\end{array}$ & $\begin{array}{c}49 \\
(12)\end{array}$ & $\begin{array}{l}50 \mathrm{~L} \\
(13)\end{array}$ & $\begin{array}{l}50 \mathrm{M} \\
(14)\end{array}$ & $\begin{array}{l}52 \mathrm{~L} \\
(15)\end{array}$ & $\begin{array}{l}56 \mathrm{~L} \\
(16)\end{array}$ & $\begin{array}{l}56 \mathrm{M} \\
(17)\end{array}$ & $\begin{array}{l}\text { LOAD } \\
\text { (18) }\end{array}$ & $\begin{array}{l}\text { CLIMATE } \\
\text { (19) }\end{array}$ & $\begin{array}{l}\text { OTHER } \\
(20)\end{array}$ \\
\hline A10E & 114736 & 0 & 78229 & 36507 & 0 & 0 & 0 & 0 & 0 & 0 & 0 & 0 & 13 & 0 & 0 & 0 & 0 & 100 & 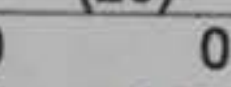 \\
\hline $\mathrm{A} 12 \mathrm{E}$ & 29729 & 0 & 297 & 26756 & 0 & 0 & 0 & 0 & 0 & 0 & 46 & 45 & 0 & 0 & 0 & 0 & 0 & 96.48 & 3.52 \\
\hline A29E & 17392 & 0 & 0 & 16232 & 0 & 0 & 0 & 0 & 0 & 0 & 0 & 0 & 0 & 17392 & 313 & 0 & 0 & 94.17 & 5.83 \\
\hline A6E & 11148 & 0 & 0 & 11148 & 0 & 0 & 0 & 0 & 0 & 0 & 0 & 0 & 0 & 0 & 0 & 0 & 0 & 100 & 0 \\
\hline A9E & 37626 & 0 & 9406 & 0 & 0 & 0 & 0 & 1609 & 188 & 0 & 0 & 0 & 0 & 0 & 0 & 0 & 0 & 100 & 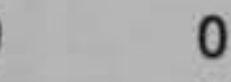 \\
\hline T17E & 5574 & 0 & 0 & 2787 & 0 & 0 & 0 & 41 & 265 & 16 & 0 & 176 & 0 & 390 & 0 & 0 & 0 & 100 & 0 \\
\hline T18E & 50493 & 0 & 0 & 50493 & 0 & 0 & 0 & 0 & 0 & 0 & 0 & 69 & 0 & 0 & 0 & 0 & 0 & 100 & 0 \\
\hline T1E & 6967 & 0 & 0 & 1481 & 1742 & 0 & 873 & 0 & 1198 & 0 & 0 & 0 & 0 & 0 & 0 & 0 & 0 & 75.04 & 24.96 \\
\hline T20E & 34839 & 811 & 3389 & 15545 & 14366 & 0 & 0 & 0 & 167 & 0 & 0 & 0 & 0 & 0 & 0 & 0 & 18.46 & 81.54 & 0 \\
\hline T21E & 5574 & 0 & 0 & 3579 & 0 & 54 & 0 & 56 & 347 & 0 & 0 & 0 & 0 & 0 & 0 & 0 & 0 & 92.46 & 7.54 \\
\hline T25E & 12542 & 0 & 0 & 12542 & 0 & 0 & 0 & 0 & 0 & 0 & 0 & 0 & 0 & 0 & 0 & 0 & 0 & 100 & 0 \\
\hline T26E & 25084 & 0 & 0 & 22839 & 0 & 0 & 0 & 84 & 546 & 0 & 0 & 0 & 0 & 0 & 0 & 75 & 0 & 86.24 & 13.76 \\
\hline T5E & 4646 & 0 & 0 & 4646 & 0 & 0 & 0 & 0 & 0 & 0 & 0 & 0 & 0 & 0 & 0 & 0 & 0 & 100 & 0 \\
\hline T6E & 25084 & 557 & 948 & 22297 & 0 & 0 & 0 & 14 & 56 & 0 & 0 & 0 & 0 & 0 & 0 & 0 & 28.36 & 71.64 & 0 \\
\hline Total & 381434 & 1368 & 92269 & 226851 & 16108 & 54 & 873 & 1804 & 2765 & 16 & 46 & 289 & 13 & 17782 & 313 & 75 & 3.34 & 92.68 & 3.97 \\
\hline Percent & & 0.36 & 24.19 & 59.47 & 4.22 & 0.01 & 0.23 & 0.47 & 0.73 & 0.00 & 0.01 & 0.08 & 0.00 & 4.66 & 0.08 & .02 & & & \\
\hline
\end{tabular}


TABLE A-2. Biggs AAF 1989 PCI

\begin{tabular}{|c|c|c|c|c|c|c|c|}
\hline $\begin{array}{c}\text { Feature } \\
\text { (1) }\end{array}$ & $\begin{array}{c}\text { Area } \\
\text { (2) }\end{array}$ & $\begin{array}{l}43 \mathrm{~L} \\
\text { (3) }\end{array}$ & $\begin{array}{l}43 \mathrm{M} \\
(4)\end{array}$ & $\begin{array}{c}43 \mathrm{H} \\
(5)\end{array}$ & $\begin{array}{l}\text { LOAD } \\
(6)\end{array}$ & $\begin{array}{l}\text { CLIMATE } \\
\text { (7) }\end{array}$ & $\begin{array}{l}\text { OTHER } \\
(8)\end{array}$ \\
\hline $\mathrm{A} 10 \mathrm{E}$ & 114736 & 0 & 0 & 107087 & 0 & 100 & 0 \\
\hline A12E & 29729 & 0 & 0 & 29729 & 0 & 100 & 0 \\
\hline A20E & 4181 & 0 & 0 & 4181 & 0 & 100 & 0 \\
\hline A21E & 1394 & 0 & 0 & 1394 & 0 & 100 & 0 \\
\hline A6E & 11148 & 0 & 0 & 11148 & 0 & 100 & 0 \\
\hline A7E & 1324 & 0 & 0 & 1324 & 0 & 100 & 0 \\
\hline A9E & 37626 & 0 & 37626 & 0 & 0 & 100 & 0 \\
\hline T10E & 3995 & 0 & 3995 & 0 & 0 & 100 & 0 \\
\hline $\mathrm{T} 11 \mathrm{E}$ & 5923 & 0 & 5923 & 0 & 0 & 100 & 0 \\
\hline T16E & 7739 & 7739 & 0 & 0 & 0 & 100 & 0 \\
\hline T20E & 34839 & 0 & 34839 & 0 & 0 & 100 & 0 \\
\hline T5E & 4646 & 0 & 0 & 4646 & 0 & 100 & 0 \\
\hline T6E & 25084 & 0 & 0 & 25084 & 0 & 100 & 0 \\
\hline T7E & 4645 & 0 & 0 & 4645 & 0 & 100 & 0 \\
\hline Total & 287007 & 7739 & 82382 & 189237 & 0 & 100 & 0 \\
\hline Percent & & 2.70 & 28.70 & 65.93 & & & \\
\hline
\end{tabular}


TABLE A-3. Biggs AAF 1994 PCI

\begin{tabular}{|c|c|c|c|c|c|c|}
\hline $\begin{array}{l}\text { Feature } \\
\text { (1) }\end{array}$ & $\begin{array}{l}\text { Area } \\
\text { (2) }\end{array}$ & $\begin{array}{l}43 \mathrm{M} \\
(3)\end{array}$ & $\begin{array}{l}43 \mathrm{H} \\
(4)\end{array}$ & $\begin{array}{l}\text { LOAD } \\
(5)\end{array}$ & $\begin{array}{l}\text { CLIMATE } \\
(6)\end{array}$ & $\begin{array}{l}\text { OTHER } \\
(7)\end{array}$ \\
\hline $\mathrm{A} 10 \mathrm{E}$ & 114736 & 0 & 114736 & 0 & 100 & 0 \\
\hline A20E & 4181 & 0 & 4181 & 0 & 100 & 0 \\
\hline A21E & 1394 & 0 & 1394 & 0 & 100 & 0 \\
\hline A6E & 11148 & 0 & 11148 & 0 & 100 & 0 \\
\hline A9E & 37626 & 37626 & 0 & 0 & 100 & 0 \\
\hline T10E & 3995 & 3995 & 0 & 0 & 100 & 0 \\
\hline T11E & 5923 & 5923 & 0 & 0 & 100 & 0 \\
\hline T16E & 7739 & 7739 & 0 & 0 & 100 & 0 \\
\hline T20E & 34839 & 34839 & 0 & 0 & 100 & 0 \\
\hline T5E & 4646 & 0 & 4646 & 0 & 100 & 0 \\
\hline T6E & 25084 & 0 & 25084 & 0 & 100 & 0 \\
\hline T7E & 4645 & 1858 & 2787 & 0 & 100 & 0 \\
\hline Total & 255954 & 91979 & 163975 & 0 & 100 & $\overline{0}$ \\
\hline Percent & & 35.94 & 64.06 & & & \\
\hline
\end{tabular}


TABLE A-4. Butts AAF 1984 PCI

\begin{tabular}{|c|c|c|c|c|c|c|c|c|c|c|}
\hline $\begin{array}{c}\text { Feature } \\
\text { (1) }\end{array}$ & $\begin{array}{l}\text { Area } \\
(2)\end{array}$ & $\begin{array}{l}41 \mathrm{~L} \\
\text { (3) }\end{array}$ & $\begin{array}{l}48 \mathrm{~L} \\
(4)\end{array}$ & $\begin{array}{c}48 \mathrm{M} \\
(5)\end{array}$ & $\begin{array}{l}48 \mathrm{H} \\
(6)\end{array}$ & $\begin{array}{l}50 \mathrm{~L} \\
(7)\end{array}$ & $\begin{array}{l}53 \mathrm{~L} \\
(8)\end{array}$ & $\begin{array}{l}\text { LOAD } \\
(9)\end{array}$ & $\begin{array}{c}\text { CLIMATE } \\
(10)\end{array}$ & $\begin{array}{c}\text { OTHER } \\
(11)\end{array}$ \\
\hline A1E & 3135 & 0 & 36 & 50 & 0 & 0 & 0 & 0 & 100 & 0 \\
\hline A2E & 4993 & 0 & 250 & 61 & 0 & 0 & 0 & 0 & 100 & 0 \\
\hline A3E & 23964 & 0 & 428 & 621 & 0 & 14 & 41 & 26.21 & 73.79 & 0 \\
\hline R10E & 6967 & 0 & 70 & 114 & 28 & 0 & 0 & 0 & 100 & 0 \\
\hline R11E & 1394 & 0 & 18 & 0 & 0 & 0 & 0 & 0 & 100 & 0 \\
\hline R2E & 3484 & 0 & 19 & 0 & 0 & 0 & 3 & 67.32 & 32.68 & 0 \\
\hline R3E & 3484 & 0 & 102 & 0 & 0 & 0 & 0 & 0 & 100 & 0 \\
\hline R4I & 17837 & 0 & 470 & 196 & 0 & 0 & 0 & 0 & 100 & 0 \\
\hline R5E & 3484 & 0 & 103 & 0 & 0 & 0 & 0 & 0 & 100 & 0 \\
\hline R6E & 3484 & 0 & 133 & 0 & 0 & 0 & 0 & 0 & 100 & 0 \\
\hline R7E & 1394 & 0 & 13 & 59 & 0 & 0 & 0 & 0 & 100 & 0 \\
\hline R8E & 6967 & 0 & 101 & 188 & 0 & 0 & 0 & 0 & 100 & 0 \\
\hline R9I & 2090 & 0 & 22 & 84 & 0 & 0 & 0 & 0 & 100 & 0 \\
\hline T1E & 4645 & 180 & 160 & 176 & 3 & 0 & 0 & 45.21 & 54.79 & 0 \\
\hline T2E & 2739 & 0 & 114 & 58 & 0 & 0 & 2 & 22.65 & 77.35 & 0 \\
\hline T4E & 585 & 0 & 7 & 0 & 0 & 0 & 0 & 0 & 100 & 0 \\
\hline Total & 90649 & 180 & 2046 & 1605 & 30 & 14 & 46 & 10 & 90 & 0 \\
\hline Percent & & 0.20 & 2.26 & 1.77 & 0.03 & 0.02 & 0.05 & & & \\
\hline
\end{tabular}


TABLE A-5. Butts AAF 1989 PCI

\begin{tabular}{|c|c|c|c|c|c|c|c|c|c|c|c|c|c|c|}
\hline $\begin{array}{c}\text { Feature } \\
\text { (1) }\end{array}$ & $\begin{array}{l}\text { Area } \\
\text { (2) }\end{array}$ & $\begin{array}{l}41 \mathrm{~L} \\
(3)\end{array}$ & $\begin{array}{l}43 \mathrm{~L} \\
(4)\end{array}$ & $\begin{array}{l}43 \mathrm{M} \\
(5)\end{array}$ & $\begin{array}{l}48 \mathrm{~L} \\
(6)\end{array}$ & $\begin{array}{l}48 \mathrm{M} \\
(7)\end{array}$ & $\begin{array}{l}48 \mathrm{H} \\
(8)\end{array}$ & $\begin{array}{l}50 \mathrm{~L} \\
(9)\end{array}$ & $\begin{array}{l}50 \mathrm{M} \\
(10)\end{array}$ & $\begin{array}{l}52 \mathrm{H} \\
(11)\end{array}$ & $\begin{array}{l}53 \mathrm{M} \\
(12)\end{array}$ & $\begin{array}{l}\text { LOAD } \\
(13)\end{array}$ & $\begin{array}{l}\text { CLIMATE } \\
(14)\end{array}$ & $\begin{array}{c}\text { OTHER } \\
(15)\end{array}$ \\
\hline A1E & 3135 & 0 & 0 & 0 & 204 & 187 & 0 & 0 & 0 & 3135 & 0 & 0 & 100 & 0 \\
\hline A2E & 4993 & 0 & 936 & 0 & 165 & 42 & 0 & 0 & 12 & 4910 & 0 & 0 & 100 & 0 \\
\hline A3E & 23964 & 0 & 5242 & 0 & 878 & 2088 & 18 & 6 & 0 & 23964 & 0 & 0 & 100 & 0 \\
\hline R10E & 6967 & 0 & 58 & 0 & 901 & 178 & 21 & 0 & 0 & 6967 & 0 & 0 & 100 & 0 \\
\hline R11E & 1394 & 0 & 0 & 0 & 153 & 40 & 0 & 0 & 0 & 1394 & 0 & 0 & 100 & 0 \\
\hline R1E & 3484 & 11 & 0 & 2293 & 77 & 14 & 0 & 0 & 0 & 3484 & 8 & 17.43 & 82.57 & 0 \\
\hline R2E & 3484 & 0 & 0 & 0 & 116 & 0 & 0 & 0 & 0 & 0 & 0 & 0 & 100 & 0 \\
\hline R3E & 3484 & 0 & 0 & 0 & 143 & 0 & 0 & 0 & 0 & 0 & 0 & 0 & 100 & 0 \\
\hline R4I & 17837 & 0 & 0 & 0 & 769 & 0 & 0 & 0 & 0 & 0 & 0 & 0 & 100 & 0 \\
\hline R5E & 3484 & 0 & 0 & 0 & 141 & 0 & 0 & 0 & 0 & 0 & 0 & 0 & 100 & 0 \\
\hline R6E & 3484 & 0 & 0 & 0 & 157 & 0 & 0 & 0 & 0 & 0 & 0 & 0 & 100 & 0 \\
\hline R7E & 1394 & 0 & 373 & 42 & 35 & 6 & 0 & 0 & 0 & 1394 & 0 & 0 & 100 & 0 \\
\hline R8E & 6967 & 0 & 683 & 0 & 493 & 143 & 0 & 0 & 0 & 6967 & 0 & 0 & 100 & 0 \\
\hline R9I & 2090 & 0 & 0 & 0 & 325 & 63 & 0 & 0 & 0 & 2090 & 0 & 0 & 100 & 0 \\
\hline T1E & 4645 & 111 & 1897 & 0 & 742 & 88 & 0 & 0 & 0 & 4645 & 0 & 16.9 & 83.1 & 0 \\
\hline T2E & 2739 & 41 & 377 & 0 & 211 & 109 & 0 & 0 & 0 & 2739 & 0 & 15.62 & 84.38 & 0 \\
\hline T4E & 585 & 0 & 0 & 0 & 38 & 9 & 1 & 0 & 0 & 0 & 0 & 0 & 100 & 0 \\
\hline Total & 94133 & 163 & 9565 & 2334 & 5547 & 2966 & 40 & 6 & 12 & 61691 & 8 & 3 & 97 & 0 \\
\hline Percent & & 0.17 & 10.16 & 2.48 & 5.89 & 3.15 & 0.04 & 0.01 & 0.01 & 65.54 & 0.01 & & & \\
\hline
\end{tabular}


TABLE A-6. Butts AAF 1993 PCI

\begin{tabular}{|c|c|c|c|c|c|c|c|c|c|c|c|c|c|c|c|c|c|c|}
\hline $\begin{array}{l}\text { Feature } \\
\text { (1) }\end{array}$ & $\begin{array}{l}\text { Area } \\
\text { (2) }\end{array}$ & $\begin{array}{l}41 \mathrm{~L} \\
(3)\end{array}$ & $\begin{array}{l}41 \mathrm{H} \\
(4)\end{array}$ & $\begin{array}{l}43 \mathrm{~L} \\
(5)\end{array}$ & $\begin{array}{c}43 \mathrm{M} \\
(6)\end{array}$ & $\begin{array}{l}43 \mathrm{H} \\
(7)\end{array}$ & $\begin{array}{l}48 \mathrm{~L} \\
(8)\end{array}$ & $\begin{array}{c}48 \mathrm{M} \\
(9)\end{array}$ & $\begin{array}{l}48 \mathrm{H} \\
(10)\end{array}$ & $\begin{array}{l}50 \mathrm{~L} 5 \\
\text { (11) }\end{array}$ & $\begin{array}{l}50 \mathrm{M} \\
(12)\end{array}$ & $\begin{array}{l}52 \mathrm{~L} \\
(13)\end{array}$ & $\begin{array}{l}52 \mathrm{H} \\
(14)\end{array}$ & $\begin{array}{l}53 \mathrm{M} \\
(15)\end{array}$ & $\begin{array}{l}53 \mathrm{H} \\
(16)\end{array}$ & $\begin{array}{l}\text { LOAD } \\
\text { (17) }\end{array}$ & $\begin{array}{l}\text { CLIMATE } \\
(18)\end{array}$ & $\begin{array}{l}\text { OTHER } \\
(19)\end{array}$ \\
\hline$\overline{\mathrm{A} 1 \mathrm{E}}$ & 3135 & 0 & 0 & 0 & 3135 & 0 & 0 & 0 & 0 & 0 & 0 & 0 & 3135 & 0 & 0 & 0 & 100 & 0 \\
\hline A2E & 4993 & 0 & 0 & 0 & 0 & 4993 & 0 & 0 & 0 & 0 & 7 & 0 & 4993 & 54 & 250 & 33 & 67 & 0 \\
\hline A3E & 23964 & 0 & 0 & 23964 & 0 & 0 & 0 & 0 & 0 & 10 & 0 & & 23964 & 0 & 0 & 0 & 100 & 0 \\
\hline R10E & 6967 & 0 & 0 & 2322 & 2090 & 0 & 113 & 179 & 0 & 0 & 0 & 0 & 6967 & 0 & 0 & 0 & 100 & 0 \\
\hline R11E & 1394 & 0 & 0 & 0 & 1394 & 0 & 123 & 105 & 0 & 0 & 0 & 1394 & 0 & 0 & 0 & 0 & 100 & 0 \\
\hline R1E & 3484 & 0 & 0 & 0 & 0 & 3484 & 0 & 0 & 0 & 0 & 0 & 0 & 3484 & 0 & 8 & 14 & 86 & 0 \\
\hline R2E & 3484 & 0 & 0 & 0 & 0 & 0 & 30 & 132 & 0 & 0 & 0 & 0 & 0 & 0 & 0 & 0 & 100 & 0 \\
\hline R3E & 3484 & 24 & 0 & 0 & 0 & 0 & 24 & 149 & 0 & 0 & 0 & 0 & 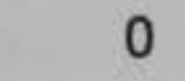 & 0 & 0 & 36 & 64 & 0 \\
\hline R4I & 17837 & 11 & 0 & 0 & 0 & 0 & 165 & 778 & 0 & 0 & 0 & 0 & 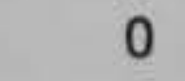 & c & 0 & 20 & 80 & 0 \\
\hline R5E & 3484 & 25 & 0 & 0 & 0 & 0 & 33 & 133 & 0 & 0 & 0 & 0 & 0 & 0 & 0 & 39 & 61 & 0 \\
\hline R6E & 3484 & 0 & 0 & 0 & 0 & 0 & 42 & 156 & 0 & 0 & 0 & 0 & 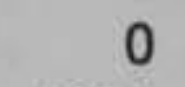 & 0 & 0 & 0 & 100 & 0 \\
\hline R7E & 1394 & 42 & 0 & 1352 & 0 & 0 & 0 & 0 & 0 & 0 & 0 & 0 & 1394 & 0 & 0 & 23 & 77 & 0 \\
\hline R8E & 6967 & 0 & 0 & 2322 & 4645 & 0 & 0 & 0 & 0 & 0 & 0 & 0 & 6967 & 0 & 0 & 0 & 100 & 0 \\
\hline R9I & 2090 & 0 & 0 & 1045 & 697 & 0 & 0 & 0 & 0 & 0 & 0 & 0 & 2090 & 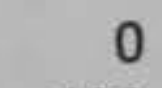 & 0 & 0 & 100 & 0 \\
\hline T1E & 4645 & 0 & 332 & 0 & 0 & 4313 & 0 & 0 & 0 & 0 & 0 & 0 & 4645 & 100 & 0 & 39 & 61 & 0 \\
\hline T2E & 2739 & 0 & ? & 0 & 2739 & 0 & 0 & 0 & 0 & 0 & 0 & 0 & 2739 & 0 & 0 & 0 & 100 & 0 \\
\hline T4E & 585 & 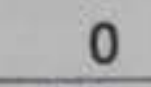 & 0 & 0 & 0 & 0 & 0 & 7 & 20 & 0 & 0 & 0 & 585 & 0 & 0 & 0 & 100 & 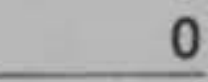 \\
\hline Total & 4133 & 101 & 332 & 31007 & 14700 & 12790 & 530 & 1638 & 20 & 10 & 7 & 1394 & 60966 & 153 & 258 & 12 & 88 & $=$ \\
\hline 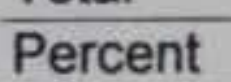 & & 0.11 & 35 & 94 & 15.62 & 13.59 & 0.56 & 1.74 & 0.02 & 01 & 0.01 & 1.48 & 64.77 & 0.16 & 0.27 & & & \\
\hline
\end{tabular}


TABLE A-7. Cairns AAF 1985 PCI

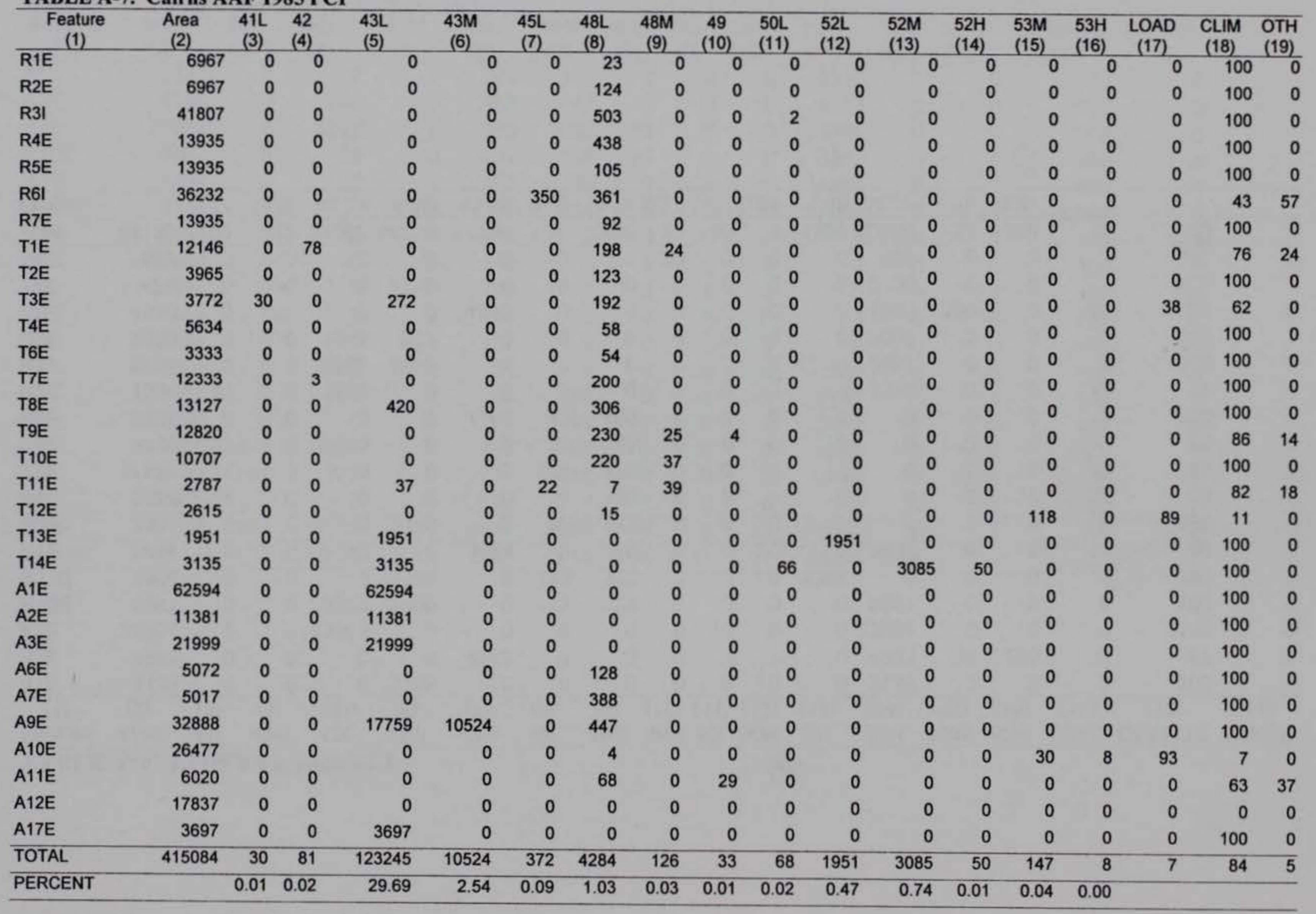


TABLE A-8. Cairns AAF 1989 PCI

\begin{tabular}{|c|c|c|c|c|c|c|c|c|c|c|c|c|c|c|c|c|c|c|}
\hline $\begin{array}{c}\text { Feature } \\
\text { (1) }\end{array}$ & $\begin{array}{c}\text { Area } \\
(2)\end{array}$ & $\begin{array}{l}41 \mathrm{~L} \\
(3)\end{array}$ & $\begin{array}{l}43 L \\
(4)\end{array}$ & $\begin{array}{l}43 \mathrm{M} \\
(5)\end{array}$ & $\begin{array}{l}43 \mathrm{H} \\
(6)\end{array}$ & $\begin{array}{l}44 \mathrm{~L} \\
\text { (7) }\end{array}$ & $\begin{array}{l}45 \mathrm{~L} \\
(8)\end{array}$ & $\begin{array}{l}48 \mathrm{~L} \\
(9)\end{array}$ & $\begin{array}{l}48 \mathrm{M} \\
(10)\end{array}$ & $\begin{array}{c}49 \\
(11)\end{array}$ & $\begin{array}{l}50 \mathrm{~L} \\
(12)\end{array}$ & $\begin{array}{l}52 \mathrm{~L} \\
(13)\end{array}$ & $\begin{array}{l}52 \mathrm{M} \\
(14)\end{array}$ & $\begin{array}{l}53 \mathrm{~L} \\
(15)\end{array}$ & $\begin{array}{l}55 \mathrm{~L} \\
\text { (16) }\end{array}$ & $\begin{array}{l}\text { LOAD } \\
\text { (17) }\end{array}$ & $\begin{array}{l}\text { CLIM } \\
\text { (18) }\end{array}$ & $\begin{array}{l}\text { OTH } \\
\text { (19) }\end{array}$ \\
\hline R1E & 6967 & 0 & 0 & 0 & 0 & 975 & 0 & 88 & 0 & 0 & 0 & 6967 & 0 & 0 & 0 & 0 & 49 & 51 \\
\hline R2E & 6967 & 0 & 0 & 0 & 0 & 1393 & 0 & 576 & 0 & 0 & 0 & 6967 & 0 & 0 & 0 & 0 & 55 & 45 \\
\hline R31 & 41807 & 0 & 0 & 0 & 0 & 6794 & 0 & 1990 & 199 & 0 & 0 & 41807 & 0 & 0 & 0 & 0 & 58 & 42 \\
\hline R4E & 13935 & 0 & 0 & 0 & 0 & 2090 & 70 & 555 & 350 & 0 & 0 & 11612 & 0 & 0 & 0 & 0 & 59 & 41 \\
\hline R5E & 13935 & 0 & 0 & 0 & 0 & 0 & 125 & 779 & 0 & 0 & 0 & 13935 & 0 & 512 & 0 & 31 & 60 & 9 \\
\hline R61 & 36232 & 0 & 0 & 0 & 0 & 0 & 1156 & 1472 & 20 & 0 & 0 & 25846 & 0 & 135 & 0 & 17 & 60 & 23 \\
\hline R7E & 13935 & 0 & 0 & 0 & 0 & 0 & 79 & 489 & 0 & 0 & 0 & 13935 & 0 & 855 & 0 & 38 & 57 & 6 \\
\hline T1E & 12146 & 0 & 0 & 0 & 0 & 0 & 0 & 266 & 117 & 0 & 0 & 0 & 0 & 0 & 0 & 0 & 100 & 0 \\
\hline T2E & 3965 & 0 & 0 & 0 & 0 & 0 & 0 & 152 & 0 & 0 & 0 & 0 & 0 & 0 & 0 & 0 & 100 & 0 \\
\hline T3E & 3772 & 11 & 905 & 0 & 0 & 0 & 0 & 220 & 30 & 0 & 0 & 3017 & 0 & 226 & 0 & 32 & 68 & 0 \\
\hline T4E & 5634 & 0 & 584 & 0 & 0 & 0 & 0 & 126 & 0 & 0 & 376 & 967 & 0 & 0 & 0 & 0 & 100 & 0 \\
\hline T6E & 3333 & 0 & 0 & 0 & 0 & 0 & 2 & 93 & 41 & 0 & 0 & 3055 & 0 & 0 & 0 & 0 & 99 & 1 \\
\hline T7E & 12333 & 0 & 370 & 0 & 0 & 0 & 4 & 587 & 102 & 0 & 0 & 4933 & 0 & 359 & 20 & 25 & 67 & 8 \\
\hline T8E & 13127 & 0 & 1877 & 0 & 0 & 0 & 113 & 361 & 351 & 215 & 0 & 79 & 26 & 160 & 0 & 20 & 67 & 13 \\
\hline T9E & 12820 & 0 & 0 & 0 & 0 & 0 & 0 & 486 & 233 & 0 & 0 & 6410 & 15 & 0 & 0 & 0 & 100 & 0 \\
\hline T10E & 10707 & 0 & 0 & 0 & 0 & 0 & 0 & 435 & 88 & 0 & 0 & 2498 & 0 & 0 & 0 & 0 & 100 & 0 \\
\hline T11E & 2787 & 0 & 11 & 0 & 0 & 0 & 0 & 32 & 0 & 0 & 0 & 9 & 0 & 0 & 0 & 0 & 100 & 0 \\
\hline T12E & 2615 & 0 & 0 & 0 & 0 & 0 & 3 & 26 & 0 & 0 & 0 & 0 & 0 & 0 & 0 & 0 & 94 & 6 \\
\hline T13E & 1951 & 0 & 0 & 0 & 0 & 0 & 9 & 143 & 57 & 0 & 0 & 1951 & 0 & 0 & 0 & 0 & 96 & 4 \\
\hline T14E & 3135 & 0 & 1881 & 1254 & 0 & 0 & 0 & 0 & 0 & 0 & 0 & 0 & 0 & 0 & 0 & 0 & 100 & 0 \\
\hline $\mathrm{A} 1 \mathrm{E}$ & 62594 & 0 & 62594 & 0 & 0 & 0 & 0 & 0 & 0 & 0 & 0 & 0 & 0 & 0 & 0 & 0 & 100 & 0 \\
\hline A2E & 11381 & 0 & 11381 & 0 & 0 & 0 & 0 & 0 & 0 & 0 & 0 & 0 & 0 & 0 & 0 & 0 & 100 & 0 \\
\hline A3E & 21999 & 0 & 21999 & 0 & 0 & 0 & 0 & 0 & 0 & 0 & 0 & 0 & 0 & 0 & 0 & 0 & 100 & 0 \\
\hline A6E & 5072 & 0 & 0 & 0 & 0 & 0 & 0 & 219 & 0 & 0 & 0 & 0 & 0 & 0 & 0 & 0 & 100 & 0 \\
\hline A7E & 5017 & 0 & 0 & 0 & 0 & 0 & 0 & 348 & 0 & 0 & 0 & 0 & 0 & 0 & 0 & 0 & 100 & 0 \\
\hline A9E & 32888 & 0 & 0 & 31864 & 439 & 0 & 0 & 0 & 18 & 0 & 0 & 32888 & 0 & 0 & 0 & 0 & 100 & 0 \\
\hline A10E & 26477 & 0 & 0 & 0 & 0 & 0 & 0 & 1722 & 38 & 0 & 0 & 26477 & 0 & 0 & 0 & 0 & 100 & 0 \\
\hline $\mathrm{A} 11 \mathrm{E}$ & 6020 & 0 & 0 & 0 & 0 & 0 & 24 & 25 & 67 & 0 & 0 & 6020 & 0 & 0 & 96 & 0 & 69 & 31 \\
\hline $\mathrm{A} 12 \mathrm{E}$ & 17837 & 0 & 0 & 0 & 0 & 0 & 0 & 37 & 0 & 0 & 0 & 0 & 0 & 0 & 0 & 0 & 100 & 0 \\
\hline A17E & 3697 & 0 & 0 & 3697 & 0 & 0 & 0 & 0 & 0 & 0 & 0 & 0 & 0 & 0 & 0 & 0 & 100 & 0 \\
\hline TOTAL & 415084 & 11 & 101602 & 36816 & 439 & 11253 & 1585 & 11226 & 1711 & 215 & 376 & 209374 & 42 & 2248 & 116 & 5 & 85 & 9 \\
\hline Percent & & 0.00 & 24.48 & 8.87 & 0.11 & 2.71 & 0.38 & 2.70 & 0.41 & 0.05 & 0.09 & 50.44 & 0.01 & 0.54 & 0.03 & & & \\
\hline
\end{tabular}




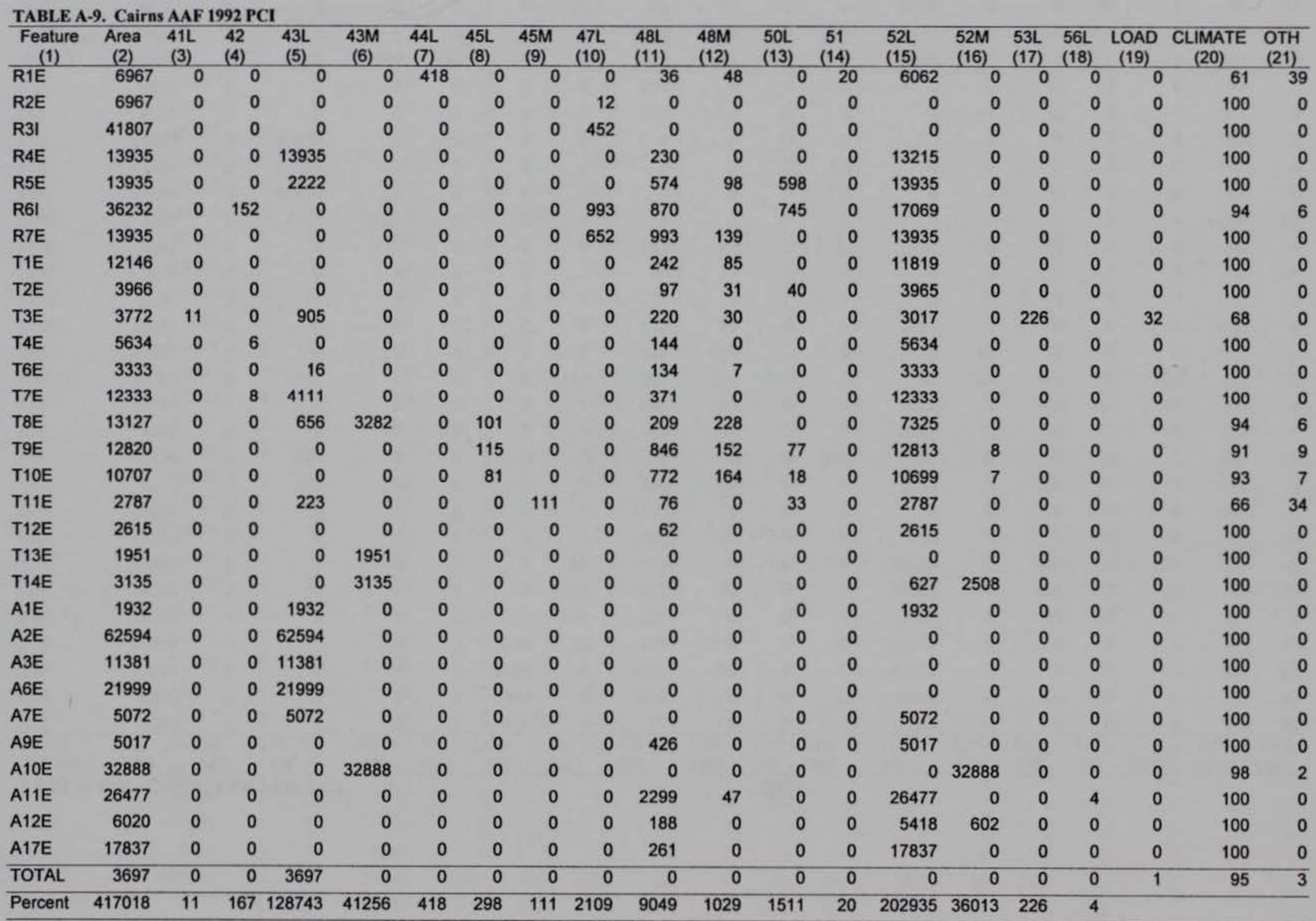


TABLE A-10. Forney AAF 1986 PCI

\begin{tabular}{|c|c|c|c|c|c|c|c|c|}
\hline $\begin{array}{l}\text { Feature } \\
\text { (1) }\end{array}$ & $\begin{array}{l}\text { Area } \\
\text { (2) }\end{array}$ & $\begin{array}{l}41 \mathrm{~L} \\
(3)\end{array}$ & $\begin{array}{l}48 \mathrm{~L} \\
(4)\end{array}$ & $\begin{array}{l}48 \mathrm{M} \\
(5)\end{array}$ & $\begin{array}{l}50 \mathrm{~L} \\
(6)\end{array}$ & $\begin{array}{c}\text { LOAD } \\
\text { (7) }\end{array}$ & $\begin{array}{l}\text { CLIMATE } \\
(8)\end{array}$ & $\begin{array}{l}\text { OTHER } \\
\text { (9) }\end{array}$ \\
\hline A1B & 20581 & 0 & 2195 & 524 & 0 & 0 & 100 & 0 \\
\hline R1A & 7246 & 0 & 371 & 161 & 12 & 0 & 100 & 0 \\
\hline R2A & 26199 & 50 & 1861 & 1898 & 0 & 14 & 86 & 0 \\
\hline R3A & 44245 & 74 & 2779 & 2846 & 0 & 14 & 86 & 0 \\
\hline R4A & 7037 & 0 & 458 & 266 & 18 & 0 & 100 & 0 \\
\hline T1A & 58808 & 0 & 442 & 402 & 0 & 0 & 100 & 0 \\
\hline Total & 164117 & 124 & 8106 & 6097 & 29 & 5 & 95 & 0 \\
\hline Percent & & 0.08 & 4.94 & 3.72 & 0.02 & & & \\
\hline
\end{tabular}

TABLE A-11. Forney AAF 1992 PCI

\begin{tabular}{|c|c|c|c|c|c|}
\hline $\begin{array}{c}\text { Feature } \\
\text { (1) }\end{array}$ & $\begin{array}{l}\text { Area } \\
\text { (2) }\end{array}$ & $\begin{array}{l}43 \mathrm{~L} \\
(3)\end{array}$ & $\begin{array}{l}\text { LOAD } \\
(4)\end{array}$ & $\begin{array}{l}\text { CLIMATE } \\
(5)\end{array}$ & $\begin{array}{l}\text { OTHER } \\
(6)\end{array}$ \\
\hline $\mathrm{A} 1 \mathrm{E}$ & 20112 & 20112 & 0 & 100 & 0 \\
\hline T1E & 5881 & 5881 & 0 & 100 & 0 \\
\hline R6E & 7037 & 7037 & 0 & 100 & 0 \\
\hline R5E & 6898 & 6898 & 0 & 100 & 0 \\
\hline R31 & 19509 & 19509 & 0 & 100 & 0 \\
\hline R41 & 37347 & 37347 & 0 & 100 & 0 \\
\hline R1E & 7246 & 7246 & 0 & 100 & 0 \\
\hline R2E & 6689 & 6689 & 0 & 100 & 0 \\
\hline Total & 110719 & 110719 & 0 & 100 & 0 \\
\hline Percent & & 100 & & & \\
\hline
\end{tabular}


TABLE A-12. Forney AAF 1996 PCI

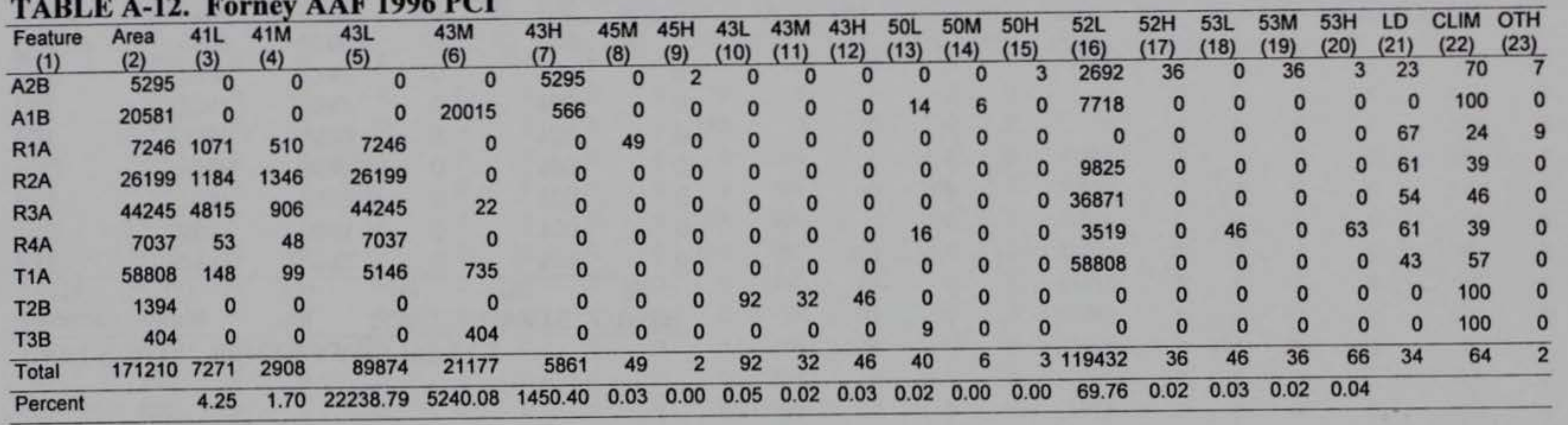


TABLE A-13. Hood AAF 1984 PCI

\begin{tabular}{|c|c|c|c|c|c|c|c|c|c|c|}
\hline $\begin{array}{c}\text { Feature } \\
(1)\end{array}$ & $\begin{array}{l}\text { Area } \\
(2)\end{array}$ & $\begin{array}{l}48 \mathrm{~L} \\
(3)\end{array}$ & $\begin{array}{l}48 \mathrm{M} \\
(4)\end{array}$ & $\begin{array}{l}49 \\
(5)\end{array}$ & $\begin{array}{l}50 \mathrm{~L} \\
(6)\end{array}$ & $\begin{array}{l}52 \mathrm{~L} \\
(7)\end{array}$ & $\begin{array}{c}52 M \\
(8)\end{array}$ & $\begin{array}{l}\text { LOAD } \\
\text { (9) }\end{array}$ & $\begin{array}{l}\text { CLIMATE } \\
(10)\end{array}$ & $\begin{array}{c}\text { OTHER } \\
\text { (11) }\end{array}$ \\
\hline A15E & 16723 & 0 & 0 & 0 & 0 & 0 & 0 & 0 & 0 & 0 \\
\hline A19E & 13936 & 0 & 0 & 0 & 0 & 0 & 0 & 0 & 0 & 0 \\
\hline A21E & 14865 & 0 & 0 & 0 & 0 & 0 & 0 & 0 & 0 & 0 \\
\hline R1E & 14716 & 477 & 1281 & 0 & 0 & 7358 & 7358 & 0 & 100 & 0 \\
\hline R2E & 13378 & 399 & 89 & 0 & 0 & 0 & 0 & 0 & 100 & 0 \\
\hline R3I & 21579 & 347 & 321 & 0 & 0 & 0 & 0 & 0 & 100 & 0 \\
\hline R4E & 13378 & 502 & 96 & 0 & 0 & 0 & 0 & 0 & 100 & 0 \\
\hline T1E-1 & 8175 & 0 & 0 & 0 & 0 & 0 & 0 & 0 & 0 & 0 \\
\hline $\mathrm{T} 2 \mathrm{E}$ & 13006 & 118 & 355 & 62 & 0 & 0 & 0 & 0 & 88 & 12 \\
\hline T3E & 9058 & 26 & 21 & 149 & 0 & 0 & 0 & 0 & 66 & 34 \\
\hline T4E & 5871 & 91 & 474 & 0 & 6 & 0 & 0 & 0 & 100 & 0 \\
\hline T5E & 2601 & 0 & 0 & 0 & 0 & 0 & 0 & 0 & 0 & 0 \\
\hline T6E & 1598 & 0 & 5 & 0 & 9 & 0 & 0 & 0 & 100 & 0 \\
\hline T7E & 3345 & 0 & 0 & 0 & 0 & 0 & 0 & 0 & 0 & 0 \\
\hline T8E & 3901 & 13 & 33 & 0 & 129 & 0 & 0 & 0 & 100 & 0 \\
\hline T9E & 3716 & 154 & 0 & 0 & 0 & 0 & 0 & 0 & 100 & 0 \\
\hline Total & 159845 & 2128 & 2676 & 211 & 144 & 7358 & 7358 & 0 & 60 & 3 \\
\hline Percent & & 1.33 & 1.67 & 0.13 & 0.09 & 4.60 & 4.60 & & & \\
\hline
\end{tabular}


TABLE A-14. Hood AAF 1988 PCI

\begin{tabular}{|c|c|c|c|c|c|c|c|c|c|c|c|c|c|c|}
\hline $\begin{array}{l}\text { Feature } \\
\text { (1) }\end{array}$ & $\begin{array}{l}\text { Area } \\
\text { (2) }\end{array}$ & $\begin{array}{l}41 \mathrm{~L} \\
\text { (3) }\end{array}$ & $\begin{array}{l}43 \mathrm{~L} \\
(4)\end{array}$ & $\begin{array}{l}43 \mathrm{M} \\
(5)\end{array}$ & $\begin{array}{l}48 \mathrm{~L} \\
(6)\end{array}$ & $\begin{array}{l}48 \mathrm{M} \\
(7)\end{array}$ & $\begin{array}{l}49 \\
(8)\end{array}$ & $\begin{array}{l}50 \mathrm{~L} \\
(9)\end{array}$ & $\begin{array}{l}50 \mathrm{H} \\
(10)\end{array}$ & $\begin{array}{l}52 \mathrm{~L} \\
(11)\end{array}$ & $\begin{array}{l}53 \mathrm{~L} \\
(12)\end{array}$ & $\begin{array}{l}\text { LOAD } \\
(13)\end{array}$ & $\begin{array}{l}\text { CLIMATE } \\
(14)\end{array}$ & $\begin{array}{l}\text { OTHER } \\
(15)\end{array}$ \\
\hline A15E & 16723 & 39 & 0 & 0 & 676 & 63 & 22 & 0 & 254 & 0 & 584 & 42 & 55 & 3 \\
\hline $\mathrm{A} 19 \mathrm{E}$ & 13936 & 0 & 0 & 0 & 201 & 0 & 0 & 0 & 0 & 1672 & 0 & 0 & 100 & 0 \\
\hline A21E & 14865 & 0 & 0 & 0 & 13 & 0 & 0 & 0 & 0 & 0 & 0 & 0 & 100 & 0 \\
\hline A23E & 1742 & 0 & 0 & 0 & 164 & 0 & 0 & 0 & 0 & 1742 & 0 & 0 & 100 & 0 \\
\hline$A 24 E$ & 1858 & 0 & 0 & 1858 & 0 & 0 & 0 & 4 & 0 & 1858 & 0 & 0 & 100 & 0 \\
\hline A2E & 8361 & 0 & 0 & 0 & 28 & 583 & 0 & 0 & 0 & 0 & 0 & 0 & 100 & 0 \\
\hline A3E & 4646 & 0 & 0 & 0 & 9 & 311 & 0 & 0 & 0 & 0 & 0 & 0 & 100 & 0 \\
\hline A4E & 1742 & 0 & 0 & 0 & 1 & 0 & 0 & 0 & 0 & 1742 & 0 & 0 & 100 & 0 \\
\hline A5E & 32051 & 0 & 0 & 0 & 6 & 0 & 0 & 0 & 0 & 31410 & 0 & 0 & 100 & 0 \\
\hline $\mathrm{A} 8 \mathrm{E}$ & 53512 & 0 & 0 & 0 & 1770 & 0 & 0 & 0 & 0 & 0 & 0 & 0 & 100 & 0 \\
\hline R1E & 14716 & 0 & 9320 & 5396 & 834 & 0 & 0 & 0 & 0 & 14225 & 0 & 0 & 100 & 0 \\
\hline R2E & 13378 & 0 & 0 & 0 & 1006 & 0 & 0 & 0 & 0 & 12932 & 0 & 0 & 100 & 0 \\
\hline R3I & 21579 & 0 & 0 & 0 & 318 & 0 & 0 & 0 & 0 & 17880 & 0 & 0 & 100 & 0 \\
\hline R4E & 13378 & 0 & 0 & 0 & 267 & 0 & 0 & 0 & 0 & 12040 & 0 & 0 & 100 & 0 \\
\hline T10E-1 & 929 & 0 & 0 & 0 & 0 & 0 & 0 & 0 & 0 & 0 & 0 & 0 & 0 & 0 \\
\hline T10E-2 & 1022 & 0 & 0 & 0 & 21 & 0 & 0 & 0 & 0 & 0 & 0 & 0 & 100 & 0 \\
\hline $\mathrm{T} 11 \mathrm{E}$ & 1486 & 0 & 0 & 0 & 0 & 0 & 0 & 0 & 0 & 0 & 0 & 0 & 0 & 0 \\
\hline $\mathrm{T} 12 \mathrm{E}$ & 8547 & 0 & 0 & 0 & 2 & 0 & 0 & 0 & 0 & 0 & 0 & 0 & 100 & 0 \\
\hline T1E-1 & 8175 & 0 & 0 & 0 & 14 & 0 & 0 & 0 & 0 & 2725 & 0 & 0 & 100 & 0 \\
\hline T1E-2 & 1951 & 0 & 0 & 0 & 0 & 0 & 0 & 0 & 0 & 0 & 0 & 0 & 0 & 0 \\
\hline $\mathrm{T} 2 \mathrm{E}$ & 13006 & 0 & 0 & 0 & 324 & 0 & 0 & 0 & 0 & 9538 & 0 & 0 & 100 & 0 \\
\hline T3E & 9058 & 0 & 0 & 0 & 44 & 0 & 0 & 0 & 0 & 6729 & 0 & 0 & 100 & 0 \\
\hline T5E & 2601 & 0 & 0 & 0 & 0 & 0 & 0 & 0 & 0 & 1541 & 0 & 0 & 100 & 0 \\
\hline T6E & 1598 & 0 & 0 & 0 & 54 & 0 & 0 & 0 & 0 & 0 & 0 & 0 & 100 & 0 \\
\hline T7E & 3345 & 0 & 0 & 0 & 6 & 0 & 0 & 0 & 0 & 0 & 0 & 0 & 100 & 0 \\
\hline T8E & 3901 & 0 & 0 & 0 & 33 & 0 & 0 & 7 & 0 & 6 & 0 & 0 & 100 & 0 \\
\hline T9E & 3716 & 0 & 0 & 0 & 2 & 1 & 0 & 0 & 0 & 3121 & 0 & 0 & 100 & 0 \\
\hline Total & 271822 & 39 & 9320 & 7254 & 5793 & 958 & 22 & 11 & 254 & 119162 & 584 & 2 & 87 & 0 \\
\hline Percent & & 0.01 & 3.43 & 2.67 & 2.13 & 0.35 & 0.01 & 0.00 & 0.09 & 43.84 & 0.21 & & & \\
\hline
\end{tabular}


TABLE A-15. Hood AAF 1993 PCI

\begin{tabular}{|c|c|c|c|c|c|c|c|c|c|c|c|c|c|c|c|c|c|}
\hline $\begin{array}{c}\text { Feature } \\
\text { (1) }\end{array}$ & $\begin{array}{l}\text { Area } \\
(2)\end{array}$ & $\begin{array}{l}41 \mathrm{~L} \\
\text { (3) }\end{array}$ & $\begin{array}{l}41 \mathrm{M} \\
(4)\end{array}$ & $\begin{array}{l}43 \mathrm{~L} \\
(5)\end{array}$ & $\begin{array}{c}43 \mathrm{M} \\
(6)\end{array}$ & $\begin{array}{l}45 \mathrm{~L} \\
(7)\end{array}$ & $\begin{array}{l}47 \mathrm{~L} \\
(8)\end{array}$ & $\begin{array}{l}48 \mathrm{~L} \\
(9)\end{array}$ & $\begin{array}{l}48 \mathrm{M} \\
(10)\end{array}$ & $\begin{array}{l}50 \mathrm{~L} \\
\text { (11) }\end{array}$ & $\begin{array}{l}50 \mathrm{M} \\
(12)\end{array}$ & $\begin{array}{l}52 \mathrm{~L} \\
(13)\end{array}$ & $\begin{array}{l}52 \mathrm{M} \\
(14)\end{array}$ & $\begin{array}{l}53 \mathrm{M} \\
(15)\end{array}$ & $\begin{array}{l}\text { LOAD } \\
(16)\end{array}$ & $\begin{array}{l}\text { CLIM } \\
(17)\end{array}$ & $\begin{array}{l}\text { OTH } \\
(18)\end{array}$ \\
\hline A15E & 16723 & 48 & 234 & 0 & 0 & 0 & 0 & 535 & 0 & 1433 & 38 & 239 & 0 & 0 & 55 & 45 & 0 \\
\hline $\mathrm{A} 19 \mathrm{E}$ & 13936 & 0 & 0 & 0 & 0 & 70 & 0 & 711 & 0 & 0 & 0 & 13936 & 0 & 0 & 0 & 97 & 7 \\
\hline A21E & 14865 & 0 & 0 & 0 & 0 & 0 & 0 & 203 & 0 & 0 & 0 & 0 & 0 & 0 & 0 & 100 & 0 \\
\hline A23E & 1742 & 0 & 0 & 0 & 0 & 0 & 0 & 33 & 57 & 0 & 0 & 1742 & 0 & 0 & 0 & 100 & 0 \\
\hline A24E & 1858 & 0 & 0 & 0 & 0 & 0 & 0 & 33 & 0 & 0 & 0 & 0 & 0 & 0 & 0 & 100 & 0 \\
\hline A2E & 8361 & 0 & 0 & 0 & 0 & 0 & 7 & 30 & 595 & 0 & 0 & 0 & 0 & 0 & 0 & 100 & 0 \\
\hline A3E & 4646 & 0 & 0 & 0 & 0 & 0 & 0 & 23 & 316 & 0 & 0 & 0 & 0 & 0 & 0 & 100 & 0 \\
\hline A4E & 1742 & 0 & 0 & 0 & 0 & 0 & 0 & 72 & 0 & 0 & 0 & 1742 & 0 & 0 & 0 & 100 & 0 \\
\hline A5E & 32051 & 0 & 0 & 0 & 0 & 0 & 0 & 1750 & 0 & 0 & 0 & 32051 & 0 & 0 & 0 & 100 & 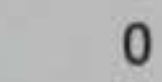 \\
\hline A8E & 53512 & 0 & 0 & 0 & 0 & 0 & 0 & 2011 & 0 & 0 & 0 & 0 & 0 & 0 & 0 & 100 & 0 \\
\hline R1E & 14716 & 0 & 0 & 7358 & 7358 & 0 & 0 & 0 & 0 & 0 & 0 & 7358 & 7358 & 0 & 0 & 100 & 0 \\
\hline R2E & 13378 & 0 & 0 & 0 & 0 & 0 & 0 & 1009 & 0 & 0 & 0 & 13378 & 0 & 0 & 0 & 100 & 0 \\
\hline R3I & 21579 & 0 & 0 & 0 & 0 & 0 & 0 & 1072 & 0 & 0 & 0 & 21579 & 0 & 0 & 0 & 100 & 0 \\
\hline R4E & 13378 & 0 & 0 & 0 & 0 & 0 & 0 & 685 & 0 & 0 & 0 & 13378 & 0 & 0 & 0 & 100 & 0 \\
\hline T10E-1 & 929 & 0 & 0 & 0 & 0 & 0 & 0 & 9 & 0 & 0 & 0 & 0 & 0 & 0 & 0 & 100 & 0 \\
\hline T10E-2 & 1022 & 0 & 0 & 0 & 0 & 0 & 0 & 0 & 20 & 0 & 0 & 0 & 0 & 6 & 57 & 43 & 0 \\
\hline T11E & 1486 & 0 & 0 & 0 & 0 & 0 & 0 & 4 & 0 & 0 & 0 & 93 & 0 & 0 & 0 & 100 & 0 \\
\hline $\mathrm{T} 12 \mathrm{E}$ & 8547 & 0 & 0 & 0 & 0 & 0 & 0 & 67 & 0 & 0 & 0 & 0 & 0 & 0 & 0 & 100 & 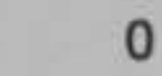 \\
\hline T1E-1 & 8175 & 0 & 115 & 0 & 0 & 0 & 0 & 52 & 0 & 358 & 0 & 8175 & 0 & 0 & 45 & 55 & 0 \\
\hline T1E-2 & 1951 & 0 & 0 & 0 & 0 & 0 & 0 & 0 & 0 & 0 & 0 & 0 & 0 & 0 & 0 & 0 & 0 \\
\hline T2E & 13006 & 0 & 0 & 0 & 0 & 0 & 0 & 635 & 14 & 0 & 0 & 13006 & 0 & 0 & 0 & 100 & 0 \\
\hline T3E & 9058 & 0 & 0 & 0 & 0 & 0 & 0 & 53 & 0 & 0 & 0 & 9058 & 0 & 0 & 0 & 100 & 0 \\
\hline T5E & 2601 & 0 & 0 & 0 & 0 & 0 & 0 & 4 & 0 & 0 & 0 & 2601 & 0 & 0 & 0 & 100 & 0 \\
\hline T6E & 1598 & 0 & 0 & 0 & 0 & 0 & 0 & 26 & 0 & 0 & 0 & 1598 & 0 & 0 & 0 & 100 & 0 \\
\hline T7E & 3345 & 13 & 0 & 0 & 0 & 0 & 0 & 17 & 0 & 0 & 0 & 3345 & 0 & 0 & 30 & 70 & 0 \\
\hline T8E & 3901 & 0 & 0 & 0 & 0 & 0 & 0 & 87 & 24 & 44 & 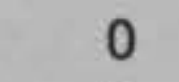 & 3901 & 0 & 0 & 0 & 100 & 0 \\
\hline T9E & 3716 & 0 & 0 & 0 & 0 & 0 & 0 & 18 & 10 & 0 & 0 & 3716 & 0 & 0 & 0 & 100 & 0 \\
\hline Total & 271822 & 61 & 349 & 7358 & 7358 & 70 & 7 & 9137 & 1036 & 1835 & 38 & 150895 & 7358 & 6 & 7 & 89 & 0 \\
\hline Percent & & 0.02 & 0.13 & 2.71 & 2.71 & 0.03 & 0.00 & 3.36 & 0.38 & 0.68 & 0.01 & 55.51 & 2.71 & 0.00 & & & \\
\hline
\end{tabular}


TABLE A-16. Hunter AAF 1982 PCI

\begin{tabular}{|c|c|c|c|c|c|c|c|c|c|c|c|c|}
\hline $\begin{array}{l}\text { Feature } \\
\text { (1) }\end{array}$ & $\begin{array}{l}\text { Area } \\
(2)\end{array}$ & $\begin{array}{l}43 \mathrm{~L} \\
(3)\end{array}$ & $\begin{array}{l}43 \mathrm{M} \\
(4)\end{array}$ & $\begin{array}{l}43 \mathrm{H} \\
\text { (5) }\end{array}$ & $\begin{array}{l}45 \mathrm{~L} \\
(6)\end{array}$ & $\begin{array}{l}47 \mathrm{~L} \\
\text { (7) }\end{array}$ & $\begin{array}{l}48 \mathrm{~L} \\
(8)\end{array}$ & $\begin{array}{l}49 \\
(9)\end{array}$ & $\begin{array}{l}52 \mathrm{~L} \\
(10)\end{array}$ & $\begin{array}{l}\text { LOAD } \\
(11)\end{array}$ & $\begin{array}{l}\text { CLIMATE } \\
\text { (12) }\end{array}$ & $\begin{array}{l}\text { OTHER } \\
(13) \\
\end{array}$ \\
\hline $\mathrm{A} 1 \mathrm{E}$ & 9511 & 0 & 9511 & 0 & 0 & 0 & 0 & 0 & 0 & 0 & 100 & 0 \\
\hline A7E & 19626 & 0 & 19626 & 0 & 0 & 0 & 0 & 0 & 0 & 0 & 100 & 0 \\
\hline$A 8 E$ & 32127 & 0 & 32127 & 0 & 0 & 0 & 0 & 0 & 0 & 0 & 100 & 0 \\
\hline A10E & 29119 & 0 & 29119 & 0 & 0 & 0 & 0 & 0 & 0 & 0 & 100 & 0 \\
\hline A12E & 3693 & 0 & 3693 & 0 & 0 & 0 & 0 & 0 & 0 & 0 & 100 & 0 \\
\hline A13E & 17866 & 0 & 17866 & 0 & 0 & 0 & 0 & 0 & 0 & 0 & 100 & 0 \\
\hline A17E & 16781 & 16781 & 0 & 0 & 0 & 0 & 0 & 0 & 0 & 0 & 100 & 0 \\
\hline A19E & 45465 & 45465 & 0 & 0 & 0 & 0 & 0 & 0 & 0 & 0 & 100 & 0 \\
\hline A20E & 28972 & 0 & 28972 & 0 & 0 & 0 & 0 & 0 & 0 & 0 & 100 & 0 \\
\hline A21E & 11148 & 0 & 0 & 0 & 0 & 0 & 13 & 0 & 0 & 0 & 100 & 0 \\
\hline $\mathrm{A} 30 \mathrm{E}$ & 51329 & 0 & 0 & 0 & 71 & 181 & 406 & 17 & 0 & 0 & 68 & 32 \\
\hline R3E & 14864 & 0 & 0 & 0 & 116 & 0 & 0 & 0 & 0 & 0 & 0 & 100 \\
\hline R4I & 156078 & 0 & 0 & 0 & 0 & 0 & 107 & 0 & 1080 & 0 & 100 & 0 \\
\hline R5E & 18580 & 0 & 0 & 0 & 0 & 0 & 0 & 0 & 2 & 0 & 100 & 0 \\
\hline T1E & 10214 & 5107 & 0 & 0 & 0 & 0 & 802 & 0 & 0 & 0 & 100 & 0 \\
\hline T2E & 6271 & 1568 & 0 & 0 & 0 & 0 & 107 & 0 & 0 & 0 & 100 & 0 \\
\hline T3E & 11148 & 0 & 0 & 0 & 0 & 0 & 446 & 0 & 0 & 0 & 100 & 0 \\
\hline T4E-1 & 4877 & 975 & 0 & 0 & 0 & 0 & 202 & 0 & 0 & 0 & 100 & 0 \\
\hline T4E-2 & 3716 & 0 & 0 & 0 & 0 & 0 & 111 & 0 & 0 & 0 & 100 & 0 \\
\hline T5E & 27871 & 4645 & 0 & 0 & 0 & 0 & 1301 & 0 & 0 & 0 & 100 & 0 \\
\hline T6E & 4528 & 0 & 0 & 0 & 0 & 0 & 0 & 0 & 0 & 0 & 0 & 0 \\
\hline T8E & 25084 & 13545 & 0 & 0 & 0 & 0 & 2379 & 0 & 0 & 0 & 100 & 0 \\
\hline T9E & 15236 & 1016 & 8126 & 1016 & 0 & 0 & 142 & 0 & 0 & 0 & 100 & 0 \\
\hline $\mathrm{T} 10 \mathrm{E}$ & 69677 & 64317 & 5360 & 0 & 0 & 0 & 0 & 0 & 0 & 0 & 100 & 0 \\
\hline TOTAL & 633783 & 153420 & 154400 & 1016 & 187 & 181 & 6016 & 17 & 1081 & 0 & 90 & 5 \\
\hline PERCENT & & 24.21 & 24.36 & 0.16 & 0.03 & 0.03 & 0.95 & 0.00 & 0.17 & & & \\
\hline
\end{tabular}


TABLE A-17. Hunter AAF 1986 PCI

\begin{tabular}{|c|c|c|c|c|c|c|c|c|c|c|c|c|c|c|}
\hline $\begin{array}{c}\text { Feature } \\
\text { (1) }\end{array}$ & $\begin{array}{l}\text { Area } \\
(2)\end{array}$ & $\begin{array}{l}43 \mathrm{~L} \\
(3)\end{array}$ & $\begin{array}{l}45 \mathrm{~L} \\
(4)\end{array}$ & $\begin{array}{l}45 \mathrm{M} \\
(5)\end{array}$ & $\begin{array}{l}47 \mathrm{~L} \\
(6)\end{array}$ & $\begin{array}{l}48 \mathrm{~L} \\
(7)\end{array}$ & $\begin{array}{l}48 \mathrm{M} \\
(8)\end{array}$ & $\begin{array}{l}49 \\
(9)\end{array}$ & $\begin{array}{l}50 \mathrm{~L} \\
(10)\end{array}$ & $\begin{array}{l}52 \mathrm{~L} \\
(11)\end{array}$ & $\begin{array}{l}53 \mathrm{~L} \\
(12)\end{array}$ & $\begin{array}{l}\text { LOAD } \\
(13)\end{array}$ & $\begin{array}{l}\text { CLIMATE } \\
(14)\end{array}$ & $\begin{array}{c}\text { OTHER } \\
(15)\end{array}$ \\
\hline$\overline{\mathrm{A} 1 \mathrm{E}}$ & 9511 & 0 & 43 & 0 & 59 & 276 & 2 & 0 & 0 & 0 & 0 & 0 & 84 & 16 \\
\hline A7E & 19626 & 0 & 0 & 0 & 0 & 4 & 0 & 0 & 38 & 0 & 0 & 0 & 100 & 0 \\
\hline A8E & 32127 & 0 & 0 & 0 & 49 & 216 & 0 & 0 & 60 & 0 & 0 & 0 & 100 & 0 \\
\hline A17E & 16781 & 0 & 0 & 0 & 0 & 0 & 0 & 0 & 0 & 0 & 0 & 0 & 0 & 0 \\
\hline A19E & 45465 & 0 & 0 & 0 & 0 & 606 & 0 & 0 & 0 & 4546 & 4 & 35 & 65 & 0 \\
\hline A20E & 28972 & 0 & 36 & 0 & 0 & 43 & 0 & 91 & 78 & 0 & 0 & 0 & 100 & 0 \\
\hline A21E & 11148 & 0 & 0 & 0 & 0 & 13 & 0 & 0 & 0 & 0 & 0 & 0 & 100 & 0 \\
\hline $\mathrm{A} 30 \mathrm{E}$ & 51329 & 0 & 71 & 0 & 181 & 406 & 0 & 17 & 0 & 0 & 0 & 0 & 68 & 32 \\
\hline R3E & 14864 & 0 & 0 & 0 & 0 & 643 & 0 & 0 & 0 & 24 & 0 & 0 & 100 & 0 \\
\hline R4I & 156078 & 0 & 0 & 45 & 0 & 5793 & 185 & 9 & 54 & 1717 & 0 & 0 & 74 & 26 \\
\hline R5E & 18580 & 0 & 15 & 0 & 0 & 112 & 0 & 0 & 94 & 242 & 0 & 0 & 97 & 3 \\
\hline T1E & 10214 & 115 & 0 & 0 & 0 & 681 & 0 & 0 & 0 & 0 & 0 & 0 & 100 & 0 \\
\hline T2E & 6271 & 0 & 0 & 0 & 0 & 278 & 0 & 0 & 188 & 0 & 0 & 0 & 100 & 0 \\
\hline T3E & 11148 & 0 & 0 & 0 & 0 & 349 & 0 & 0 & 0 & 134 & 0 & 0 & 100 & 0 \\
\hline T4E-1 & 4877 & 0 & 0 & 0 & 0 & 518 & 0 & 0 & 0 & 43 & 0 & 0 & 100 & 0 \\
\hline T4E-2 & 0 & 0 & 0 & 0 & 0 & 0 & 0 & 0 & 0 & 0 & 0 & & & \\
\hline T5E & 27871 & 0 & 12 & 0 & 0 & 1270 & 0 & 0 & 0 & 180 & 0 & 0 & 98 & 2 \\
\hline T6E & 4528 & 0 & 0 & 0 & 0 & 36 & 0 & 0 & 0 & 7 & 0 & 0 & 100 & 0 \\
\hline T8E & 25084 & 5464 & 0 & 0 & 0 & 1535 & 0 & 0 & 0 & 0 & 0 & 0 & 100 & 0 \\
\hline T9E & 15236 & 69 & 0 & 0 & 0 & 634 & 0 & 0 & 0 & 220 & 0 & 0 & 100 & 0 \\
\hline T10E & 69677 & 0 & 0 & 0 & 0 & 2361 & 0 & 0 & 1035 & 259 & 0 & 0 & 100 & 0 \\
\hline TOTAL & 579388 & 5648 & 178 & 45 & 289 & 15774 & 187 & 117 & 1547 & 7371 & 4 & 2 & 89 & 4 \\
\hline PERCENT & & 0.97 & 0.03 & 0.01 & 0.05 & 2.72 & 0.03 & 0.02 & 0.27 & 1.27 & 0.00 & & & \\
\hline
\end{tabular}


TABLE A-18. Hunter AAF 1992 PCI

\begin{tabular}{|c|c|c|c|c|c|c|c|c|c|c|c|c|c|c|}
\hline $\begin{array}{c}\text { Feature } \\
\text { (1) }\end{array}$ & $\begin{array}{l}\text { Area } \\
(2)\end{array}$ & $\begin{array}{l}41 \mathrm{~L} \\
\text { (3) }\end{array}$ & $\begin{array}{l}43 \mathrm{~L} \\
(4)\end{array}$ & $\begin{array}{l}43 \mathrm{M} \\
(5)\end{array}$ & $\begin{array}{l}45 \mathrm{M} \\
(6)\end{array}$ & $\begin{array}{l}47 \mathrm{~L} \\
\text { (7) }\end{array}$ & $\begin{array}{l}47 \mathrm{M} \\
(8)\end{array}$ & $\begin{array}{l}48 \mathrm{~L} \\
(9)\end{array}$ & $\begin{array}{l}48 \mathrm{M} \\
(10)\end{array}$ & $\begin{array}{c}49 \\
(11)\end{array}$ & $\begin{array}{l}50 \mathrm{~L} \\
(12)\end{array}$ & $\begin{array}{l}\text { LOAD } \\
(13)\end{array}$ & $\begin{array}{c}\text { CLIMATE } \\
(15)\end{array}$ & $\begin{array}{l}\text { OTHER } \\
(16)\end{array}$ \\
\hline A1E & 9511 & 0 & 0 & 0 & 0 & 317 & 79 & 250 & 0 & 0 & 0 & 0 & 100 & 0 \\
\hline A7E & 19626 & 0 & 0 & 0 & 0 & 0 & 0 & 1003 & 0 & 0 & 0 & 0 & 100 & 0 \\
\hline $\mathrm{A} 8 \mathrm{E}$ & 32127 & 0 & 11209 & 71 & 0 & 0 & 0 & 272 & 0 & 155 & 0 & 0 & 93 & 7 \\
\hline A17E & 16781 & 0 & 0 & 0 & 0 & 0 & 0 & 178 & 117 & 0 & 0 & 0 & 100 & 0 \\
\hline A19E & 45465 & 218 & 9093 & 0 & 0 & 0 & 0 & 432 & 391 & 0 & 0 & 28 & 72 & 0 \\
\hline A20E & 28972 & 0 & 0 & 0 & 0 & 0 & 0 & 1453 & 0 & 0 & 79 & 0 & 100 & 0 \\
\hline A21E & 11148 & 0 & 0 & 0 & 4 & 0 & 0 & 131 & 0 & 0 & 0 & 0 & 51 & 49 \\
\hline A30E & 51329 & 0 & 51 & 0 & 0 & 0 & 0 & 3187 & 0 & 0 & 0 & 0 & 100 & 0 \\
\hline R3E & 14864 & 0 & 178 & 0 & 0 & 0 & 0 & 859 & 0 & 0 & 0 & 0 & 100 & 0 \\
\hline R4I & 156078 & 360 & 150915 & 0 & 0 & 0 & 0 & 0 & 0 & 0 & 0 & 21 & 79 & 0 \\
\hline R5E & 18580 & 0 & 5110 & 0 & 0 & 0 & 0 & 520 & 0 & 0 & 42 & 0 & 100 & 0 \\
\hline T1E & 10214 & 0 & 2278 & 0 & 0 & 0 & 0 & 476 & 0 & 0 & 0 & 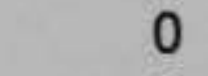 & 100 & 0 \\
\hline T2E & 6271 & 0 & 5128 & 0 & 0 & 0 & 9 & 13 & 4 & 0 & 0 & 0 & 100 & 0 \\
\hline T4E-1 & 4877 & 0 & 4877 & 0 & 0 & 0 & 0 & 0 & 0 & 0 & 0 & 0 & 100 & 0 \\
\hline T4E-2 & 3716 & 0 & 1858 & 0 & 0 & 0 & 0 & 126 & 0 & 0 & 0 & 0 & 100 & 0 \\
\hline T5E & 27871 & 0 & 0 & 0 & 0 & 1150 & 0 & 249 & 0 & 0 & 0 & 0 & 100 & 0 \\
\hline T6E & 4528 & 0 & 0 & 0 & 0 & 0 & 0 & 147 & 0 & 0 & 0 & 0 & 100 & 0 \\
\hline T8E & 25084 & 0 & 16875 & 0 & 0 & 0 & 0 & 139 & 0 & 0 & 0 & 0 & 100 & 0 \\
\hline T9E & 15236 & 0 & 2285 & 0 & 0 & 0 & 0 & 716 & 0 & 0 & 0 & 0 & 100 & 0 \\
\hline T10E & 69677 & 0 & 8959 & 0 & 0 & 124 & 0 & 2643 & 184 & 0 & 309 & 0 & 100 & 0 \\
\hline TOTAL & 571956 & 578 & 218816 & 71 & 4 & 1592 & 88 & 12793 & 697 & 155 & 430 & 2 & 95 & 3 \\
\hline PERCENT & & 0.10 & 38.26 & 0.01 & 0.00 & 0.28 & 0.02 & 2.24 & 0.12 & 0.03 & 0.08 & & & \\
\hline
\end{tabular}


TABLE A-19. Libby AAF 1987 PCI

\begin{tabular}{|c|c|c|c|c|c|c|c|c|c|c|c|c|c|c|c|c|c|c|c|c|}
\hline $\begin{array}{l}\text { Feature } \\
\text { (1) }\end{array}$ & $\begin{array}{l}\text { Area } \\
\text { (2) }\end{array}$ & $\begin{array}{l}41 \mathrm{~L} \\
(3)\end{array}$ & $\begin{array}{l}41 \mathrm{M} \\
(4)\end{array}$ & $\begin{array}{l}42 \\
(5)\end{array}$ & $\begin{array}{l}43 \mathrm{~L} \\
(6)\end{array}$ & $\begin{array}{c}43 \mathrm{M} \\
(7)\end{array}$ & $\begin{array}{c}43 \mathrm{H} \\
(8)\end{array}$ & $\begin{array}{l}44 \mathrm{~L} \\
(9)\end{array}$ & $\begin{array}{l}48 \mathrm{~L} \\
(10)\end{array}$ & $\begin{array}{l}48 \mathrm{M} \\
(11)\end{array}$ & $\begin{array}{c}49 \\
(12)\end{array}$ & $\begin{array}{l}50 \mathrm{~L} \\
(13)\end{array}$ & $\begin{array}{l}50 \mathrm{M} \\
(14)\end{array}$ & $\begin{array}{l}52 \mathrm{~L} \\
(15)\end{array}$ & $\begin{array}{l}52 \mathrm{M} \\
(16)\end{array}$ & $\begin{array}{l}53 \mathrm{~L} \\
(17)\end{array}$ & $\begin{array}{ll}53 \mathrm{M} & 53 \mathrm{H} \\
(18) & (19) \\
\end{array}$ & $\begin{array}{l}\text { LD } \\
(20)\end{array}$ & $\begin{array}{l}\text { CLIM } \\
(21)\end{array}$ & $\begin{array}{l}\text { OTH } \\
\text { (22) }\end{array}$ \\
\hline R11I & 13935 & 0 & 766 & 1324 & 435 & 8796 & 0 & 2613 & 0 & 0 & 0 & 0 & 3 & 1742 & 12193 & 0 & 0 & 18 & 68 & 14 \\
\hline R121 & 2090 & 0 & 0 & 0 & 0 & 0 & 0 & 0 & 0 & 0 & 0 & 0 & 0 & 0 & 0 & 0 & 0 & 0 & 0 & 0 \\
\hline R13E & 6967 & 0 & 0 & 0 & 0 & 0 & 0 & 0 & 0 & 0 & 0 & 0 & 0 & 0 & 0 & 0 & 0 & 0 & 0 & 0 \\
\hline R3I & 126813 & 0 & 0 & 0 & 0 & 0 & 0 & 0 & 1299 & 0 & 0 & 0 & 0 & 0 & 0 & 0 & 0 & 0 & 100 & 0 \\
\hline R6E & 9290 & 0 & 0 & 0 & 0 & 0 & 0 & 0 & 0 & 0 & 0 & 0 & 0 & 0 & 0 & 0 & 0 & 0 & 0 & 0 \\
\hline R7I & 12077 & 0 & 0 & 0 & 0 & 0 & 0 & 0 & 0 & 0 & 0 & 0 & 0 & 0 & 0 & 0 & 0 & 0 & 0 & 0 \\
\hline R8I & 19509 & 0 & 0 & 0 & 1951 & 7804 & 0 & 1 & 0 & 0 & 0 & 0 & 0 & 9755 & 0 & 0 & 0 & 0 & 97 & 3 \\
\hline R9E & 7432 & 0 & 0 & 0 & 1486 & 5946 & 0 & 0 & 0 & 0 & 0 & 0 & 0 & 7432 & 0 & 0 & 0 & 0 & 100 & 0 \\
\hline T2E & 6529 & 0 & 0 & 0 & 0 & 0 & 0 & 0 & 0 & 0 & 56 & 0 & 0 & 0 & 0 & ? & 0 & 0 & 0 & 100 \\
\hline T3E & 3484 & 0 & 0 & 0 & 0 & 0 & 0 & 0 & 4 & 0 & 1 & 0 & 0 & 0 & 0 & 0 & 0 & 0 & 56 & 44 \\
\hline T4E & 6529 & 0 & 0 & 0 & 0 & 0 & 0 & 0 & 0 & 0 & 0 & 0 & 0 & 0 & 0 & 0 & 0 & 0 & 0 & 0 \\
\hline T4E-2 & 5574 & 0 & 0 & 0 & 5574 & 0 & 0 & 0 & 0 & 0 & 0 & 0 & 0 & 0 & 0 & 0 & 0 & 0 & 100 & 0 \\
\hline T5E & 5216 & 0 & 0 & 0 & 0 & 0 & 0 & 0 & 165 & 41 & 0 & 0 & 0 & 0 & 0 & 0 & 0 & 0 & 100 & 0 \\
\hline T7E & 6875 & 5 & 7 & 0 & 737 & 4223 & 0 & 0 & 21 & 103 & 0 & 0 & 69 & 1964 & 3928 & 0 & 0 & 11 & 89 & 0 \\
\hline T8E & 6804 & 0 & 0 & 0 & 945 & 2646 & 0 & 0 & 108 & 101 & 0 & 30 & 0 & 6048 & 0 & 0 & 0 & 0 & 100 & 0 \\
\hline T9E & 780 & 0 & 0 & 4 & 0 & 0 & 0 & 0 & 50 & 20 & 0 & 0 & 0 & 0 & 0 & 0 & 0 & 0 & 92 & 8 \\
\hline $\mathrm{T} 10 \mathrm{E}$ & 13471 & 0 & 1670 & 0 & 1470 & 6980 & 2939 & 0 & 0 & 0 & 0 & 490 & 0 & 1225 & 11757 & 686 & 737 & 40 & 60 & 0 \\
\hline T11E & 5342 & 0 & 0 & 0 & 0 & 0 & 0 & 0 & 0 & 0 & 0 & 0 & 0 & 0 & 0 & 0 & 0 & 0 & 0 & 0 \\
\hline $\mathrm{A} 10 \mathrm{E}$ & 6178 & 0 & 0 & 0 & 0 & 5148 & 0 & 0 & 0 & 0 & 0 & 0 & 0 & 0 & 5148 & 0 & 0 & 0 & 100 & 0 \\
\hline A11E & 1821 & 0 & 0 & 0 & 0 & 910 & 910 & 0 & 0 & 0 & 0 & 0 & 0 & 0 & 1821 & 0 & 0 & 0 & 100 & 0 \\
\hline A6E & 40970 & 0 & 0 & 0 & 0 & 40970 & 0 & 0 & 0 & 0 & 0 & 0 & 3605 & 0 & 32776 & 0 & 020485 & 41 & 59 & 0 \\
\hline A9E & 3057 & 0 & 0 & 0 & 0 & 3057 & 0 & 0 & 0 & 0 & 0 & 0 & 0 & 0 & 0 & 0 & 0 & 0 & 100 & 0 \\
\hline TOTAL & 310744 & 5 & 2444 & 1328 & 12598 & 94842 & 3850 & 2614 & 1646 & 264 & 57 & 520 & 3680 & 28166 & 75985 & 686 & 73720485 & 5 & 62 & 7 \\
\hline Percent & & 0.00 & 0.79 & 0.43 & 4.05 & 30.52 & 1.24 & 0.84 & 0.53 & 0.09 & 0.02 & 0.17 & 1.18 & 9.06 & 24.45 & 0.22 & 0.24 & & & \\
\hline
\end{tabular}


TABLE A-20. Libby AAF 1995 PCI

\begin{tabular}{|c|c|c|c|c|c|c|c|c|c|c|c|c|c|c|c|c|c|c|c|}
\hline $\begin{array}{l}\text { Feature } \\
\text { (1) }\end{array}$ & $\begin{array}{l}\text { Area } \\
\text { (2) }\end{array}$ & $\begin{array}{l}41 \mathrm{~L} \\
(3)\end{array}$ & $\begin{array}{l}41 \mathrm{M} \\
(4)\end{array}$ & $\begin{array}{l}43 \mathrm{~L} \\
(5)\end{array}$ & $\begin{array}{c}43 \mathrm{M} \\
(6)\end{array}$ & $\begin{array}{c}45 \mathrm{H} \\
(7)\end{array}$ & $\begin{array}{l}46 \\
(8)\end{array}$ & $\begin{array}{l}48 \mathrm{~L} \\
(9)\end{array}$ & $\begin{array}{l}48 \mathrm{M} \\
(10)\end{array}$ & $\begin{array}{l}48 \mathrm{H} \\
(11)\end{array}$ & $\begin{array}{c}49 \\
(12)\end{array}$ & $\begin{array}{l}50 \mathrm{~L} \\
(13)\end{array}$ & $\begin{array}{c}51 \\
(14)\end{array}$ & $\begin{array}{l}52 \mathrm{~L} \\
(15)\end{array}$ & $\begin{array}{l}52 \mathrm{M} \\
(16)\end{array}$ & $\begin{array}{l}55 \mathrm{~L} \\
(17)\end{array}$ & $\begin{array}{l}\text { LD } \\
\text { (18) }\end{array}$ & $\begin{array}{l}\text { CLIM } \\
(19)\end{array}$ & $\begin{array}{l}\text { OTH } \\
\text { (20) }\end{array}$ \\
\hline R6A & 9290 & 0 & 0 & 0 & 0 & 0 & 0 & 342 & 226 & 0 & 0 & 0 & 0 & 0 & 1858 & 0 & 0 & 100 & 0 \\
\hline $\mathrm{R} 7 \mathrm{C}$ & 250 & 243 & 31 & 0 & 0 & 75 & 0 & 465 & 1239 & 631 & 0 & 353 & 2508 & 14423 & 0 & 0 & 21 & 7 & 22 \\
\hline $\mathrm{R} 8 \mathrm{C}$ & 3 & 0 & 0 & 0 & 0 & 0 & 0 & 85 & 9 & 8 & 0 & 7 & 0 & 0 & 0 & 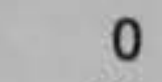 & & 0 & 0 \\
\hline R9A & ) & 0 & 0 & 0 & 0 & 0 & 0 & 146 & 220 & 0 & 0 & 3 & 0 & 0 & 0 & 12 & ( & 1 & 19 \\
\hline T7B & 5 & 12 & 0 & 0 & 0 & 0 & 0 & 8 & 13 & 0 & 0 & 0 & 0 & 0 & 0 & 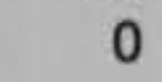 & 51 & 9 & 0 \\
\hline T8B & 85 & 0 & 0 & 8505 & 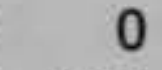 & 0 & 8 & 0 & 0 & 0 & 57 & 0 & 0 & 0 & 0 & 0 & 0 & 92 & 8 \\
\hline T9B & 844 & 0 & 0 & 0 & 844 & 0 & 0 & 0 & 0 & 0 & 0 & 0 & 0 & 0 & 0 & 0 & 0 & 100 & 0 \\
\hline TOTAL & 65016 & 255 & 31 & 8505 & 844 & 75 & 8 & 1046 & 1748 & 639 & 57 & 363 & 2508 & 14423 & 1858 & 12 & 10 & 83 & 7 \\
\hline Percent & & 0.39 & 0.05 & 13.08 & 1.30 & 0.120 & 0.01 & 1.61 & 2.69 & 0.98 & 0.09 & 0.56 & 3.86 & 22.18 & 2.86 & 0.02 & & & \\
\hline
\end{tabular}


TABLE A-21. Los Alamitos 1985 PCI

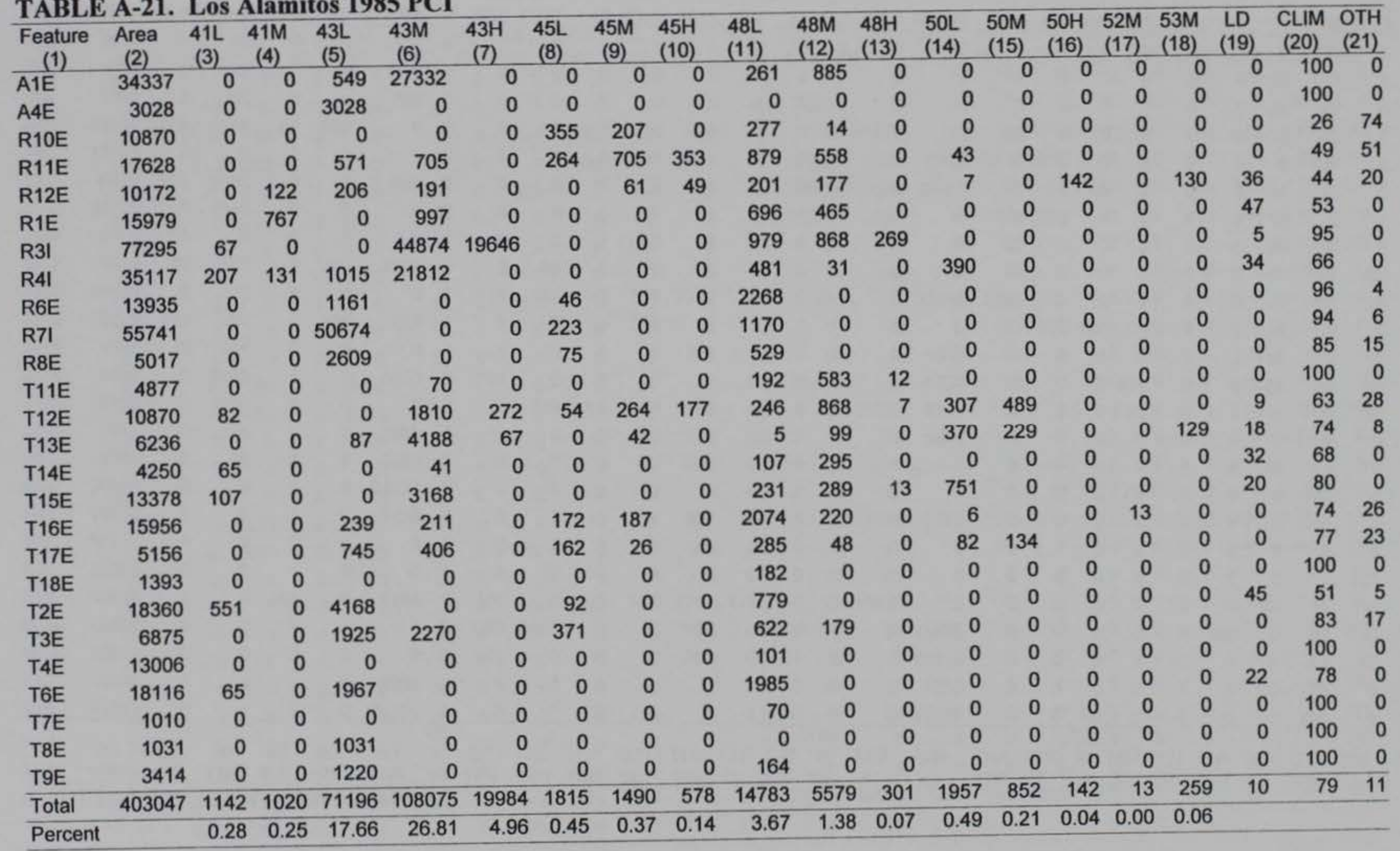


TABLE A-22. Los Alamitos 1990 PCI

\begin{tabular}{llllllllllllllllllllllllllll}
\hline Feat. Area & $41 \mathrm{~L}$ & $41 \mathrm{M}$ & $41 \mathrm{H}$ & $43 \mathrm{~L}$ & $43 \mathrm{M}$ & 45 & $45 \mathrm{M}$ & $45 \mathrm{H}$ & $47 \mathrm{M}$ & $48 \mathrm{~L}$ & $48 \mathrm{M}$ & $48 \mathrm{H}$ & $50 \mathrm{~L}$ & 50 & 51 & $52 \mathrm{~L}$ & $52 \mathrm{M}$ & $53 \mathrm{~L}$ & 53 & $53 \mathrm{H}$ & $54 \mathrm{M}$ & $56 \mathrm{M}$ & $\mathrm{LD}$ & $\mathrm{CLIM}$ & $\mathrm{OTH}$
\end{tabular}

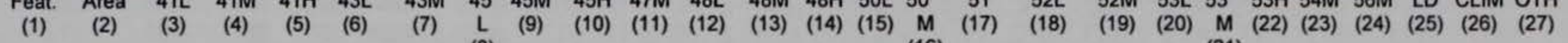

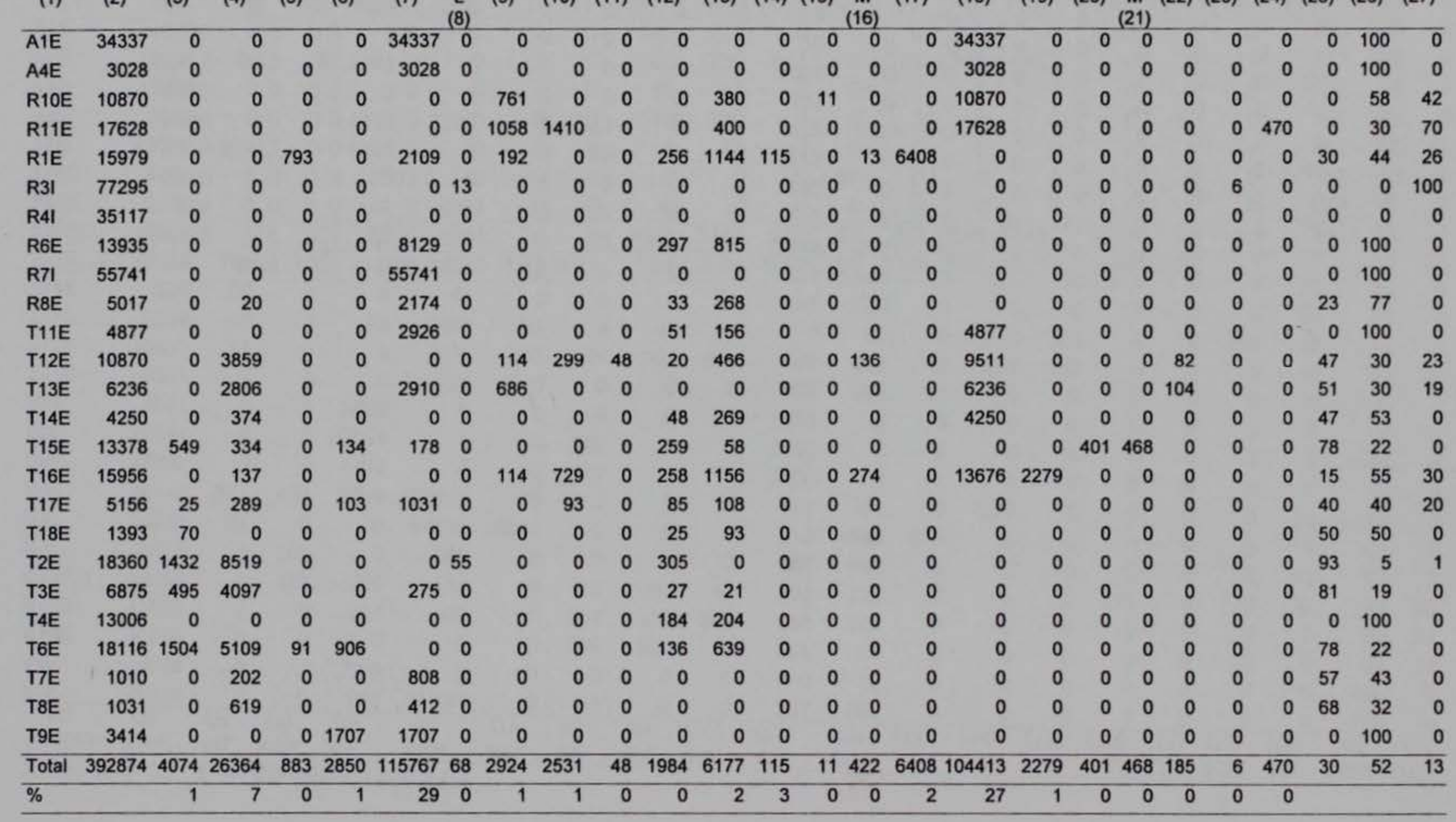


TABLE A-23. Los Alamitos 1993 PCI

\begin{tabular}{|c|c|c|c|c|c|c|c|c|c|c|c|c|c|c|c|c|c|c|c|c|c|c|c|}
\hline $\begin{array}{l}\text { Feature } \\
\text { (1) }\end{array}$ & $\begin{array}{l}\text { Area } \\
\text { (2) }\end{array}$ & $\begin{array}{l}41 \mathrm{~L} \\
\text { (3) }\end{array}$ & $\begin{array}{l}41 \mathrm{M} \\
(4)\end{array}$ & $\begin{array}{l}43 \mathrm{~L} \\
(5)\end{array}$ & $\begin{array}{c}43 \mathrm{M} \\
(6)\end{array}$ & $\begin{array}{c}43 \mathrm{H} \\
(7)\end{array}$ & $\begin{array}{l}45 \mathrm{~L} \\
(8)\end{array}$ & $\begin{array}{l}45 \mathrm{M} \\
(9)\end{array}$ & $\begin{array}{l}45 \mathrm{H} \\
(10)\end{array}$ & $\begin{array}{l}48 \mathrm{~L} \\
\text { (11) }\end{array}$ & $\begin{array}{l}48 M \\
\text { (12) }\end{array}$ & $\begin{array}{l}50 M \\
(13)\end{array}$ & $\begin{array}{l}52 \mathrm{~L} \\
(14)\end{array}$ & $\begin{array}{l}52 M \\
(15)\end{array}$ & $\begin{array}{l}52 \mathrm{H} \\
(16)\end{array}$ & $\begin{array}{l}53 \mathrm{~L} \\
(17)\end{array}$ & $\begin{array}{l}53 \mathrm{M} \\
(18)\end{array}$ & $\begin{array}{l}53 \mathrm{H} \\
(19)\end{array}$ & $\begin{array}{l}54 \mathrm{M} \\
(20)\end{array}$ & $\begin{array}{l}56 \mathrm{H} \\
(21)\end{array}$ & $\begin{array}{l}\text { LD } \\
\text { (22) }\end{array}$ & $\begin{array}{l}\text { CLIM } \\
\text { (23) }\end{array}$ & $\begin{array}{l}\text { OTH } \\
\text { (24) }\end{array}$ \\
\hline $\mathrm{A} 1 \mathrm{E}$ & 34337 & 0 & 0 & 0 & 0 & 0 & 0 & 0 & 0 & 0 & 0 & 0 & 0 & 0 & 0 & 0 & 0 & 0 & 0 & 0 & 0 & 0 & 0 \\
\hline A4E & 3028 & 0 & 0 & 0 & 3028 & 0 & 0 & 0 & 0 & 0 & 0 & 0 & 3028 & 0 & 0 & 0 & 0 & 0 & 0 & 0 & 0 & 100 & 0 \\
\hline R10E & 10870 & 0 & 78 & 0 & 0 & 0 & 0 & 217 & 2283 & 0 & 423 & 0 & 0 & 10870 & 0 & 0 & 0 & 0 & 0 & 178 & 12 & 35 & 53 \\
\hline R11E & 17628 & 0 & 226 & 0 & 0 & 0 & 0 & 0 & 1699 & 221 & 3643 & 0 & 14103 & 1763 & 1763 & 141 & 240 & 0 & 0 & 0 & 26 & 55 & 18 \\
\hline R12E & 10172 & 0 & 178 & 0 & 2543 & 0 & 0 & 234 & 0 & 56 & 92 & 0 & 2543 & 5086 & 2543 & 0 & 31 & 203 & 0 & 0 & 33 & 59 & 8 \\
\hline R1E & 15979 & 0 & 1055 & 0 & 14925 & 0 & 0 & 0 & 0 & 0 & 0 & 0 & 12783 & 3196 & 0 & 192 & 384 & 0 & 0 & 0 & 48 & 52 & 0 \\
\hline R31 & 77295 & 0 & 0 & 0 & 0 & 0 & 0 & 0 & 0 & 1248 & 0 & 0 & 0 & 0 & 0 & 0 & 0 & 0 & 15 & 0 & 0 & 52 & 48 \\
\hline R41 & 35117 & 0 & 0 & 0 & 0 & 0 & 0 & 0 & 0 & 4 & 0 & 0 & 0 & 0 & 0 & 0 & 0 & 0 & 0 & 0 & 0 & 100 & 0 \\
\hline R6E & 13935 & 0 & 0 & 0 & 0 & 0 & 0 & 0 & 0 & 0 & 0 & 0 & 0 & 0 & 0 & 0 & 0 & 0 & 0 & 0 & 0 & 0 & 0 \\
\hline R7I & 55741 & 0 & 0 & 0 & 0 & 0 & 0 & 0 & 0 & 0 & 0 & 0 & 0 & 0 & 0 & 0 & 0 & 0 & 0 & 0 & 0 & 0 & 0 \\
\hline R8E & 5017 & 0 & 0 & 0 & 0 & 0 & 0 & 0 & 0 & 0 & 0 & 0 & 0 & 0 & 0 & 0 & 0 & 0 & 0 & 0 & 0 & 0 & 0 \\
\hline T11E & 4877 & 0 & 98 & 0 & 3609 & 0 & 0 & 0 & 0 & 21 & 79 & 0 & 4877 & 0 & 0 & 0 & 0 & 0 & 0 & 0 & 28 & 72 & 0 \\
\hline $\mathrm{T} 12 \mathrm{E}$ & 10870 & 0 & 3804 & 0 & 6993 & 0 & 0 & 0 & 370 & 0 & 0 & 72 & 0 & 10870 & 0 & 0 & 0 & 0 & 0 & 0 & 33 & 50 & 17 \\
\hline $\mathrm{T} 13 \mathrm{E}$ & 6236 & 0 & 0 & 0 & 0 & 0 & 0 & 0 & 0 & 0 & 0 & 0 & 0 & 0 & 0 & 0 & 0 & 0 & 0 & 0 & 0 & 0 & 0 \\
\hline $\mathrm{T} 14 \mathrm{E}$ & 4250 & 0 & 0 & 0 & 0 & 0 & 0 & 0 & 0 & 0 & 0 & 0 & 0 & 0 & 0 & 0 & 0 & 0 & 0 & 0 & 0 & 0 & 0 \\
\hline T15E & 13378 & 0 & 0 & 0 & 0 & 0 & 0 & 0 & 0 & 0 & 0 & 0 & 0 & 0 & 0 & 0 & 0 & 0 & 0 & 0 & 0 & 0 & 0 \\
\hline T16E & 15956 & 0 & 1340 & 0 & 3191 & 3191 & 0 & 0 & 3574 & 115 & 294 & 128 & 0 & 12765 & 3191 & 0 & 0 & 0 & 0 & 0 & 16 & 65 & 19 \\
\hline T17E & 5156 & 82 & 660 & 0 & 1856 & 0 & 0 & 297 & 0 & 34 & 896 & 0 & 0 & 0 & 0 & 10 & 0 & 0 & 0 & 0 & 45 & 40 & 15 \\
\hline T18E & 1393 & 0 & 0 & 0 & 0 & 0 & 0 & 0 & 0 & 0 & 0 & 0 & 0 & 0 & 0 & 0 & 0 & 0 & 0 & 0 & 0 & 0 & 0 \\
\hline T2E & 18360 & 15147 & 0 & 3213 & 0 & 0 & 0 & 14 & 46 & 0 & 0 & 0 & 0 & 0 & 0 & 0 & 0 & 0 & 0 & 0 & 63 & 18 & 19 \\
\hline T3E & 6875 & 0 & 0 & 0 & 0 & 0 & 24 & 286 & 0 & 0 & 0 & 0 & 0 & 0 & 0 & 0 & 0 & 0 & 0 & 0 & 0 & 0 & 100 \\
\hline T4E & 13006 & 0 & 0 & 0 & 0 & 0 & 0 & 0 & 0 & 0 & 0 & 0 & 0 & 0 & 0 & 0 & 0 & 0 & 0 & 0 & 0 & 0 & 0 \\
\hline T6E & 18116 & 0 & 0 & 0 & 0 & 0 & 0 & 0 & 0 & 0 & 0 & 0 & 0 & 0 & 0 & 0 & 0 & 0 & 0 & 0 & 0 & 0 & 0 \\
\hline T7E & 1010 & 0 & 0 & 0 & 0 & 0 & 0 & 0 & 0 & 0 & 0 & 0 & 0 & 0 & 0 & 0 & 0 & 0 & 0 & 0 & 0 & 0 & 0 \\
\hline T8E & 1031 & 0 & 0 & 0 & 0 & 0 & 0 & 0 & 0 & 0 & 0 & 0 & 0 & 0 & 0 & 0 & 0 & 0 & 0 & 0 & 0 & 0 & 0 \\
\hline T9E & 3414 & 0 & 0 & 0 & 0 & 0 & 0 & 0 & 0 & 0 & 0 & 0 & 0 & 0 & 0 & 0 & 0 & 0 & 0 & 0 & 0 & 0 & 0 \\
\hline Total & 403047 & 15229 & 7439 & 3213 & 36145 & 3191 & 24 & 1048 & 7972 & 1699 & 5426 & 200 & 37335 & 44549 & 7497 & 343 & 654 & 203 & 15 & 178 & 12 & 27 & 11 \\
\hline Percent & & 3.78 & 1.85 & 0.80 & 8.97 & 0.79 & 0 & 0.26 & 1.98 & 0 & 1.35 & 0.05 & 9.26 & 11.05 & 1.86 & 0.09 & 0 & 0 & 0 & 0 & & & \\
\hline
\end{tabular}


TABLE A-24. Marshall AAF 1983 PCI

\begin{tabular}{|c|c|c|c|c|c|c|c|}
\hline $\begin{array}{l}\text { Feature } \\
\text { (1) }\end{array}$ & $\begin{array}{l}\text { Area } \\
\text { (2) }\end{array}$ & $\begin{array}{c}43 \mathrm{M} \\
(3)\end{array}$ & $\begin{array}{l}45 \mathrm{~L} \\
(4)\end{array}$ & $\begin{array}{l}49 \\
(5)\end{array}$ & $\begin{array}{l}\text { LOAD } \\
(6)\end{array}$ & $\begin{array}{l}\text { CLIMATE } \\
(7)\end{array}$ & $\begin{array}{l}\text { OTHER } \\
(8) \\
\end{array}$ \\
\hline $\mathrm{A} 6 \mathrm{E}$ & 8916 & 8791 & 24 & 198 & 0 & 88 & 12 \\
\hline Total & 8916 & 8791 & 24 & 198 & 0 & 88 & 12 \\
\hline Percent & & 98.60 & 0.26 & 2.22 & & & \\
\hline
\end{tabular}

TABLE A-25. Marshall AAF 1987 PCI

\begin{tabular}{lccrrrrrrrrr}
\hline $\begin{array}{l}\text { Feature } \\
(1)\end{array}$ & $\begin{array}{c}\text { Area } \\
(2)\end{array}$ & $\begin{array}{c}43 \mathrm{M} \\
(3)\end{array}$ & $\begin{array}{c}45 \mathrm{~L} \\
(4)\end{array}$ & $\begin{array}{c}45 \mathrm{M} \\
(5)\end{array}$ & $\begin{array}{c}45 \mathrm{H} \\
(6)\end{array}$ & $\begin{array}{c}49 \\
(7)\end{array}$ & $\begin{array}{c}50 \mathrm{~L} \\
(8)\end{array}$ & $\begin{array}{c}\text { LOAD } \\
(9)\end{array}$ & $\begin{array}{c}\text { CLIMATE } \\
(10)\end{array}$ & $\begin{array}{c}\text { OTHER } \\
(11)\end{array}$ \\
\hline A6E & 8916 & 8871 & 71 & 12 & 18 & 141 & 60 & 0 & 65 & 35 \\
\hline Total & 8916 & 8871 & 71 & 12 & 18 & 141 & 60 & 0 & 65 & 35 \\
\hline Percent & & 99.50 & 0.80 & 0.14 & 0.20 & 1.58 & 0.68 & & & \\
\hline
\end{tabular}

TABLE A-26. Marshall AAF 1994

\begin{tabular}{|c|c|c|c|c|c|c|c|c|c|}
\hline $\begin{array}{l}\text { Feature } \\
\text { (1) }\end{array}$ & $\begin{array}{l}\text { Area } \\
\text { (2) }\end{array}$ & $\begin{array}{c}43 \mathrm{M} \\
(3)\end{array}$ & $\begin{array}{l}43 \mathrm{H} \\
(4)\end{array}$ & $\begin{array}{l}45 \mathrm{~L} \\
(5)\end{array}$ & $\begin{array}{l}45 \mathrm{M} \\
(6)\end{array}$ & $\begin{array}{l}49 \\
(7)\end{array}$ & $\begin{array}{c}\text { LOAD } \\
(8)\end{array}$ & $\begin{array}{l}\text { CLIMATE } \\
\text { (9) }\end{array}$ & $\begin{array}{c}\text { OTHER } \\
(10) \\
\end{array}$ \\
\hline $\mathrm{A} 6 \mathrm{E}$ & 8916 & 7667 & 892 & 178 & 267 & 71 & 0 & 69 & 31 \\
\hline Total & 8916 & 7667 & 892 & 178 & 267 & 71 & 0 & 69 & 31 \\
\hline Percent & & 86.00 & 10.00 & 2.00 & 3.00 & 0.80 & & & \\
\hline
\end{tabular}


TABLE A-27. McCoy AAF 1985 PCI

\begin{tabular}{|c|c|c|c|c|c|c|c|c|c|c|c|}
\hline $\begin{array}{c}\text { Feature } \\
\text { (1) }\end{array}$ & $\begin{array}{l}\text { Area } \\
(2)\end{array}$ & $\begin{array}{l}41 \mathrm{~L} \\
\text { (3) }\end{array}$ & $\begin{array}{l}43 \mathrm{~L} \\
(4)\end{array}$ & $\begin{array}{l}45 \mathrm{~L} \\
(5)\end{array}$ & $\begin{array}{l}48 \mathrm{~L} \\
(6)\end{array}$ & $\begin{array}{l}48 \mathrm{M} \\
(7)\end{array}$ & $\begin{array}{l}49 \\
(8)\end{array}$ & $\begin{array}{l}52 \mathrm{~L} \\
(9)\end{array}$ & $\begin{array}{l}\text { LOAD } \\
(10)\end{array}$ & $\begin{array}{l}\text { CLIMATE } \\
\text { (11) }\end{array}$ & $\begin{array}{l}\text { OTHER } \\
\text { (12) }\end{array}$ \\
\hline A1E & 8325 & 36 & 0 & 0 & 1734 & 9 & 23 & 0 & 24 & 70 & 5 \\
\hline A2E & 10219 & 0 & 0 & 0 & 970 & 0 & 205 & 0 & 0 & 81 & 19 \\
\hline R4E & 16723 & 0 & 477 & 0 & 858 & 55 & 0 & 0 & 0 & 100 & 0 \\
\hline R5E & 9290 & 0 & 186 & 155 & 404 & 8 & 0 & 0 & 0 & 73 & 27 \\
\hline R6E & 6386 & 0 & 0 & 0 & 310 & 4 & 0 & 0 & 0 & 100 & 0 \\
\hline T1E & 6735 & 81 & 0 & 254 & 1175 & 0 & 0 & 289 & 29 & 49 & 22 \\
\hline T2E & 2090 & 0 & 348 & 0 & 415 & 0 & 0 & 18 & 0 & 100 & 0 \\
\hline T3E & 2229 & 0 & 0 & 0 & 201 & 0 & 0 & 0 & 0 & 100 & 0 \\
\hline T4E & 1765 & 0 & 0 & 0 & 89 & 0 & 0 & 0 & 0 & 100 & 0 \\
\hline T5E & 1189 & 0 & 0 & 0 & 95 & 0 & 0 & 0 & 0 & 100 & 0 \\
\hline Total & 64951 & 117 & 1011 & 409 & 6252 & 75 & 228 & 307 & 5 & 87 & 7 \\
\hline Percent & & 0.18 & 1.56 & 0.63 & 9.63 & 0.12 & 0.35 & 0.47 & & & \\
\hline
\end{tabular}


TABLE A-28. McCoy AAF 1993 PCI

\begin{tabular}{|c|c|c|c|c|c|c|c|c|c|c|c|c|c|c|}
\hline $\begin{array}{l}\text { Feature } \\
\text { (1) }\end{array}$ & $\begin{array}{l}\text { Area } \\
\text { (2) }\end{array}$ & $\begin{array}{l}41 \mathrm{~L} \\
\text { (3) }\end{array}$ & $\begin{array}{l}43 \mathrm{~L} \\
\text { (4) }\end{array}$ & $\begin{array}{c}43 \mathrm{M} \\
(5)\end{array}$ & $\begin{array}{l}45 \mathrm{~L} \\
(6)\end{array}$ & $\begin{array}{l}45 \mathrm{M} \\
(7)\end{array}$ & $\begin{array}{l}48 \mathrm{~L} \\
(8)\end{array}$ & $\begin{array}{l}48 \mathrm{M} \\
(9)\end{array}$ & $\begin{array}{l}48 \mathrm{H} \\
(10)\end{array}$ & $\begin{array}{c}49 \\
(11)\end{array}$ & $\begin{array}{l}50 \mathrm{~L} \\
(12)\end{array}$ & $\begin{array}{l}\text { LOAD } \\
\text { (13) }\end{array}$ & $\begin{array}{l}\text { CLIMATE } \\
\text { (14) }\end{array}$ & $\begin{array}{c}\text { OTHER } \\
\text { (15) }\end{array}$ \\
\hline $\mathrm{A} 1 \mathrm{E}$ & 8325 & 0 & 0 & 0 & 0 & 0 & 365 & 22 & 0 & 0 & 50 & 0 & 92 & 8 \\
\hline A2E & 10219 & 51 & 0 & 0 & 0 & 0 & 232 & 0 & 0 & 0 & 0 & 64 & 36 & 0 \\
\hline A3E & 4334 & 0 & 0 & 0 & 0 & 0 & 161 & 137 & 0 & 0 & 0 & 0 & 100 & 0 \\
\hline A4E & 4181 & 0 & 0 & 0 & 0 & 0 & 43 & 213 & 0 & 0 & 0 & 0 & 100 & 0 \\
\hline R2E & 39019 & 0 & 0 & 0 & 0 & 0 & 0 & 0 & 0 & 0 & 0 & 0 & 100 & 0 \\
\hline R4E & 16723 & 45 & 0 & 0 & 0 & 0 & 273 & 0 & 0 & 0 & 0 & 61 & 39 & 0 \\
\hline R5E & 9290 & 0 & 0 & 0 & 0 & 0 & 69 & 0 & 0 & 0 & 0 & n & 100 & 0 \\
\hline R6E & 6386 & 0 & 0 & 0 & 0 & 0 & 10 & 0 & 0 & 0 & 0 & 0 & 100 & 0 \\
\hline T1E & 6735 & 0 & 1740 & 135 & 0 & 0 & 251 & 6 & 0 & 0 & 0 & $v$ & 100 & 0 \\
\hline T2E & 2090 & 0 & 348 & 0 & 0 & 0 & 115 & 4 & 0 & 0 & 0 & 0 & 100 & 0 \\
\hline T3E & 2229 & 0 & 0 & 0 & 0 & 0 & 46 & 0 & 0 & 0 & 0 & 0 & 100 & 0 \\
\hline T4E & 1765 & 0 & 0 & 0 & 0 & 0 & 13 & 0 & 0 & 0 & 0 & 0 & 100 & 0 \\
\hline T5E & 1189 & 0 & 0 & 0 & 6 & 6 & 17 & 0 & 0 & 0 & 0 & 0 & 31 & 69 \\
\hline T6E & 7343 & 0 & 0 & 0 & 0 & 0 & 0 & 0 & 0 & 0 & 0 & 0 & 100 & 0 \\
\hline T7E & 3620 & 0 & 0 & 0 & 0 & 0 & 37 & 105 & 1 & 0 & 0 & 0 & 100 & 0 \\
\hline Total & 123448 & 96 & 2088 & 135 & 6 & 6 & 1633 & 486 & 1 & 0 & 50 & 8 & 87 & 5 \\
\hline Percent & & 0.08 & 1.69 & 0.11 & 0.00 & 0.00 & 1.32 & 0.39 & 0.00 & 0.00 & 0.04 & & & \\
\hline
\end{tabular}


TABLE A-29. Muir AAF 1987 PCI

\begin{tabular}{|c|c|c|c|c|c|c|c|c|c|c|c|c|c|c|c|c|c|c|c|c|c|}
\hline $\begin{array}{l}\text { Feature } \\
\text { (1) }\end{array}$ & $\begin{array}{l}\text { Area } \\
\text { (2) }\end{array}$ & $\begin{array}{l}41 \mathrm{~L} \\
(3)\end{array}$ & $\begin{array}{l}41 \mathrm{M} \\
(4)\end{array}$ & $\begin{array}{l}42 \\
(5)\end{array}$ & $\begin{array}{l}43 \mathrm{~L} \\
(6)\end{array}$ & $\begin{array}{c}43 \mathrm{M} \\
(7)\end{array}$ & $\begin{array}{c}43 \mathrm{H} \\
(8)\end{array}$ & $\begin{array}{l}45 \mathrm{~L} \\
(9)\end{array}$ & $\begin{array}{l}45 \mathrm{M} \\
(10)\end{array}$ & $\begin{array}{l}48 \mathrm{~L} \\
(11)\end{array}$ & $\begin{array}{l}48 \mathrm{M} \\
(12)\end{array}$ & $\begin{array}{l}48 \mathrm{H} \\
(13)\end{array}$ & $\begin{array}{c}49 \\
(14)\end{array}$ & $\begin{array}{l}50 \mathrm{~L} \\
(15)\end{array}$ & $\begin{array}{l}50 M \\
(16)\end{array}$ & $\begin{array}{l}52 \mathrm{M} \\
(17)\end{array}$ & $\begin{array}{l}52 \mathrm{H} \\
(18)\end{array}$ & $\begin{array}{l}53 \mathrm{~L} \\
(19)\end{array}$ & $\begin{array}{l}\text { LD } \\
\text { (20) }\end{array}$ & $\begin{array}{l}\text { CLIM } \\
(21)\end{array}$ & $\begin{array}{l}\text { OTH } \\
\text { (22) }\end{array}$ \\
\hline$\overline{\mathrm{A} 1 \mathrm{E}}$ & 870 & 0 & 0 & 0 & 0 & 0 & 0 & 0 & 0 & 33 & 0 & 0 & 0 & 0 & 0 & 0 & 0 & 0 & 0 & 100 & 0 \\
\hline A2E & 1568 & 0 & 0 & 124 & 111 & 39 & 0 & 0 & 0 & 81 & 11 & 0 & 0 & 0 & 0 & 0 & 0 & 0 & 0 & 63 & 37 \\
\hline A3E & 3019 & 0 & 10 & 0 & 167 & 183 & 0 & 0 & 40 & 62 & 58 & 8 & 0 & 0 & 0 & 0 & 0 & 0 & 15 & 70 & 14 \\
\hline $\mathrm{A} 4 \mathrm{E}$ & 1568 & 0 & 0 & 0 & 0 & 0 & 0 & 0 & 0 & 49 & 100 & 9 & 0 & 0 & 0 & 0 & 0 & 0 & 0 & 100 & 0 \\
\hline $\mathrm{A} 6 \mathrm{E}$ & 4181 & 0 & 0 & 0 & 0 & 0 & 0 & 0 & 0 & 0 & 0 & 0 & 45 & 0 & 0 & 0 & 0 & 0 & 0 & 0 & 100 \\
\hline R1E & 30843 & 122 & 29 & 95 & 0 & 350 & 0 & 0 & 0 & 1258 & 862 & 262 & 0 & 45 & 155 & 0 & 2 & 0 & 22 & 76 & 2 \\
\hline T1E & 1568 & 0 & 0 & 0 & 0 & 0 & 0 & 16 & 0 & 43 & 8 & 0 & 0 & 0 & 0 & 0 & 0 & 0 & 0 & 73 & 27 \\
\hline T2E & 4988 & 24 & 29 & 0 & 1283 & 214 & 0 & 1 & 0 & 335 & 61 & 0 & 0 & 0 & 0 & 0 & 0 & 9 & 40 & 60 & 0 \\
\hline T3E & 5161 & 0 & 0 & 0 & 0 & 0 & 0 & 0 & 0 & 1 & 0 & 0 & 1 & 0 & 0 & 0 & 0 & 0 & 0 & 56 & 44 \\
\hline T4E & 15004 & 180 & 72 & 0 & 1940 & 2660 & 0 & 0 & 0 & 679 & 273 & 33 & 0 & 1 & 0 & 0 & 0 & 3 & 38 & 62 & 0 \\
\hline T5E & 5518 & 0 & 0 & 0 & 0 & 0 & 0 & 0 & 0 & 4 & 0 & 0 & 26 & 0 & 0 & 0 & 0 & 0 & 0 & 68 & 32 \\
\hline T6E & 3874 & 29 & 29 & 0 & 0 & 3209 & 65 & 4 & 0 & 3 & 1 & 0 & 1 & 0 & 0 & 0 & 0 & 58 & 43 & 55 & 2 \\
\hline T7E & 7200 & 35 & 0 & 0 & 3280 & 0 & 0 & 0 & 0 & 282 & 52 & 6 & 6 & 0 & 0 & 0 & 0 & 0 & 19 & 78 & 3 \\
\hline T8E & 2903 & 0 & 0 & 0 & 0 & 0 & 0 & 0 & 0 & 16 & 31 & 0 & 0 & 0 & 0 & 0 & 0 & 0 & 0 & 100 & 0 \\
\hline Total & 88265 & 391 & 169 & 220 & 6781 & 6655 & 65 & 21 & 40 & 2845 & 1457 & 317 & 77 & 46 & 155 & 0 & 2 & 69 & 13 & 69 & 19 \\
\hline Percent & & 0.44 & 0.19 & 0.25 & 7.68 & 7.54 & 0.07 & 0.02 & 0.05 & 3.22 & 1.65 & 0.36 & 0.09 & 0.05 & 0.18 & 0.00 & 0.00 & 0.08 & & & \\
\hline
\end{tabular}


TABLE A-30. Muir AAF 1993 PCI

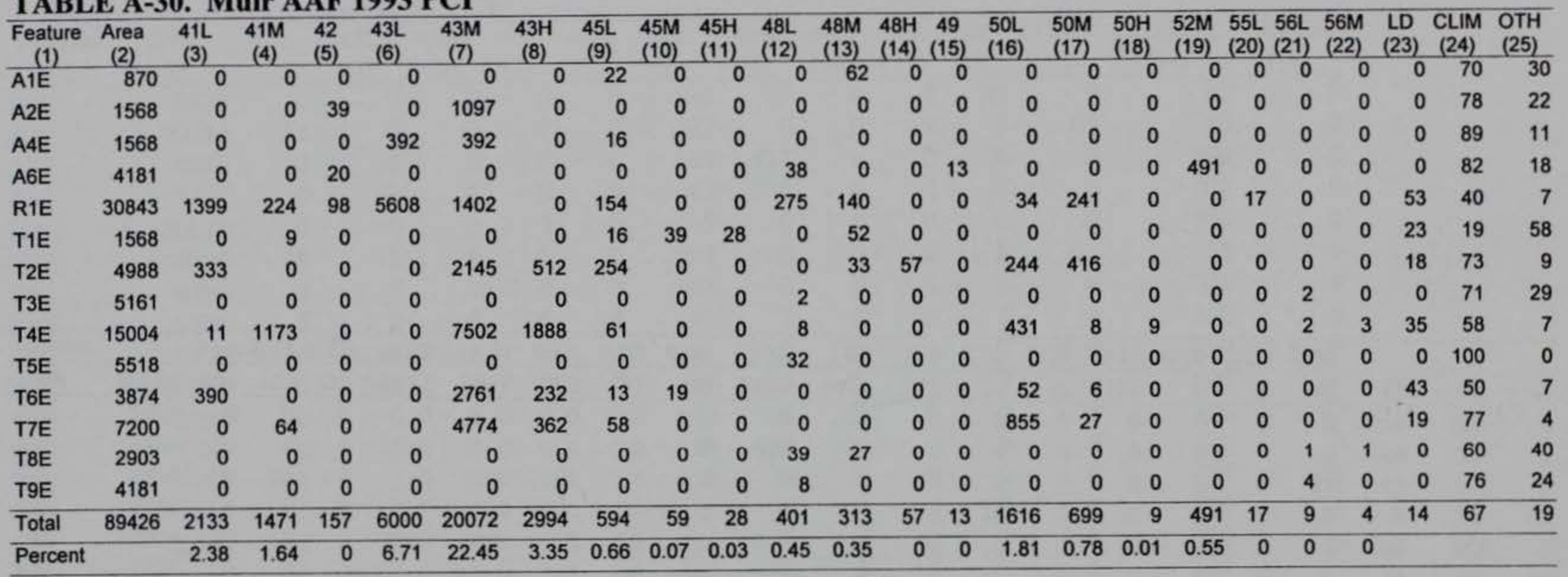


TABLE A-31. Phillips AAF 1986 PCI

\begin{tabular}{|c|c|c|c|c|c|c|c|c|c|c|c|c|c|c|c|c|c|c|c|c|c|}
\hline $\begin{array}{l}\text { Feature } \\
\text { (1) }\end{array}$ & $\begin{array}{l}\text { Area } \\
\text { (2) }\end{array}$ & $\begin{array}{l}43 \mathrm{~L} \\
(3)\end{array}$ & $\begin{array}{c}43 \mathrm{M} \\
(4)\end{array}$ & $\begin{array}{c}43 \mathrm{H} \\
(5)\end{array}$ & $\begin{array}{l}45 \mathrm{~L} \\
(6)\end{array}$ & $\begin{array}{l}45 \mathrm{M} \\
(7)\end{array}$ & $\begin{array}{l}47 \mathrm{~L} \\
(8)\end{array}$ & $\begin{array}{c}47 \mathrm{M} \\
(9)\end{array}$ & $\begin{array}{l}47 \mathrm{H} \\
\text { (10) }\end{array}$ & $\begin{array}{l}48 \mathrm{~L} \\
\text { (11) }\end{array}$ & $\begin{array}{l}48 \mathrm{M} \\
(12)\end{array}$ & $\begin{array}{l}48 \mathrm{H} \\
(13)\end{array}$ & $\begin{array}{c}49 \\
(14)\end{array}$ & $\begin{array}{l}50 \mathrm{~L} \\
\text { (15) }\end{array}$ & $\begin{array}{l}52 \mathrm{~L} \\
(16)\end{array}$ & $\begin{array}{l}52 \mathrm{M} \\
(17)\end{array}$ & $\begin{array}{l}52 \mathrm{H} \\
(18)\end{array}$ & $\begin{array}{l}56 \mathrm{~L} \\
\text { (19) }\end{array}$ & $\begin{array}{l}\text { LD } \\
(20)\end{array}$ & $\begin{array}{l}\text { CLIM } \\
\text { (21) }\end{array}$ & $\begin{array}{l}\text { OTH } \\
\text { (22) }\end{array}$ \\
\hline $\mathrm{A} 2 \mathrm{E}$ & 11288 & 169 & 6547 & 677 & 14 & 0 & 0 & 734 & 0 & 71 & 0 & 0 & 0 & 0 & 11288 & 0 & 0 & 183 & 0 & 97 & 3 \\
\hline A3E & 29729 & 0 & 0 & 0 & 0 & 0 & 0 & 0 & 0 & 0 & 0 & 0 & 8 & 0 & 0 & 0 & 0 & 0 & 0 & 0 & 100 \\
\hline A4E & 4366 & 742 & 2489 & 262 & 0 & 65 & 0 & 0 & 0 & 15 & 26 & 70 & 0 & 0 & 3493 & 655 & 218 & 0 & 0 & 92 & 8 \\
\hline R10E & 4877 & 1463 & 0 & 0 & 0 & 0 & 0 & 0 & 0 & 42 & 358 & 0 & 0 & 0 & 4877 & 0 & 0 & 0 & 0 & 100 & 0 \\
\hline R11E & 2787 & 1616 & 0 & 0 & 0 & 0 & 0 & 188 & 14 & 20 & 0 & 14 & 0 & 0 & 2787 & 0 & 0 & 56 & 0 & 96 & 4 \\
\hline R12I & 39391 & 16413 & 0 & 0 & 0 & 0 & 0 & 0 & 0 & 355 & 2320 & 298 & 0 & 0 & 39391 & 0 & 0 & 0 & 0 & 100 & 0 \\
\hline R13E & 11148 & 743 & 0 & 0 & 0 & 0 & 0 & 0 & 0 & 74 & 446 & 446 & 0 & 0 & 11148 & 0 & 0 & 0 & 0 & 100 & 0 \\
\hline R14E & 2787 & 0 & 84 & 0 & 0 & 0 & 320 & 167 & 56 & 56 & 7 & 0 & 0 & 0 & 2787 & 0 & 0 & 0 & 0 & 100 & 0 \\
\hline R15E & 1742 & 0 & 871 & 0 & 0 & 0 & 10 & 52 & 21 & 52 & 0 & 0 & 0 & 0 & 1742 & 0 & 0 & 0 & 0 & 100 & 0 \\
\hline R16E & 12193 & 1658 & 1219 & 29 & 0 & 0 & 0 & 0 & 0 & 251 & 283 & 488 & 0 & 0 & 12193 & 0 & 0 & 0 & 0 & 100 & 0 \\
\hline R171 & 35628 & 0 & 35628 & 0 & 0 & 0 & 0 & 0 & 0 & 0 & 0 & 0 & 0 & 0 & 35628 & 0 & 0 & 0 & 0 & 100 & 0 \\
\hline R18E & 9754 & 0 & 9754 & 0 & 0 & 0 & 0 & 0 & 0 & 0 & 0 & 0 & 0 & 0 & 9754 & 0 & 0 & 0 & 0 & 100 & 0 \\
\hline R19E & 4181 & 84 & 3135 & 836 & 0 & 0 & 0 & 105 & 418 & 0 & 0 & 0 & 0 & 0 & 4181 & 0 & 0 & 0 & 0 & 100 & 0 \\
\hline R1E & 18580 & 0 & 0 & 0 & 0 & 0 & 0 & 0 & 0 & 0 & 0 & 0 & 0 & 352 & 0 & 0 & 0 & 0 & 0 & 100 & 0 \\
\hline R21 & 20438 & 0 & 0 & 0 & 0 & 0 & 0 & 0 & 0 & 65 & 0 & 0 & 0 & 0 & 0 & 0 & 0 & 0 & 0 & 100 & 0 \\
\hline R3I & 76924 & 0 & 0 & 0 & 0 & 0 & 0 & 0 & 0 & 0 & 0 & 0 & 0 & 0 & 0 & 0 & 0 & 0 & 0 & 0 & 0 \\
\hline R4I & 14121 & 0 & 0 & 0 & 0 & 0 & 0 & 0 & 0 & 42 & 0 & 0 & 0 & 212 & 0 & 0 & 0 & 0 & 0 & 100 & 0 \\
\hline R5I & 11148 & 0 & 0 & 0 & 0 & 0 & 0 & 0 & 0 & 15 & 0 & 0 & 0 & 6 & 0 & 0 & 0 & 0 & 0 & 100 & 0 \\
\hline R6I & 14864 & 0 & 0 & 0 & 0 & 0 & 0 & 0 & 0 & 0 & 0 & 0 & 0 & 0 & 0 & 0 & 0 & 0 & 0 & 0 & 0 \\
\hline R71 & 38833 & 30512 & 0 & 0 & 0 & 0 & 0 & 0 & 0 & 194 & 0 & 0 & 0 & 78 & 0 & 0 & 0 & 0 & 0 & 100 & 0 \\
\hline R8E & 18580 & 0 & 0 & 0 & 0 & 0 & 0 & 0 & 0 & 0 & 0 & 0 & 0 & 0 & 0 & 0 & 0 & 0 & 0 & 0 & 0 \\
\hline R9E & 4877 & 0 & 429 & 0 & 0 & 0 & 98 & 390 & 0 & 0 & 0 & 0 & 0 & 0 & 4877 & 0 & 0 & 0 & 0 & 100 & 0 \\
\hline T1E & 9058 & 2246 & 906 & 0 & 0 & 0 & 0 & 0 & 0 & 100 & 408 & 111 & 0 & 0 & 9058 & 0 & 0 & 0 & 0 & 100 & 0 \\
\hline T2E & 9627 & 0 & 0 & 0 & 0 & 0 & 0 & 0 & 0 & 10 & 0 & 0 & 0 & 1 & 0 & 0 & 0 & 0 & 0 & 100 & 0 \\
\hline T3E & 14110 & 1003 & 3825 & 0 & 0 & 0 & 0 & 0 & 0 & 303 & 563 & 102 & 0 & 0 & 14110 & 0 & 0 & 31 & 0 & 99 & 1 \\
\hline T4E & 6967 & 0 & 0 & 0 & 0 & 0 & 0 & 0 & 0 & 8 & 0 & 0 & 0 & 0 & 0 & 0 & 0 & 0 & 0 & 100 & 0 \\
\hline T5E & 3158 & 106 & 227 & 0 & 0 & 0 & 0 & 0 & 0 & 19 & 60 & 64 & 0 & 0 & 3158 & 0 & 0 & 0 & 0 & 100 & 0 \\
\hline Total & 431157 & 56757 & 65115 & 1805 & 14 & 65 & 428 & 1636 & 509 & 1692 & 4470 & 1593 & 8 & 648 & 170472 & 655 & 218 & 271 & 0 & 85 & 4 \\
\hline Percent & & 13.16 & 15.10 & 0.42 & 0.00 & 0.02 & 0.10 & 0.38 & 0.12 & 0.39 & 1.04 & 0.37 & 0.00 & 0.15 & 39.54 & 0.15 & 0.05 & 0.06 & & & \\
\hline
\end{tabular}


TABLE A-32. Phillips AAF 1993 PCI

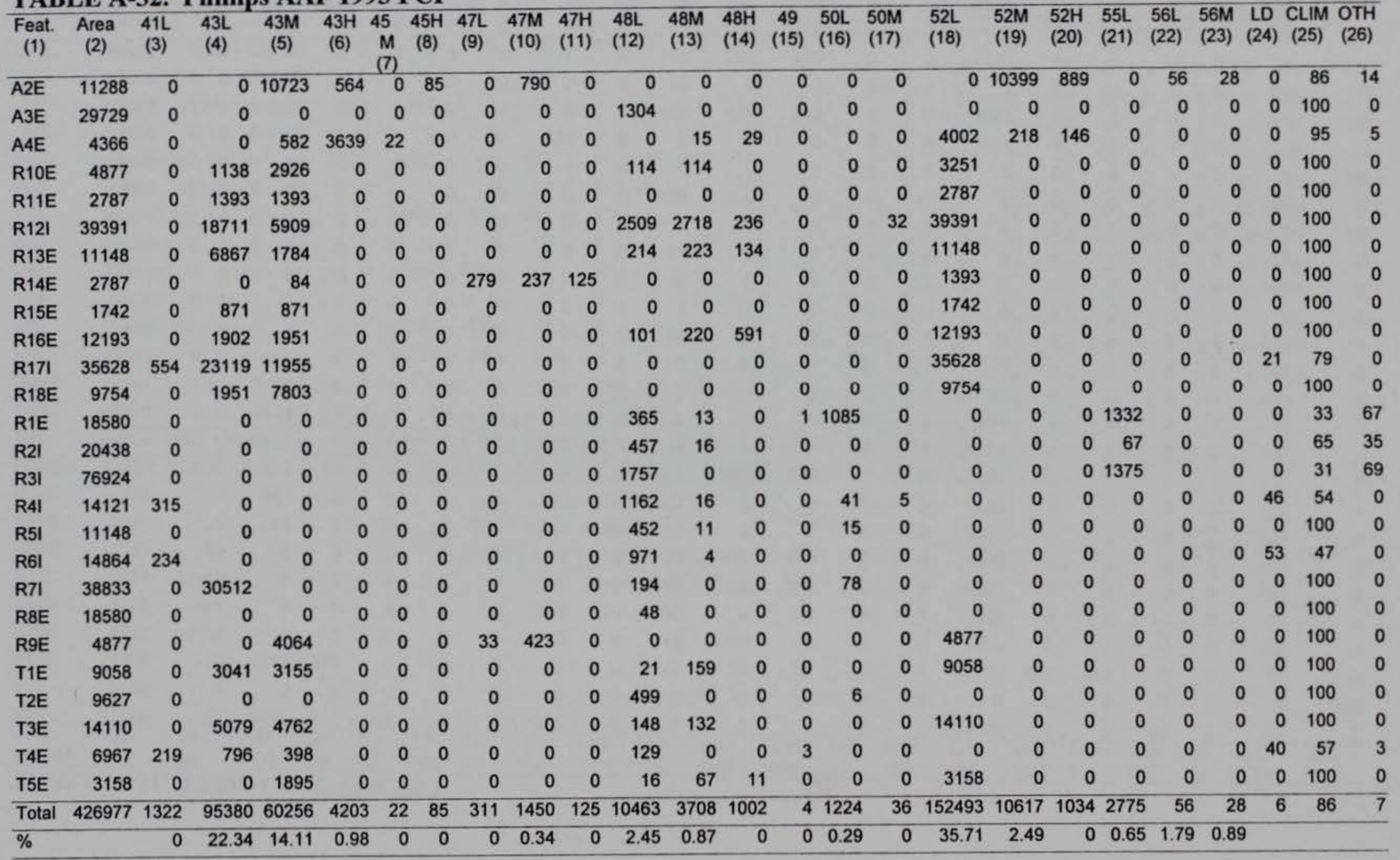


TABLE A-33. Redstone AAF 1987 PCI

\begin{tabular}{|c|c|c|c|c|c|c|c|c|c|c|c|c|c|}
\hline $\begin{array}{c}\text { Feature } \\
\text { (1) }\end{array}$ & $\begin{array}{c}\text { Area } \\
(2)\end{array}$ & $\begin{array}{l}42 \\
(3)\end{array}$ & $\begin{array}{l}43 \mathrm{~L} \\
(4)\end{array}$ & $\begin{array}{c}43 \mathrm{M} \\
(5)\end{array}$ & $\begin{array}{l}48 \mathrm{~L} \\
(6)\end{array}$ & $\begin{array}{c}48 \mathrm{M} \\
(7)\end{array}$ & $\begin{array}{l}49 \\
(8)\end{array}$ & $\begin{array}{l}50 \mathrm{~L} \\
(9)\end{array}$ & $\begin{array}{c}51 \\
(10)\end{array}$ & $\begin{array}{l}52 \mathrm{~L} \\
(11)\end{array}$ & $\begin{array}{l}\text { LOAD } \\
(12)\end{array}$ & $\begin{array}{c}\text { CLIMATE } \\
(13)\end{array}$ & $\begin{array}{c}\text { OTHER } \\
(14)\end{array}$ \\
\hline R2E & 69677 & 15 & 69677 & 0 & 0 & 0 & 0 & 0 & 59494 & 10827 & 0 & 51 & 49 \\
\hline R3E & 6567 & 1 & 6567 & 0 & 0 & 0 & 0 & 0 & 6567 & 1806 & 0 & 51 & 49 \\
\hline R4E & 20206 & 2 & 12629 & 758 & 455 & 222 & 0 & 3 & 20206 & 0 & 0 & 59 & 41 \\
\hline T1E & 3112 & 0 & 3112 & 0 & 0 & 0 & 0 & 13 & 2490 & 0 & 0 & 46 & 54 \\
\hline T2E & 3112 & 0 & 3112 & 0 & 0 & 0 & 0 & 124 & 3112 & 0 & 0 & 47 & 53 \\
\hline T3E & 2550 & 0 & 39 & 0 & 262 & 0 & 0 & 17 & 0 & 0 & 0 & 100 & 0 \\
\hline T4E & 1858 & 0 & 0 & 0 & 85 & 0 & 1 & 0 & 0 & 0 & 0 & 87 & 13 \\
\hline TOTAL & 107082 & 18 & 95136 & 758 & 801 & 222 & 1 & 157 & 91868 & 12633 & 0 & 63 & 37 \\
\hline PERCENT & & 0.02 & 88.84 & 0.71 & 0.75 & 0.21 & 0.00 & 0.15 & 85.79 & 11.80 & & & \\
\hline
\end{tabular}

TABLE A-34. Redstone AAF 1993 PCI

\begin{tabular}{|c|c|c|c|c|c|c|c|c|c|c|c|c|}
\hline $\begin{array}{l}\text { Feature } \\
\text { (1) }\end{array}$ & $\begin{array}{l}\text { Area } \\
(2)\end{array}$ & $\begin{array}{l}41 \mathrm{~L} \\
\text { (3) }\end{array}$ & $\begin{array}{c}41 \mathrm{M} \\
(4)\end{array}$ & $\begin{array}{l}42 \\
(5)\end{array}$ & $\begin{array}{l}43 \mathrm{~L} \\
\text { (6) }\end{array}$ & $\begin{array}{l}48 \mathrm{~L} \\
\text { (7) }\end{array}$ & $\begin{array}{c}48 \mathrm{M} \\
(8)\end{array}$ & $\begin{array}{l}50 \mathrm{~L} \\
(9)\end{array}$ & $\begin{array}{l}53 \mathrm{~L} \\
(10)\end{array}$ & $\begin{array}{l}\text { LOAD } \\
\text { (11) }\end{array}$ & $\begin{array}{l}\text { CLIMATE } \\
\text { (12) }\end{array}$ & $\begin{array}{l}\text { OTHER } \\
(13) \\
\end{array}$ \\
\hline R2E & 69677 & 0 & 0 & 0 & 0 & 755 & 0 & 0 & 0 & 0 & 100 & 0 \\
\hline R3E & 6567 & 0 & 0 & 197 & 0 & 35 & 0 & 0 & 0 & 0 & 21 & 79 \\
\hline R4E & 20206 & 0 & 0 & 0 & 0 & 189 & 0 & 0 & 5 & 64 & 36 & 0 \\
\hline T1E & 3112 & 0 & 0 & 0 & 0 & 55 & 0 & 0 & 0 & 0 & 100 & 0 \\
\hline $\mathrm{T} 2 \mathrm{E}$ & 3112 & 0 & 0 & 0 & 0 & 30 & 0 & 0 & 0 & 0 & 100 & 0 \\
\hline T3E & 2550 & 75 & 9 & 0 & 0 & 0 & 172 & 0 & 0 & 63 & 37 & 0 \\
\hline T4E & 1858 & 0 & 0 & 0 & 1412 & 7 & 0 & 0 & 0 & 0 & 100 & 0 \\
\hline TOTAL & 107082 & 75 & 9 & 197 & 1412 & 1072 & 172 & 0 & 5 & 18 & 71 & 11 \\
\hline PERCENT & & 0.07 & 0.01 & 0.18 & 1.32 & 1.00 & 0.16 & 0.00 & 0.00 & & & \\
\hline
\end{tabular}


TABLE A-35. Selah AAF 1985 PCI

\begin{tabular}{|c|c|c|c|c|c|c|c|c|c|c|c|c|c|c|}
\hline $\begin{array}{c}\text { Feature } \\
\text { (1) }\end{array}$ & $\begin{array}{l}\text { Area } \\
\text { (2) }\end{array}$ & $\begin{array}{l}41 \mathrm{~L} \\
\text { (3) }\end{array}$ & $\begin{array}{l}45 \mathrm{~L} \\
\text { (4) }\end{array}$ & $\begin{array}{l}46 \\
(5)\end{array}$ & $\begin{array}{l}48 \mathrm{~L} \\
(6)\end{array}$ & $\begin{array}{c}48 \mathrm{M} \\
(7)\end{array}$ & $\begin{array}{l}48 \mathrm{H} \\
(8)\end{array}$ & $\begin{array}{l}50 \mathrm{~L} \\
(9)\end{array}$ & $\begin{array}{l}53 \mathrm{~L} \\
(10)\end{array}$ & $\begin{array}{l}53 \mathrm{M} \\
(11)\end{array}$ & $\begin{array}{l}53 \mathrm{H} \\
(12)\end{array}$ & $\begin{array}{l}\text { LOAD } \\
\text { (13) }\end{array}$ & $\begin{array}{l}\text { CLIMATE } \\
(14)\end{array}$ & $\begin{array}{l}\text { OTHER } \\
(15) \\
\end{array}$ \\
\hline $\mathrm{A} 1 \mathrm{E}$ & 2391 & 5 & 5 & 0 & 162 & 0 & 0 & 0 & 0 & 0 & 0 & 28 & 70 & 2 \\
\hline R1E & 850 & 0 & 0 & 0 & 42 & 3 & 0 & 0 & 0 & 0 & 0 & 0 & 100 & 0 \\
\hline R2E & 4891 & 13 & 0 & 0 & 244 & 158 & 6 & 41 & 0 & 0 & 0 & 18 & 82 & 0 \\
\hline R3E & 1226 & 28 & 0 & 0 & 78 & 38 & 0 & 0 & 0 & 0 & 0 & 43 & 57 & 0 \\
\hline R4I & 10772 & 308 & 0 & 0 & 879 & 203 & 0 & 0 & 0 & 0 & 0 & 46 & 54 & 0 \\
\hline R5I & 1191 & 5 & 0 & 39 & 66 & 22 & 0 & 0 & 0 & 0 & 0 & 22 & 55 & 22 \\
\hline R6I & 6612 & 20 & 0 & 0 & 655 & 19 & 0 & 0 & 0 & 0 & 0 & 27 & 73 & 0 \\
\hline R7E & 933 & 0 & 0 & 0 & 70 & 12 & 0 & 0 & 0 & 0 & 0 & 0 & 100 & 0 \\
\hline R8E & 3483 & 0 & 0 & 0 & 324 & 3 & 0 & 0 & 0 & 0 & 0 & 0 & 100 & 0 \\
\hline R9E & 2550 & 1 & 0 & 0 & 146 & 15 & 0 & 0 & 0 & 0 & 0 & 22 & 78 & 0 \\
\hline T1E & 5786 & 0 & 0 & 0 & 420 & 25 & 0 & 0 & 14 & 0 & 0 & 28 & 72 & 0 \\
\hline T2E & 13896 & 0 & 0 & 0 & 1281 & 8 & 0 & 0 & 22 & 50 & 56 & 68 & 32 & 0 \\
\hline T3E & 2391 & 0 & 0 & 0 & 206 & 4 & 17 & 0 & 0 & 0 & 0 & 35 & 65 & 0 \\
\hline Total & 56974 & 380 & 5 & 39 & 4572 & 511 & 23 & 41 & 37 & 50 & 56 & 26 & 72 & 2 \\
\hline Percent & & 0.67 & 0.01 & 0.07 & 8.02 & 0.90 & 0.04 & 0.07 & 0.06 & 0.09 & 0.10 & & & \\
\hline
\end{tabular}


TABLE A-36. Selah AAF 1994 PCI

\begin{tabular}{|c|c|c|c|c|c|c|c|c|c|c|c|c|c|c|c|c|c|c|}
\hline $\begin{array}{l}\text { Feature } \\
\text { (1) }\end{array}$ & $\begin{array}{l}\text { Area } \\
\text { (2) }\end{array}$ & $\begin{array}{l}41 \mathrm{~L} \\
(3)\end{array}$ & $\begin{array}{l}41 \mathrm{M} \\
(4)\end{array}$ & $\begin{array}{l}41 \mathrm{H} \\
(5)\end{array}$ & $\begin{array}{l}43 \mathrm{~L} \\
(6)\end{array}$ & $\begin{array}{c}43 \mathrm{M} \\
(7)\end{array}$ & $\begin{array}{l}43 \mathrm{H} \\
(8)\end{array}$ & $\begin{array}{l}45 \mathrm{~L} \\
(9)\end{array}$ & $\begin{array}{l}45 \mathrm{M} \\
(10)\end{array}$ & $\begin{array}{l}48 \mathrm{~L} \\
(11)\end{array}$ & $\begin{array}{l}48 \mathrm{M} \\
(12)\end{array}$ & $\begin{array}{l}48 \mathrm{H} \\
(13)\end{array}$ & $\begin{array}{l}50 \mathrm{~L} \\
(14)\end{array}$ & $\begin{array}{l}50 \mathrm{M} \\
(15)\end{array}$ & $\begin{array}{l}50 \mathrm{H} \\
(16)\end{array}$ & $\begin{array}{c}\text { LOAD } \\
(17)\end{array}$ & $\begin{array}{l}\text { CLIMATE } \\
(18)\end{array}$ & $\begin{array}{c}\text { OTHER } \\
(19)\end{array}$ \\
\hline $\mathrm{A} 1 \mathrm{E}$ & 2391 & 0 & 0 & 0 & 19 & 7 & 0 & 27 & 0 & 108 & 80 & 0 & 0 & 0 & 0 & 0 & 87 & 13 \\
\hline R1E & 850 & 0 & 0 & 0 & 0 & 0 & 0 & 0 & 0 & 76 & 4 & 0 & 0 & 0 & 0 & 0 & 100 & 0 \\
\hline R2E & 4891 & 3 & 8 & 236 & 0 & 0 & 0 & 0 & 0 & 69 & 96 & 123 & 3 & 33 & 7 & 59 & 41 & 0 \\
\hline R3E & 1226 & 0 & 0 & 0 & 0 & 0 & 1226 & 0 & 0 & 0 & 0 & 0 & 0 & 0 & 0 & 0 & 100 & 0 \\
\hline R4I & 10772 & 0 & 384 & 0 & 0 & 2825 & 0 & 0 & 0 & 0 & 580 & 766 & 0 & 0 & 0 & 29 & 71 & 0 \\
\hline R5I & 1191 & 0 & 0 & 12 & 0 & 0 & 0 & 0 & 0 & 0 & 107 & 0 & 0 & 0 & 0 & 51 & 49 & 0 \\
\hline R6I & 6612 & 24 & 94 & 0 & 0 & 0 & 0 & 0 & 0 & 0 & 468 & 248 & 0 & 0 & 0 & 40 & 60 & 0 \\
\hline R7E & 933 & 0 & 0 & 0 & 0 & 0 & 0 & 0 & 0 & 0 & 103 & 0 & 0 & 0 & 0 & 0 & 100 & 0 \\
\hline R8E & 3483 & 0 & 0 & 0 & 0 & 0 & 0 & 0 & 0 & 209 & 115 & 0 & 0 & 0 & 0 & 0 & 100 & 0 \\
\hline R9E & 2550 & 0 & 0 & 0 & 0 & 0 & 0 & 0 & 0 & 179 & 51 & 0 & 0 & 0 & 0 & 0 & 100 & 0 \\
\hline T1E & 5786 & 0 & 0 & 0 & 0 & 434 & 0 & 0 & 0 & 0 & 407 & 24 & 0 & 0 & 0 & 0 & 100 & 0 \\
\hline T2E & 13896 & 56 & 35 & 35 & 3766 & 864 & 0 & 0 & 35 & 17 & 1181 & 7 & 0 & 0 & 0 & 36 & 59 & 5 \\
\hline T3E & 2391 & 0 & 0 & 0 & 0 & 159 & 0 & 0 & 0 & 0 & 155 & 20 & 0 & 0 & 0 & 0 & 100 & 0 \\
\hline Total & 56974 & 83 & 521 & 283 & 3784 & 4290 & 1226 & 27 & 35 & 657 & 3349 & 1188 & 3 & 33 & 7 & 17 & 82 & 1 \\
\hline Percent & & 0.15 & 0.91 & 0.50 & 6.64 & 7.53 & 2.15 & 0.05 & 0.06 & 1.15 & 5.88 & 2.09 & 0.00 & 0.06 & 0.01 & & & \\
\hline
\end{tabular}


TABLE A-37. Simmons AAF 1985 PCI

\begin{tabular}{|c|c|c|c|c|c|c|c|c|c|c|}
\hline $\begin{array}{l}\text { Feature } \\
\text { (1) }\end{array}$ & $\begin{array}{l}\text { Area } \\
(2)\end{array}$ & $\begin{array}{l}43 \mathrm{~L} \\
(3)\end{array}$ & $\begin{array}{l}43 \mathrm{M} \\
(4)\end{array}$ & $\begin{array}{l}48 \mathrm{~L} \\
(5)\end{array}$ & $\begin{array}{c}48 \mathrm{M} \\
(6)\end{array}$ & $\begin{array}{l}49 \\
(7)\end{array}$ & $\begin{array}{l}50 \mathrm{~L} \\
(8)\end{array}$ & $\begin{array}{l}\text { LOAD } \\
(9)\end{array}$ & $\begin{array}{l}\text { CLIMATE } \\
(10)\end{array}$ & $\begin{array}{c}\text { OTHER } \\
(11)\end{array}$ \\
\hline R1E & 4645 & 0 & 0 & 16 & 0 & 0 & 0 & 0 & 100 & 0 \\
\hline R2E & 4645 & 0 & 0 & 119 & 0 & 0 & 0 & 0 & 100 & 0 \\
\hline R3I & 14865 & 0 & 0 & 224 & 0 & 0 & 0 & 0 & 100 & 0 \\
\hline R4E & 4645 & 0 & 0 & 42 & 0 & 0 & 0 & 0 & 100 & 0 \\
\hline R5E & 4645 & 0 & 0 & 40 & 0 & 0 & 0 & 0 & 100 & 0 \\
\hline T1E & 20903 & 1291 & 232 & 651 & 205 & 6 & 0 & 0 & 96 & 4 \\
\hline T3E & 6968 & 0 & 0 & 112 & 0 & 0 & 0 & 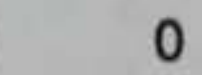 & 76 & 24 \\
\hline T4E & 2323 & 337 & 139 & 75 & 10 & 0 & 0 & 0 & 100 & 0 \\
\hline T5E & 2323 & 418 & 139 & 60 & 1 & 0 & 0 & $\sigma$ & 100 & 0 \\
\hline T12E & 13936 & 0 & 0 & 223 & 0 & 0 & 0 & 0 & 100 & 0 \\
\hline A2E & 25084 & 0 & 25084 & 0 & 0 & 0 & 0 & 0 & 100 & 0 \\
\hline TOTAL & 104981 & 2046 & 25594 & 1562 & 216 & 7 & 0 & 0 & 97 & 3 \\
\hline PERCENT & & 1.95 & 24.38 & 1.49 & 0.21 & 0.01 & 0.00 & & & \\
\hline
\end{tabular}


TABLE A-38. Simmons AAF 1989 PCI

\begin{tabular}{|c|c|c|c|c|c|c|c|c|c|c|c|c|c|c|c|}
\hline $\begin{array}{c}\text { Feature } \\
(1)\end{array}$ & $\begin{array}{l}\text { Area } \\
(2)\end{array}$ & $\begin{array}{l}41 \mathrm{~L} \\
\text { (3) }\end{array}$ & $\begin{array}{l}43 \mathrm{~L} \\
(4)\end{array}$ & $\begin{array}{l}43 \mathrm{M} \\
(5)\end{array}$ & $\begin{array}{l}48 \mathrm{~L} \\
(6)\end{array}$ & $\begin{array}{l}48 \mathrm{M} \\
(7)\end{array}$ & $\begin{array}{l}48 \mathrm{H} \\
(8)\end{array}$ & $\begin{array}{l}50 \mathrm{~L} \\
(9)\end{array}$ & $\begin{array}{l}50 \mathrm{M} \\
(10)\end{array}$ & $\begin{array}{l}52 \mathrm{~L} \\
(11)\end{array}$ & $\begin{array}{l}52 \mathrm{M} \\
(12)\end{array}$ & $\begin{array}{l}54 \mathrm{~L} \\
(13)\end{array}$ & $\begin{array}{l}\text { LOAD } \\
(14)\end{array}$ & $\begin{array}{c}\text { CLIMATE } \\
(15)\end{array}$ & $\begin{array}{l}\text { OTHER } \\
(16)\end{array}$ \\
\hline R1E & 4645 & 0 & 0 & 0 & 530 & 0 & 0 & 0 & 0 & 2081 & 0 & 0 & 0 & 100 & 0 \\
\hline R2E & 4645 & 0 & 0 & 0 & 556 & 95 & 0 & 0 & 0 & 2323 & 0 & 0 & 0 & 100 & 0 \\
\hline R3I & 14865 & 0 & 0 & 0 & 1085 & 682 & 166 & 0 & 0 & 5224 & 0 & 0 & 0 & 100 & 0 \\
\hline R4E & 4645 & 0 & 0 & 0 & 298 & 137 & 25 & 0 & 0 & 2323 & 0 & 0 & 0 & 100 & 0 \\
\hline R5E & 4645 & 0 & 0 & 0 & 237 & 221 & 7 & 0 & 0 & 3066 & 650 & 0 & 0 & 100 & 0 \\
\hline T1E & 20903 & 0 & 314 & 7734 & 380 & 599 & 0 & 0 & 0 & 12124 & 0 & 0 & 0 & 100 & 0 \\
\hline T3E & 6968 & 0 & 0 & 0 & 112 & 142 & 0 & 0 & 0 & 6072 & 0 & 0 & 0 & 100 & 0 \\
\hline T4E & 2323 & 0 & 511 & 929 & 21 & 68 & 0 & 0 & 0 & 1916 & 0 & 0 & 0 & 100 & 0 \\
\hline T5E & 2323 & 17 & 174 & 441 & 89 & 155 & 35 & 3 & 0 & 1161 & 0 & 0 & 12 & 88 & 0 \\
\hline T12E & 13936 & 0 & 0 & 0 & 128 & 275 & 0 & 1 & 390 & 13936 & 0 & 8 & 0 & 97 & 3 \\
\hline T13E & 3345 & 0 & 0 & 0 & 0 & 0 & 0 & 0 & 0 & 0 & 0 & 0 & 0 & 0 & 0 \\
\hline T14E & 8083 & 0 & 0 & 0 & 0 & 0 & 0 & 0 & 0 & 0 & 0 & 0 & 0 & 0 & 0 \\
\hline T15E & 5574 & 0 & 0 & 0 & 0 & 0 & 0 & 0 & 0 & 0 & 0 & 0 & 0 & 0 & 0 \\
\hline $\mathrm{A} 2 \mathrm{E}$ & 25084 & 0 & 0 & 25084 & 0 & 0 & 0 & 0 & 0 & 0 & 0 & 0 & 0 & 100 & 0 \\
\hline TOTAL & 121982 & 17 & 999 & 34188 & 3437 & 2374 & 233 & 4 & 390 & 50225 & 650 & 8 & 1 & 78 & 0 \\
\hline PERCENT & & 0.01 & 0.82 & 28.03 & 2.82 & 1.95 & 0.19 & 0.00 & 0.32 & 41.17 & 0.53 & 0.01 & & & \\
\hline
\end{tabular}


TABLE A-39. Simmons AAF 1993 PCI

\begin{tabular}{|c|c|c|c|c|c|c|c|c|c|c|}
\hline $\begin{array}{l}\text { Feature } \\
\text { (1) }\end{array}$ & $\begin{array}{c}\text { Area } \\
\text { (2) }\end{array}$ & $\begin{array}{l}41 \mathrm{~L} \\
(3)\end{array}$ & $\begin{array}{l}43 \mathrm{~L} \\
(4)\end{array}$ & $\begin{array}{l}48 \mathrm{~L} \\
(5)\end{array}$ & $\begin{array}{l}49 \\
(6)\end{array}$ & $\begin{array}{l}50 \mathrm{~L} \\
(7)\end{array}$ & $\begin{array}{l}53 \mathrm{~L} \\
(8)\end{array}$ & $\begin{array}{l}\text { LOAD } \\
(9)\end{array}$ & $\begin{array}{l}\text { CLIMATE } \\
(10)\end{array}$ & $\begin{array}{l}\text { OTHER } \\
\text { (11) }\end{array}$ \\
\hline R1E & 4645 & 0 & 0 & 0 & 0 & 0 & 0 & 0 & 0 & 0 \\
\hline R2E & 4645 & 0 & 0 & 0 & 0 & 0 & 0 & 0 & 0 & 0 \\
\hline R3I & 14865 & 0 & 0 & 0 & 0 & 0 & 0 & 0 & 0 & 0 \\
\hline R4E & 4645 & 0 & 0 & 0 & 0 & 0 & 0 & 0 & 0 & 0 \\
\hline R5E & 4645 & 0 & 0 & 0 & 0 & 0 & 0 & 0 & 0 & 0 \\
\hline T1E & 20903 & 0 & 0 & 454 & 3 & 1 & 0 & 0 & 83 & 17 \\
\hline T3E & 6968 & 0 & 0 & 0 & 17 & 0 & 0 & 0 & 0 & 100 \\
\hline T4E & 2323 & 0 & 0 & 26 & 0 & 0 & 0 & 0 & 100 & 0 \\
\hline T5E & 2323 & 0 & 93 & 33 & 0 & 0 & 0 & 0 & 100 & 0 \\
\hline T13E & 3345 & 0 & 920 & 0 & 0 & 0 & 0 & 0 & 100 & 0 \\
\hline T14E & 8083 & 0 & 1386 & 0 & 0 & 0 & 115 & 46 & 54 & 0 \\
\hline T15E & 5574 & 237 & 0 & 1 & 1 & 0 & 0 & 88 & 6 & 5 \\
\hline T16E & 9197 & 0 & 0 & 0 & 3 & 0 & 0 & 0 & 0 & 100 \\
\hline A2E & 25084 & 0 & 0 & 52 & 31 & 0 & 0 & 0 & 72 & 28 \\
\hline TOTAL & 117244 & 237 & 2398 & 567 & 55 & 1 & 115 & 10 & 37 & 18 \\
\hline PERCENT & & 0.20 & 2.05 & 0.48 & 0.05 & 0.00 & 0.10 & & & \\
\hline
\end{tabular}


TABLE A-40. Wheeler-Sack AAF 1985 PCI

\begin{tabular}{|c|c|c|c|c|c|c|c|c|c|c|c|c|c|}
\hline $\begin{array}{l}\text { Feature } \\
\text { (1) }\end{array}$ & $\begin{array}{l}\text { Area } \\
\text { (2) }\end{array}$ & $\begin{array}{l}42 \\
(3)\end{array}$ & $\begin{array}{l}43 \mathrm{~L} \\
(4)\end{array}$ & $\begin{array}{l}45 \mathrm{~L} \\
(5)\end{array}$ & $\begin{array}{l}45 \mathrm{M} \\
(6)\end{array}$ & $\begin{array}{l}48 \mathrm{~L} \\
(7)\end{array}$ & $\begin{array}{l}48 \mathrm{M} \\
(8)\end{array}$ & $\begin{array}{l}52 \mathrm{~L} \\
(9)\end{array}$ & $\begin{array}{l}53 \mathrm{~L} \\
(10)\end{array}$ & $\begin{array}{l}53 \mathrm{M} \\
(11)\end{array}$ & $\begin{array}{l}\text { LOAD } \\
(12)\end{array}$ & $\begin{array}{l}\text { CLIMATE } \\
\text { (13) }\end{array}$ & $\begin{array}{l}\text { OTHER } \\
(14)\end{array}$ \\
\hline T1E & 17768 & 0 & 17768 & 0 & 0 & 0 & 0 & 888 & 0 & 0 & 0 & 100 & 0 \\
\hline T2E & 5039 & 0 & 5039 & 0 & 0 & 0 & 0 & 0 & 0 & 0 & 0 & 100 & 0 \\
\hline T3E & 2787 & 0 & 2787 & 0 & 0 & 0 & 0 & 0 & 0 & 0 & 0 & 100 & 0 \\
\hline T5E & 37263 & 2650 & 0 & 1254 & 686 & 869 & 101 & 4 & 124 & 174 & 27 & 14 & 59 \\
\hline T7E & 8361 & 0 & 8361 & 0 & 0 & 0 & 0 & 0 & 0 & 0 & 0 & 100 & 0 \\
\hline Total & 71218 & 2650 & 33955 & 1254 & 686 & 869 & 101 & 893 & 124 & 174 & 5 & 83 & 12 \\
\hline Percent & & 3.72 & 47.68 & 1.76 & 0.96 & 1.22 & 0.14 & 1.25 & 0.17 & 0.24 & & & \\
\hline
\end{tabular}


TABLE A-41. Wheeler-Sack AAF 1993 PCI

\begin{tabular}{|c|c|c|c|c|c|c|c|c|c|c|c|c|c|}
\hline $\begin{array}{c}\text { Feature } \\
\text { (1) }\end{array}$ & $\begin{array}{l}\text { Area } \\
(2)\end{array}$ & $\begin{array}{l}41 \mathrm{M} \\
(3)\end{array}$ & $\begin{array}{l}43 \mathrm{M} \\
(4)\end{array}$ & $\begin{array}{l}48 \mathrm{~L} \\
(5)\end{array}$ & $\begin{array}{l}48 \mathrm{M} \\
(6)\end{array}$ & $\begin{array}{l}49 \\
(7)\end{array}$ & $\begin{array}{l}50 \mathrm{~L} \\
(8)\end{array}$ & $\begin{array}{l}52 \mathrm{M} \\
(9)\end{array}$ & $\begin{array}{l}53 \mathrm{M} \\
(10)\end{array}$ & $\begin{array}{l}53 \mathrm{H} \\
\text { (11) }\end{array}$ & $\begin{array}{l}\text { LOAD } \\
(12)\end{array}$ & $\begin{array}{l}\text { CLIMATE } \\
\text { (13) }\end{array}$ & $\begin{array}{l}\text { OTHER } \\
(14)\end{array}$ \\
\hline T10E & 15329 & 0 & 0 & 0 & 0 & 0 & 0 & 0 & 0 & 0 & 0 & 0 & 0 \\
\hline T11E & 3233 & 0 & 0 & 0 & 0 & 0 & 0 & 0 & 0 & 0 & 0 & 0 & 0 \\
\hline $\mathrm{T} 12 \mathrm{E}$ & 8436 & 0 & 0 & 0 & 0 & 0 & 0 & 0 & 0 & 0 & 0 & 0 & 0 \\
\hline T13E & 2044 & 0 & 0 & 0 & 0 & 0 & 0 & 0 & 0 & 0 & 0 & 0 & 0 \\
\hline T14E & 24396 & 0 & 0 & 0 & 0 & 0 & 0 & 0 & 0 & 0 & 0 & 0 & 0 \\
\hline T15E & 2568 & 0 & 0 & 0 & 0 & 0 & 0 & 0 & 0 & 0 & 0 & 0 & 0 \\
\hline T1E & 17768 & 0 & 0 & 115 & 93 & 195 & 0 & 0 & 107 & 20 & 72 & 22 & 6 \\
\hline $\mathrm{T} 2 \mathrm{E}$ & 5039 & 0 & 5039 & 0 & 0 & 0 & 0 & 0 & 0 & 0 & 0 & 100 & 0 \\
\hline T3E & 2787 & 104 & 1022 & 31 & 28 & 0 & 28 & 11 & 56 & 0 & 54 & 46 & 0 \\
\hline T5E & 37263 & 0 & 0 & 1407 & 47 & 0 & 0 & 0 & 0 & 0 & 0 & 100 & 0 \\
\hline T7E & 8361 & 0 & 0 & 0 & 0 & 0 & 0 & 0 & 0 & 0 & 0 & 0 & 0 \\
\hline T8E & 3345 & 0 & 0 & 0 & 0 & 0 & 0 & 0 & 0 & 0 & 0 & 0 & 0 \\
\hline T9E & 1486 & 0 & 0 & 0 & 0 & 0 & 0 & 0 & 0 & 0 & 0 & 0 & 0 \\
\hline Total & 132055 & 104 & 6061 & 1553 & 168 & 195 & 28 & 11 & 162 & 20 & 10 & 21 & 0 \\
\hline Percent & & 0.08 & 4.59 & 1.18 & 0.13 & 0.15 & 0.02 & 0.01 & 0.12 & 0.02 & & & \\
\hline
\end{tabular}




\section{APPENDIX B \\ WEIGHTED PCI DETERMINATIONS}

The tables contained in this appendix report the overall PCI, on a scale from 0 to 100 , for all the asphalt concrete features of each airfield for each evaluation. These tables also report the area of the features in square meters, the weight of the feature for that airfield (the area of the feature divided by the total areas of asphalt concrete features for that airfield) and the weight times the PCI. At the bottom of each table is the overall average PCI, the area of all the features for that airfield, the total weight (1.00) and the overall weighted PCI. Chapter IV provides a more detailed explanation of the calculations and the purpose for making these determinations. 
TABLE B-1. Biggs AAF 1984 Weighted PCI

\begin{tabular}{ccccc}
\hline $\begin{array}{c}\text { PCl } \\
(1)\end{array}$ & $\begin{array}{c}\text { Feature } \\
(2)\end{array}$ & $\begin{array}{c}\text { Area } \\
(3)\end{array}$ & $\begin{array}{c}\text { WEIGHT } \\
(4)\end{array}$ & $\begin{array}{c}\text { WT X PCI } \\
(5)\end{array}$ \\
\hline 57 & A10E & 114736 & 0.30 & 17.15 \\
48 & A12E & 29729 & 0.08 & 3.74 \\
41 & A29E & 17392 & 0.05 & 1.87 \\
46 & A6E & 11148 & 0.03 & 1.34 \\
76 & A9E & 37626 & 0.10 & 7.50 \\
45 & T17E & 5574 & 0.01 & 0.66 \\
45 & T18E & 50493 & 0.13 & 5.96 \\
31 & T1E & 6967 & 0.02 & 0.57 \\
32 & T20E-P & 34839 & 0.09 & 2.92 \\
44 & T21E-P & 5574 & 0.01 & 0.64 \\
46 & T25E & 12542 & 0.03 & 1.51 \\
44 & T26E & 25084 & 0.07 & 2.89 \\
46 & T5E & 4646 & 0.01 & 0.56 \\
44 & T6E & 25084 & 0.07 & 2.89 \\
\hline 46.07 & Total & 381434 & 1.00 & 50.20 \\
\hline
\end{tabular}

TABLE B-2. Biggs AAF Weighted PCI 1989

\begin{tabular}{ccccc}
\hline $\mathrm{PCl}$ & $\begin{array}{c}\text { Feature } \\
(1)\end{array}$ & $\begin{array}{c}\text { Area } \\
(2)\end{array}$ & $\begin{array}{c}\text { WEIGHT } \\
(4)\end{array}$ & $\begin{array}{c}\text { WT X PCI } \\
(5)\end{array}$ \\
\hline 26 & A10E & 114736 & 0.40 & 10.39 \\
21 & A12E & 29729 & 0.10 & 2.18 \\
21 & A20E & 4181 & 0.01 & 0.31 \\
21 & A21E & 1394 & 0.00 & 0.10 \\
21 & A6E & 11148 & 0.04 & 0.82 \\
21 & A7E & 1324 & 0.00 & 0.10 \\
46 & A9E & 37626 & 0.13 & 6.03 \\
46 & T10E & 3995 & 0.01 & 0.64 \\
46 & T11E & 5923 & 0.02 & 0.95 \\
64 & T16E-P & 7739 & 0.03 & 1.73 \\
46 & T20E-P & 34839 & 0.12 & 5.58 \\
21 & T5E & 4646 & 0.02 & 0.34 \\
21 & T6E & 25084 & 0.09 & 1.84 \\
21 & T7E & 4645 & 0.02 & 0.34 \\
\hline 31.57 & Total & 287007 & 1.00 & 31.33 \\
\hline \multicolumn{5}{c}{} \\
\hline
\end{tabular}


TABLE B-3. Biggs AAF Weighted PCI 1992

\begin{tabular}{ccccc}
\hline PCI & $\begin{array}{c}\text { Feature } \\
(1)\end{array}$ & $\begin{array}{c}\text { Area } \\
(3)\end{array}$ & $\begin{array}{c}\text { WEIGHT } \\
(4)\end{array}$ & $\begin{array}{c}\text { WT X PCI } \\
(5)\end{array}$ \\
\hline 21 & A10E & 114736 & 0.45 & 9.41 \\
21 & A20E & 4181 & 0.02 & 0.34 \\
21 & A21E & 1394 & 0.01 & 0.11 \\
21 & A6E & 11148 & 0.04 & 0.91 \\
46 & A9E & 37626 & 0.15 & 6.76 \\
46 & T10E & 3995 & 0.02 & 0.72 \\
46 & T11E & 5923 & 0.02 & 1.06 \\
46 & T16E-P & 7739 & 0.03 & 1.39 \\
46 & T20E-P & 34839 & 0.14 & 6.26 \\
21 & T5E & 4646 & 0.02 & 0.38 \\
21 & T6E & 25084 & 0.10 & 2.06 \\
31 & T7E & 4645 & 0.02 & 0.56 \\
\hline 32.25 & Total & 255954 & 1.00 & 29.98 \\
\hline
\end{tabular}

TABLE B-4. Butts AAF Weighted PCI 1984

\begin{tabular}{ccccc}
\hline PCl & Feature & Area & WEIGHT & WT X PCI \\
$(1)$ & $(2)$ & $(3)$ & $(4)$ & $(5)$ \\
\hline 81 & A1E & 3135 & 0.03 & 2.80 \\
80 & A2E & 4993 & 0.06 & 4.41 \\
76 & A3E & 23964 & 0.26 & 20.09 \\
76 & R10E & 6967 & 0.08 & 5.84 \\
94 & R11E & 1394 & 0.02 & 1.45 \\
91 & R2E & 3484 & 0.04 & 3.50 \\
90 & R3E & 3484 & 0.04 & 3.46 \\
84 & R4I & 17837 & 0.20 & 16.53 \\
90 & R5E & 3484 & 0.04 & 3.46 \\
87 & R6E & 3484 & 0.04 & 3.34 \\
71 & R7E & 1394 & 0.02 & 1.09 \\
77 & R8E & 6967 & 0.08 & 5.92 \\
72 & R9I & 2090 & 0.02 & 1.66 \\
61 & T1E-P & 4645 & 0.05 & 3.13 \\
76 & T2E-P & 2739 & 0.03 & 2.30 \\
94 & T4E-P & 585 & 0.01 & 0.61 \\
\hline 81.25 & Total & 90649 & 1.00 & 79.58 \\
\hline
\end{tabular}


TABLE B-5. Butts AAF Weighted PCI 1989

\begin{tabular}{ccccc}
\hline $\mathrm{PCl}$ & $\begin{array}{c}\text { Feature } \\
(1)\end{array}$ & $\begin{array}{c}\text { Area } \\
(2)\end{array}$ & $\begin{array}{c}\text { WEIGHT } \\
(4)\end{array}$ & $\begin{array}{c}\text { WT X PCI } \\
(5)\end{array}$ \\
\hline 20 & A1E & 3135 & 0.03 & 0.67 \\
19 & A2E & 4993 & 0.05 & 1.01 \\
16 & A3E & 23964 & 0.25 & 4.07 \\
17 & R10E & 6967 & 0.07 & 1.26 \\
20 & R11E & 1394 & 0.01 & 0.30 \\
16 & R1E & 3484 & 0.04 & 0.59 \\
88 & R2E & 3484 & 0.04 & 3.26 \\
86 & R3E & 3484 & 0.04 & 3.18 \\
86 & R4I & 17837 & 0.19 & 16.30 \\
87 & R5E & 3484 & 0.04 & 3.22 \\
86 & R6E & 3484 & 0.04 & 3.18 \\
17 & R7E & 1394 & 0.01 & 0.25 \\
16 & R8E & 6967 & 0.07 & 1.18 \\
20 & R9I & 2090 & 0.02 & 0.44 \\
14 & T1E-P & 4645 & 0.05 & 0.69 \\
16 & T2E-P & 2739 & 0.03 & 0.47 \\
74 & T4E-P & 585 & 0.01 & 0.46 \\
\hline 41.06 & Total & 94133 & 1.00 & 40.53 \\
\hline
\end{tabular}

TABLE B-6. Butts AAF Weighted PCI 1993

\begin{tabular}{ccccc}
\hline $\begin{array}{c}\text { PCI } \\
(1)\end{array}$ & $\begin{array}{c}\text { Feature } \\
(2)\end{array}$ & $\begin{array}{c}\text { Area } \\
(3)\end{array}$ & $\begin{array}{c}\text { WEIGHT } \\
(4)\end{array}$ & $\begin{array}{c}\text { WT X PCI } \\
(5)\end{array}$ \\
\hline 18 & A1E & 3135 & 0.03 & 0.60 \\
3 & A2E & 4993 & 0.05 & 0.16 \\
24 & A3E & 23964 & 0.25 & 6.11 \\
21 & R10E & 6967 & 0.07 & 1.55 \\
29 & R11E & 1394 & 0.01 & 0.43 \\
4 & R1E & 3484 & 0.04 & 0.15 \\
73 & R2E & 3484 & 0.04 & 2.70 \\
69 & R3E & 3484 & 0.04 & 2.55 \\
71 & R4I & 17837 & 0.19 & 13.45 \\
69 & R5E & 3484 & 0.04 & 2.55 \\
71 & R6E & 3484 & 0.04 & 2.63 \\
20 & R7E & 1394 & 0.01 & 0.30 \\
20 & R8E & 6967 & 0.07 & 1.48 \\
22 & R9I & 2090 & 0.02 & 0.49 \\
3 & T1E-P & 4645 & 0.05 & 0.15 \\
18 & T2E-P & 2739 & 0.03 & 0.52 \\
20 & T4E-P & 585 & 0.01 & 0.12 \\
\hline 32.65 & Total & 94133 & 1.00 & 35.95 \\
\hline
\end{tabular}


TABLE B-7. Cairns AAF Weighted PCI 1985

\begin{tabular}{ccccc}
\hline PCI & Feature & Area & WEIGHT & WT X PCI \\
$(1)$ & $(2)$ & $(3)$ & $(4)$ & $(5)$ \\
\hline 95 & R1E & 6967 & 0.02 & 1.59 \\
92 & R2E & 6967 & 0.02 & 1.54 \\
93 & R3I & 41807 & 0.10 & 9.37 \\
89 & R4E & 13935 & 0.03 & 2.99 \\
95 & R5E & 13935 & 0.03 & 3.19 \\
90 & R6I & 36232 & 0.09 & 7.86 \\
95 & R7E & 13935 & 0.03 & 3.19 \\
88 & T1E-P & 12146 & 0.03 & 2.58 \\
89 & T2E-P & 3965 & 0.01 & 0.85 \\
78 & T3E-P & 3772 & 0.01 & 0.71 \\
94 & T4E-P & 5634 & 0.01 & 1.28 \\
93 & T6E-P & 3333 & 0.01 & 0.75 \\
92 & T7E-P & 12333 & 0.03 & 2.73 \\
89 & T8E & 13127 & 0.03 & 2.81 \\
89 & T9E & 12820 & 0.03 & 2.75 \\
88 & T10E & 10707 & 0.03 & 2.27 \\
86 & T11E & 2787 & 0.01 & 0.58 \\
83 & T12E & 2615 & 0.01 & 0.52 \\
59 & T13E & 1951 & 0.00 & 0.28 \\
29 & T14E & 3135 & 0.01 & 0.22 \\
64 & A1E & 62594 & 0.15 & 9.65 \\
64 & A2E & 11381 & 0.03 & 1.75 \\
64 & A3E & 21999 & 0.05 & 3.39 \\
90 & A6E & 5072 & 0.01 & 1.10 \\
79 & A7E & 5017 & 0.01 & 0.95 \\
57 & A9E & 32888 & 0.08 & 4.52 \\
85 & A10E & 26477 & 0.06 & 5.42 \\
92 & A11E & 6020 & 0.01 & 1.33 \\
100 & A12E & 17837 & 0.04 & 4.30 \\
64 & A17E & 3697 & 0.01 & 0.57 \\
\hline 82.17 & TOTAL & 415084 & 1.00 & 81.04 \\
\hline & & & &
\end{tabular}


TABLE B-8. Cairns AAF Weighted PCI 1989

\begin{tabular}{|c|c|c|c|c|}
\hline $\begin{array}{l}\mathrm{PCl} \\
\text { (1) }\end{array}$ & $\begin{array}{c}\text { Feature } \\
\text { (2) }\end{array}$ & $\begin{array}{l}\text { Area } \\
\text { (3) }\end{array}$ & $\begin{array}{l}\text { WEIGHT } \\
\text { (4) }\end{array}$ & $\begin{array}{c}\text { WT XPCl } \\
(5)\end{array}$ \\
\hline 57 & R1E & 6967 & 0.02 & 0.96 \\
\hline 46 & R2E & 6967 & 0.02 & 0.77 \\
\hline 51 & R3I & 41807 & 0.10 & 5.14 \\
\hline 51 & R4E & 13935 & 0.03 & 1.71 \\
\hline 61 & R5E & 13935 & 0.03 & 2.05 \\
\hline 68 & R6I & 36232 & 0.09 & 5.94 \\
\hline 60 & R7E & 13935 & 0.03 & 2.01 \\
\hline 83 & T1E-P & 12146 & 0.03 & 2.43 \\
\hline 88 & T2E-P & 3965 & 0.01 & 0.84 \\
\hline 53 & T3E-P & 3772 & 0.01 & 0.48 \\
\hline 77 & T4E-P & 5634 & 0.01 & 1.05 \\
\hline 67 & T6E-P & 3333 & 0.01 & 0.54 \\
\hline 65 & T7E-P & 12333 & 0.03 & 1.93 \\
\hline 66 & T8E & 13127 & 0.03 & 2.09 \\
\hline 70 & T9E & 12820 & 0.03 & 2.16 \\
\hline 78 & T10E & 10707 & 0.03 & 2.01 \\
\hline 89 & T11E & 2787 & 0.01 & 0.60 \\
\hline 95 & T12E & 2615 & 0.01 & 0.60 \\
\hline 58 & T13E & 1951 & 0.00 & 0.27 \\
\hline 30 & T14E & 3135 & 0.01 & 0.23 \\
\hline 46 & $\mathrm{~A} 1 \mathrm{E}$ & 62594 & 0.15 & 6.94 \\
\hline 46 & A2E & 11381 & 0.03 & 1.26 \\
\hline 46 & A3E & 21999 & 0.05 & 2.44 \\
\hline 86 & A6E & 5072 & 0.01 & 1.05 \\
\hline 81 & A7E & 5017 & 0.01 & 0.98 \\
\hline 40 & A9E & 32888 & 0.08 & 3.17 \\
\hline 68 & A10E & 26477 & 0.06 & 4.34 \\
\hline 62 & A11E & 6020 & 0.01 & 0.90 \\
\hline 97 & $\mathrm{~A} 12 \mathrm{E}$ & 17837 & 0.04 & 4.17 \\
\hline 46 & A17E & 3697 & 0.01 & 0.41 \\
\hline 64.37 & TOTAL & 415084 & 1.00 & 59.45 \\
\hline
\end{tabular}


TABLE B-9. Cairns AAF Weighted PCI 1992

\begin{tabular}{|c|c|c|c|c|}
\hline $\begin{array}{l}\mathrm{PCl} \\
\text { (1) }\end{array}$ & $\begin{array}{c}\text { Feature } \\
\text { (2) }\end{array}$ & $\begin{array}{l}\text { Area } \\
(3)\end{array}$ & $\begin{array}{l}\text { WEIGHT } \\
\text { (4) }\end{array}$ & $\begin{array}{c}W T \times P C l \\
(5)\end{array}$ \\
\hline 62 & R1E & 6967 & 0.02 & 1.04 \\
\hline 99 & R2E & 6967 & 0.02 & 1.65 \\
\hline 96 & R3I & 41807 & 0.10 & 9.62 \\
\hline 57 & R4E & 13935 & 0.03 & 1.90 \\
\hline 58 & R5E & 13935 & 0.03 & 1.94 \\
\hline 76 & R6I & 36232 & 0.09 & 6.60 \\
\hline 63 & R7E & 13935 & 0.03 & 2.11 \\
\hline 67 & T1E-P & 12146 & 0.03 & 1.95 \\
\hline 67 & T2E-P & 3966 & 0.01 & 0.64 \\
\hline 53 & T3E-P & 3772 & 0.01 & 0.48 \\
\hline 68 & T4E-P & 5634 & 0.01 & 0.92 \\
\hline 67 & T6E-P & 3333 & 0.01 & 0.54 \\
\hline 65 & T7E-P & 12333 & 0.03 & 1.92 \\
\hline 61 & T8E & 13127 & 0.03 & 1.92 \\
\hline 63 & T9E & 12820 & 0.03 & 1.94 \\
\hline 62 & $\mathrm{~T} 10 \mathrm{E}$ & 10707 & 0.03 & 1.59 \\
\hline 61 & T11E & 2787 & 0.01 & 0.41 \\
\hline 69 & T12E & 2615 & 0.01 & 0.43 \\
\hline 46 & T13E & 1951 & 0.00 & 0.22 \\
\hline 28 & T14E & 3135 & 0.01 & 0.21 \\
\hline 59 & T15E & 1932 & 0.00 & 0.27 \\
\hline 64 & A1E & 62594 & 0.15 & 9.61 \\
\hline 64 & $\mathrm{~A} 2 \mathrm{E}$ & 11381 & 0.03 & 1.75 \\
\hline 64 & A3E & 21999 & 0.05 & 3.38 \\
\hline 59 & A6E & 5072 & 0.01 & 0.72 \\
\hline 69 & A7E & 5017 & 0.01 & 0.83 \\
\hline 25 & A9E & 32888 & 0.08 & 1.97 \\
\hline 67 & $\mathrm{~A} 10 \mathrm{E}$ & 26477 & 0.06 & 4.25 \\
\hline 65 & A11E & 6020 & 0.01 & 0.94 \\
\hline 70 & $\mathrm{~A} 12 \mathrm{E}$ & 17837 & 0.04 & 2.99 \\
\hline 64 & A17E & 3697 & 0.01 & 0.57 \\
\hline 63.16 & TOTAL & 417018 & 1.00 & 65.30 \\
\hline
\end{tabular}


TABLE B-10. Forney AAF Weighted PCI 1986

\begin{tabular}{ccccc}
\hline PCl & Feature & Area & WEIGHT & WT X PCI \\
$(1)$ & $(2)$ & $(3)$ & $(4)$ & $(5)$ \\
\hline 71 & A1B & 20581 & 0.13 & 8.90 \\
76 & R1A & 7246 & 0.04 & 3.36 \\
62 & R2A & 26199 & 0.16 & 9.90 \\
65 & R3A & 44245 & 0.27 & 17.52 \\
72 & R4A & 7037 & 0.04 & 3.09 \\
64 & T1A-P & 58808 & 0.36 & 22.93 \\
\hline 68.33 & Total & 164117 & 1.00 & 65.70 \\
\hline
\end{tabular}

TABLE B-11. Forney AAF Weighted PCI 1992

\begin{tabular}{ccccc}
\hline PCI & Feature & Area & WEIGHT & WT X PCI \\
$(1)$ & $(2)$ & $(3)$ & $(4)$ & $(5)$ \\
\hline 64 & A1E & 20112 & 0.18 & 11.63 \\
64 & T1E-P & 5881 & 0.05 & 3.40 \\
64 & R6E & 7037 & 0.06 & 4.07 \\
64 & R5E & 6898 & 0.06 & 3.99 \\
64 & R31 & 19509 & 0.18 & 11.28 \\
64 & R41 & 37347 & 0.34 & 21.59 \\
64 & R1E & 7246 & 0.07 & 4.19 \\
64 & R2E & 6689 & 0.06 & 3.87 \\
\hline 64 & Total & 110719 & 1.00 & 64.00 \\
\hline
\end{tabular}

TABLE B-12. Forney AAF Weighted PCI 1996

\begin{tabular}{ccccc}
\hline $\mathrm{PCl}$ & $\begin{array}{c}\text { Feature } \\
(1)\end{array}$ & $\begin{array}{c}\text { Area } \\
(2)\end{array}$ & $\begin{array}{c}\text { WEIGHT } \\
(3)\end{array}$ & $\begin{array}{c}\text { WT } \times \text { PCI } \\
(5)\end{array}$ \\
\hline 13 & A2B & 5295 & 0.03 & 0.40 \\
39 & A1B & 20581 & 0.12 & 4.69 \\
28 & R1A & 7246 & 0.04 & 1.19 \\
34 & R2A & 26199 & 0.15 & 5.20 \\
32 & R3A & 44245 & 0.26 & 8.27 \\
46 & R4A & 7037 & 0.04 & 1.89 \\
32 & T1A-P & 58808 & 0.34 & 10.99 \\
57 & T2B & 1394 & 0.01 & 0.46 \\
42 & T3B & 404 & 0.00 & 0.10 \\
\hline 35.89 & Total & 171210 & 1.00 & 33.19 \\
\hline
\end{tabular}


TABLE B-13. Hood AAF Weighted PCI 1984

\begin{tabular}{ccccc}
\hline PCI & Feature & Area & WEIGHT & WT X PCI \\
$(1)$ & $(2)$ & $(3)$ & $(4)$ & $(5)$ \\
\hline 100 & A15E & 16723 & 0.10 & 10.46 \\
100 & A19E & 13936 & 0.09 & 8.72 \\
100 & A21E & 14865 & 0.09 & 9.30 \\
43 & R1E & 14716 & 0.09 & 3.96 \\
85 & R2E & 13378 & 0.08 & 7.11 \\
82 & R3I & 21579 & 0.13 & 11.07 \\
83 & R4E & 13378 & 0.08 & 6.95 \\
100 & T1E-1-P & 8175 & 0.05 & 5.11 \\
76 & T2E & 13006 & 0.08 & 6.18 \\
85 & T3E & 9058 & 0.06 & 4.82 \\
62 & T4E & 5871 & 0.04 & 2.28 \\
100 & T5E & 2601 & 0.02 & 1.63 \\
92 & T6E & 1598 & 0.01 & 0.92 \\
100 & T7E-P & 3345 & 0.02 & 2.09 \\
84 & T8E-P & 3901 & 0.02 & 2.05 \\
76 & T9E & 3716 & 0.02 & 1.77 \\
\hline 85.5 & Total & 159845 & 1.00 & 84.42 \\
\hline
\end{tabular}


TABLE B-14. Hood AAF Weighted PCI 1988

\begin{tabular}{ccccc}
\hline $\mathrm{PCl}$ & $\begin{array}{c}\text { Feature } \\
(1)\end{array}$ & $\begin{array}{c}\text { Area } \\
(3)\end{array}$ & $\begin{array}{c}\text { WEIGHT } \\
(4)\end{array}$ & $\begin{array}{c}\text { WT X PCI } \\
(5)\end{array}$ \\
\hline 74 & A15E & 16723 & 0.06 & 4.55 \\
89 & A19E & 13936 & 0.05 & 4.56 \\
98 & A21E & 14865 & 0.05 & 5.36 \\
64 & A23E & 1742 & 0.01 & 0.41 \\
40 & A24E & 1858 & 0.01 & 0.27 \\
65 & A2E & 8361 & 0.03 & 2.00 \\
66 & A3E & 4646 & 0.02 & 1.13 \\
71 & A4E & 1742 & 0.01 & 0.45 \\
72 & A5E & 32051 & 0.12 & 8.49 \\
95 & A8E & 53512 & 0.20 & 18.70 \\
40 & R1E & 14716 & 0.05 & 2.17 \\
68 & R2E & 13378 & 0.05 & 3.35 \\
72 & R3I & 21579 & 0.08 & 5.72 \\
72 & R4E & 13378 & 0.05 & 3.54 \\
100 & T10E-1 & 929 & 0.00 & 0.34 \\
83 & T10E-2 & 1022 & 0.00 & 0.31 \\
100 & T11E & 1486 & 0.01 & 0.55 \\
99 & T12E & 8547 & 0.03 & 3.11 \\
88 & T1E-1-P & 8175 & 0.03 & 2.65 \\
100 & T1E-2 & 1951 & 0.01 & 0.72 \\
73 & T2E & 13006 & 0.05 & 3.49 \\
76 & T3E & 9058 & 0.03 & 2.53 \\
78 & T5E & 2601 & 0.01 & 0.75 \\
89 & T6E & 1598 & 0.01 & 0.52 \\
96 & T7E-P & 3345 & 0.01 & 1.18 \\
93 & T8E-P & 3901 & 0.01 & 1.33 \\
72 & T9E & 3716 & 0.01 & 0.98 \\
\hline 79 & Total & 271822 & 1.00 & 79.18 \\
\hline & & & &
\end{tabular}


TABLE B-15. Hood AAF Weighted PCI 1993

\begin{tabular}{ccccc}
\hline $\mathrm{PCl}$ & $\begin{array}{c}\text { Feature } \\
(1)\end{array}$ & $\begin{array}{c}\text { Area } \\
(3)\end{array}$ & $\begin{array}{c}\text { WEIGHT } \\
(4)\end{array}$ & $\begin{array}{c}\text { WT XPCl } \\
(5)\end{array}$ \\
\hline 69 & A15E & 16723 & 0.06 & 4.24 \\
67 & A19E & 13936 & 0.05 & 3.43 \\
94 & A21E & 14865 & 0.05 & 5.14 \\
64 & A23E & 1742 & 0.01 & 0.41 \\
92 & A24E & 1858 & 0.01 & 0.63 \\
65 & A2E & 8361 & 0.03 & 2.00 \\
65 & A3E & 4646 & 0.02 & 1.11 \\
69 & A4E & 1742 & 0.01 & 0.44 \\
69 & A5E & 32051 & 0.12 & 8.14 \\
87 & A8E & 53512 & 0.20 & 17.13 \\
28 & R1E & 14716 & 0.05 & 1.52 \\
69 & R2E & 13378 & 0.05 & 3.40 \\
69 & R3I & 21579 & 0.08 & 5.48 \\
69 & R4E & 13378 & 0.05 & 3.40 \\
88 & T10E-1 & 929 & 0.00 & 0.30 \\
76 & T10E-2 & 1022 & 0.00 & 0.29 \\
94 & T11E & 1486 & 0.01 & 0.51 \\
95 & T12E & 8547 & 0.03 & 2.99 \\
63 & T1E-1-P & 8175 & 0.03 & 1.89 \\
100 & T1E-2 & 1951 & 0.01 & 0.72 \\
67 & T2E & 13006 & 0.05 & 3.21 \\
70 & T3E & 9058 & 0.03 & 2.33 \\
71 & T5E & 2601 & 0.01 & 0.68 \\
69 & T6E & 1598 & 0.01 & 0.41 \\
69 & T7E-P & 3345 & 0.01 & 0.85 \\
65 & T8E-P & 3901 & 0.01 & 0.93 \\
69 & T9E & 3716 & 0.01 & 0.94 \\
\hline 73.04 & Total & 271822 & 1.00 & 72.51 \\
\hline & & & &
\end{tabular}


TABLE B-16. Hunter AAF Weighted PCI 1982

\begin{tabular}{|c|c|c|c|c|}
\hline $\begin{array}{l}\mathrm{PCl} \\
(1)\end{array}$ & $\begin{array}{c}\text { Feature } \\
(2)\end{array}$ & $\begin{array}{c}\text { Area } \\
(3)\end{array}$ & $\begin{array}{l}\text { WEIGHT } \\
(4)\end{array}$ & $\begin{array}{c}\text { WT } \times \text { PCl } \\
(5)\end{array}$ \\
\hline 46 & A1E & 9511 & 0.02 & 0.69 \\
\hline 46 & A7E & 19626 & 0.03 & 1.42 \\
\hline 46 & A8E & 32127. & 0.05 & 2.33 \\
\hline 46 & A10E & 29119 & 0.05 & 2.11 \\
\hline 46 & $\mathrm{~A} 12 \mathrm{E}$ & 3693 & 0.01 & 0.27 \\
\hline 46 & A13E & 17866 & 0.03 & 1.30 \\
\hline 64 & A17E & 16781 & 0.03 & 1.69 \\
\hline 64 & A19E & 45465 & 0.07 & 4.59 \\
\hline 46 & A2OE & 28972 & 0.05 & 2.10 \\
\hline 98 & A21E & 11148 & 0.02 & 1.72 \\
\hline 93 & A30E & 51329 & 0.08 & 7.53 \\
\hline 94 & R3E & 14864 & 0.02 & 2.20 \\
\hline 97 & R4I & 156078 & 0.25 & 23.89 \\
\hline 99 & R5E & 18580 & 0.03 & 2.90 \\
\hline 68 & T1E-P & 10214 & 0.02 & 1.10 \\
\hline 79 & T2E & 6271 & 0.01 & 0.78 \\
\hline 88 & T3E & 11148 & 0.02 & 1.55 \\
\hline 74 & T4E-1 & 4877 & 0.01 & 0.57 \\
\hline 89 & T4E-2 & 3716 & 0.01 & 0.52 \\
\hline 78 & T5E & 27871 & 0.04 & 3.43 \\
\hline 100 & T6E & 4528 & 0.01 & 0.71 \\
\hline 65 & T8E-P & 25084 & 0.04 & 2.57 \\
\hline 56 & T9E-P & 15236 & 0.02 & 1.35 \\
\hline 62 & T10E & 69677 & 0.11 & 6.82 \\
\hline 70.42 & TOTAL & 633783 & 1.00 & 74.16 \\
\hline
\end{tabular}


TABLE B-17. Hunter AAF Weighted PCI 1986

\begin{tabular}{ccccc}
\hline $\mathrm{PCl}$ & $\begin{array}{c}\text { Feature } \\
(1)\end{array}$ & $\begin{array}{c}\text { Area } \\
(2)\end{array}$ & $\begin{array}{c}\text { WEIGHT } \\
(4)\end{array}$ & $\begin{array}{c}\text { WT X PCI } \\
(5)\end{array}$ \\
\hline 84 & A1E & 9511 & 0.02 & 1.38 \\
98 & A7E & 19626 & 0.03 & 3.32 \\
95 & A8E & 32127 & 0.06 & 5.27 \\
100 & A17E & 16781 & 0.03 & 2.90 \\
90 & A19E & 45465 & 0.08 & 7.06 \\
96 & A20E & 28972 & 0.05 & 4.80 \\
98 & A21E & 11148 & 0.02 & 1.89 \\
93 & A30E & 51329 & 0.09 & 8.24 \\
86 & R3E & 14864 & 0.03 & 2.21 \\
85 & R4I & 156078 & 0.27 & 22.90 \\
91 & R5E & 18580 & 0.03 & 2.92 \\
79 & T1E-P & 10214 & 0.02 & 1.39 \\
83 & T2E & 6271 & 0.01 & 0.90 \\
87 & T3E & 11148 & 0.02 & 1.67 \\
74 & T4E-1 & 4877 & 0.01 & 0.62 \\
83 & T5E & 27871 & 0.05 & 3.99 \\
94 & T6E & 4528 & 0.01 & 0.73 \\
73 & T8E-P & 25084 & 0.04 & 3.16 \\
83 & T9E-P & 15236 & 0.03 & 2.18 \\
86 & T10E & 69677 & 0.12 & 10.34 \\
\hline 87.9 & TOTAL & 579388 & 1.00 & 87.87 \\
\hline
\end{tabular}


TABLE B-18. Hunter AAF Weighted PCI 1993

\begin{tabular}{ccccc}
\hline PCI & Feature & Area & WEIGHT & WT XPCl \\
$(1)$ & $(2)$ & $(3)$ & $(4)$ & $(5)$ \\
\hline 83 & A1E & 9511 & 0.02 & 1.38 \\
85 & A7E & 19626 & 0.03 & 2.92 \\
68 & A8E & 32127 & 0.06 & 3.82 \\
89 & A17E & 16781 & 0.03 & 2.61 \\
78 & A19E & 45465 & 0.08 & 6.20 \\
85 & A20E & 28972 & 0.05 & 4.31 \\
93 & A21E & 11148 & 0.02 & 1.81 \\
81 & A30E & 51329 & 0.09 & 7.27 \\
80 & R3E & 14864 & 0.03 & 2.08 \\
63 & R41 & 156078 & 0.27 & 17.19 \\
73 & R5E & 18580 & 0.03 & 2.37 \\
74 & T1E-P & 10214 & 0.02 & 1.32 \\
65 & T2E & 6271 & 0.01 & 0.71 \\
64 & T4E-1 & 4877 & 0.01 & 0.55 \\
67 & T4E-2 & 3716 & 0.01 & 0.44 \\
86 & T5E & 27871 & 0.05 & 4.19 \\
88 & T6E & 4528 & 0.01 & 0.70 \\
67 & T8E-P & 25084 & 0.04 & 2.94 \\
77 & T9E-P & 15236 & 0.03 & 2.05 \\
80 & T10E & 69677 & 0.12 & 9.75 \\
\hline 77.3 & TOTAL & 571956 & 1.00 & 74.60 \\
\hline
\end{tabular}


TABLE B-19. Libby AAF Weighted PCI 1987

\begin{tabular}{ccccc}
\hline PCI & Feature & Area & WEIGHT & WT XPCI \\
$(1)$ & $(2)$ & $(3)$ & $(4)$ & $(5)$ \\
\hline 24 & R10E & 0 & 0.00 & 0.00 \\
12 & R111 & 13935 & 0.04 & 0.54 \\
100 & R121 & 2090 & 0.01 & 0.67 \\
100 & R13E & 6967 & 0.02 & 2.24 \\
96 & R3I & 126813 & 0.41 & 39.18 \\
100 & R6E & 9290 & 0.03 & 2.99 \\
100 & R71 & 12077 & 0.04 & 3.89 \\
72 & R8I & 19509 & 0.06 & 4.52 \\
40 & R9E & 7432 & 0.02 & 0.96 \\
96 & T2E & 6529 & 0.02 & 2.02 \\
98 & T3E & 3484 & 0.01 & 1.10 \\
100 & T4E & 6529 & 0.02 & 2.10 \\
64 & T4E-2 & 5574 & 0.02 & 1.15 \\
82 & T5E & 5216 & 0.02 & 1.38 \\
32 & T7E & 6875 & 0.02 & 0.71 \\
49 & T8E & 6804 & 0.02 & 1.07 \\
74 & T9E & 780 & 0.00 & 0.19 \\
6 & T10E-P & 13471 & 0.04 & 0.26 \\
100 & T11E & 5342 & 0.02 & 1.72 \\
37 & A10E & 6178 & 0.02 & 0.74 \\
8 & A11E & 1821 & 0.01 & 0.05 \\
3 & A6E & 40970 & 0.13 & 0.40 \\
46 & A9E & 3057 & 0.01 & 0.45 \\
\hline 62.57 & TOTAL & 310744 & 1.00 & 68.30 \\
\hline
\end{tabular}

TABLE B-20. Libby AAF Weighted PCI 1995

\begin{tabular}{ccccc}
\hline $\mathrm{PCl}$ & $\begin{array}{c}\text { Feature } \\
(1)\end{array}$ & $\begin{array}{c}\text { Area } \\
(2)\end{array}$ & $\begin{array}{c}\text { WEIGHT } \\
(4)\end{array}$ & $\begin{array}{c}\text { WT X PCI } \\
(5)\end{array}$ \\
\hline 70 & R6A & 9290 & 0.14 & 10.00 \\
42 & R7C & 25084 & 0.39 & 16.20 \\
85 & R8C & 6503 & 0.10 & 8.50 \\
76 & R9A & 9290 & 0.14 & 10.86 \\
92 & T7B & 5500 & 0.08 & 7.78 \\
62 & T8B & 8505 & 0.13 & 8.11 \\
46 & T9B & 844 & 0.01 & 0.60 \\
\hline 67.57 & TOTAL & 65016 & 1.00 & 62.06 \\
\hline
\end{tabular}


TABLE B-21. Los Alamitos AAF Weighted PCI 1985

\begin{tabular}{ccccc}
\hline PCI & Feature & Area & WEIGHT & WT X PCI \\
$(1)$ & $(2)$ & $(3)$ & $(4)$ & $(5)$ \\
\hline 45 & A1E & 34337 & 0.09 & 3.83 \\
46 & A4E & 3028 & 0.01 & 0.35 \\
73 & R10E & 10870 & 0.03 & 1.97 \\
57 & R11E & 17628 & 0.04 & 2.49 \\
56 & R12E & 10172 & 0.03 & 1.41 \\
57 & R1E & 15979 & 0.04 & 2.26 \\
31 & R3I & 77295 & 0.19 & 5.95 \\
51 & R4I & 35117 & 0.09 & 4.44 \\
67 & R6E & 13935 & 0.03 & 2.32 \\
63 & R7I & 55741 & 0.14 & 8.71 \\
60 & R8E & 5017 & 0.01 & 0.75 \\
49 & T11E-P & 4877 & 0.01 & 0.59 \\
36 & T12E & 10870 & 0.03 & 0.97 \\
37 & T13E & 6236 & 0.02 & 0.57 \\
60 & T14E & 4250 & 0.01 & 0.63 \\
59 & T15E & 13378 & 0.03 & 1.96 \\
68 & T16E-P & 15956 & 0.04 & 2.69 \\
58 & T17E-P & 5156 & 0.01 & 0.74 \\
72 & T18E & 1393 & 0.00 & 0.25 \\
67 & T2E-P & 18360 & 0.05 & 3.05 \\
42 & T3E-P & 6875 & 0.02 & 0.72 \\
94 & T4E-P & 13006 & 0.03 & 3.03 \\
69 & T6E-P & 18116 & 0.04 & 3.10 \\
81 & T7E-P & 1010 & 0.00 & 0.20 \\
64 & T8E-P & 1031 & 0.00 & 0.16 \\
69 & T9E & 3414 & 0.01 & 0.58 \\
\hline 58.88 & Total & 403047 & 1.00 & 53.74 \\
\hline & & & &
\end{tabular}


TABLE B-22. Los Alamitos AAF Weighted PCI 1990

\begin{tabular}{ccccc}
\hline $\mathrm{PCl}$ & $\begin{array}{c}\text { Feature } \\
(1)\end{array}$ & $\begin{array}{c}\text { Area } \\
(3)\end{array}$ & $\begin{array}{c}\text { WEIGHT } \\
(4)\end{array}$ & $\begin{array}{c}\text { WT X PCl } \\
(5)\end{array}$ \\
\hline 42 & A1E & 34337 & 0.09 & 3.67 \\
42 & A4E & 3028 & 0.01 & 0.32 \\
48 & R10E & 10870 & 0.03 & 1.33 \\
34 & R11E & 17628 & 0.04 & 1.53 \\
28 & R1E & 15979 & 0.04 & 1.14 \\
99 & R3I & 77295 & 0.20 & 19.48 \\
100 & R4I & 35117 & 0.09 & 8.94 \\
48 & R6E & 13935 & 0.04 & 1.70 \\
46 & R7I & 55741 & 0.14 & 6.53 \\
47 & R8E & 5017 & 0.01 & 0.60 \\
48 & T11E-P & 4877 & 0.01 & 0.60 \\
15 & T12E & 10870 & 0.03 & 0.42 \\
12 & T13E & 6236 & 0.02 & 0.19 \\
39 & T14E & 4250 & 0.01 & 0.42 \\
47 & T15E & 13378 & 0.03 & 1.60 \\
37 & T16E-P & 15956 & 0.04 & 1.50 \\
36 & T17E-P & 5156 & 0.01 & 0.47 \\
56 & T18E & 1393 & 0.00 & 0.20 \\
18 & T2E-P & 18360 & 0.05 & 0.84 \\
15 & T3E-P & 6875 & 0.02 & 0.26 \\
82 & T4E-P & 13006 & 0.03 & 2.71 \\
25 & T6E-P & 18116 & 0.05 & 1.15 \\
23 & T7E-P & 1010 & 0.00 & 0.06 \\
16 & T8E-P & 1031 & 0.00 & 0.04 \\
53 & T9E & 3414 & 0.01 & 0.46 \\
\hline 42.24 & Total & 392874 & 1.00 & 56.16 \\
\hline & & & &
\end{tabular}


TABLE B-23. Los Alamitos AAF Weighted PCI 1993

\begin{tabular}{ccccc}
\hline PCl & Feature & Area & WEIGHT & WT X PCl \\
$(1)$ & $(2)$ & $(3)$ & $(4)$ & $(5)$ \\
\hline 100 & A1E & 34337 & 0.09 & 8.52 \\
42 & A4E & 3028 & 0.01 & 0.32 \\
10 & R10E & 10870 & 0.03 & 0.27 \\
22 & R11E & 17628 & 0.04 & 0.96 \\
20 & R12E & 10172 & 0.03 & 0.50 \\
22 & R1E & 15979 & 0.04 & 0.87 \\
92 & R31 & 77295 & 0.19 & 17.64 \\
99 & R4I & 35117 & 0.09 & 8.63 \\
100 & R6E & 13935 & 0.03 & 3.46 \\
100 & R7I & 55741 & 0.14 & 13.83 \\
100 & R8E & 5017 & 0.01 & 1.24 \\
40 & T11E-P & 4877 & 0.01 & 0.48 \\
3 & T12E & 10870 & 0.03 & 0.08 \\
100 & T13E & 6236 & 0.02 & 1.55 \\
100 & T14E & 4250 & 0.01 & 1.05 \\
100 & T15E & 13378 & 0.03 & 3.32 \\
5 & T16E-P & 15956 & 0.04 & 0.20 \\
20 & T17E-P & 5156 & 0.01 & 0.26 \\
100 & T18E & 1393 & 0.00 & 0.35 \\
25 & T2E-P & 18360 & 0.05 & 1.14 \\
84 & T3E-P & 6875 & 0.02 & 1.43 \\
100 & T4E-P & 13006 & 0.03 & 3.23 \\
100 & T6E-P & 18116 & 0.04 & 4.49 \\
100 & T7E-P & 1010 & 0.00 & 0.25 \\
100 & T8E-P & 1031 & 0.00 & 0.26 \\
100 & T9E & 3414 & 0.01 & 0.85 \\
\hline 68.62 & Total & 403047 & 1.00 & 75.18 \\
\hline & & & &
\end{tabular}


TABLE B-24. Marshall AAF PCIs for 1983, 1987 and 1994

\begin{tabular}{cccc}
$\begin{array}{c}\text { Year } \\
(1)\end{array}$ & $\begin{array}{c}\text { PCI } \\
(2)\end{array}$ & $\begin{array}{c}\text { Feature } \\
(3)\end{array}$ & $\begin{array}{c}\text { Area } \\
(4)\end{array}$ \\
\hline 1983 & 43 & A6E & 8916 \\
\hline 1987 & 41 & A6E & 8916 \\
\hline 1994 & 33 & A6E & 8916 \\
\hline
\end{tabular}

TABLE B-25. McCoy AAF Weighted PCI 1985

\begin{tabular}{ccccc}
\hline PCI & Feature & Area & WEIGHT & WT X PCI \\
$(1)$ & $(2)$ & $(3)$ & $(4)$ & $(5)$ \\
\hline 61 & A1E & 8325 & 0.13 & 7.82 \\
72 & A2E & 10219 & 0.16 & 11.33 \\
81 & R4E & 16723 & 0.26 & 20.85 \\
81 & R5E & 9290 & 0.14 & 11.59 \\
84 & R6E & 6386 & 0.10 & 8.26 \\
66 & T1E-P & 6735 & 0.10 & 6.84 \\
65 & T2E-P & 2090 & 0.03 & 2.09 \\
77 & T3E & 2229 & 0.03 & 2.64 \\
86 & T4E & 1765 & 0.03 & 2.34 \\
79 & T5E & 1189 & 0.02 & 1.45 \\
\hline 75.2 & Total & 64951 & 1.00 & 75.21 \\
\hline
\end{tabular}

TABLE B-26. McCoy AAF Weighted PCI 1993

\begin{tabular}{ccccc}
\hline PCI & $\begin{array}{c}\text { Feature } \\
(1)\end{array}$ & $\begin{array}{c}\text { Area } \\
(3)\end{array}$ & $\begin{array}{c}\text { WEIGHT } \\
(4)\end{array}$ & $\begin{array}{c}\text { WT X PCI } \\
(5)\end{array}$ \\
\hline 84 & A1E & 8325 & 0.07 & 5.66 \\
87 & A2E & 10219 & 0.08 & 7.20 \\
75 & A3E & 4334 & 0.04 & 2.63 \\
70 & A4E & 4181 & 0.03 & 2.37 \\
99 & R2E & 39019 & 0.32 & 31.29 \\
91 & R4E & 16723 & 0.14 & 12.33 \\
95 & R5E & 9290 & 0.08 & 7.15 \\
98 & R6E & 6386 & 0.05 & 5.07 \\
71 & T1E-P & 6735 & 0.05 & 3.87 \\
75 & T2E-P & 2090 & 0.02 & 1.27 \\
91 & T3E & 2229 & 0.02 & 1.64 \\
95 & T4E & 1765 & 0.01 & 1.36 \\
85 & T5E & 1189 & 0.01 & 0.82 \\
99 & T6E-P & 7343 & 0.06 & 5.89 \\
75 & T7E-P & 3620 & 0.03 & 2.20 \\
\hline 86 & Total & 123448 & 1.00 & 90.76 \\
\hline & & & &
\end{tabular}


TABLE B-27. Muir AAF Weighted PCI 1987

\begin{tabular}{ccccc}
\hline PCI & Feature & $\begin{array}{c}\text { Area } \\
(1)\end{array}$ & $\begin{array}{c}\text { WEIGHT } \\
(2)\end{array}$ & $\begin{array}{c}\text { WT XPCI } \\
(5)\end{array}$ \\
\hline 87 & A1E & 870 & 0.01 & 0.86 \\
52 & A2E & 1568 & 0.02 & 0.92 \\
43 & A3E & 3019 & 0.03 & 1.47 \\
63 & A4E & 1568 & 0.02 & 1.12 \\
95 & A6E & 4181 & 0.05 & 4.50 \\
62 & R1E & 30843 & 0.35 & 21.67 \\
84 & T1E & 1568 & 0.02 & 1.49 \\
58 & T2E-P & 4988 & 0.06 & 3.28 \\
98 & T3E-P & 5161 & 0.06 & 5.73 \\
55 & T4E-P & 15004 & 0.17 & 9.35 \\
96 & T5E & 5518 & 0.06 & 6.00 \\
39 & T6E & 3874 & 0.04 & 1.71 \\
63 & T7E & 7200 & 0.08 & 5.14 \\
86 & T8E & 2903 & 0.03 & 2.83 \\
\hline 70.07 & Total & 88265 & 1.00 & 66.07 \\
\hline
\end{tabular}

TABLE B-28. Muir AAF Weighted PCI 1993

\begin{tabular}{ccccc}
\hline PCI & $\begin{array}{c}\text { Feature } \\
(1)\end{array}$ & $\begin{array}{c}\text { Area } \\
(3)\end{array}$ & $\begin{array}{c}\text { WEIGHT } \\
(4)\end{array}$ & $\begin{array}{c}\text { WT XPCI } \\
(5)\end{array}$ \\
\hline 66 & A1E & 870 & 0.01 & 0.64 \\
49 & A2E & 1568 & 0.02 & 0.86 \\
63 & A4E & 1568 & 0.02 & 1.10 \\
72 & A6E & 4181 & 0.05 & 3.37 \\
55 & R1E & 30843 & 0.34 & 18.97 \\
51 & T1E & 1568 & 0.02 & 0.89 \\
31 & T2E-P & 4988 & 0.06 & 1.73 \\
98 & T3E-P & 5161 & 0.06 & 5.66 \\
35 & T4E-P & 15004 & 0.17 & 5.87 \\
96 & T5E & 5518 & 0.06 & 5.92 \\
25 & T6E & 3874 & 0.04 & 1.08 \\
38 & T7E & 7200 & 0.08 & 3.06 \\
85 & T8E & 2903 & 0.03 & 2.76 \\
97 & T9E & 4181 & 0.05 & 4.53 \\
\hline 61.5 & Total & 89426 & 1.00 & 56.45 \\
\hline & & & &
\end{tabular}


TABLE B-29. Phillips AAF Weighted PCI 1986

\begin{tabular}{ccccc}
\hline PCl & $\begin{array}{c}\text { Feature } \\
(1)\end{array}$ & $\begin{array}{c}\text { Area } \\
(3)\end{array}$ & $\begin{array}{c}\text { WEIGHT } \\
(4)\end{array}$ & $\begin{array}{c}\text { WT X PCI } \\
(5)\end{array}$ \\
\hline 30 & A2E & 11288 & 0.03 & 0.79 \\
99 & A3E & 29729 & 0.07 & 6.83 \\
17 & A4E & 4366 & 0.01 & 0.17 \\
46 & R10E & 4877 & 0.01 & 0.52 \\
37 & R11E & 2787 & 0.01 & 0.24 \\
45 & R12I & 39391 & 0.09 & 4.11 \\
41 & R13E & 11148 & 0.03 & 1.06 \\
39 & R14E & 2787 & 0.01 & 0.25 \\
38 & R15E & 1742 & 0.00 & 0.15 \\
40 & R16E & 12193 & 0.03 & 1.13 \\
42 & R17I & 35628 & 0.08 & 3.47 \\
42 & R18E & 9754 & 0.02 & 0.95 \\
9 & R19E & 4181 & 0.01 & 0.09 \\
95 & R1E & 18580 & 0.04 & 4.09 \\
97 & R2I & 20438 & 0.05 & 4.60 \\
100 & R3I & 76924 & 0.18 & 17.84 \\
94 & R4I & 14121 & 0.03 & 3.08 \\
97 & R5I & 11148 & 0.03 & 2.51 \\
100 & R6I & 14864 & 0.03 & 3.45 \\
69 & R7I & 38833 & 0.09 & 6.21 \\
100 & R8E & 18580 & 0.04 & 4.31 \\
31 & R9E & 4877 & 0.01 & 0.35 \\
48 & T1E-P & 9058 & 0.02 & 1.01 \\
98 & T2E-P & 9627 & 0.02 & 2.19 \\
47 & T3E-P & 14110 & 0.03 & 1.54 \\
99 & T4E & 6967 & 0.02 & 1.60 \\
49 & T5E & 3158 & 0.01 & 0.36 \\
\hline 61.07 & Total & 431157 & 1.00 & 72.90 \\
\hline & & & &
\end{tabular}


TABLE B-30. Phillips AAF Weighted PCI 1993

\begin{tabular}{ccccc}
\hline$P C I$ & Feature & Area & WEIGHT & WT XPCI \\
$(1)$ & $(2)$ & $(3)$ & $(4)$ & $(5)$ \\
\hline 8 & A2E & 11288 & 0.03 & 0.21 \\
86 & A3E & 29729 & 0.07 & 5.99 \\
14 & A4E & 4366 & 0.01 & 0.14 \\
45 & R10E & 4877 & 0.01 & 0.51 \\
40 & R11E & 2787 & 0.01 & 0.26 \\
40 & R12I & 39391 & 0.09 & 3.69 \\
40 & R13E & 11148 & 0.03 & 1.04 \\
39 & R14E & 2787 & 0.01 & 0.25 \\
40 & R15E & 1742 & 0.00 & 0.16 \\
36 & R16E & 12193 & 0.03 & 1.03 \\
44 & R171 & 35628 & 0.08 & 3.67 \\
41 & R18E & 9754 & 0.02 & 0.94 \\
55 & R1E & 18580 & 0.04 & 2.39 \\
87 & R21 & 20438 & 0.05 & 4.16 \\
83 & R31 & 76924 & 0.18 & 14.95 \\
70 & R41 & 14121 & 0.03 & 2.31 \\
84 & R51 & 11148 & 0.03 & 2.19 \\
73 & R6I & 14864 & 0.03 & 2.54 \\
69 & R71 & 38833 & 0.09 & 6.28 \\
97 & R8E & 18580 & 0.04 & 4.22 \\
31 & R9E & 4877 & 0.01 & 0.35 \\
46 & T1E-P & 9058 & 0.02 & 0.98 \\
83 & T2E-P & 9627 & 0.02 & 1.87 \\
47 & T3E-P & 14110 & 0.03 & 1.55 \\
74 & T4E & 6967 & 0.02 & 1.21 \\
46 & T5E & 3158 & 0.01 & 0.34 \\
\hline 54.54 & Total & 426977 & 1.00 & 63.27 \\
\hline
\end{tabular}

TABLE B-31. Redstone AAF Weighted PCI 1987

\begin{tabular}{ccccc}
\hline PCl & Feature & Area & WEIGHT & WT X PCl \\
$(1)$ & $(2)$ & $(3)$ & $(4)$ & $(5)$ \\
\hline 42 & R2E & 69677 & 0.65 & 27.33 \\
36 & R3E & 6567 & 0.06 & 2.21 \\
36 & R4E & 20206 & 0.19 & 6.79 \\
44 & T1E-P & 3112 & 0.03 & 1.28 \\
40 & T2E-P & 3112 & 0.03 & 1.16 \\
71 & T3E & 2550 & 0.02 & 1.69 \\
85 & T4E & 1858 & 0.02 & 1.47 \\
\hline 50.57 & TOTAL & 107082 & 1.00 & 41.94 \\
\hline
\end{tabular}


TABLE B-32. Redstone AAF Weighted PCI 1993

\begin{tabular}{ccccc}
\hline PCI & Feature & Area & WEIGHT & WT X PCI \\
$(1)$ & $(2)$ & $(3)$ & $(4)$ & $(5)$ \\
\hline 94 & R2E & 69677 & 0.65 & 61.16 \\
81 & R3E & 6567 & 0.06 & 4.97 \\
93 & R4E & 20206 & 0.19 & 17.55 \\
92 & T1E-P & 3112 & 0.03 & 2.67 \\
94 & T2E-P & 3112 & 0.03 & 2.73 \\
55 & T3E & 2550 & 0.02 & 1.31 \\
68 & T4E & 1858 & 0.02 & 1.18 \\
\hline 82.43 & TOTAL & 107082 & 1.00 & 91.58 \\
\hline
\end{tabular}

TABLE B-33. Selah AAF Weighted PCI 1985

\begin{tabular}{ccccc}
\hline PCI & Feature & Area & WEIGHT & WT X PCI \\
$(1)$ & $(2)$ & $(3)$ & $(4)$ & $(5)$ \\
\hline 76 & A1E & 2391 & 0.04 & 3.19 \\
80 & R1E & 850 & 0.01 & 1.19 \\
68 & R2E & 4891 & 0.09 & 5.84 \\
60 & R3E & 1226 & 0.02 & 1.29 \\
59 & R41 & 10772 & 0.19 & 11.15 \\
69 & R5I & 1191 & 0.02 & 1.44 \\
70 & R6I & 6612 & 0.12 & 8.12 \\
75 & R7E & 933 & 0.02 & 1.23 \\
75 & R8E & 3483 & 0.06 & 4.59 \\
79 & R9E & 2550 & 0.04 & 3.54 \\
75 & T1E-P & 5786 & 0.10 & 7.62 \\
71 & T2E-P & 13896 & 0.24 & 17.32 \\
69 & T3E-P & 2391 & 0.04 & 2.90 \\
\hline 71.23 & Total & 56974 & 1.00 & 69.41 \\
\hline
\end{tabular}


TABLE B-34. Selah AAF Weighted PCI 1994

\begin{tabular}{|c|c|c|c|c|}
\hline $\begin{array}{l}\mathrm{PCl} \\
\text { (1) }\end{array}$ & $\begin{array}{l}\text { Feature } \\
\text { (2) }\end{array}$ & $\begin{array}{c}\text { Area } \\
\text { (3) }\end{array}$ & $\begin{array}{l}\text { WEIGHT } \\
\text { (4) }\end{array}$ & $\begin{array}{l}\text { WT XPCl } \\
\text { (5) }\end{array}$ \\
\hline 67 & A1E & 2391 & 0.04 & 2.81 \\
\hline 60 & R1E & 850 & 0.01 & 0.89 \\
\hline 40 & R2E & 4891 & 0.09 & 3.43 \\
\hline 21 & R3E & 1226 & 0.02 & 0.45 \\
\hline 33 & R4I & 10772 & 0.19 & 6.24 \\
\hline 52 & R5I & 1191 & 0.02 & 1.09 \\
\hline 48 & R6I & 6612 & 0.12 & 5.57 \\
\hline 61 & R7E & 933 & 0.02 & 1.00 \\
\hline 72 & R8E & 3483 & 0.06 & 4.40 \\
\hline 76 & R9E & 2550 & 0.04 & 3.40 \\
\hline 62 & T1E-P & 5786 & 0.10 & 6.30 \\
\hline 51 & T2E-P & 13896 & 0.24 & 12.44 \\
\hline 64 & T3E-P & 2391 & 0.04 & 2.69 \\
\hline 54.38 & Total & 56974 & 1.00 & 50.71 \\
\hline
\end{tabular}

TABLE B-35. Simmons AAF Weighted PCI 1985

\begin{tabular}{ccccc}
\hline $\mathrm{PCl}$ & Feature & Area & WEIGHT & WT X PCI \\
$(1)$ & $(2)$ & $(3)$ & $(4)$ & $(5)$ \\
\hline 96 & R1E & 4645 & 0.04 & 4.25 \\
90 & R2E & 4645 & 0.04 & 3.98 \\
93 & R3I & 14865 & 0.14 & 13.17 \\
95 & R4E & 4645 & 0.04 & 4.20 \\
94 & R5E & 4645 & 0.04 & 4.16 \\
79 & T1E-P & 20903 & 0.20 & 15.73 \\
92 & T3E & 6968 & 0.07 & 6.11 \\
70 & T4E & 2323 & 0.02 & 1.55 \\
69 & T5E-P & 2323 & 0.02 & 1.53 \\
93 & T12E & 13936 & 0.13 & 12.35 \\
46 & A2E & 25084 & 0.24 & 10.99 \\
\hline 83.36 & TOTAL & 104981 & 1.00 & 78.01 \\
\hline
\end{tabular}


TABLE B-36. Simmons AAF Weighted PCI 1989

\begin{tabular}{ccccc}
\hline$P C l$ & Feature & Area & WEIGHT & WT X PCI \\
$(1)$ & $(2)$ & $(3)$ & $(4)$ & $(5)$ \\
\hline 70 & R1E & 4645 & 0.04 & 2.67 \\
63 & R2E & 4645 & 0.04 & 2.40 \\
57 & R3I & 14865 & 0.12 & 6.95 \\
63 & R4E & 4645 & 0.04 & 2.40 \\
54 & R5E & 4645 & 0.04 & 2.06 \\
53 & T1E-P & 20903 & 0.17 & 9.08 \\
66 & T3E & 6968 & 0.06 & 3.77 \\
42 & T4E & 2323 & 0.02 & 0.80 \\
40 & T5E-P & 2323 & 0.02 & 0.76 \\
63 & T12E & 13936 & 0.11 & 7.20 \\
100 & T13E & 3345 & 0.03 & 2.74 \\
100 & T14E & 8083 & 0.07 & 6.63 \\
100 & T15E & 5574 & 0.05 & 4.57 \\
46 & A2E & 25084 & 0.21 & 9.46 \\
\hline 65.5 & TOTAL & 121982 & 1.00 & 61.47 \\
\hline
\end{tabular}


TABLE B-37. Simmons AAF Weighted PCI 1993

\begin{tabular}{ccccc}
\hline PCI & Feature & $\begin{array}{c}\text { Area } \\
(1)\end{array}$ & $\begin{array}{c}\text { WEIGHT } \\
(2)\end{array}$ & $\begin{array}{c}\text { WT X PCI } \\
(5)\end{array}$ \\
\hline 100 & R1E & 4645 & 0.04 & 3.96 \\
100 & R2E & 4645 & 0.04 & 3.96 \\
100 & R3I & 14865 & 0.13 & 12.68 \\
100 & R4E & 4645 & 0.04 & 3.96 \\
100 & R5E & 4645 & 0.04 & 3.96 \\
91 & T1E-P & 20903 & 0.18 & 16.22 \\
98 & T3E & 6968 & 0.06 & 5.82 \\
94 & T4E & 2323 & 0.02 & 1.86 \\
89 & T5E-P & 2323 & 0.02 & 1.76 \\
79 & T13E & 3345 & 0.03 & 2.25 \\
84 & T14E & 8083 & 0.07 & 5.79 \\
87 & T15E & 5574 & 0.05 & 4.14 \\
99 & T16E & 9197 & 0.08 & 7.77 \\
97 & A2E & 25084 & 0.21 & 20.75 \\
\hline 94.14 & TOTAL & 117244 & 1.00 & 94.90 \\
\hline
\end{tabular}

TABLE B-38. Wheeler-Sack AAF Weighted PCI 1985

\begin{tabular}{ccccc}
\hline PCI & Feature & Area & WEIGHT & WT XPCI \\
$(1)$ & $(2)$ & $(3)$ & $(4)$ & $(5)$ \\
\hline 63 & T1E-P & 17768 & 0.25 & 15.72 \\
64 & T2E-P & 5039 & 0.07 & 4.53 \\
64 & T3E & 2787 & 0.04 & 2.50 \\
62 & T5E-P & 37263 & 0.52 & 32.44 \\
64 & T7E-P & 8361 & 0.12 & 7.51 \\
\hline 63 & Total & 71218 & 1.00 & 62.70 \\
\hline
\end{tabular}


TABLE B-39. Wheeler-Sack AAF Weighted PCI 1993

\begin{tabular}{ccccc}
\hline PCI & Feature & Area & WEIGHT & WT X PCI \\
$(1)$ & $(2)$ & $(3)$ & $(4)$ & $(5)$ \\
\hline 100 & T10E-P & 15329 & 0.12 & 11.61 \\
100 & T11E-P & 3233 & 0.02 & 2.45 \\
100 & T12E-P & 8436 & 0.06 & 6.39 \\
100 & T13E & 2044 & 0.02 & 1.55 \\
100 & T14E & 24396 & 0.18 & 18.47 \\
100 & T15E-P & 2568 & 0.02 & 1.94 \\
74 & T1E-P & 17768 & 0.13 & 9.96 \\
46 & T2E & 5039 & 0.04 & 1.76 \\
44 & T3E & 2787 & 0.02 & 0.93 \\
87 & T5E-P & 37263 & 0.28 & 24.55 \\
100 & T7E-P & 8361 & 0.06 & 6.33 \\
100 & T8E-P & 3345 & 0.03 & 2.53 \\
100 & T9E & 1486 & 0.01 & 1.13 \\
\hline 88.54 & Total & 132055 & 1.00 & 89.59 \\
\hline \multicolumn{7}{c}{} & & &
\end{tabular}




\section{APPENDIX C \\ CONSTRUCTION DATA}

The tables in this appendix contain summary construction data from the pavement evaluation reports. The construction data listed includes thickness in millimeters of the asphalt concrete thickness, base, subbase (if any), and overlays (if any). Also listed for each feature is the base, subbase (if any) and subgrade type, as reported in the evaluation report. The final columns list construction dates, including original construction and when any overlays were placed.

The material types listed in the tables are as reported in the evaluation reports. Some of the materials are described in terms of the unified soil classification system. Following is a list of the unified soil classification letter abbreviations and the word descriptions for the material types listed in the tables in this appendix: GW - well graded gravel, GP - poorly graded gravel, GC - clayey gravel, GM - silty gravel, SP - poorly graded sand, SC - clayey sand, SM - silty sand, $\mathrm{ML}$ - low plasticity silt, $\mathrm{CL}$ - low plasticity clay, and $\mathrm{CH}$ - high plasticity clay. 
TABLE C-1. Physical Properties and Construction History of Biggs AAF Layer Thicknesses $(\mathrm{mm}) \quad$ Material

Construction Dates

\begin{tabular}{|c|c|c|c|c|c|c|c|c|c|c|}
\hline $\begin{array}{c}\text { Feature } \\
\text { (1) }\end{array}$ & $\begin{array}{l}\text { Asphalt } \\
\text { Concrete } \\
\text { (2) }\end{array}$ & $\begin{array}{c}\text { Base } \\
\text { (3) }\end{array}$ & $\begin{array}{c}\text { Subbase } \\
\text { (4) }\end{array}$ & $\begin{array}{c}\text { Overlays } \\
\text { (5) }\end{array}$ & $\begin{array}{c}\text { Base } \\
\text { (6) }\end{array}$ & $\begin{array}{c}\text { Subbase } \\
\text { (7) }\end{array}$ & $\begin{array}{c}\text { Subgrade } \\
\text { (8) }\end{array}$ & $\begin{array}{c}\text { Original } \\
\text { (9) }\end{array}$ & Overlay & verlay 2 \\
\hline A10E & 76 & 152 & 0 & 127 & soilcement & & SM & 1942 & 1959 & 1980 \\
\hline A12E & 76 & 152 & 0 & 0 & GW & & SM & 1953 & & \\
\hline A20E & 76 & 152 & 0 & 0 & GW & & SM & 1953 & & \\
\hline A21E & 102 & 254 & 0 & 0 & GW-GM & & SM & 1953 & & \\
\hline A29E & 51 & 152 & 0 & 38 & soilcement & & SM & 1942 & 1956 & \\
\hline A6E & 76 & 152 & 0 & 0 & GW & & SM & 1953 & & \\
\hline A7E & 102 & 254 & 0 & 0 & GW-GM & & SC & 1953 & & \\
\hline A9E & 76 & 152 & 0 & 51 & soilcement & & SM & 1942 & 1980 & \\
\hline T10E & 76 & 152 & 0 & 152 & soilcement & & SM & 1942 & 1953 & \\
\hline T11E & 102 & 178 & 0 & 0 & GW-GC & & $\mathrm{SC}$ & 1954 & & \\
\hline T16E & 229 & 152 & 0 & 0 & soilcement & & SM-SC & 1942 & 1953 & \\
\hline T17E & 51 & 203 & 0 & 25 & GW-GM & & SM & 1943 & 1953 & \\
\hline T18E & 51 & 203 & 0 & 25 & GW-GM & & SM & 1943 & 1953 & \\
\hline T1E & 51 & 203 & 0 & 76 & GW-GM & & SP & 1943 & 1952 & 1955 \\
\hline T20E & 102 & 254 & 0 & 0 & GW-GM & & SM/SC-SM & 1953 & & \\
\hline T21E & 102 & 152 & 152 & 0 & GW-GM & GW-GM & SM-SC & 1953 & & \\
\hline T25E & 51 & 152 & 0 & 76 & soilcement & & SM & 1942 & 1955 & \\
\hline T26E & 51 & 152 & 0 & 76 & soilcement & & SP & 1942 & 1955 & \\
\hline T5E & 102 & 254 & 0 & 0 & GW-GM & & SM-SC & 1953 & & \\
\hline T6E & 102 & 254 & 0 & 0 & GW-GM & & SM-SC & 1953 & & \\
\hline T7E & 102 & 330 & 0 & 0 & GW-GM & & SC & 1953 & & \\
\hline
\end{tabular}


TABLE C-2. Physical Properties and Construction History of Butts AAF Layer Thicknesses (mm) Material

Construction Dates

\begin{tabular}{|c|c|c|c|c|c|c|c|c|c|c|c|c|}
\hline $\begin{array}{c}\text { Feature } \\
\text { (1) }\end{array}$ & $\begin{array}{c}\text { Asphalt } \\
\text { Concrete } \\
\text { (2) }\end{array}$ & $\begin{array}{l}\text { Base } \\
\text { (3) }\end{array}$ & $\begin{array}{c}\text { Subbase } \\
\text { (4) }\end{array}$ & $\begin{array}{l}\text { Overlays } \\
\text { (5) }\end{array}$ & $\begin{array}{c}\text { Base } \\
\text { (6) }\end{array}$ & $\begin{array}{c}\text { Subbase } \\
\text { (7) }\end{array}$ & $\begin{array}{c}\text { Subgrade } \\
\text { (8) }\end{array}$ & $\begin{array}{c}\text { Original } \\
\text { (9) }\end{array}$ & $\begin{array}{c}\text { Overlay } 1 \\
\text { (10) }\end{array}$ & $\begin{array}{c}\text { Overlay } \\
2 \\
(11)\end{array}$ & $\begin{array}{c}\text { Overlay } \\
3 \\
(12)\end{array}$ & $\begin{array}{c}\text { Overlay } \\
4 \\
(13)\end{array}$ \\
\hline A1E & 51 & 152 & 203 & 25 & Stab Agg & Gravel & $\mathrm{CL}$ & 1964 & 1973 & & & \\
\hline A2E & 51 & 152 & 203 & 25 & Stab Agg & Gravel & $\mathrm{CL}$ & 1964 & 1973 & & & \\
\hline A3E & 25 & 152 & 203 & 51 & Stab Agg & Gravel & $\mathrm{CL}$ & 1964 & 1973 & & & \\
\hline R10E & 51 & 152 & 203 & 25 & Stab Agg & Gravel & $\mathrm{CL}$ & 1964 & 1973 & & & \\
\hline R11E & 51 & 152 & 203 & 25 & Stab Agg & Gravel & $\mathrm{CL}$ & 1964 & 1973 & & & \\
\hline R1E & 25 & 229 & 0 & 25 & Gravel & & $C L$ & 1960 & 1973 & & & \\
\hline R2E & 76 & 610 & 0 & 140 & Gravel & & $\mathrm{CL}$ & 1959 & 1965 & 1969 & 1973 & 1986 \\
\hline R3E & 76 & 457 & 0 & 140 & Gravel & & $\mathrm{CL}$ & 1959 & 1965 & 1969 & 1973 & 1986 \\
\hline R4I & 76 & 457 & 0 & 140 & Gravel & & $\mathrm{CL}$ & 1959 & 1965 & 1969 & 1973 & 1986 \\
\hline R5E & 76 & 457 & 0 & 140 & Gravel & & $\mathrm{CL}$ & 1959 & 1965 & 1969 & 1973 & 1986 \\
\hline R6E & 76 & 610 & 0 & 140 & Gravel & & $\mathrm{CL}$ & 1965 & 1969 & 1973 & 1986 & \\
\hline R7E & 51 & 152 & 203 & 25 & Stab Agg & Gravel & $C L$ & 1964 & 1973 & & & \\
\hline R8E & 51 & 152 & 203 & 25 & Stab Agg & Gravel & $\mathrm{CL}$ & 1964 & 1973 & & & \\
\hline R9I & 51 & 152 & 203 & 25 & Stab Agg & Gravel & $\mathrm{CL}$ & 1964 & 1973 & & & \\
\hline T1E & 25 & 229 & 0 & 25 & Gravel & & $\mathrm{CL}$ & 1960 & 1973 & & & \\
\hline $\mathrm{T} 2 \mathrm{E}$ & 51 & 152 & 203 & 25 & Stab Agg & Gravel & $\mathrm{CL}$ & 1964 & 1973 & & & \\
\hline T4E & 51 & 152 & 203 & 0 & Stab Agg & Gravel & $\mathrm{CL}$ & 1964 & & & & \\
\hline
\end{tabular}


TABLE C-3. Physical Properties and Construction History of Cairns AAF Layer Thicknesses (mm) Material

Construction Dates

\begin{tabular}{|c|c|c|c|c|c|c|c|c|c|c|c|}
\hline Feature & $\begin{array}{c}\text { Asphalt } \\
\text { Concrete } \\
\text { (2) }\end{array}$ & Base & Subbase & Overlays & $\begin{array}{c}\text { Base } \\
\text { (6) }\end{array}$ & $\begin{array}{c}\text { Subbase } \\
\text { (7) }\end{array}$ & $\begin{array}{c}\text { Subgrade } \\
\text { (8) }\end{array}$ & $\begin{array}{l}\text { Original } \\
\text { (9) }\end{array}$ & $\begin{array}{c}\text { Overlay } 1 \\
\text { (10) }\end{array}$ & $\begin{array}{c}\text { Overlay } \\
2 \\
(11)\end{array}$ & $\begin{array}{c}\text { Overlay } \\
3 \\
(12)\end{array}$ \\
\hline R1E & 89 & 203 & 0 & 38 & ClayeySand & & SM-SC & 1966 & 1979 & & \\
\hline R2E & 51 & 203 & 0 & 140 & ClayeySand & & SM-SC & 1942 & 1960 & 1979 & 1990 \\
\hline R3I & 51 & 203 & 0 & 140 & ClayeySand & & SM-SC & 1942 & 1960 & 1979 & 1990 \\
\hline R4E & 51 & 203 & 0 & 140 & ClayeySand & & SM-SC & 1942 & 1960 & 1979 & \\
\hline R5E & 51 & 203 & 0 & 140 & ClayeySand & & SM-SC & 1942 & 1960 & 1979 & \\
\hline R6I & 51 & 203 & 0 & 140 & ClayeySand & & SM-SC & 1942 & 1960 & 1979 & 1990 \\
\hline R7E & 51 & 203 & 0 & 140 & ClayeySand & & SM-SC & 1942 & 1960 & 1979 & \\
\hline T1E & 51 & 203 & 0 & 102 & ClayeySand & & SM-SC & 1942 & 1961 & 1979 & \\
\hline T2E & 51 & 152 & 0 & 0 & CrushedAgg & & SM-SC & 1969 & & & \\
\hline T3E & 38 & 203 & 0 & 0 & SandClay & & SM-SC & 1965 & & & \\
\hline T4E & 51 & 203 & 0 & 102 & ClayeySand & & SM-SC & 1942 & 1961 & 1979 & \\
\hline T6E & 51 & 152 & 0 & 0 & CrushedAgg & & SM-SC & 1969 & & & \\
\hline T7E & 51 & 203 & 0 & 102 & ClayeySand & & SM-SC & 1942 & 1961 & 1979 & \\
\hline T8E & 51 & 203 & 0 & 102 & ClayeySand & & SM-SC & 1942 & 1961 & 1979 & 1992 \\
\hline T9E & 51 & 203 & 0 & 102 & ClayeySand & & SM-SC & 1942 & 1961 & 1979 & \\
\hline $\mathrm{T} 10 \mathrm{E}$ & 51 & 203 & 0 & 102 & ClayeySand & & SM-SC & 1942 & 1961 & 1979 & \\
\hline $\mathrm{T} 11 \mathrm{E}$ & 51 & 203 & 0 & 102 & ClayeySand & & SM-SC & 1942 & 1961 & 1979 & \\
\hline T12E & 51 & 203 & 0 & 102 & ClayeySand & & SM-SC & 1942 & 1961 & 1979 & \\
\hline T13E & 76 & 178 & 152 & 0 & CrushedSlag & ClayeySand & SM-SC & 1959 & & & \\
\hline $\mathrm{T} 14 \mathrm{E}$ & 13 & 152 & 0 & 152 & RolledRock & & SM-SC & 1942 & & & \\
\hline $\mathrm{T} 15 \mathrm{E}$ & 76 & 178 & 102 & 76 & CrushedAgg & SandClay & SM-SC & 1959 & 1961 & 1979 & \\
\hline A1E & 102 & 152 & 0 & 0 & ClayeySand & & SM-SC & 1956 & 1992 & & \\
\hline A2E & 76 & 178 & 0 & 0 & CrushedSlag & & SM-SC & 1959 & 1992 & & \\
\hline $\mathrm{A} 3 \mathrm{E}$ & 102 & 152 & 0 & 0 & ClayeySand & & SM-SC & 1956 & 1992 & & \\
\hline $\mathrm{A} 6 \mathrm{E}$ & 76 & 0 & 0 & 76 & & & SM-SC & & 1961 & 1979 & \\
\hline A7E & 51 & 152 & 0 & 0 & CrushedAgg & & SM-SC & 1969 & & & \\
\hline A9E & 51 & 203 & 0 & 102 & ClayeySand & & SM-SC & 1942 & 1960 & & \\
\hline A10E & 51 & 203 & 0 & 140 & ClayeySand & & SM-SC & 1942 & 1960 & 1982 & \\
\hline A11E & 51 & 0 & 0 & 38 & & & SM-SC & & 1983 & & \\
\hline $\mathrm{A} 12 \mathrm{E}$ & 51 & 203 & 0 & 0 & StabAgg & & SM-SC & 1982 & & & \\
\hline A17E & 76 & 178 & 0 & 0 & Crush & Slag & SM-SC & 1959 & & & \\
\hline
\end{tabular}


TABLE C-4. Physical Properties and Construction History of Forney AAF

$$
\text { Layer Thicknesses (mm) }
$$

\begin{tabular}{|c|c|c|c|c|c|c|c|c|c|c|}
\hline $\begin{array}{c}\text { Feature } \\
\text { (1) }\end{array}$ & $\begin{array}{l}\text { Asphalt } \\
\text { Concrete } \\
\text { (2) }\end{array}$ & $\begin{array}{l}\text { Base } \\
\text { (3) }\end{array}$ & $\begin{array}{c}\text { Subbase } \\
\text { (4) }\end{array}$ & $\begin{array}{c}\text { Overlays } \\
\text { (5) }\end{array}$ & $\begin{array}{c}\text { Base } \\
\text { (6) }\end{array}$ & $\begin{array}{c}\text { Subbase } \\
\text { (7) }\end{array}$ & $\begin{array}{c}\text { Subgrade } \\
\text { (8) }\end{array}$ & $\begin{array}{c}\text { Original } \\
\text { (9) }\end{array}$ & $\begin{array}{c}\text { Overlay } \\
1 \\
(10)\end{array}$ & $\begin{array}{c}\text { Overlay } \\
2 \\
(11)\end{array}$ \\
\hline A1B & 38 & 152 & 432 & 76 & GW(CrushedStone) & GP(CrushedStone) & $\mathrm{CH}-\mathrm{CL}$ & 1960 & & \\
\hline A2B & 38 & 152 & 432 & 0 & GW(CrushedStone) & GP(CrushedStone) & $\mathrm{CH}-\mathrm{CL}$ & NA & & \\
\hline R1A & 114 & 152 & 432 & 0 & GW(CrushedStone) & GP(CrushedStone) & $\mathrm{CH}-\mathrm{CL}$ & 1960 & 1980 & 1982 \\
\hline R2A & 64 & 152 & 432 & 76 & GW(CrushedStone) & GP(CrushedStone) & $\mathrm{CH}-\mathrm{CL}$ & 1960 & 1980 & \\
\hline R3A & 64 & 152 & 432 & 76 & GW(CrushedStone) & GP(CrushedStone) & $\mathrm{CH}-\mathrm{CL}$ & 1960 & 1980 & \\
\hline R4A & 51 & 152 & 432 & 51 & GW(CrushedStone) & GP(CrushedStone) & $\mathrm{CH}-\mathrm{CL}$ & 1960 & 1980 & \\
\hline T1A & 38 & 152 & 432 & 76 & GW(CrushedStone) & GP(CrushedStone) & $\mathrm{CH}-\mathrm{CL}$ & 1960 & 1980 & \\
\hline
\end{tabular}


TABLE C-5. Physical Properties and Construction History of Hood AAF

\section{Layer Thicknesses $(\mathrm{mm}) \quad$ Material}

Construction Dates

\begin{tabular}{|c|c|c|c|c|c|c|c|c|c|c|c|c|}
\hline Feature & $\begin{array}{c}\text { Asphalt } \\
\text { Concrete } \\
\text { (2) }\end{array}$ & Base & Subbase & Overlays & $\begin{array}{l}\text { Base } \\
\text { (6) }\end{array}$ & $\begin{array}{c}\text { Subbase : } \\
\text { (7) }\end{array}$ & Subgrade & Original & $\begin{array}{c}\text { Overlay } \\
1 \\
(10)\end{array}$ & $\begin{array}{c}\text { Overlay } \\
2 \\
(11)\end{array}$ & $\begin{array}{c}\text { Overlay } \\
3 \\
(12)\end{array}$ & $\begin{array}{c}\text { Overlay } \\
4 \\
(13)\end{array}$ \\
\hline A15E & 51 & 152 & 152 & 0 & StabAgg & LimeStab & $\mathrm{CH}-\mathrm{CL}$ & 1983 & & & & \\
\hline A19E & 51 & 152 & 152 & 0 & StabAgg & LimeStab & $\mathrm{CH}-\mathrm{CL}$ & 1983 & & & & \\
\hline A21E & 51 & 152 & 152 & 0 & StabAgg & LimeStab & $\mathrm{CH}-\mathrm{CL}$ & 1983 & & & & \\
\hline A23E & 51 & 152 & 0 & 76 & StabAgg & & $\mathrm{CH}-\mathrm{CL}$ & 1970 & 1978 & 1980 & & \\
\hline A24E & 51 & 152 & 152 & 51 & StabAgg & LimeStab & $\mathrm{CH}-\mathrm{CL}$ & 1983 & & & & \\
\hline $\mathrm{A} 2 \mathrm{E}$ & 51 & 254 & 0 & 0 & CrushedLimestone & & $\mathrm{CH}-\mathrm{CL}$ & 1943 & 1947 & 1955 & & \\
\hline A3E & 102 & 203 & 0 & 0 & CrushedLimestone & & $\mathrm{CH}-\mathrm{CL}$ & 1943 & 1947 & 1955 & & \\
\hline A4E & 1.5 & 152 & 0 & 89 & StabAgg & & $\mathrm{CH}-\mathrm{CL}$ & & & & & \\
\hline A5E & 76 & 152 & 0 & 0 & StabAgg & & $\mathrm{CH}-\mathrm{CL}$ & & & & & \\
\hline $\mathrm{A} 8 \mathrm{E}$ & 51 & 152 & 152 & 51 & StabAgg & LimeStab & $\mathrm{CH}-\mathrm{CL}$ & 1984 & & & & \\
\hline R1E & 51 & 254 & 0 & 0 & CrushedLimestone & & CH-CL & 1942 & 1970 & 1971 & 1990 & \\
\hline $\mathrm{R} 2 \mathrm{E}$ & 51 & 254 & 0 & 102 & CrushedLimestone & & $\mathrm{CH}-\mathrm{CL}$ & 1942 & 1958 & 1990 & 1993 & \\
\hline R3I & 51 & 254 & 0 & 102 & CrushedLimestone & & $\mathrm{CH}-\mathrm{CL}$ & 1942 & 1958 & 1971 & 1990 & \\
\hline R4E & 51 & 203 & 0 & 102 & CrushedLimestone & & $\mathrm{CH}-\mathrm{CL}$ & 1942 & 1958 & 1990 & & \\
\hline T10E-1 & 76 & 178 & 152 & 0 & StabAgg & LimeStab & $\mathrm{CH}-\mathrm{CL}$ & 1943 & 1947 & 1955 & 1989 & \\
\hline T10E-2 & 51 & 254 & 0 & 51 & CrushedLimestone & & $\mathrm{CH}-\mathrm{CL}$ & 1943 & 1947 & 1955 & & \\
\hline T11E & 76 & 178 & 0 & 0 & StabAgg & & $\mathrm{CH}-\mathrm{CL}$ & 1984 & 1987 & & & \\
\hline T12E & 76 & 178 & 152 & 0 & StabAgg & LimeStab & & 1984 & 1987 & & & \\
\hline T1E-1 & 51 & 152 & 152 & 0 & StabAgg & LimeStab & $\mathrm{CH}-\mathrm{CL}$ & 1983 & & & & \\
\hline T1E-2 & 76 & 178 & 152 & 0 & StabAgg & LimeStab & $\mathrm{CH}-\mathrm{CL}$ & 1987 & & & & \\
\hline T2E & 51 & 152 & 0 & 51 & StabAgg & & $\mathrm{CH}-\mathrm{CL}$ & 1942 & 1960 & 1970 & 1979 & 1990 \\
\hline T3E & 38 & 152 & 0 & 89 & StabAgg & & $\mathrm{CH}-\mathrm{CL}$ & 1942 & 1960 & 1970 & 1978 & \\
\hline T5E & 51 & 152 & 152 & 0 & StabAgg & LimeStab & $\mathrm{CH}-\mathrm{CL}$ & 1942 & 1958 & 1971 & 1983 & \\
\hline T6E & 51 & 152 & 0 & 51 & StabAgg & & $\mathrm{CH}-\mathrm{CL}$ & 1942 & 1960 & 1980 & 1990 & \\
\hline T7E & 51 & 152 & 152 & 0 & StabAgg & LimeStab & $\mathrm{CH}-\mathrm{CL}$ & 1942 & 1971 & 1983 & 1991 & \\
\hline T8E & 51 & 152 & 0 & 76 & StabAgg & & $\mathrm{CH}-\mathrm{CL}$ & 1960 & 1970 & 1980 & 1993 & \\
\hline T9E & 51 & 254 & 0 & 51 & CrushedLimestone & & $\mathrm{CH}-\mathrm{CL}$ & 1943 & 1947 & 1955 & 1970 & 1993 \\
\hline
\end{tabular}


TABLE C-6. Physical Properties and Construction History of Hunter AAF

\begin{tabular}{|c|c|c|c|c|c|c|c|c|c|c|c|}
\hline \multirow[b]{2}{*}{$\begin{array}{c}\text { Feature } \\
\text { (1) }\end{array}$} & \multicolumn{4}{|c|}{ Layer Thicknesses $(\mathrm{mm})$} & \multicolumn{3}{|c|}{ Material } & \multicolumn{4}{|c|}{ Construction Dates } \\
\hline & $\begin{array}{l}\text { Asphalt } \\
\text { Concrete } \\
\text { (2) }\end{array}$ & $\begin{array}{l}\text { Base } \\
\text { (3) }\end{array}$ & $\begin{array}{c}\text { Subbase } \\
\text { (4) }\end{array}$ & $\begin{array}{l}\text { Overlays } \\
\text { (5) }\end{array}$ & $\begin{array}{l}\text { Base } \\
(6) \\
\end{array}$ & $\begin{array}{c}\text { Subbase } \\
\text { (7) }\end{array}$ & $\begin{array}{c}\text { Subgrade } \\
\text { (8) }\end{array}$ & $\begin{array}{c}\text { Original } \\
\text { (9) }\end{array}$ & $\begin{array}{c}\text { Overlay } \\
1 \\
(10)\end{array}$ & $\begin{array}{c}\text { Overlay } \\
2 \\
(11)\end{array}$ & $\begin{array}{c}\text { Overlay } \\
3 \\
(12)\end{array}$ \\
\hline A1E & 102 & 152 & 203 & 0 & PCC & & SP & 1942 & 1952 & 1984 & \\
\hline A7E & 216 & 0 & 203 & 38 & & & SP & 1928 & 1941 & 1984 & \\
\hline A8E & 102 & 152 & 203 & 0 & WaterBoundMacadam & SP-SM & SP & 1952 & 1984 & & \\
\hline A17E & 102 & 152 & 0 & 0 & WaterBoundMacadam & SP-SM & SP & 1952 & 1984 & & \\
\hline A19E & 102 & 152 & 203 & 0 & WaterBoundMacadam & SP-SM & SP & 1952 & 1984 & & \\
\hline A20E & 216 & 0 & 203 & 38 & & & SP & 1928 & 1941 & 1944 & \\
\hline A21E & 102 & 203 & 203 & 0 & Limerock & SP-SM & SP & 1952 & & . & \\
\hline A30E & 102 & 152 & 203 & 0 & WaterBoundMacadam & SP-SM & SP & 1952 & 1984 & & \\
\hline R3E & 102 & 203 & 203 & 76 & Limerock & SP-SM & SP & 1951 & 1959 & 1984 & \\
\hline R4I & 102 & 203 & 203 & 76 & Limerock & SP-SM & SP & 1951 & 1959 & 1984 & \\
\hline R5E & 102 & 203 & 203 & 127 & Limerock & SP-SM & SP & 1951 & 1955 & 1959 & 1984 \\
\hline T1E & 102 & 203 & 203 & 51 & Limerock & SP-SM & SP & 1951 & 1984 & & \\
\hline T2E & 102 & 203 & 203 & 51 & Limerock & SP-SM & SP & 1951 & 1984 & & \\
\hline T4E-1 & 102 & 203 & 203 & 51 & Limerock & SP-SM & SP & 1951 & 1984 & & \\
\hline T5E & 178 & 152 & 203 & 51 & PCC & & SP & 1941 & 1952 & 1984 & \\
\hline T6E & 102 & 203 & 203 & 102 & Limerock & SP-SM & SP & 1951 & 1981 & 1984 & \\
\hline T8E & 102 & 203 & 0 & 51 & Limerock & SP-SM & SP & 1951 & 1984 & & \\
\hline T9E & 102 & 203 & 0 & 89 & Limerock & SP-SM & SP & 1951 & 1959 & 1984 & \\
\hline T10E & 178 & 152 & 0 & 51 & PCC & & SP & 1941 & 1952 & 1984 & \\
\hline
\end{tabular}


TABLE C-7. Physical Properties and Construction History of Libby AAF

\begin{tabular}{|c|c|c|c|c|c|c|c|}
\hline \multirow[b]{2}{*}{ Feature } & \multicolumn{3}{|c|}{ Layer Thicknesses (mm) } & \multicolumn{2}{|l|}{ Material } & \multicolumn{2}{|c|}{ Construction Dates } \\
\hline & $\begin{array}{c}\text { Asphalt } \\
\text { Concrete } \\
\text { (2) }\end{array}$ & $\begin{array}{l}\text { Base } \\
\text { (3) }\end{array}$ & $\begin{array}{c}\text { Overlays } \\
\text { (4) }\end{array}$ & $\begin{array}{l}\text { Base } \\
\text { (5) }\end{array}$ & $\begin{array}{c}\text { Subgrade } \\
\text { (6) }\end{array}$ & $\begin{array}{c}\text { Original } \\
\text { (7) }\end{array}$ & $\begin{array}{c}\text { Overlay } 1 \\
\text { (8) }\end{array}$ \\
\hline R11I & 51 & 152 & 51 & CrushedAgg & SC & 1985 & \\
\hline R12I & 102 & 152 & 0 & CrushedAgg & SC & 1985 & \\
\hline R13E & 102 & 152 & 0 & CrushedAgg & SC & & \\
\hline R3I & 102 & 152 & 0 & CrushedAgg & SC & 1985 & \\
\hline R6E & 102 & 152 & 0 & StabAgg & SC & 1985 & \\
\hline R7I & 102 & 152 & 0 & StabAgg & SC & 1985 & \\
\hline R8I & 51 & 152 & 51 & StabAgg & SC & 1964 & 1987 \\
\hline R9E & 51 & 152 & 51 & StabAgg & SC & 1964 & 1987 \\
\hline T2E & 102 & 152 & 0 & CrushedAgg & SC & 1985 & \\
\hline T3E & 102 & 152 & 0 & CrushedAgg & SC & 1985 & \\
\hline T4E & 102 & 152 & 25 & CrushedAgg & SC & 1987 & \\
\hline T4E-2 & 51 & 152 & 25 & StabAgg & SC & 1987 & \\
\hline T5E & 51 & 152 & 51 & StabAgg & SC & 1961 & 1986 \\
\hline T7E & 102 & 152 & 0 & StabAgg & SC & 1987 & \\
\hline T8E & 51 & 152 & 0 & StabAgg & SC & 1975 & \\
\hline T9E & 51 & 152 & 0 & StabAgg & SC & 1975 & \\
\hline T10E & 102 & 152 & 0 & StabAgg & SC & 1987 & \\
\hline $\mathrm{T} 11 \mathrm{E}$ & 102 & 152 & 0 & CrushedAgg & SC & 1985 & \\
\hline A10E & 51 & 152 & 51 & StabAgg & SC & 1961 & 1987 \\
\hline A11E & 51 & 152 & 0 & StabAgg & SC & 1961 & \\
\hline A6E & 25 & 102 & 0 & ClayeyGravelly Sand & SC & 1961 & \\
\hline A9E & 51 & 152 & 51 & StabAgg & SC & 1961 & 1987 \\
\hline
\end{tabular}


TABLE C-8. Physical Properties and Construction History of Los Alamitos AAF Layer Thicknesses (mm)

Material

Construction Dates

\begin{tabular}{|c|c|c|c|c|c|c|c|c|c|}
\hline Feature & $\begin{array}{c}\text { Asphalt } \\
\text { Concrete } \\
\text { (2) }\end{array}$ & $\begin{array}{c}\text { Base } \\
\text { (3) }\end{array}$ & $\begin{array}{c}\text { Subbase } \\
\text { (4) }\end{array}$ & $\begin{array}{l}\text { Overlays } \\
\text { (5) }\end{array}$ & Base & $\begin{array}{c}\text { Subbase } \\
\text { (7) }\end{array}$ & Subgrade & Original & $\begin{array}{c}\text { Overlay } 1 \\
\text { (10) }\end{array}$ \\
\hline A1E & 76 & 254 & 457 & 25 & GM & & $\mathrm{ML}$ & 1942 & 1959 \\
\hline A4E & 64 & 660 & 0 & 0 & GP-GM & & ML & 1942 & \\
\hline R10E & 76 & 178 & 0 & 0 & $\begin{array}{c}\text { Cement Treated } \\
\text { Sand }\end{array}$ & & ML & 1941 & \\
\hline R11E & 64 & 76 & 102 & 0 & Crusher Rock & Gravel & $M L$ & 1941 & \\
\hline R12E & 64 & 76 & 102 & 0 & Crusher Rock & Gravel & ML & 1941 & \\
\hline R1E & 64 & 102 & 305 & 0 & GP-GM & Select & ML & 1944 & \\
\hline R3I & 64 & 102 & 305 & 241 & GP & SM & ML & 1944 & \\
\hline R4I & 76 & 229 & 381 & 76 & GM & SM & ML & 1951 & \\
\hline R6E & 64 & 152 & 102 & 165 & GM-GP & Gravel & ML & 1951 & \\
\hline R7I & 64 & 152 & 102 & 165 & GM-GP & Gravel & ML & 1951 & \\
\hline R8E & 64 & 152 & 102 & 165 & GM-GP & Gravel & ML & 1951 & \\
\hline T11E & 64 & 102 & 305 & 0 & Crusher Run & Select & ML & 1944 & \\
\hline $\mathrm{T} 12 \mathrm{E}$ & 64 & 102 & 305 & 0 & Crusher Run & Select & $M L$ & 1944 & \\
\hline T13E & 64 & 102 & 305 & 25 & Crusher Run & Select & $M L$ & 1944 & \\
\hline T14E & 76 & 229 & 381 & 25 & Crusher Run & & $M L$ & 1951 & \\
\hline T15E & 64 & 76 & 102 & 0 & Select Base & Crushed Rock & $M L$ & 1941 & \\
\hline T16E & 64 & 76 & 102 & 0 & Crusher Run & Gravel & $M L$ & 1942 & \\
\hline T17E & 64 & 76 & 102 & 0 & Crusher Run & Gravel & ML & 1942 & \\
\hline T18E & 64 & 229 & 0 & 102 & & & ML & 1942 & \\
\hline T2E & 76 & 229 & 381 & 0 & GW-GM & SM & ML & 1951 & \\
\hline T3E & 76 & 229 & 0 & 25 & GP & & $M L$ & 1958 & \\
\hline T4E & 102 & 203 & 457 & 25 & GP & & ML & 1964 & \\
\hline T6E & 64 & 229 & 0 & 102 & & & ML & 1942 & 1955 \\
\hline T7E & 64 & 229 & 0 & 102 & & & $M L$ & 1942 & 1955 \\
\hline T8E & 64 & 152 & 102 & 114 & GM-GP & Gravel & ML & 1942 & 1950 \\
\hline T9E & 76 & 229 & 381 & 25 & Crusher run & & $M L$ & 1951 & \\
\hline
\end{tabular}


TABLE C-9. Physical Properties and Construction History of Marshall AAF

$$
\text { Layer Thicknesses }(\mathrm{mm})
$$

Material

Construction Dates

\begin{tabular}{cccccccc} 
Feature & $\begin{array}{c}\text { Asphalt } \\
\text { Concrete }\end{array}$ & Base & Overlays & Base & Subgrade & Original & Overlay 1 \\
$(1)$ & $(2)$ & $(3)$ & $(4)$ & $(5)$ & $(6)$ & $(7)$ & $(8)$ \\
\hline A6E & 102 & 483 & 0 & Crushed Stone & ML-CL & 1958 & \\
\hline
\end{tabular}

TABLE C-10. Physical Properties and Construction History of McCoy AAF

\begin{tabular}{|c|c|c|c|c|c|c|c|c|c|c|}
\hline \multirow{3}{*}{$\begin{array}{c}\text { Feature } \\
\text { (1) }\end{array}$} & \multicolumn{4}{|c|}{ Layer Thicknesses (mm) } & \multicolumn{3}{|c|}{ Material } & \multicolumn{3}{|c|}{ Construction Dates } \\
\hline & $\begin{array}{l}\text { Asphalt } \\
\text { Concrete }\end{array}$ & Base & Subbase & Overlays & Base & Subbase & $\begin{array}{c}\text { Subgrade } \\
\text { (8) }\end{array}$ & $\begin{array}{c}\text { Original } \\
\text { (9) }\end{array}$ & $\begin{array}{c}\text { Overlay } \\
1 \\
\text { (10) }\end{array}$ & $\begin{array}{c}\text { Overlay } \\
2 \\
(11)\end{array}$ \\
\hline & (2) & (3) & (4) & (5) & & (7) & (8) & $\begin{array}{c}\text { (9) } \\
1051\end{array}$ & & \\
\hline A1E & 51 & 330 & 0 & 51 & Clayey Sandy Gravel & & SM & 1951 & 1979 & \\
\hline A2E & 102 & 330 & 0 & 0 & Clayey Sandy Gravel & & SM & 1975 & & \\
\hline A3E & 76 & 305 & 0 & 0 & Clayey Sandy Gravel & & SM-SP & 1988 & & \\
\hline A4E & 76 & 305 & 0 & 0 & Clayey Sandy Gravel & & SM-SP & 1988 & & \\
\hline R2E & 102 & 203 & 127 & 0 & Asphalt Stab Open Graded & Pulverized AC & SM-SP & 1992 & & \\
\hline R4E & 25 & 381 & 0 & 140 & Silty Gravelly Sand & & GM-GP & 1951 & 1975 & 1979 \\
\hline R5E & 25 & 381 & 0 & 102 & Silty Gravelly Sand & & GM-GP & 1951 & 1975 & 1979 \\
\hline R6E & 25 & 381 & 0 & 102 & Silty Gravelly Sand & & GM-GP & 1951 & 1975 & 1979 \\
\hline T1E & 51 & 330 & 0 & 64 & Clayey Sandy Gravel & & SP & 1951 & 1979 & \\
\hline T2E & 25 & 330 & 0 & 127 & Clayey Sandy Gravel & & SM & 1951 & 1975 & 1979 \\
\hline T3E & 114 & 330 & 0 & 0 & Clayey Sandy Gravel & & SM & 1975 & & \\
\hline T4E & 114 & 330 & 0 & 0 & Clayey Sandy Gravel & & SM & 1975 & & \\
\hline T5E & 114 & 330 & 0 & 0 & Clayey Sandy Gravel & & SM & 1975 & 1992 & \\
\hline T6E & 102 & 305 & 0 & 0 & Agg P-208 & & SM-SP & NA & & \\
\hline T7E & 76 & 305 & 0 & 0 & Clayey Sandy Gravel & & SM-SP & 1988 & & \\
\hline
\end{tabular}


TABLE C-11. Physical Properties and Construction History of Muir AAF

\begin{tabular}{|c|c|c|c|c|c|c|c|}
\hline \multirow[b]{2}{*}{ Feature } & \multicolumn{4}{|c|}{ Layer Thicknesses (mm) } & \multicolumn{3}{|c|}{ Material } \\
\hline & Asphalt & Base & Subbase & Overlays & Base & Subbase & Subgrade \\
\hline (1) & (2) & (3) & (4) & (5) & (6) & (7) & (8) \\
\hline A1E & 51 & 152 & 0 & 0 & Crushed Stone & & Decomposed Shale \\
\hline $\mathrm{A} 2 \mathrm{E}$ & 51 & 152 & 0 & 0 & Crushed Stone & & Decomposed Shale \\
\hline A4E & 51 & 152 & 0 & 0 & Crushed Stone & & Decomposed Shale \\
\hline $\mathrm{A} 6 \mathrm{E}$ & 191 & 152 & 0 & 0 & Crushed Stone & & Decomposed Shale \\
\hline R1E & 64 & 152 & 102 & 38 & Crushed Stone & Soil Cement & Decomposed Shale \\
\hline T1E & 51 & 152 & 0 & 0 & Crushed Stone & & Decomposed Shale \\
\hline T2E & 51 & 152 & 0 & 0 & Crushed Stone & & Decomposed Shale \\
\hline T3E & 51 & 152 & 102 & 0 & Crushed Stone & Soil Cement & Decomposed Shale \\
\hline T4E & 51 & 152 & 0 & 0 & Crushed Stone & & Decomposed Shale \\
\hline T5E & 51 & 152 & 102 & 0 & Crushed Stone & Soil Cement & Decomposed Shale \\
\hline T6E & 51 & 152 & 0 & 0 & Crushed Stone & & Decomposed Shale \\
\hline T7E & 51 & 152 & 0 & 0 & Crushed Stone & & Decomposed Shale \\
\hline T8E & 51 & 152 & 0 & 0 & Crushed Stone & & Decomposed Shale \\
\hline T9E & 51 & 152 & 102 & 0 & Crushed Stone & Soil Cement & Decomposed Shale \\
\hline
\end{tabular}


TABLE C-12. Physical Properties and Construction History of Phillips AAF Layer Thicknesses $(\mathrm{mm})$

\section{Material}

Construction Dates

\begin{tabular}{|c|c|c|c|c|c|c|c|c|c|c|}
\hline Feature & $\begin{array}{c}\text { Asphalt } \\
\text { Concrete } \\
\text { (2) }\end{array}$ & $\begin{array}{c}\text { Base } \\
\text { (3) }\end{array}$ & $\begin{array}{c}\text { Subbase } \\
\text { (4) }\end{array}$ & $\begin{array}{l}\text { Overlays } \\
\text { (5) }\end{array}$ & $\begin{array}{c}\text { Base } \\
\text { (6) }\end{array}$ & $\begin{array}{c}\text { Subbase } \\
\text { (7) }\end{array}$ & $\begin{array}{c}\text { Subgrade } \\
\text { (8) }\end{array}$ & $\begin{array}{l}\text { Original } \\
\text { (9) }\end{array}$ & $\begin{array}{c}\text { Overlay } \\
1 \\
(10)\end{array}$ & $\begin{array}{c}\text { Overlay } \\
2 \\
(11) \\
\end{array}$ \\
\hline A2E & 102 & 152 & 457 & 0 & PCC & & $\mathrm{CL}$ & 1955 & & \\
\hline A3E & 76 & 152 & 305 & 102 & Silty Sandy Gravel (GM) & Silty Sandy Gravel (GP-GM) & $C L$ & 1955 & 1983 & \\
\hline A4E & 89 & 152 & 0 & 0 & Silty Sandy Gravel (GM) & Gravelly Silty Sand (SM) & $\mathrm{CL}$ & 1955 & & \\
\hline R10E & 102 & 457 & 152 & 76 & Silty Gravelly Sand (SM) & & $\mathrm{CL}$ & 1943 & 1955 & \\
\hline R11E & 89 & 152 & 0 & 0 & PCC & Silty Sandy Gravel (GP-GM) & $\mathrm{CL}$ & 1943 & 1955 & \\
\hline R12I & 102 & 457 & 0 & 76 & Silty Gravelly Sand (SM) & & $\mathrm{CL}$ & 1943 & 1955 & \\
\hline R13E & 102 & 457 & 152 & 76 & Silty Gravelly Sand (SM) & & $\mathrm{CL}$ & 1943 & 1955 & \\
\hline R14E & 76 & 152 & 152 & 0 & PCC & Silty Sandy Gravel (GP-GM) & $\mathrm{CL}$ & 1955 & & \\
\hline R15E & 51 & 152 & 0 & 0 & PCC & Silty Sandy Gravel (GP-GM) & $\mathrm{CL}$ & 1943 & 1955 & \\
\hline R16E & 102 & 457 & 0 & 51 & Silty Gravelly Sand (SM) & & $\mathrm{CL}$ & 1943 & 1955 & \\
\hline R17I & 102 & 457 & 0 & 51 & Silty Gravelly Sand (SM) & & $C L$ & 1943 & 1955 & \\
\hline R18E & 102 & 457 & 254 & 51 & Silty Gravelly Sand (SM) & & $\mathrm{CL}$ & 1943 & 1955 & \\
\hline R1E & 152 & 406 & 254 & 0 & Graded Crushed Agg & Gravelly Silty Sand (SM) & $\mathrm{CL}$ & 1983 & & \\
\hline R2I & 152 & 406 & 381 & 0 & Graded Crushed Agg & Gravelly Silty Sand (SM) & $\mathrm{CL}$ & 1983 & & \\
\hline R3I & 152 & 406 & 457 & 0 & Graded Crushed Agg & Gravelly Silty Sand (SM) & $\mathrm{CL}$ & 1943 & 1955 & 1983 \\
\hline R4I & 76 & 152 & 457 & 102 & Silty Sandy Gravel (GM) & Gravelly Silty Sand (SM) & $\mathrm{CL}$ & 1943 & 1983 & \\
\hline R5I & 76 & 152 & 457 & 102 & Silty Sandy Gravel (GM) & Gravelly Silty Sand (SM) & $\mathrm{CL}$ & 1943 & 1955 & 1983 \\
\hline R6I & 76 & 152 & 457 & 102 & Silty Sandy Gravel (GM) & Gravelly Silty Sand (SM) & $\mathrm{CL}$ & 1943 & 1983 & \\
\hline R7I & 76 & 152 & 457 & 102 & Silty Sandy Gravel (GM) & Gravelly Silty Sand (SM) & $\mathrm{CL}$ & 1943 & 1955 & 1983 \\
\hline R8E & 76 & 152 & 152 & 102 & Silty Sandy Gravel (GM) & Gravelly Silty Sand (SM) & $\mathrm{CL}$ & 1955 & 1983 & \\
\hline R9E & 102 & 152 & 0 & 0 & PCC & Silty Sandy Gravel (GP-GM) & $\mathrm{CL}$ & 1943 & 1955 & \\
\hline T1E & 89 & 457 & 0 & 76 & Silty Gravelly Sand (SM) & & $\mathrm{CL}$ & 1943 & 1955 & \\
\hline T2E & 89 & 457 & 0 & 178 & Silty Gravelly Sand (SM) & & $\mathrm{CL}$ & 1943 & 1955 & 1983 \\
\hline T3E & 89 & 457 & 457 & 76 & Silty Gravelly Sand (SM) & & $\mathrm{CL}$ & 1943 & 1955 & \\
\hline T4E & 76 & 152 & 305 & 102 & Silty Sandy Gravel (GM) & Silty Sandy Gravel (GP-GM) & $\mathrm{CL}$ & 1955 & 1983 & \\
\hline T5E & 89 & 152 & 0 & 0 & Silty Sandy Gravel (GM) & Gravelly Silty Sand (SM) & $\mathrm{CL}$ & 1955 & & \\
\hline
\end{tabular}


TABLE C-13. Physical Properties and Construction History of Redstone AAF Layer Thicknesses (mm) Material

Construction Dates

\begin{tabular}{|c|c|c|c|c|c|c|c|c|c|c|c|}
\hline $\begin{array}{c}\text { Feature } \\
\text { (1) }\end{array}$ & $\begin{array}{l}\text { Asphalt } \\
\text { Concrete } \\
\text { (2) }\end{array}$ & $\begin{array}{c}\text { Base } \\
\text { (3) }\end{array}$ & $\begin{array}{c}\text { Subbase } \\
\text { (4) }\end{array}$ & $\begin{array}{c}\text { Overlays } \\
\text { (5) }\end{array}$ & $\begin{array}{c}\text { Base } \\
(6) \\
\end{array}$ & $\begin{array}{c}\text { Subbase } \\
\text { (7) }\end{array}$ & $\begin{array}{c}\text { Subgrade } \\
\text { (8) }\end{array}$ & $\begin{array}{c}\text { Original } \\
\text { (9) }\end{array}$ & $\begin{array}{c}\text { Overlay } \\
1 \\
(10) \\
\end{array}$ & $\begin{array}{c}\text { Overlay } \\
2 \\
(11)\end{array}$ & $\begin{array}{c}\text { Overlay } \\
3 \\
(12) \\
\end{array}$ \\
\hline R2E & 76 & 203 & 0 & 127 & GC \& GP-GM & & $\mathrm{CL}$ & 1942 & 1961 & 1989 & \\
\hline R3E & 76 & 203 & 0 & 127 & GC \& GP-GM & & $\mathrm{CL}$ & 1942 & 1961 & 1989 & \\
\hline R4E & 76 & 152 & 102 & 25 & Crushed Limestone & SM & $\mathrm{CL}$ & 1961 & 1989 & & \\
\hline T1E & 76 & 203 & 0 & 127 & GC \& GP-GM & & $\mathrm{CL}$ & 1943 & 1961 & 1989 & \\
\hline T2E & 76 & 203 & 0 & 102 & GC \& GP-GM & & $\mathrm{CL}$ & 1943 & 1958 & 1961 & 1989 \\
\hline T3E & 76 & 305 & 0 & 0 & Stab Agg & & $\mathrm{CL}$ & 1966 & & 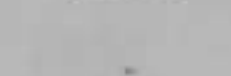 & \\
\hline T4E & 102 & 406 & 0 & 25 & Stab Agg & & $\mathrm{CL}$ & 1965 & 1986 & & \\
\hline
\end{tabular}


TABLE C-14. Physical Properties and Construction History of Selah AAF

\begin{tabular}{|c|c|c|c|c|c|c|c|}
\hline \multirow[b]{2}{*}{ Feature } & \multicolumn{3}{|c|}{ Layer Thicknesses (mm) } & \multicolumn{2}{|c|}{ Material } & \multicolumn{2}{|c|}{ Construction Dates } \\
\hline & $\begin{array}{l}\text { Asphalt } \\
\text { Concrete } \\
\text { (2) }\end{array}$ & $\begin{array}{l}\text { Base } \\
\text { (3) }\end{array}$ & $\begin{array}{c}\text { Overlays } \\
\text { (4) }\end{array}$ & $\begin{array}{c}\text { Base } \\
\text { (5) }\end{array}$ & $\begin{array}{c}\text { Subgrade } \\
(6)\end{array}$ & $\begin{array}{c}\text { Original } \\
\text { (7) }\end{array}$ & $\begin{array}{c}\text { Overlay } 1 \\
\text { (8) }\end{array}$ \\
\hline A1E & 64 & 305 & 0 & Crushed Rock & Silty Sand & 1976 & \\
\hline R1E & 51 & 305 & 0 & Crushed Rock & Silty Sand & 1976 & \\
\hline R2E & 64 & 305 & 0 & Crushed Rock & Silty Sand & 1958 & 1976 \\
\hline R3E & 51 & 305 & 0 & Crushed Rock & Silty Sand & 1958 & 1976 \\
\hline R4I & 51 & 305 & 0 & Crushed Rock & Silty Sand & 1958 & 1976 \\
\hline R5I & 64 & 305 & 0 & Crushed Rock & Silty Sand & 1958 & 1976 \\
\hline R6I & 51 & 305 & 0 & Crushed Rock & Silty Sand & 1958 & 1976 \\
\hline R7E & 64 & 305 & 0 & Crushed Rock & Silty Sand & 1976 & \\
\hline R8E & 89 & 305 & 0 & Crushed Rock & Silty Sand & 1976 & \\
\hline R9E & 64 & 305 & 0 & Crushed Rock & Silty Sand & & \\
\hline T1E & 64 & 305 & 0 & Crushed Rock & Silty Sand & 1976 & \\
\hline $\mathrm{T} 2 \mathrm{E}$ & 64 & 305 & 0 & Crushed Rock & Silty Sand & 1958 & 1976 \\
\hline T3E & 51 & 305 & 0 & Crushed Rock & Silty Sand & 1958 & 1976 \\
\hline
\end{tabular}


TABLE C-15. Physical Properties and Construction History of Simmons AAF

\begin{tabular}{ccccccccc} 
& \multicolumn{3}{c}{ Layer Thicknesses $(\mathrm{mm})$} & \multicolumn{2}{c}{ Material } & \multicolumn{3}{c}{ Construction Dates } \\
\cline { 2 - 9 } Feature & $\begin{array}{c}\text { Asphalt } \\
\text { Concrete }\end{array}$ & Base & Overlays & Base & Subgrade & Original & Overlay 1 & Overlay 2 \\
(1) & $(2)$ & $(3)$ & $(4)$ & $(5)$ & $(6)$ & $(7)$ & $(8)$ & $(9)$ \\
\hline R1E & 102 & 381 & 102 & Clayey Sand (SC) & SW-SM & 1956 & 1980 & 1993 \\
R2E & 64 & 381 & 102 & Clayey Sand (SC) & SP-SM & 1956 & 1980 & 1993 \\
R31 & 64 & 381 & 102 & Clayey Sand (SC) & SP-SM & 1956 & 1980 & 1993 \\
R4E & 64 & 381 & 102 & Clayey Sand (SC) & SP-SM & 1956 & 1980 & 1993 \\
R5E & 102 & 381 & 102 & Clayey Sand (SC) & SW-SM & 1980 & 1993 & \\
T1E & 64 & 381 & 51 & Clayey Sand (SC) & SM & 1956 & 1993 & \\
T3E & 51 & 203 & 51 & Stab Agg & SM & 1960 & 1993 & \\
T4E & 64 & 381 & 51 & Clayey Sand (SC) & SM & 1956 & 1993 & \\
T5E & 64 & 381 & 51 & Clayey Sand (SC) & SM & 1956 & 1993 & \\
T13E & 51 & 203 & 0 & Stab Agg & SC & 1988 & & \\
T14E & 51 & 203 & 0 & Stab Agg & SC & 1988 & & \\
T15E & 51 & 203 & 0 & Stab Agg & SC & 1988 & \\
T16E & 89 & 203 & 0 & Stab Agg & SC & 1993 & \\
A2E & 64 & 381 & 0 & Clayey Sand (SC) & SM & 1956 & 1993 & \\
\hline
\end{tabular}


TABLE C-16. Physical Properties and Construction History of Wheeler-Sack AAF Layer Thicknesses (mm)

Material

Construction Dates

\begin{tabular}{|c|c|c|c|c|c|c|c|c|c|}
\hline $\begin{array}{c}\text { Feature } \\
\text { (1) }\end{array}$ & $\begin{array}{c}\text { Asphalt } \\
\text { Concrete } \\
\text { (2) }\end{array}$ & $\begin{array}{c}\text { Base } \\
\text { (3) }\end{array}$ & $\begin{array}{c}\text { Subbase } \\
\text { (4) }\end{array}$ & $\begin{array}{c}\text { Overlays } \\
\text { (5) }\end{array}$ & $\begin{array}{c}\text { Base } \\
(6)\end{array}$ & $\begin{array}{c}\text { Subbase } \\
\text { (7) }\end{array}$ & $\begin{array}{c}\text { Subgrade } \\
\text { (8) }\end{array}$ & $\begin{array}{c}\text { Original } \\
\text { (9) }\end{array}$ & $\begin{array}{c}\text { Overlay } 1 \\
\text { (10) }\end{array}$ \\
\hline T10E & 152 & 102 & 152 & 0 & Granular & Granular & SP & 1992 & \\
\hline T11E & 152 & 102 & 152 & 0 & Granular & Granular & SP & 1992 & \\
\hline T12E & 152 & 102 & 152 & 0 & Granular & Granular & SP & 1992 & \\
\hline T13E & 152 & 102 & 152 & 0 & Granular & Granular & SP & 1992 & \\
\hline T14E & 152 & 102 & 152 & 0 & Granular & Granular & SP & 1992 & \\
\hline T15E & 152 & 102 & 152 & 0 & Granular & Granular & SP & 1992 & \\
\hline T1E & 38 & 152 & 0 & 51 & Crushed Stone & & SP & 1942 & 1962 \\
\hline $\mathrm{T} 2 \mathrm{E}$ & 38 & 152 & 0 & 13 & Crushed Stone & & SP & 1942 & 1976 \\
\hline T3E & 38 & 152 & 0 & 13 & Crushed Stone & & SP & 1942 & 1977 \\
\hline T5E & 76 & 152 & 0 & 76 & Dry Bound Macadam & & SP & 1927 & 1942 \\
\hline T7E & 38 & 152 & 0 & 51 & Crushed Stone & & SP & 1942 & \\
\hline T8E & 152 & 102 & 152 & 0 & Granular & Granular & SP & 1992 & \\
\hline T9E & 152 & 102 & 152 & 0 & Granular & Granular & SP & 1992 & \\
\hline
\end{tabular}




\section{APPENDIX D \\ DISTRESS DENSITY VERSUS DEDUCT VALUE CURVES}

The figures contained in this appendix show the distress density in percent versus

deduct curves for all of the distress types considered on asphalt concrete Army airfield pavements. The figures show the curves for low medium and high severity levels for those distress types that consider different severity levels. 


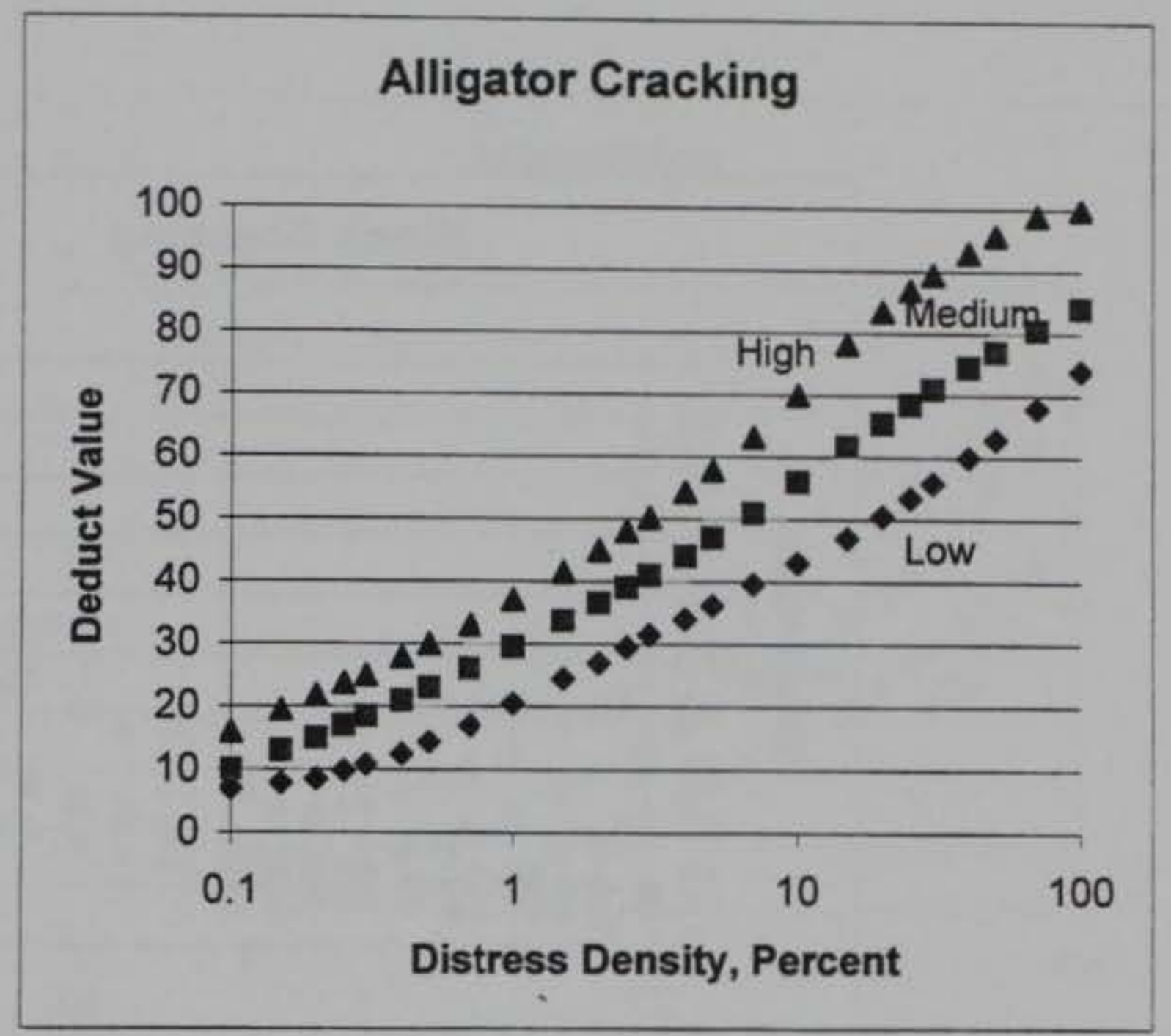

FIG D-1. Alligator Cracking Distress Density versus Deduct Curves

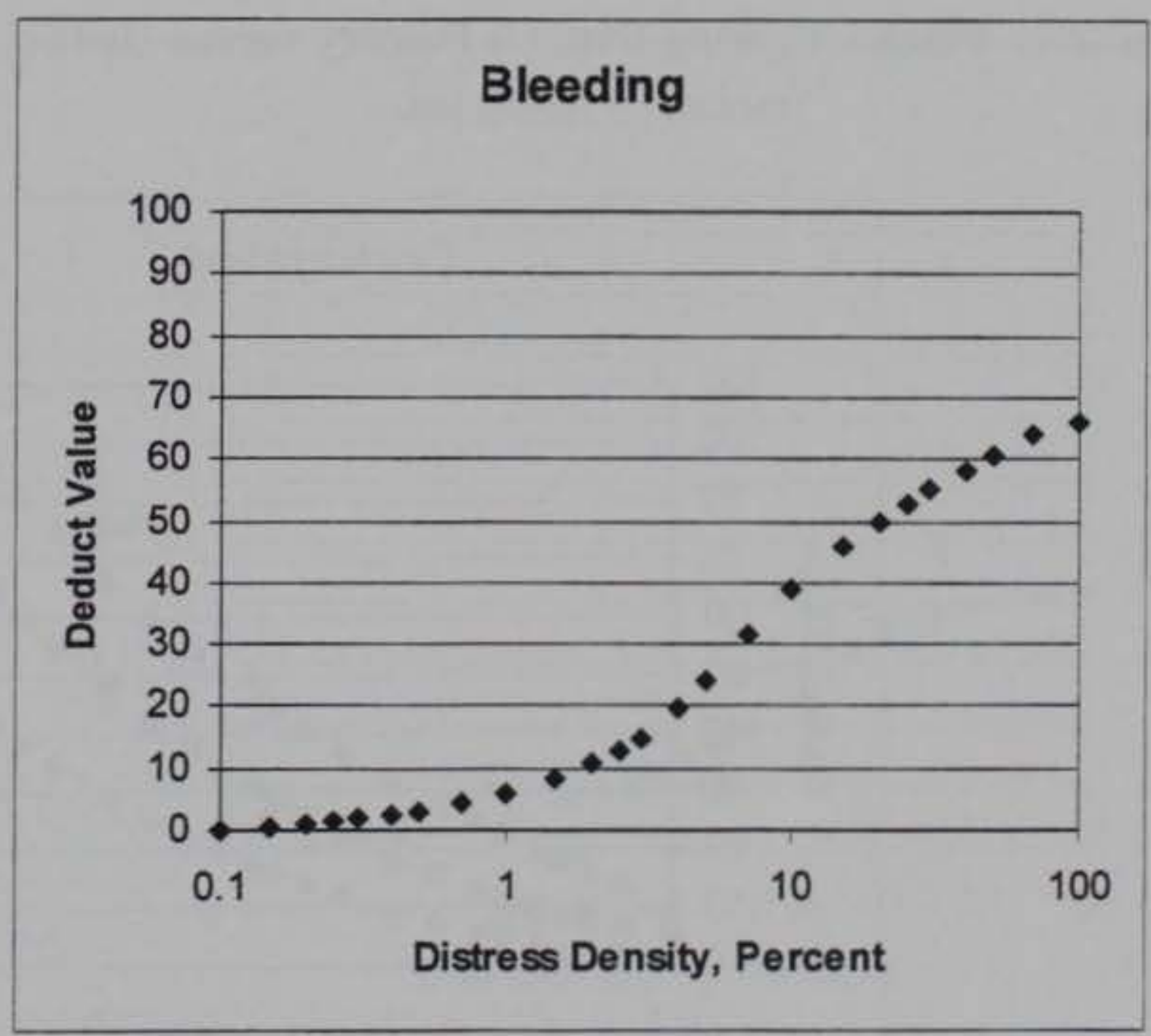

FIG D-2. Bleeding Distress Density versus Deduct Curves 


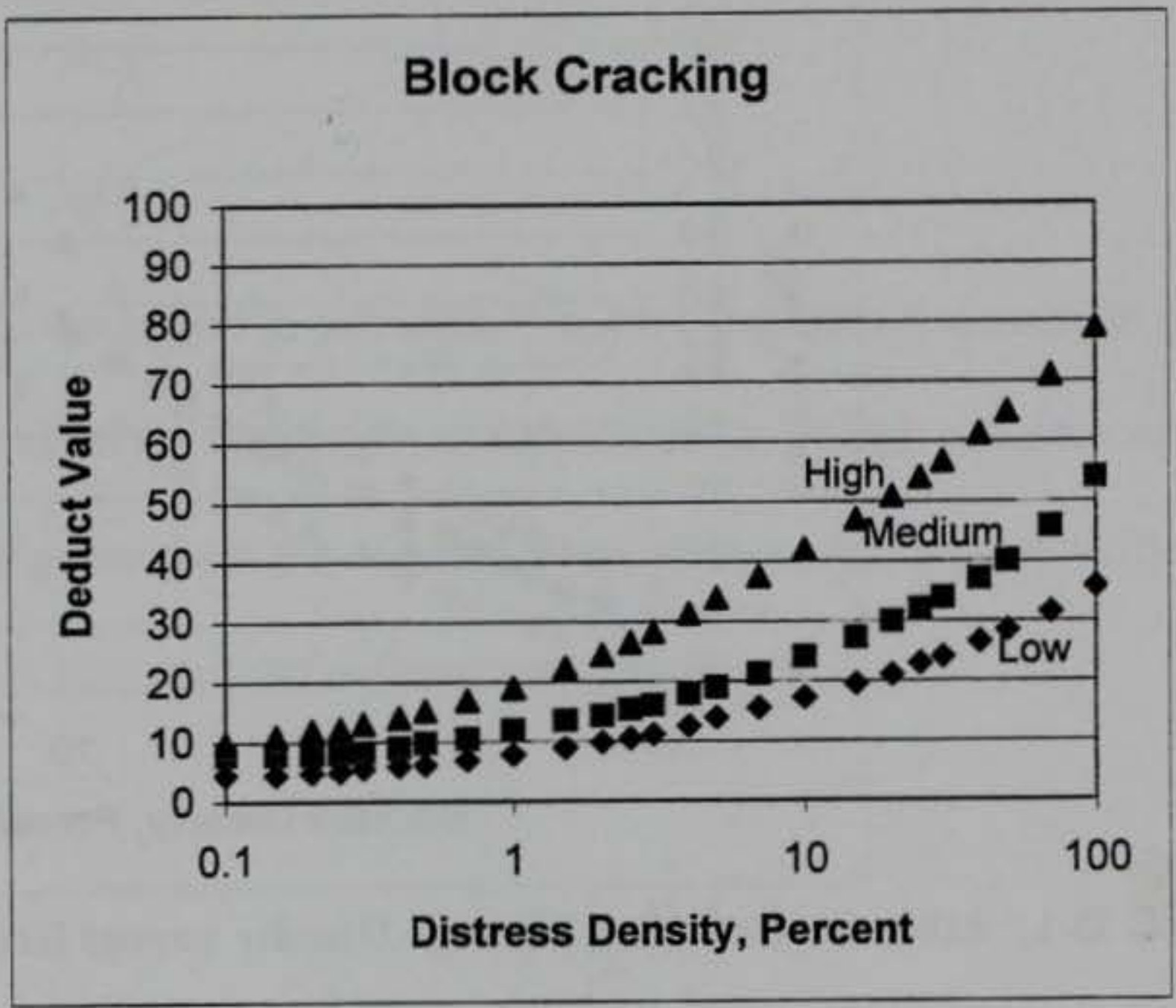

FIG D-3. Block Cracking Distress Density versus Deduct Curves

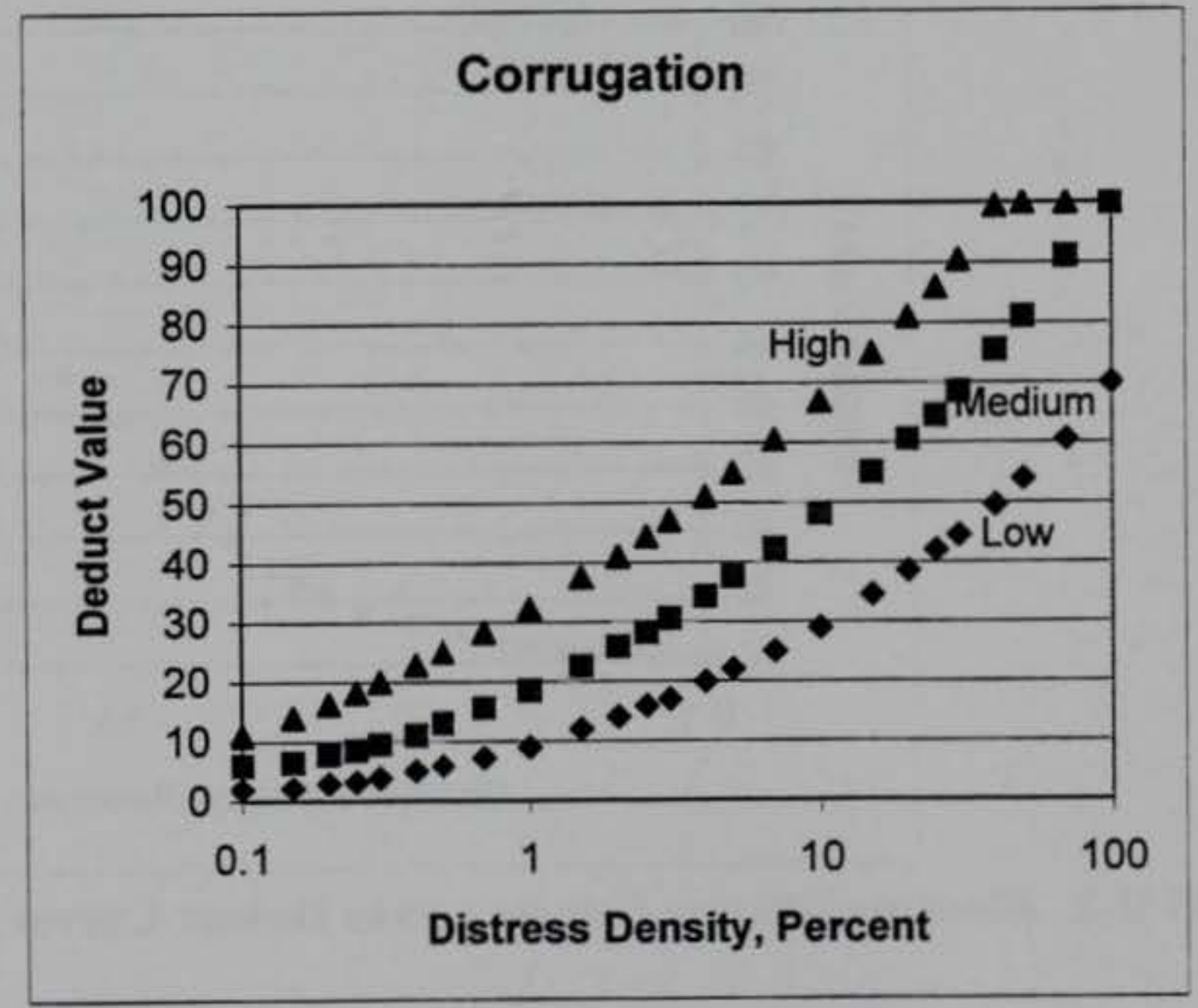

FIG D-4. Corrugation Distress Density versus Deduct Curves 


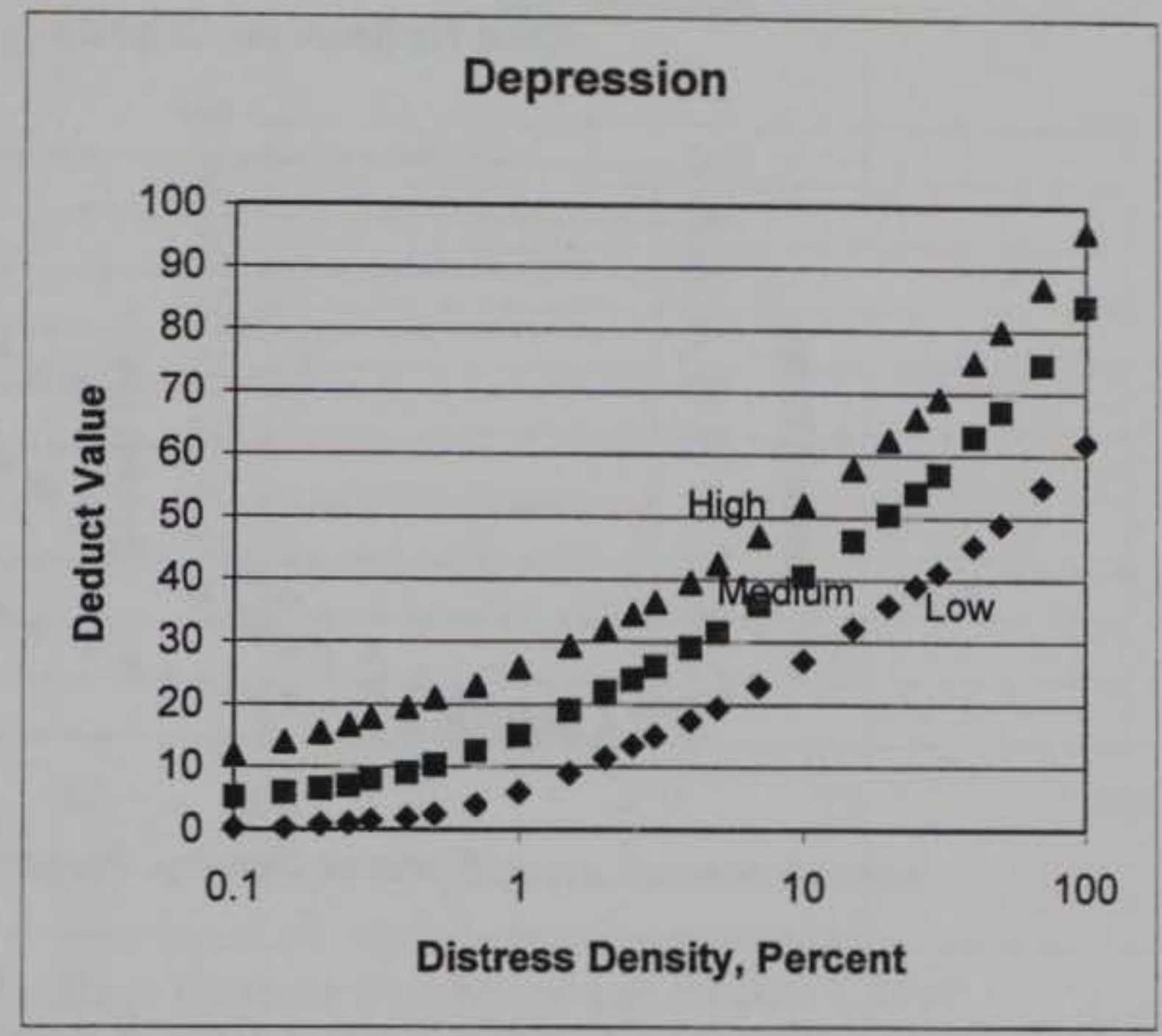

FIG D-5. Depression Distress Density versus Deduct Curves

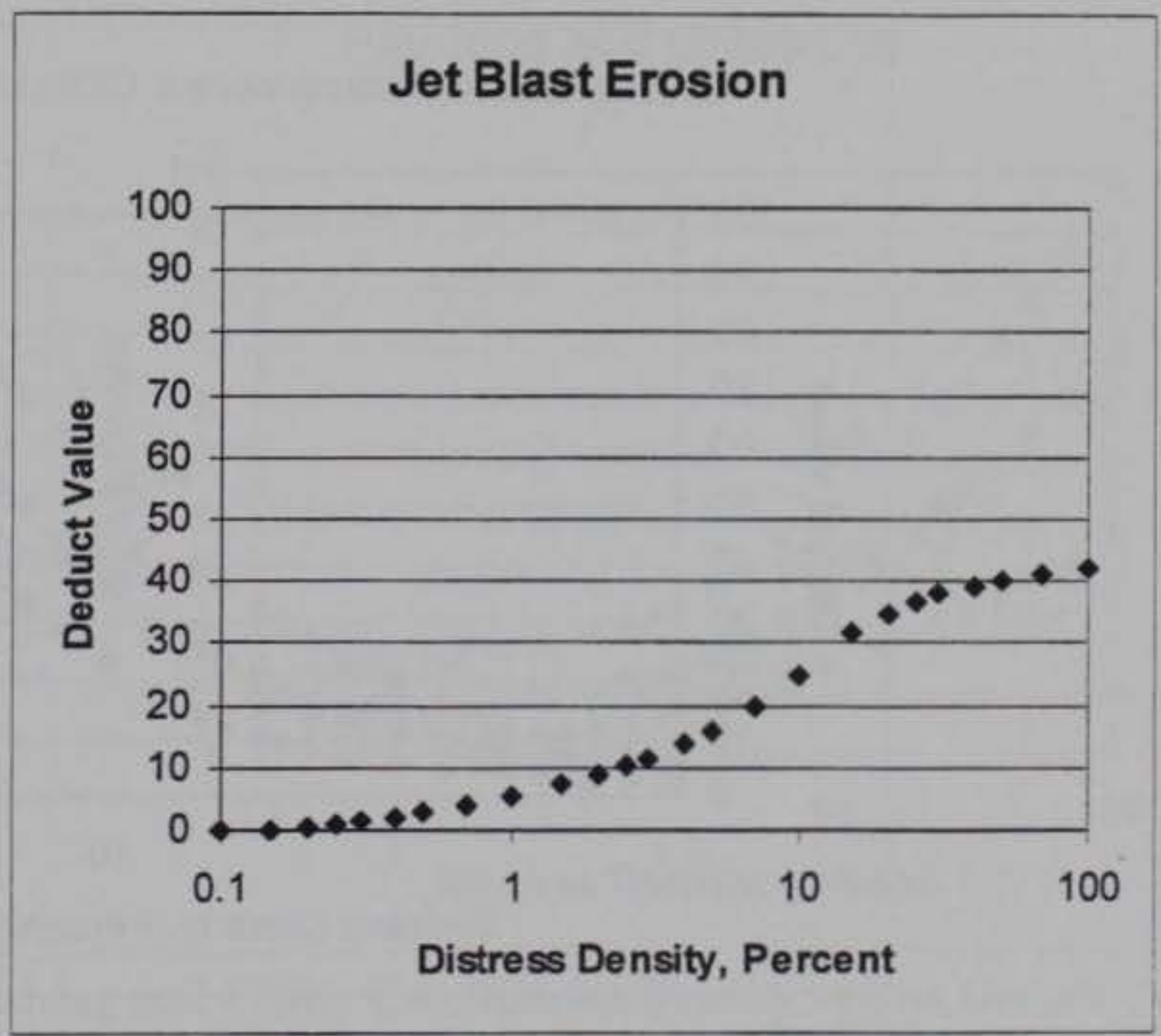

FIG D-6. Jet Blast Distress Density versus Deduct Curves 


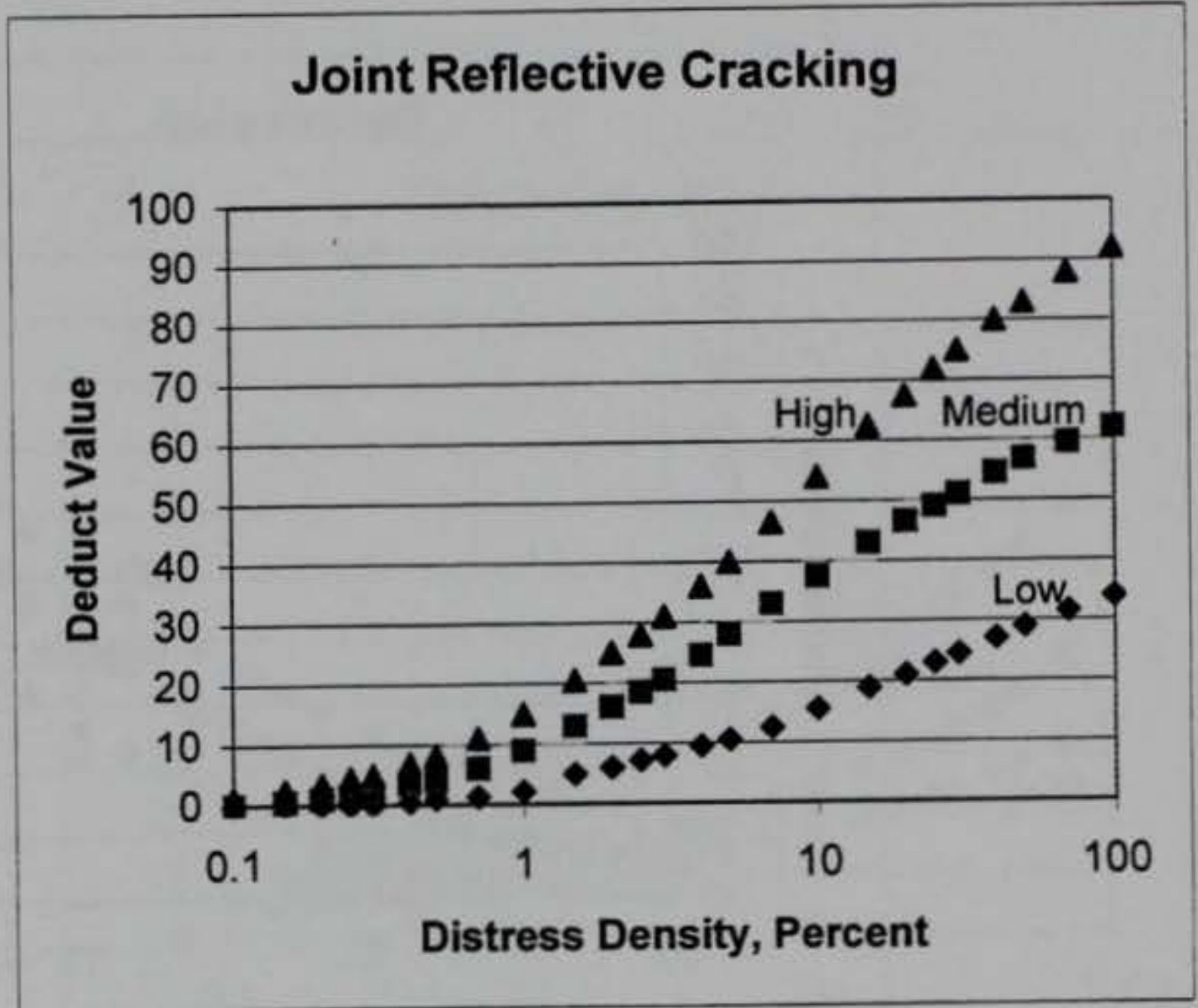

FIG D-7. Joint Reflective Cracking Distress Density versus Deduct Curves

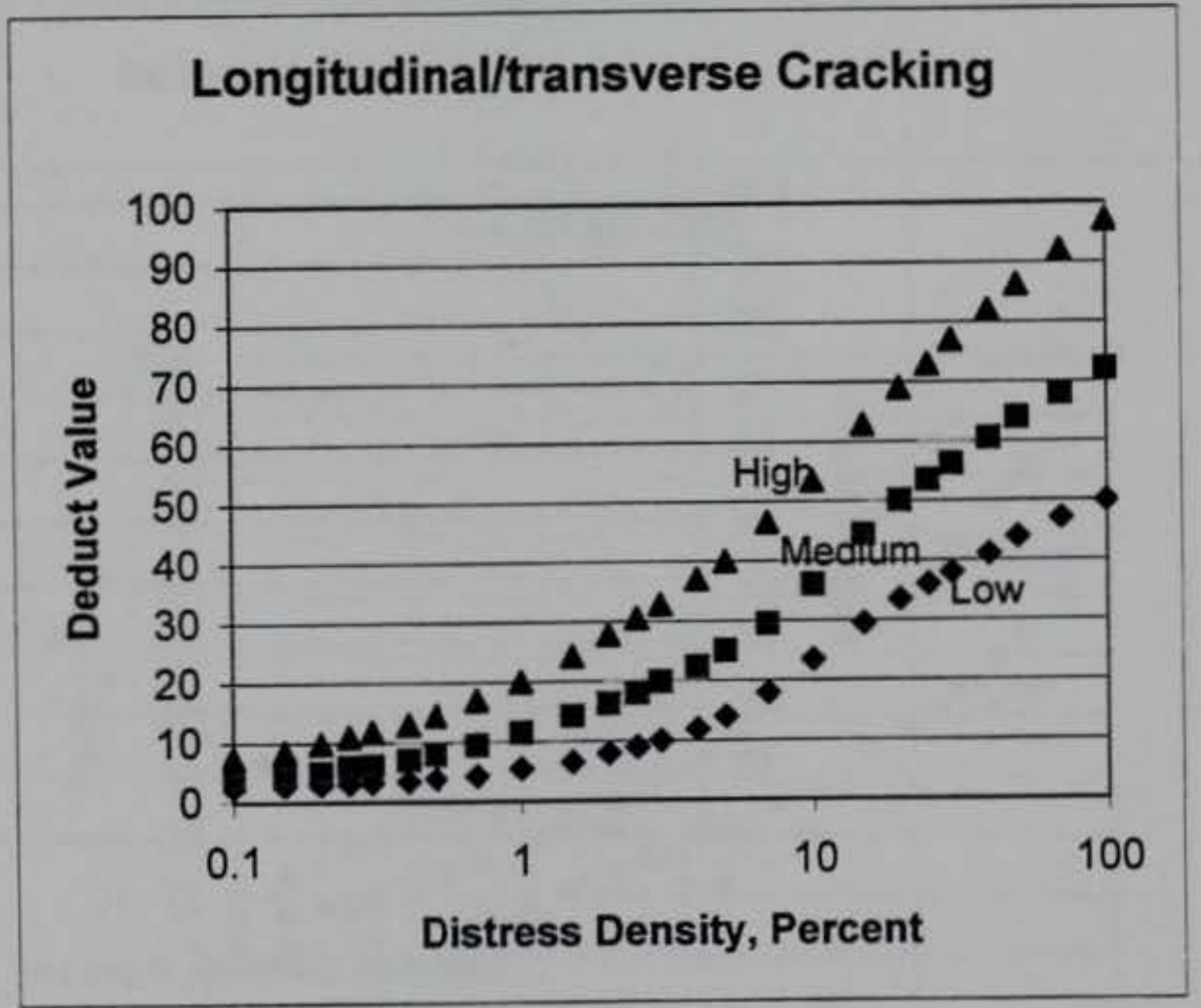

FIG D-8. Longitudinal/Transverse Cracking Distress Density versus Deduct Curves 


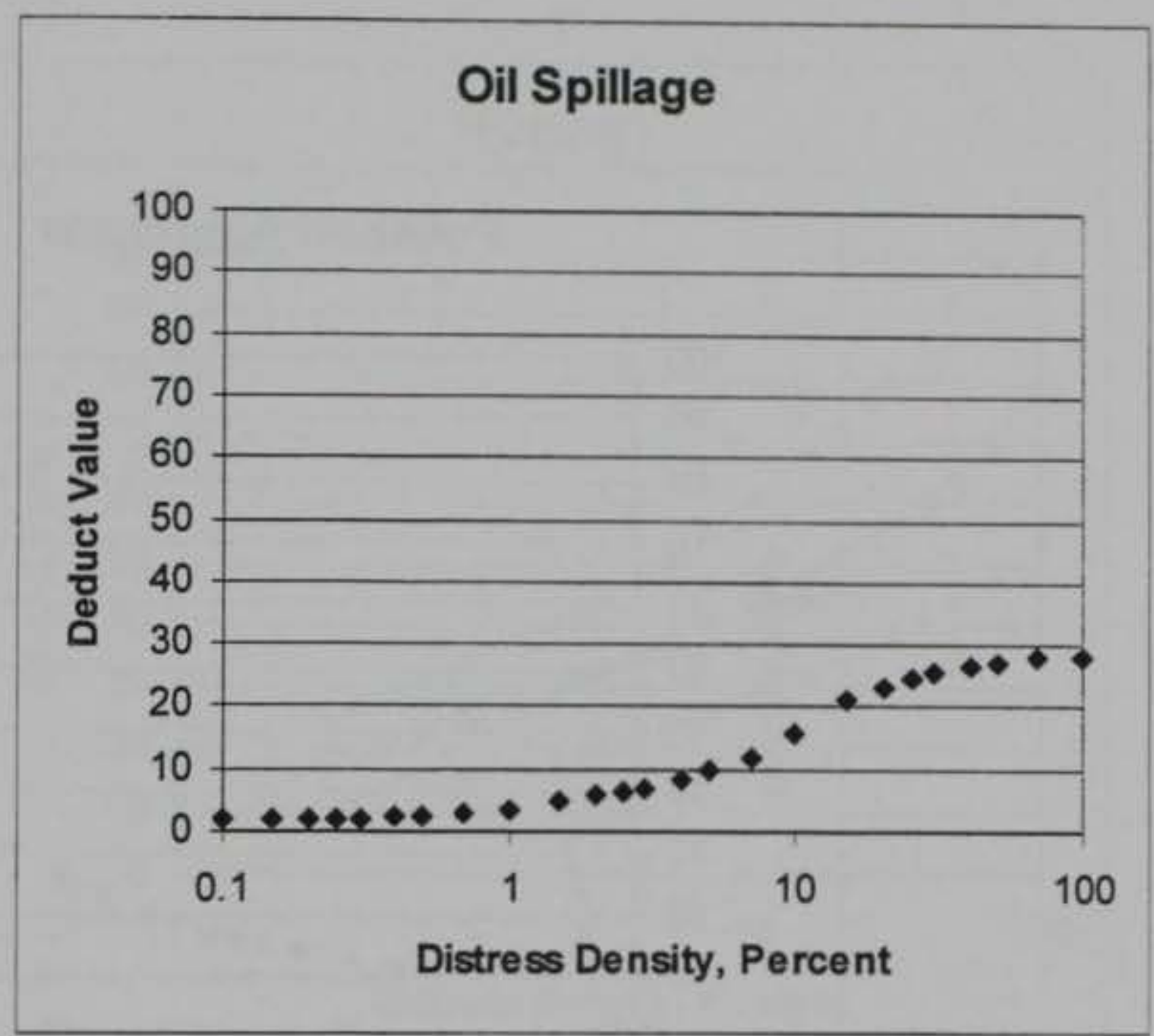

FIG D-9. Oil Spillage Distress Density versus Deduct Curve

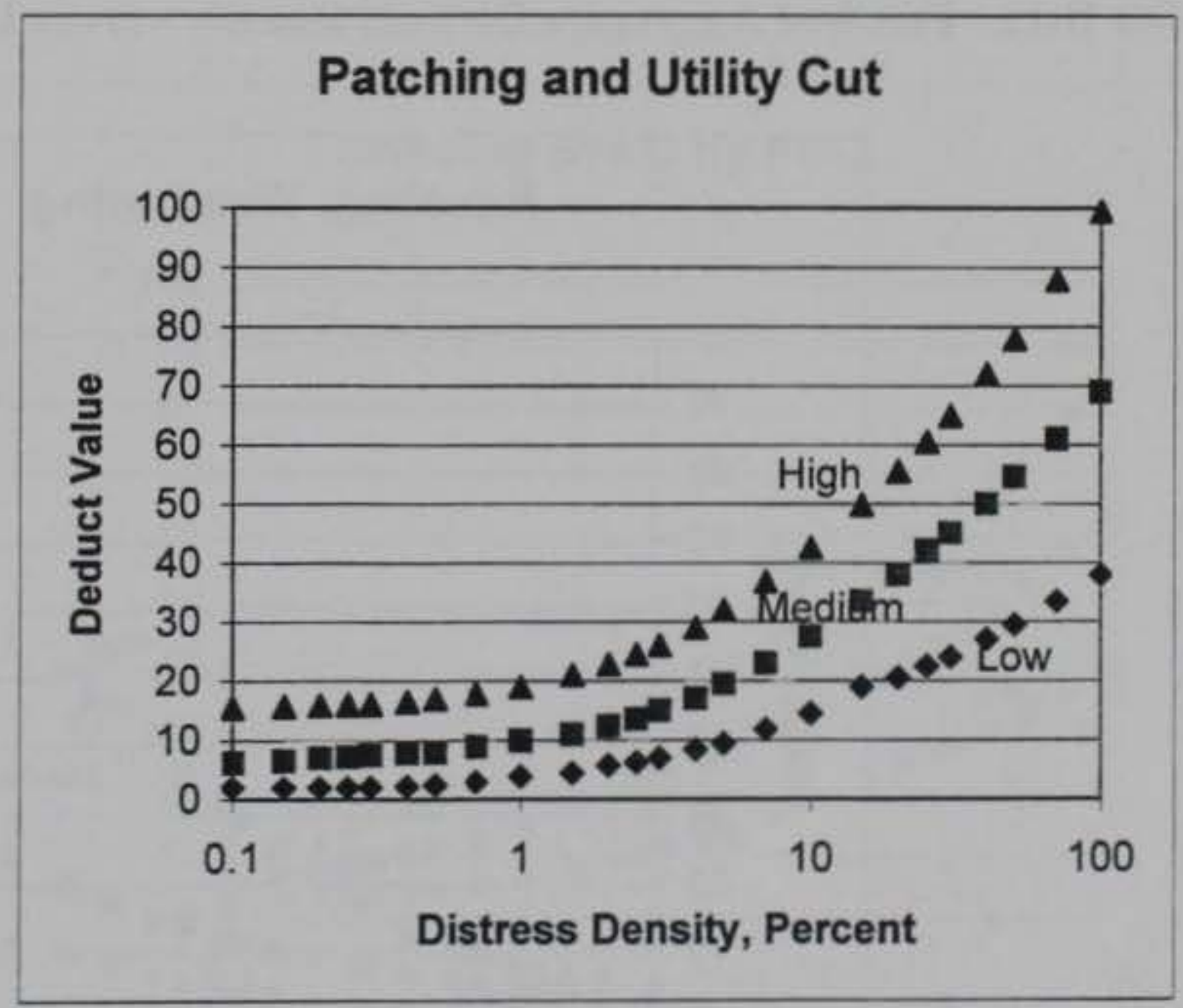

FIG D-10. Patching and Utility Cut Distress Density versus Deduct Curve 


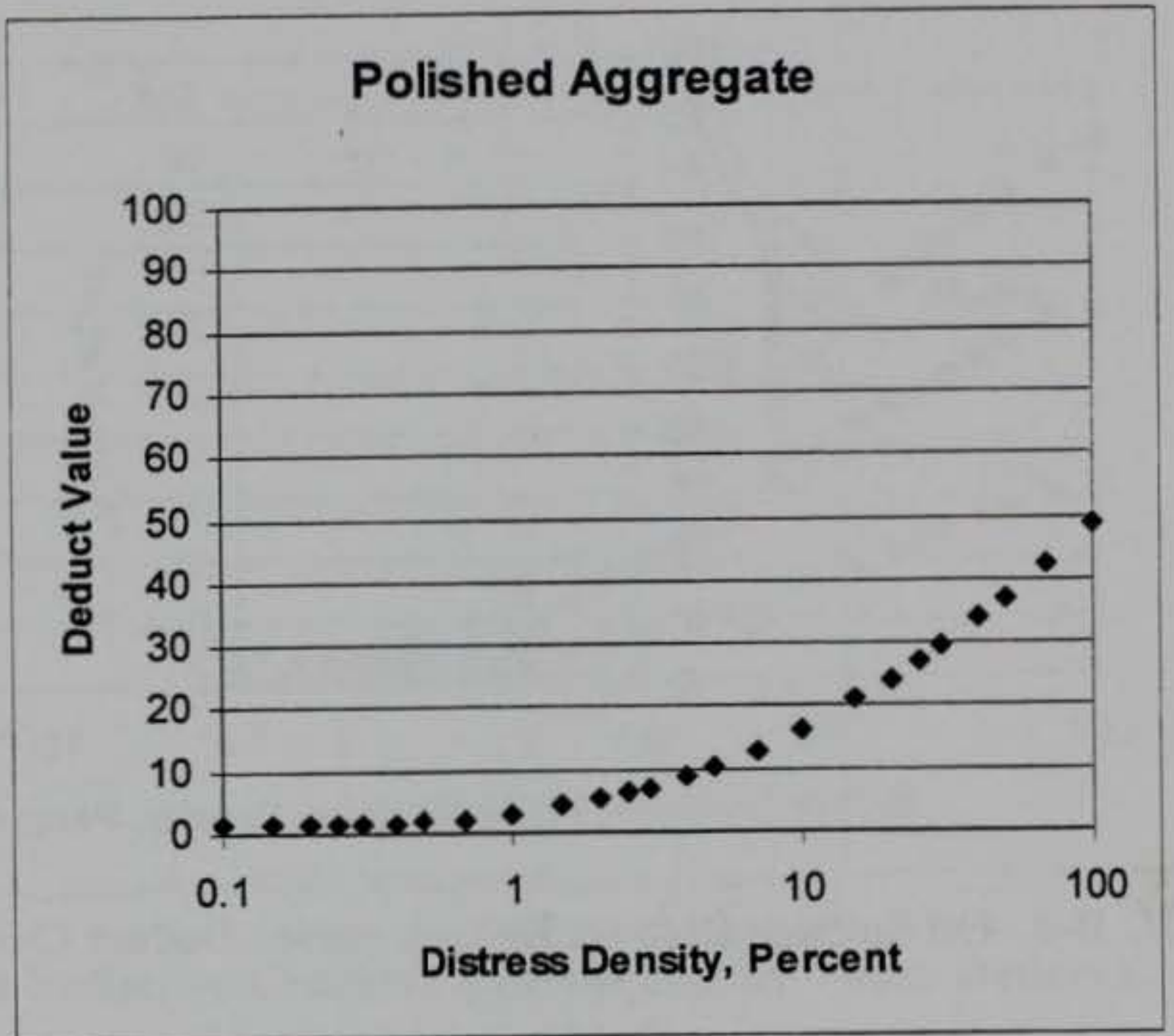

FIG D-11. Polished Aggregate Distress Density versus Deduct Curve

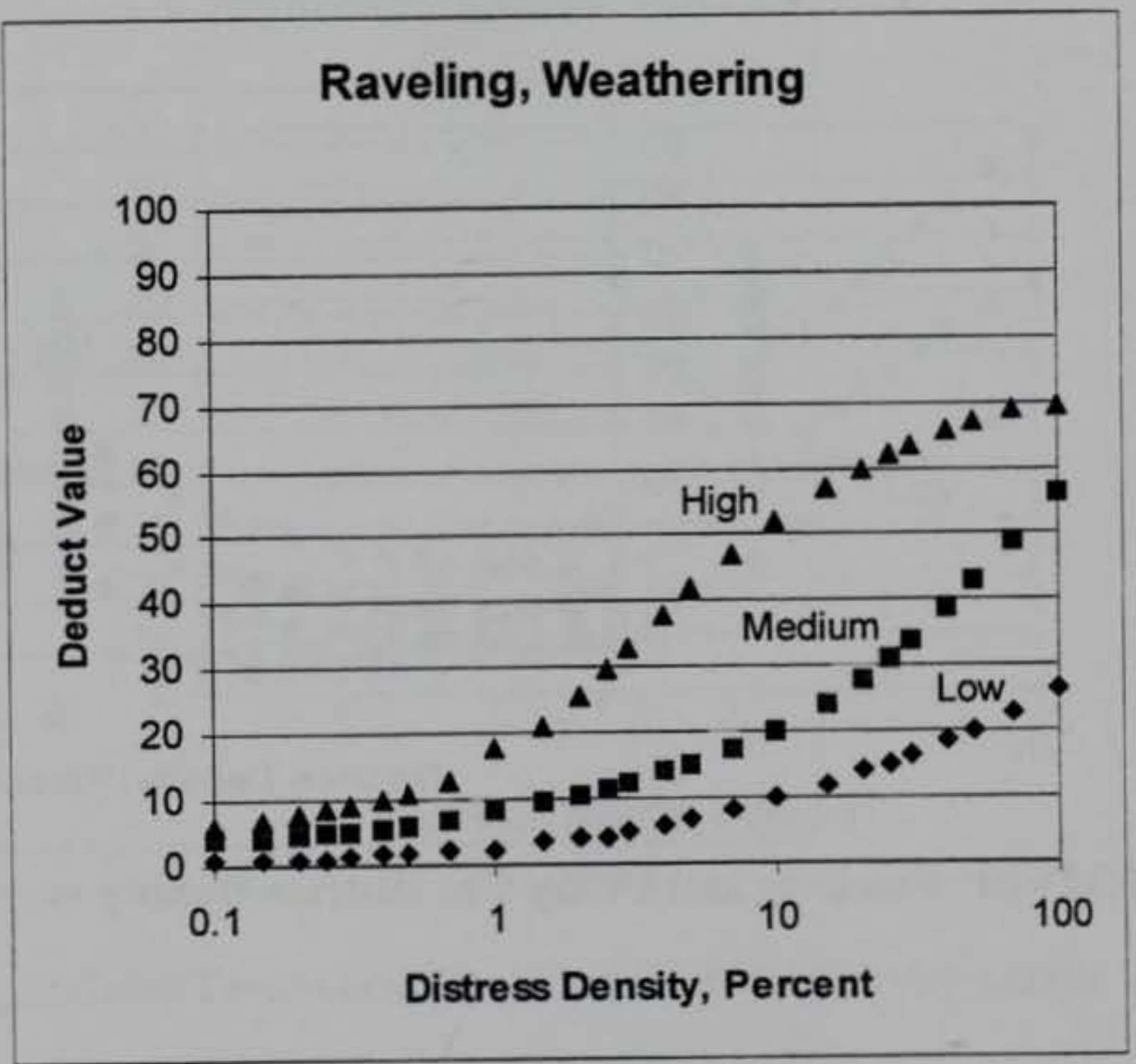

FIG D-12. Raveling/Weathering Distress Density versus Deduct Curve 


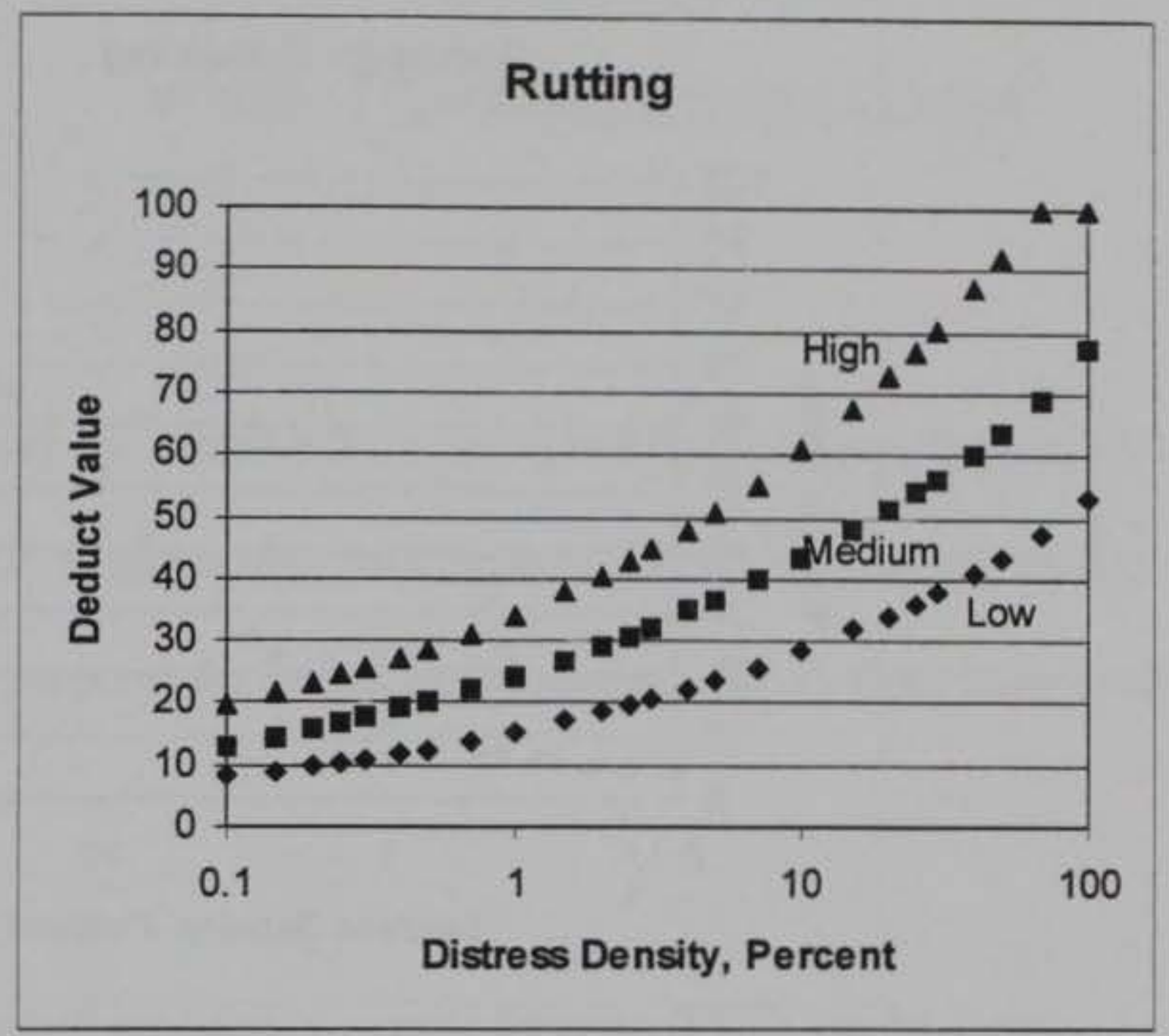

FIG D-13. Rutting Distress Density versus Deduct Curve

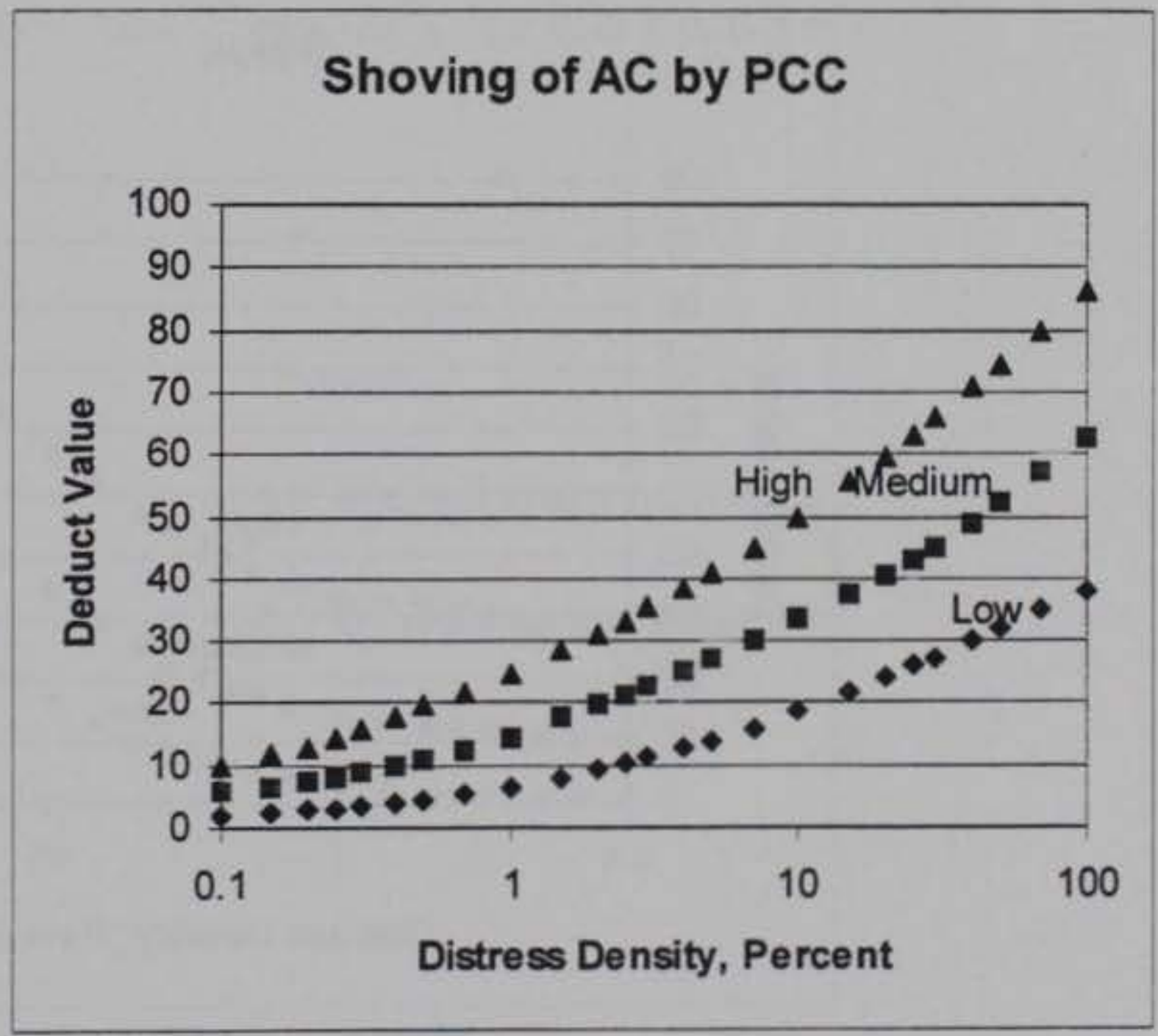

FIG D-14. Shoving of AC by PCC Distress Density versus Deduct Curve 


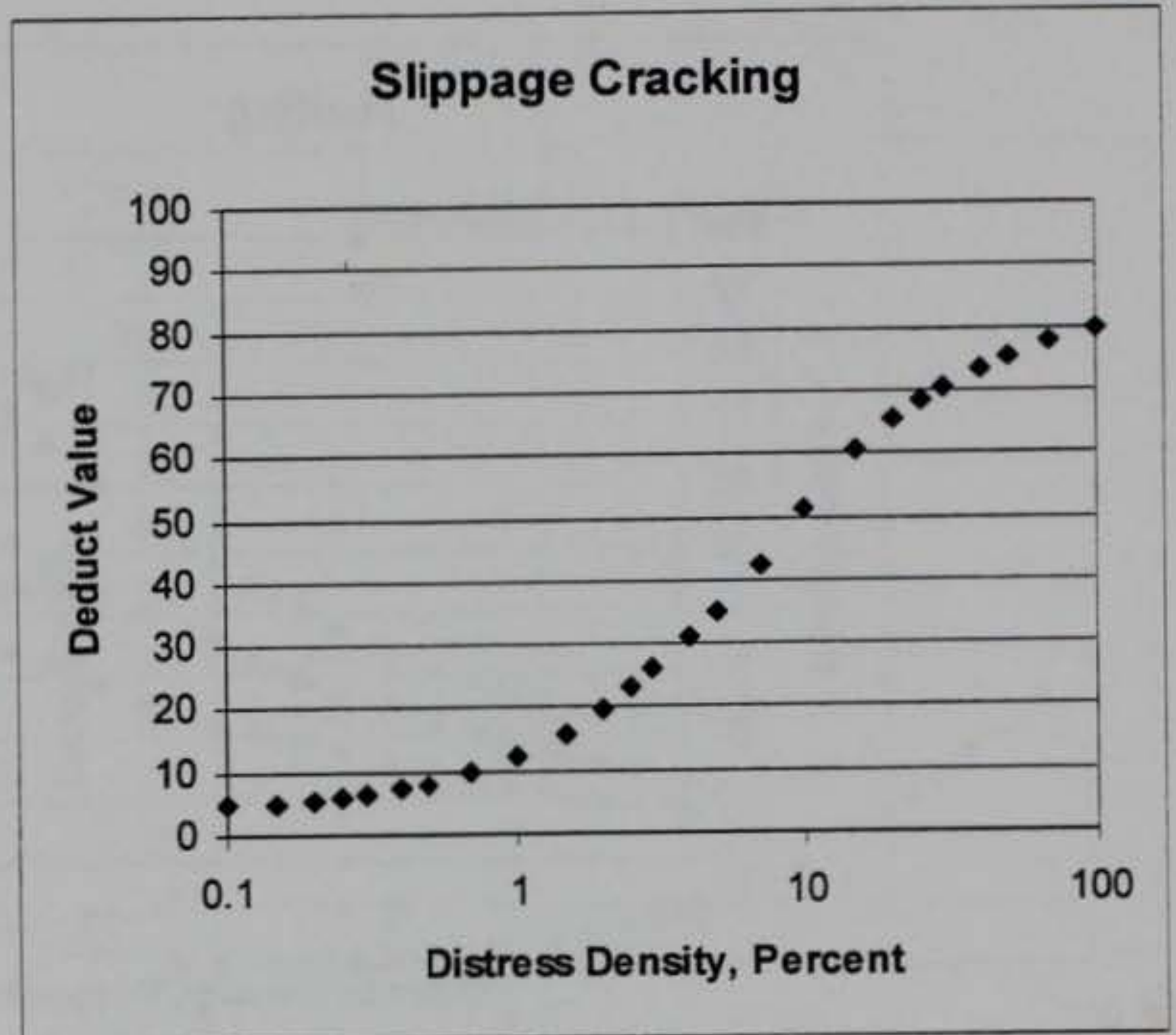

FIG D-15. Slippage Cracking Distress Density versus Deduct Curve

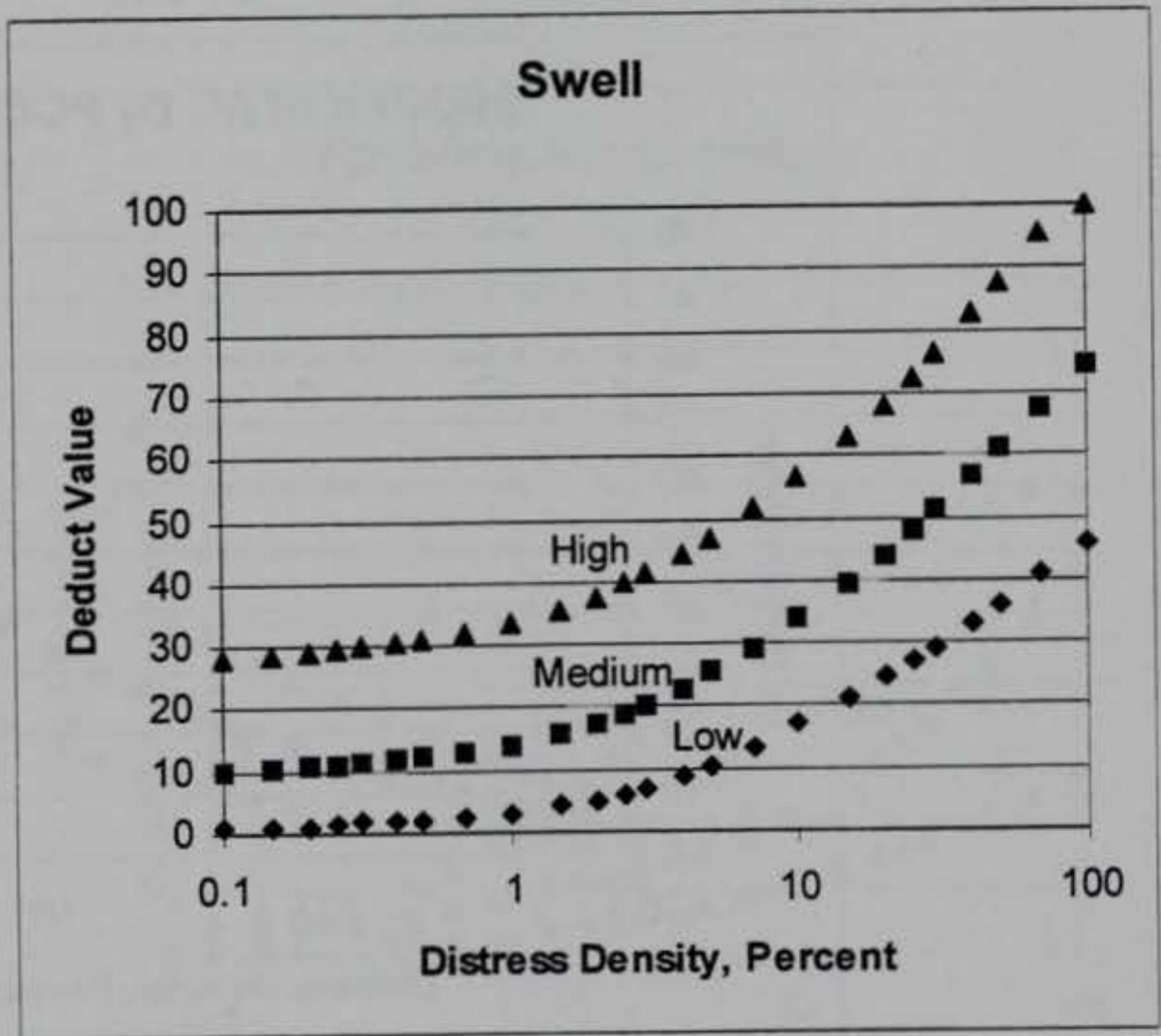

FIG D-16. Swell Distress Density versus Deduct Curve 


\section{APPENDIX E}

\section{WEIBULL DISTRIBUTION ANALYSIS}

This appendix contains the regression analysis and application of reliability using the Weibull CDF as opposed to the Gumbel CDF, which was presented in the body of the work. The purposes for including this analysis are for comparison and documentation.

The Weibull probability density function (PDF) has the form:

$$
F(t)=\alpha \beta t^{(\alpha-1)} \exp \left(-\beta t^{\alpha}\right), t \geq 0, \alpha \geq 0, \beta \geq 0
$$

Where:

$$
\begin{aligned}
& t=\text { time } \\
& \alpha=\text { Weibull shape parameter } \\
& \beta=\text { Weibull scaling parameter }
\end{aligned}
$$


The cumulative distribution function (CDF) is obtained by integrating the PDF and can be expressed as follows:

$$
F(t)=1-\exp \left(-\beta t^{\alpha}\right)
$$

The CDF ranges from zero to one. By multiplying the CDF by a factor it can be made to range from zero to any value required. A multiplying value of 100 is selected as the maximum amount of distress density achievable. Therefore the distress density at any given time will be a function of the Weibull $\mathrm{CDF}$ as shown in Equation E-3.

$$
\mathrm{DD}_{\mathrm{t}}=100\left[1-\exp \left(-\beta \mathrm{t}^{\alpha}\right)\right]
$$

Where:

$$
\mathrm{DD}_{\mathrm{t}}=\text { the distress density of a particular distress at some time } \mathrm{t}
$$

Field data were fit to the performance equation as was done for the Gumbel CDF. Table E-1 shows the results of the shape and scale parameter determinations for block cracking. The same features that were used to determine Gumbel parameters were used to determine Weibull parameters. Tables E-2 and E-3 show the Weibull shape parameters determined for features with longitudinal/transverse cracking and raveling/weathering, respectively. 
TABLE E-1. Results of Weibull CDF Parameter Determinations for Block Cracking

\begin{tabular}{lllcc}
\hline \multicolumn{1}{c}{ Airfield } & Feature & S/P & $\alpha$ & $\beta$ \\
(1) & $(2)$ & $(3)$ & $(4)$ & $(5)$ \\
\hline Biggs & A9E & S & 2.1 & 0.015 \\
Cairns & T8E & S & 3 & 0.00015 \\
Cairns & T11E & S & 2.2 & 0.0001 \\
Hunter & R5E & P & 2.1 & 0.001 \\
Hunter & T1E & P & 2 & 0.001 \\
Hunter & T8E & P & 0.78 & 0.05 \\
Hunter & T9E & P & 1.8 & 0.001 \\
Wheeler-Sack & T2E & S & 3.8 & 0.0001 \\
\hline
\end{tabular}


TABLE E-2. Results of CDF Weibull Parameter Determinations for Longitudinal/Transverse Cracking

\begin{tabular}{|c|c|c|c|c|}
\hline $\begin{array}{l}\text { Airfield } \\
\text { (1) }\end{array}$ & $\begin{array}{c}\text { Feature } \\
(2)\end{array}$ & $\begin{array}{l}\text { S/P } \\
(3)\end{array}$ & $\begin{array}{c}\alpha \\
(4)\end{array}$ & $\begin{array}{c}\beta \\
(5) \\
\end{array}$ \\
\hline Butts & R2E & $P$ & 1.7 & 0.0015 \\
\hline Butts & R3E & $P$ & 1.8 & 0.0015 \\
\hline Butts & R4I & $P$ & 1.8 & 0.0015 \\
\hline Butts & R5E & $P$ & 1.7 & 0.0015 \\
\hline Butts & R6E & $P$ & 1.8 & 0.0015 \\
\hline Cairns & R6I & $P$ & 2.3 & 0.0001 \\
\hline Cairns & T1E & $P$ & 2.3 & 0.0001 \\
\hline Cairns & T4E & $P$ & 1.9 & 0.0001 \\
\hline Cairns & T8E & $S$ & 2.6 & 0.0001 \\
\hline Cairns & T9E & $S$ & 2.5 & 0.0001 \\
\hline Cairns & T10E & $S$ & 2.4 & 0.0001 \\
\hline Cairns & T12E & $\mathrm{S}$ & 1.8 & 0.0001 \\
\hline Cairns & $\mathrm{A} 6 \mathrm{E}$ & $S$ & 2.4 & 0.0001 \\
\hline Cairns & A10E & $S$ & 2.7 & 0.0001 \\
\hline Cairns & A11E & $S$ & 2.4 & 0.0001 \\
\hline Cairns & A12E & $S$ & 1.7 & 0.0001 \\
\hline Hood & A19E & $S$ & 2.4 & 0.0001 \\
\hline Hood & A21E & $S$ & 1.8 & 0.0001 \\
\hline Hood & $\mathrm{A} 8 \mathrm{E}$ & $S$ & 1.5 & 0.0001 \\
\hline Hood & T6E & $S$ & 2.5 & 0.0001 \\
\hline Hunter & T9E & $P$ & 3.6 & 0.00001 \\
\hline Hunter & A7E & $S$ & 2.5 & 0.0001 \\
\hline Hunter & A8E & S & 2.8 & 0.00001 \\
\hline Hunter & A19E & $S$ & 2.3 & 0.0001 \\
\hline Hunter & $\mathrm{A} 30 \mathrm{E}$ & S & 2.6 & 0.0001 \\
\hline Hunter & T6E & S & 2.3 & 0.0001 \\
\hline Hunter & T10E & $S$ & 3.4 & 0.00001 \\
\hline Phillips & R2I & $P$ & 2 & 0.0001 \\
\hline Phillips & R4I & $P$ & 2.6 & 0.0001 \\
\hline Phillips & R5I & $P$ & 2.3 & 0.0001 \\
\hline Phillips & T2E & $P$ & 2.4 & 0.0001 \\
\hline Phillips & T4E & $S$ & 1.9 & 0.0001 \\
\hline Selah & R8E & $P$ & 0.5 & 0.015 \\
\hline Selah & $\mathrm{A} 1 \mathrm{E}$ & $S$ & 0.6 & 0.01 \\
\hline Simmons & R1E & $\mathrm{P}$ & 2.8 & 0.0001 \\
\hline
\end{tabular}


TABLE E-3. Results of Weibull Shape Parameter Determinations for Raveling/Weathering

\begin{tabular}{lllcc}
\multicolumn{1}{c}{$\begin{array}{c}\text { Airfield } \\
(1)\end{array}$} & Feature & S/P & $\alpha$ & $\beta$ \\
\hline Cairns & $(2)$ & $(3)$ & $(4)$ & $(5)$ \\
Cairns & T4E & P & 3.9 & 0.00001 \\
Cairns & T9E & S & 4 & 0.00001 \\
Cairns & T10E & S & 3.9 & 0.00001 \\
Cairns & T11E & S & 5.7 & $1 \mathrm{E}-07$ \\
Hood & A11E & $S$ & 1.7 & 0.01 \\
Hood & A19E & S & 3.4 & 0.0001 \\
Hood & T3E & S & 1.2 & 0.01 \\
\hline
\end{tabular}

The next step in the model development was to regress the $\alpha$ and $\beta$ parameters against the independent variables. However, before this was done, the parameters and independent variables were evaluated for correlation. The results of the correlation analyses for block cracking, longitudinal/transverse cracking and raveling and weathering are shown in Tables E-4, E-5 and E-6, respectively. 
TABLE E-4. Correlation Analysis for Block Cracking Weibull Parameters and Independent Variables

\begin{tabular}{|c|c|c|c|c|c|c|c|c|c|c|c|c|c|c|}
\hline $\begin{array}{c}\text { Factor } \\
\text { (1) }\end{array}$ & $\begin{array}{l}\text { Alpha } \\
\text { (2) }\end{array}$ & $\begin{array}{l}\text { Beta } \\
\text { (3) }\end{array}$ & $\begin{array}{l}\text { SR } \\
\text { (4) }\end{array}$ & $\begin{array}{l}\text { CC } \\
\text { (5) }\end{array}$ & $\begin{array}{l}\mathrm{H} 2 \mathrm{O} \\
(6)\end{array}$ & $\begin{array}{l}\text { HDD } \\
(7)\end{array}$ & $\begin{array}{l}\text { CDD } \\
(8)\end{array}$ & $\begin{array}{l}\text { WS } \\
\text { (9) }\end{array}$ & $\begin{array}{l}\mathrm{OC} \\
(10)\end{array}$ & $\begin{array}{l}\mathrm{RC} \\
(11)\end{array}$ & $\begin{array}{l}A C \\
\text { (12) }\end{array}$ & $\begin{array}{l}\text { FC } \\
\text { (13) }\end{array}$ & $\begin{array}{l}\text { SN } \\
(14)\end{array}$ & $\begin{array}{l}\mathrm{EL} \\
(15)\end{array}$ \\
\hline Alpha & 1.00 & & & & & & & & & & & & & \\
\hline Beta & -0.69 & 1.00 & & & & & & & & & & & & \\
\hline SR & -0.46 & 0.22 & 1.00 & & & & & & & & & & & \\
\hline $\mathrm{CC}$ & 0.36 & -0.18 & -0.99 & 1.00 & & & & & & & & & - & \\
\hline $\mathrm{H} 2 \mathrm{O}$ & -0.49 & 0.04 & -0.21 & 0.31 & 1.00 & & & & & & & & & \\
\hline HDD & 0.76 & -0.21 & -0.58 & 0.48 & -0.68 & 1.00 & & & & & & & & \\
\hline CDD & -0.78 & 0.22 & 0.55 & -0.45 & 0.70 & -1.00 & 1.00 & & & & & & & \\
\hline WS & 0.36 & 0.03 & -0.47 & 0.44 & -0.53 & 0.79 & -0.76 & 1.00 & & & & & & \\
\hline OC & -0.67 & 0.29 & -0.06 & 0.19 & 0.65 & -0.51 & 0.55 & 0.07 & 1.00 & & & & & \\
\hline $\mathrm{RC}$ & -0.82 & 0.33 & 0.27 & -0.14 & 0.66 & -0.76 & 0.80 & -0.22 & 0.93 & 1.00 & & & & \\
\hline AC & -0.60 & 0.04 & 0.67 & -0.59 & 0.39 & -0.84 & 0.84 & -0.55 & 0.46 & 0.70 & 1.00 & & & \\
\hline FC & -.. & -.. & -. & -.. & -.. & 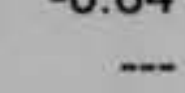 & -. & ... & --- & -.. & - & 1.00 & & \\
\hline SN & -0.06 & 0.15 & 0.82 & -0.87 & -0.73 & -0.01 & -0.02 & 0.03 & -0.38 & -0.16 & 0.25 & - & 1.00 & \\
\hline $\mathrm{EL}$ & -0.71 & 0.40 & 0.55 & -0.46 & 0.10 & -0.51 & 0.54 & 0.09 & 0.72 & 0.81 & 0.65 & - & 0.37 & 1.00 \\
\hline EP & -0.24 & 0.27 & -0.14 & 0.20 & -0.12 & 0.19 & -0.15 & 0.76 & 0.65 & 0.46 & 0.01 & -. & 0.03 & 0.67 \\
\hline
\end{tabular}


TABLE E-5. Correlation Analysis for Longitudinal/Transverse Cracking Weibull Parameters and Independent

Variables

\begin{tabular}{|c|c|c|c|c|c|c|c|c|c|c|c|c|c|c|}
\hline $\begin{array}{l}\text { Factor } \\
\text { (1) }\end{array}$ & $\begin{array}{l}\text { Alpha } \\
\text { (2) }\end{array}$ & $\begin{array}{l}\text { Beta } \\
\text { (3) }\end{array}$ & $\begin{array}{l}\text { SR } \\
\text { (4) }\end{array}$ & $\begin{array}{l}C C \\
(5)\end{array}$ & $\begin{array}{c}\mathrm{H} 2 \mathrm{O} \\
(6)\end{array}$ & $\begin{array}{l}\text { HDD } \\
(7)\end{array}$ & $\begin{array}{c}\text { CDD } \\
(8)\end{array}$ & $\begin{array}{l}\text { WS } \\
\text { (9) }\end{array}$ & $\begin{array}{l}\mathrm{OC} \\
(10)\end{array}$ & $\begin{array}{l}\mathrm{RC} \\
(11)\end{array}$ & $\begin{array}{l}A C \\
(12)\end{array}$ & $\begin{array}{l}\text { FC } \\
\text { (13) }\end{array}$ & $\begin{array}{l}\text { SN } \\
(14)\end{array}$ & $\begin{array}{c}E L \\
(15)\end{array}$ \\
\hline Alpha & 1.00 & & & & & & & & & & & & & \\
\hline Beta & -0.70 & 1.00 & & & & & & & & & & & & \\
\hline SR & 0.20 & -0.38 & 1.00 & & & & & & & & & & & \\
\hline CC & 0.27 & 0.11 & -0.66 & 1.00 & & & & & & & & & & \\
\hline $\begin{array}{l}\mathrm{H} 2 \mathrm{O} \\
\mathrm{HDD}\end{array}$ & 0.65 & -0.54 & 0.27 & 0.44 & 1.00 & & & & & & & & & \\
\hline $\begin{array}{l}\text { HDD } \\
\text { CDD }\end{array}$ & -0.57 & 0.49 & -0.44 & -0.26 & -0.97 & 1.00 & & & & & & & & \\
\hline $\begin{array}{l}\text { CDD } \\
\text { WS }\end{array}$ & 0.53 & -0.51 & 0.51 & 0.11 & 0.91 & -0.98 & 1.00 & & & & & & & \\
\hline $\begin{array}{l}\text { WS } \\
\text { OC }\end{array}$ & -0.20 & -0.04 & 0.20 & -0.67 & -0.53 & 0.39 & -0.19 & 1.00 & & & & & & \\
\hline $\begin{array}{l}\mathrm{OC} \\
\mathrm{RC}\end{array}$ & -0.58 & 0.38 & 0.01 & -0.34 & -0.43 & 0.30 & -0.20 & 0.52 & 1.00 & & & & & \\
\hline $\begin{array}{l}\mathrm{RC} \\
\mathrm{AC}\end{array}$ & 0.26 & -0.45 & 0.28 & -0.37 & -0.22 & 0.21 & -0.11 & 0.61 & 0.11 & 1.00 & & & & \\
\hline AC & 0.27 & -0.24 & -0.14 & 0.05 & -0.20 & 0.32 & -0.36 & -0.02 & -0.51 & 0.38 & 1.00 & & & \\
\hline FC & -0.23 & -0.11 & -0.09 & -0.57 & -0.63 & 0.58 & -0.41 & 0.88 & 0.38 & 0.57 & 0.19 & 1.00 & & \\
\hline SN & -0.10 & -0.14 & 0.44 & -0.47 & 0.14 & -0.31 & 0.45 & 0.43 & 0.45 & 0.13 & -0.62 & 0.25 & 1.00 & \\
\hline EL & 0.43 & -0.18 & -0.58 & 0.84 & 0.33 & -0.13 & 0.03 & -0.38 & -0.37 & 0.13 & 0.35 & -0.23 & -0.52 & 1.00 \\
\hline EP & -0.64 & 0.77 & -0.14 & -0.21 & -0.53 & 0.37 & -0.27 & 0.50 & 0.63 & -0.17 & -0.42 & 0.29 & 0.30 & -0.39 \\
\hline
\end{tabular}


TABLE E-6. Correlation Analysis for Raveling/Weathering Weibull Parameters and Independent Variables

\begin{tabular}{|c|c|c|c|c|c|c|c|c|c|c|c|c|c|c|}
\hline $\begin{array}{l}\text { Factor } \\
\text { (1) }\end{array}$ & $\begin{array}{l}\text { Alpha } \\
\text { (2) }\end{array}$ & $\begin{array}{l}\text { Beta } \\
\text { (3) }\end{array}$ & $\begin{array}{l}\text { SR } \\
\text { (4) }\end{array}$ & $\begin{array}{l}\text { CC } \\
\text { (5) }\end{array}$ & $\begin{array}{c}\mathrm{H} 2 \mathrm{O} \\
(6)\end{array}$ & $\begin{array}{l}\text { HDD } \\
(7)\end{array}$ & $\begin{array}{l}\text { CDD } \\
(8)\end{array}$ & $\begin{array}{l}\text { WS } \\
\text { (9) }\end{array}$ & $\begin{array}{l}\mathrm{OC} \\
(10)\end{array}$ & $\begin{array}{l}\mathrm{RC} \\
\text { (11) }\end{array}$ & $\begin{array}{l}A C \\
(12)\end{array}$ & $\begin{array}{l}\text { FC } \\
(13)\end{array}$ & $\begin{array}{l}\text { SN } \\
(14)\end{array}$ & $\begin{array}{c}\text { EL } \\
(15)\end{array}$ \\
\hline Alpha & 1.00 & & & & & & & & & & & & & \\
\hline Beta & -0.90 & 1.00 & & & & & & & & & & & & \\
\hline SR & -0.60 & 0.47 & 1.00 & & & & & & & & & & & \\
\hline CC & 0.60 & -0.47 & -1.00 & 1.00 & & & & & & & & & & \\
\hline $\mathrm{H} 2 \mathrm{O}$ & 0.60 & -0.47 & -1.00 & 1.00 & 1.00 & & & & & & & & & \\
\hline HDD & 0.60 & -0.47 & -1.00 & 1.00 & 1.00 & 1.00 & & & & & & & & \\
\hline CDD & -0.60 & 0.47 & 1.00 & -1.00 & -1.00 & -1.00 & 1.00 & & & & & & & \\
\hline WS & -0.60 & 0.47 & 1.00 & -1.00 & -1.00 & -1.00 & 1.00 & 1.00 & & & & & & \\
\hline $\mathrm{OC}$ & 0.06 & -0.29 & 0.49 & -0.49 & -0.49 & -0.49 & 0.49 & 0.49 & 1.00 & & & & & \\
\hline $\mathrm{RC}$ & -0.41 & 0.36 & 0.36 & -0.36 & -0.36 & -0.36 & 0.36 & 0.36 & 0.48 & 1.00 & & & & \\
\hline$A C$ & 0.58 & -0.49 & -0.72 & 0.72 & 0.72 & 0.72 & -0.72 & -0.72 & -0.57 & -0.91 & 1.00 & & & \\
\hline FC & -0.60 & 0.47 & 1.00 & -1.00 & -1.00 & -1.00 & 1.00 & 1.00 & 0.49 & 0.36 & -0.72 & 1.00 & & \\
\hline SN & -0.83 & 0.78 & 0.77 & -0.77 & -0.77 & -0.77 & 0.77 & 0.77 & 0.38 & 0.67 & -0.85 & 0.77 & 1.00 & \\
\hline EL & 0.60 & -0.47 & -1.00 & 1.00 & 1.00 & 1.00 & -1.00 & -1.00 & -0.49 & -0.36 & 0.72 & -1.00 & -0.77 & 1.00 \\
\hline EP & -0.60 & 0.47 & 1.00 & -1.00 & -1.00 & -1.00 & 1.00 & 1.00 & 0.49 & 0.36 & -0.72 & 1.00 & 0.77 & -1.00 \\
\hline
\end{tabular}


The first observation made based on the correlation analyses are that the dependent variables, $\alpha$ and $\beta$, are negatively correlated to each other in all three cases. This observation indicates that any independent variable that effects one parameter, should have the opposite effect on the other parameter. Also, any parameter deemed appropriate for inclusion with one variable should be used for analysis with both parameters.

As for the Gumbel analysis, sky cover and cooling degree days were used to capture the effects of solar radiation and heating degree days in any regression analysis for which these factors were deemed appropriate.

\section{Regression Analysis for Block Cracking}

The independent variables that are considered appropriate as having an effect on block cracking are the same as the ones used for the Gumbel analyses.

Forward stepwise linear regression analyses were performed comparing $\alpha$ and $\beta$ to the appropriate independent variables. The independent variables were entered into the forward stepwise regression procedure in order of greatest value of correlation coefficient to least value. Variables that had a $\mathrm{P}$ value greater than .1 , indicating they were not significant at the 90 percent level, were removed as the steps progressed. The recommended forms of the equations relating the independent variables to the dependent variables are shown in equations E-4 and E-5. Equation E-5 relates $\log (\beta)$ to the 
independent variables. Because the $\beta$ values were observed to range over values of several orders of magnitude, a log relationship was examined and it provided more consistent results.

$$
\begin{aligned}
& \alpha=366-0.184(\mathrm{RC})-0.000402(\mathrm{CDD})+0.186(\mathrm{SC}) \\
& \log (\beta)=-691+0.351(\mathrm{RC})-0.00217(\mathrm{CDD})-0.808(\mathrm{SC})
\end{aligned}
$$

Where:

$$
\begin{aligned}
& \mathrm{RC}=\text { The most recent construction date (calendar year) } \\
& \mathrm{CDD}=\text { Cooling degree days }(\operatorname{deg} \mathrm{C}) \\
& \mathrm{SC}=\text { Sky cover (tenths) }
\end{aligned}
$$

Reviewing equations E-4 and E-5 shows that the independent variables have different signs in each equation, except CDD, indicating their influence is opposite on each dependent variable. The reason the signs were the same for the CDD variable in both equations was because of the relatively little influence the CDD had in the $\alpha$ equation. However, the CDD variable improved the $R^{2}$ for the $\beta$ equation enough to make it worth including. As stated previously, any independent variable used to predict one dependent variable would be used for both dependent variables. 
A sensitivity analysis was performed on equations E-4 and E-5 to determine the effect of each independent variable. Table E-7 summarizes the sensitivity analysis. The sensitivity analysis included the following: the means of each variable, the extremes of each variable with the means of the other variables, and the extremes of each variable. The resulting $\alpha$ and $\beta$ are presented in the last two columns of Table E-7.

TABLE E-7. Summary of Sensitivity Analysis for Equations 5 and 6

\begin{tabular}{ccccc}
\hline RC & CDD & SC & $\alpha$ & $\beta$ \\
$(1)$ & $(2)$ & $(3)$ & $(4)$ & $(5)$ \\
\hline 1981 & 1200 & 5.7 & 2.26 & 0.00089 \\
1976 & 1200 & 5.7 & 3.18 & $1.6 \mathrm{E}-05$ \\
1984 & 1200 & 5.7 & 1.71 & 0.010 \\
1981 & 308 & 5.7 & 2.62 & 0.077 \\
1981 & 1391 & 5.7 & 2.18 & 0.00034 \\
1981 & 1200 & 3.8 & 1.91 & 0.030 \\
1981 & 1200 & 7.1 & 2.52 & $6.6 \mathrm{E}-05$ \\
1976 & 308 & 3.8 & 3.19 & 0.046 \\
1984 & 1391 & 7.1 & 1.89 & 0.00028 \\
\hline
\end{tabular}

The values obtained for $\alpha$ and $\beta$ over the range of data are within the ranges of values observed. Therefore the equations provide reasonable estimations within the limits over which they were developed. 
Regression Analysis for Longitudinal/Transverse Cracking

The independent variables that are considered appropriate as having an effect on longitudinal/transverse cracking are the same ones used for the Gumbel analyses.

Forward stepwise linear regression procedures were conducted to determine the most suitable equations for predicting the dependent variables. The regression equations recommended for predicting $\alpha$ and $\beta$ for longitudinal/transverse cracking are shown in equations E-6 and E-7, respectively.

$\alpha=-5.39-0.0000340(\mathrm{EP})+0.000525(\mathrm{CDD})+1.03(\mathrm{SC})+0.425(\mathrm{WS})$

$\log (\beta)=6.77+0.0000322(E P)-0.000998(C D D)-1.42(S C)-0.509(W S)$

Where:

$$
\begin{aligned}
& \mathrm{EP}=\text { Evaluation pass level } \\
& \mathrm{CDD}=\text { Cooling degree days }(\operatorname{deg} \mathrm{C}) \\
& \mathrm{SC}=\text { Sky Cover (tenths) } \\
& \mathrm{WS}=\text { Wind speed }(\mathrm{m} / \mathrm{s})
\end{aligned}
$$


As expected, the signs for each variable in the $\alpha$ equation are opposite the sign in the $\beta$ equation. The $\log (\beta)$ was used as for the block cracking distress because of the range in values of $\beta$ observed. Transformations of some of the independent variables such $\log (\mathrm{EP})$ were evaluated, but none of the transformations provided an increased $\mathrm{R}^{2}$.

A sensitivity analysis was performed on the regression equations. The results of the sensitivity analysis is shown in Table E-8.

TABLE E-8. Summary of Sensitivity Analysis for Equations 6 and 7

\begin{tabular}{cccccc}
\hline$E P$ & CDD & SC & WS & $\alpha$ & $\beta$ \\
$(1)$ & $(2)$ & $(3)$ & $(4)$ & $(5)$ & $(6)$ \\
\hline 11000 & 1040 & 5.7 & 3.6 & 2.19 & 0.00016 \\
1500 & 1040 & 5.7 & 3.6 & 2.51 & $7.83 \mathrm{E}-05$ \\
50000 & 1040 & 5.7 & 3.6 & 0.86 & 0.0029 \\
11000 & 1040 & 5.7 & 3.6 & 1.78 & 0.00093 \\
11000 & 270 & 5.7 & 3.6 & 2.49 & $4.2 \mathrm{E}-05$ \\
11000 & 1618 & 5.3 & 3.6 & 1.80 & 0.00055 \\
11000 & 1040 & 5.9 & 3.6 & 2.42 & $7.73 \mathrm{E}-05$ \\
11000 & 1040 & 5.7 & 2.9 & 1.88 & 0.00038 \\
11000 & 1040 & 5.7 & 5.0 & 2.77 & $3.22 \mathrm{E}-05$ \\
1500 & 270 & 5.3 & 2.9 & 1.40 & 0.0038 \\
50000 & 1618 & 5.9 & 5.0 & 1.97 & $7.52 \mathrm{E}-05$ \\
\hline
\end{tabular}


The results of the sensitivity analyses indicate the regression equations provide values within the range of values observed for this distress type. The value of the $\alpha$ parameter is changed by a magnitude of approximately 1.5 or less over the range of each independent variable included. The $\beta$ parameter changes by approximately 2 orders of magnitude or less over the range of each independent variables.

Regression Analysis for Raveling/Weathering

The independent variables that are considered appropriate as having an effect on raveling/weathering are the same ones that were used for the Gumbel analyses.

Forward stepwise regression was attempted for both $\alpha$ and $\beta$, the results were not good. All of the analyses indicated that each independent variable had large $\mathrm{P}$ values and that they should be removed from the model. The $\mathrm{R}^{2}$ values were very low, with a maximum value of 26 for the $\alpha$ relationship and 12 for the $\beta$ relationship. The results of these analyses indicate that either there were not enough data to determine a relationship between the dependent and independent variables or that no relationship exists between the independent and dependent variables. Whichever the case, an appropriate relationship could not be developed based on the data available. 
A reliability analysis was performed similar to that used for the Gumbel model. To determine the expected value and variance of $\alpha$ and $\beta$, the first order second moment (FOSM) procedure was used. The relationships and model developed to predict the distress density growth of block cracking were used as an example to demonstrate the application of the procedures used to determine reliability.

The expected value and variance of $\alpha$ for the block cracking model were 2.4 and .39 respectively. The expected value of $\beta$ was found to be 0.0012 and the variance of $\beta$ was found to be $1.91 \mathrm{E}-05$.

The Weibull CDF equation was rearranged so that time was the value being calculated. The Weibull CDF equation in terms of $t$ is shown in Equation E-8.

$$
t_{\text {crit }}=\left[\left[\ln \left[\left(D_{t}-100\right) /(-100)\right]\right] /-\beta\right]^{\wedge}(1 / \alpha)
$$

The Monte Carlo simulation technique was used to find the probability distribution of time to $\mathrm{DD}_{\text {crit }}$. For $\alpha$, a beta distribution with a mean of 2.4 , a standard deviation of .6, a minimum value of .01 , and a maximum value of 4.79 was used. For $\beta$, the exponential distribution with a mean of 0.002 was used. The results of the Monte Carlo simulation are shown in Table E-9. 
TABLE E-9. Summary of Monte Carlo Simulation

\begin{tabular}{lccccc}
$\mathrm{DD}_{\text {cint }}$ & $\begin{array}{c}\text { Number of } \\
\text { Replicates }\end{array}$ & \multicolumn{5}{c}{ Time (yrs) to Reach DD, For Different Levels of } \\
\cline { 3 - 6 } & & $\mathrm{P}=.1$ & $\mathrm{P}=.2$ & $\mathrm{P}=.25$ & $\mathrm{P}=.5$ \\
\cline { 3 - 6 }$(1)$ & $(2)$ & $(3)$ & $(4)$ & $(5)$ & $(6)$ \\
\hline 11 & 500 & 5.3 & 6.0 & 6.5 & 8.9 \\
& 1,000 & 5.2 & 6.0 & 6.4 & 8.3 \\
& 10,000 & 5.2 & 6.0 & 6.3 & 8.4 \\
\hline 66 & 500 & 11.5 & 14.0 & 15.4 & 23.3 \\
& 1,000 & 11.6 & 13.9 & 15.0 & 21.6 \\
& 10,000 & 11.6 & 13.8 & 14.9 & 21.5 \\
\hline
\end{tabular}




\section{APPENDIX F}

\section{CURVE FITTING PROCEDURE}

In order to fit field data to a cumulative density function (CDF) curve efficiently, a spreadsheet, such as Excel@ (Microsoft 1995), is required. Before the curve fitting procedure begins, the field data must be converted to the medium severity distress density for the particular distress being analyzed as discussed in Chapter V. The appropriate regression equations for accomplishing this task are presented in Table 9. A spreadsheet can be used to convert the different severity levels of field data to the medium severity level distress density for each distress type. Figure F-1 shows the layout of the headings and columns, which can be repeated as often as required, for converting the field data to appropriate medium severity level distress density data. Figure F-1 is presented in columnar format so that it can fit a standard page. Tables F-1, F-2 and F-3 show the converted distress density data for those features that met the criteria to be used in the remainder of the study (see Chapter V) for the distress types of block cracking, longitudinal/transverse cracking, and raveling/weathering, respectively. 


\begin{tabular}{|c|l|c|c|c|c|}
\hline & \multicolumn{1}{|c|}{ A } & B & C & D & E \\
\hline 1 & \multicolumn{1}{|c|}{$\begin{array}{c}\text { Distress } \\
\text { Type }\end{array}$} & $\begin{array}{c}\text { Measured } \\
\text { Quantity for } \\
\text { Feature }\end{array}$ & $\begin{array}{c}\text { Regression } \\
\text { Equation }\end{array}$ & $\begin{array}{c}\text { Converted } \\
\text { Medium Severity } \\
\text { Distress Density }\end{array}$ & $\begin{array}{c}\text { Total for Each } \\
\text { Distress } \\
\text { Density }\end{array}$ \\
\hline 2 & $\begin{array}{l}\text { Low severity block } \\
\text { cracking }\end{array}$ & $\mathrm{X}_{1}$ & $\begin{array}{c}.0003 \mathrm{X}_{1}{ }^{2}+ \\
.3306 \mathrm{X}_{1}\end{array}$ & Value of cell C2 & $\ldots$ \\
\hline 3 & $\begin{array}{l}\text { Medium severity } \\
\text { block cracking }\end{array}$ & $\mathrm{X}_{2}$ & - & Value of cell B3 & $\ldots$ \\
\hline 4 & $\begin{array}{l}\text { High severity } \\
\text { block cracking }\end{array}$ & $\mathrm{X}_{3}$ & $\begin{array}{c}-.0899 \mathrm{X}_{3}{ }^{2} \\
+6.2481 \\
\mathrm{X}_{3}\end{array}$ & Value of cell C4 & $\begin{array}{c}\text { SUM } \\
\text { (D2+D3+D4) }\end{array}$ \\
\hline 5 & $\begin{array}{l}\text { Low severity LT } \\
\text { cracking }\end{array}$ & $\mathrm{X}_{4}$ & $\begin{array}{c}-.0027 \mathrm{X}_{4}{ }^{2} \\
+.4692 \mathrm{X}_{4}\end{array}$ & Value of cell C5 & $\ldots$ \\
\hline 6 & $\begin{array}{l}\text { Medium severity } \\
\text { LT cracking }\end{array}$ & $\mathrm{X}_{5}$ & - & Value of cell B6 & $\ldots$ \\
\hline 7 & $\begin{array}{l}\text { High severity LT } \\
\text { cracking }\end{array}$ & $\mathrm{X}_{6}$ & $\begin{array}{c}.1137 \mathrm{X}_{6}{ }^{2}{ }^{+} \\
1.5009 \mathrm{X}_{6}\end{array}$ & Value of cell B7 & $\begin{array}{c}\text { SUM } \\
\text { (D5+D6+D7) }\end{array}$ \\
\hline 8 & $\begin{array}{l}\text { Repeat Rows for } \\
\text { addition distress } \\
\text { types }\end{array}$ & & & & $\ldots$ \\
\hline
\end{tabular}

\section{FIG F-1. Spreadsheet Format for Converting Field Data to Medium Severity} Distress Density Values

TABLE F-1. Converted Distress Density Data for Block Cracking Airfield Feature Time to $\mathrm{DD}_{1}$ (years)

\begin{tabular}{ccc}
$(1)$ & $(2)$ & $(3)$ \\
\hline Biggs & A9E & 4 \\
Cairns & T8E & 6 \\
Cairns & T11E & 6 \\
Hunter & R5E & 9 \\
Hunter & T1E & 2 \\
Hunter & T8E & 2 \\
Hunter & T9E & 2 \\
Wheeler -Sack & T2E & 9
\end{tabular}

$(3)$
4
6
6
9
2
2
2
9
(percent) Time to $\mathrm{DD}_{2}$ (years)

* No data were available for this feature for a second time period.

(4)

8.45

1.06

0.44

9.32

0.37

7.34

0.15 36.60
(5)

$9 \quad 100.00$

10

13

NA*

9

9

9 17

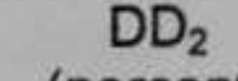

(percent)

4.79

2.66

NA*

7.52

23.60

5.03 100.00 
TABLE F-2. Converted Distress Density Data for Longitudinal/Transverse Cracking

\begin{tabular}{|c|c|c|c|c|c|c|c|}
\hline Airfield & Feature & $\begin{array}{l}\text { Time to } \\
\text { DD }_{1} \\
\text { (years) } \\
\text { (3) }\end{array}$ & $\begin{array}{c}\mathrm{DD}_{1} \\
\text { (percent) } \\
\text { (4) }\end{array}$ & $\begin{array}{l}\text { Time to } \\
\mathrm{DD}_{2} \\
\text { (years) } \\
(5)\end{array}$ & $\begin{array}{c}\mathrm{DD}_{2} \\
\text { (percent) } \\
\text { (6) }\end{array}$ & $\begin{array}{c}\text { Time to } \\
\mathrm{DD}_{3} \\
\text { (years) } \\
(7)\end{array}$ & $\begin{array}{c}\mathrm{DD}_{3} \\
\text { (percent) } \\
(8)\end{array}$ \\
\hline Butts & R2E & 3 & 1.54 & 7 & 4.17 & $N A^{*}$ & $\mathrm{NA}^{*}$ \\
\hline Butts & R3E & 3 & 1.88 & 7 & 4.59 & $\mathrm{NA}^{*}$ & $N A^{*}$ \\
\hline Butts & R4I & 3 & 1.97 & 7 & 4.79 & $\mathrm{NA}^{*}$ & $N A^{*}$ \\
\hline Butts & R5E & 3 & 1.85 & 7 & 4.27 & $\mathrm{NA}^{*}$ & $\mathrm{NA}^{*}$ \\
\hline Butts & R6E & 3 & 2.06 & 7 & 5.03 & $\mathrm{NA}^{*}$ & $\mathrm{NA}^{*}$ \\
\hline Cairns & R6I & 6 & 0.46 & 10 & 1.92 & $\mathrm{NA}^{*}$ & $\mathrm{NA}^{*}$ \\
\hline Cairns & T1E & 6 & 0.96 & 10 & 1.98 & $\mathrm{NA}^{*}$ & $\mathrm{NA}^{*}$ \\
\hline Cairns & T4E & 6 & 0.48 & 10 & 1.04 & 13 & 1.18 \\
\hline Cairns & T8E & 6 & 1.08 & 10 & 3.94 & $N A^{*}$ & $\mathrm{NA}^{*}$ \\
\hline Cairns & T9E & 6 & 1.03 & 10 & 3.56 & 13 & 4.16 \\
\hline Cairns & T10E & 6 & 1.3 & 10 & 2.68 & 13 & 4.77 \\
\hline Cairns & T12E & 6 & 0.27 & 10 & 0.46 & 13 & 1.1 \\
\hline Cairns & A6E & 6 & 1.17 & 10 & 1.98 & $\mathrm{NA}^{*}$ & $\mathrm{NA}^{*}$ \\
\hline Cairns & $\mathrm{A} 10 \mathrm{E}$ & 3 & 0.01 & 7 & 3.08 & 10 & 4.05 \\
\hline Cairns & A11E & 2 & 0.53 & 6 & 1.31 & 9 & 1.44 \\
\hline Cairns & $\mathrm{A} 12 \mathrm{E}$ & 7 & 0.1 & 10 & 0.68 & $\mathrm{NA}^{*}$ & $\mathrm{NA}^{*}$ \\
\hline Hood & A19E & 5 & 0.67 & 10 & 2.32 & $\mathrm{NA}^{*}$ & $\mathrm{NA}^{*}$ \\
\hline Hood & A21E & 5 & 0.04 & 10 & 0.64 & $\mathrm{NA}^{*}$ & $\mathrm{NA}^{*}$ \\
\hline Hood & $\mathrm{A} 8 \mathrm{E}$ & 4 & 1.52 & 9 & 1.72 & $\mathrm{NA}^{*}$ & $\mathrm{NA}^{*}$ \\
\hline Hood & T6E & 4 & 0.32 & 8 & 1.56 & $\mathrm{NA}^{*}$ & $\mathrm{NA}^{*}$ \\
\hline Hunter & T9E & 2 & 1.91 & 9 & 2.14 & $\mathrm{NA}^{*}$ & $\mathrm{NA}^{*}$ \\
\hline Hunter & A7E & 2 & 0.01 & 9 & 2.33 & $\mathrm{NA}^{*}$ & $\mathrm{NA}^{*}$ \\
\hline Hunter & A8E & 2 & 0.31 & 9 & 0.4 & $\mathrm{NA}^{*}$ & $\mathrm{NA}^{*}$ \\
\hline Hunter & $\mathrm{A} 19 \mathrm{E}$ & 2 & 0.62 & 9 & 1.3 & $\mathrm{NA}^{*}$ & $\mathrm{NA}^{*}$ \\
\hline Hunter & $\mathrm{A} 30 \mathrm{E}$ & 2 & 0.37 & 9 & 2.81 & $\mathrm{NA}^{*}$ & $\mathrm{NA}^{*}$ \\
\hline Hunter & T6E & 2 & 0.37 & 9 & 1.49 & $\mathrm{NA}^{*}$ & $\mathrm{NA}^{*}$ \\
\hline Hunter & T10E & 2 & 1.56 & 9 & 2.01 & $\mathrm{NA}^{*}$ & $\mathrm{NA}^{*}$ \\
\hline Phillips & R21 & 3 & 0.15 & 10 & 1.11 & $\mathrm{NA}^{*}$ & $\mathrm{NA}^{*}$ \\
\hline Phillips & R4I & 3 & 0.14 & 10 & 3.79 & $\mathrm{NA}^{*}$ & $\mathrm{NA}^{*}$ \\
\hline Phillips & R5I & 3 & 0.06 & 10 & 1.96 & $\mathrm{NA}^{*}$ & $\mathrm{NA}^{*}$ \\
\hline Phillips & T2E & 3 & 0.05 & 10 & 2.36 & $\mathrm{NA}^{*}$ & $\mathrm{NA}^{*}$ \\
\hline Phillips & T4E & 3 & 0.01 & 10 & 0.86 & $\mathrm{NA}^{*}$ & $N^{*}$ \\
\hline Selah & R8E & 9 & 4.23 & 18 & 6.02 & $\mathrm{NA}^{*}$ & $\mathrm{NA}^{*}$ \\
\hline Selah & $\mathrm{A} 1 \mathrm{E}$ & 9 & 3.07 & 18 & 5.41 & $\mathrm{NA}^{*}$ & $\mathrm{NA}^{*}$ \\
\hline Simmons & R1E & 5 & 0.16 & 9 & 5 & $\mathrm{NA}^{*}$ & $\mathrm{NA}^{*}$ \\
\hline
\end{tabular}

* No data were available for these features for a third time period. 


\begin{tabular}{|c|c|c|c|c|c|}
\hline $\begin{array}{l}\text { Airfield } \\
\text { (1) }\end{array}$ & $\begin{array}{c}\text { Feature } \\
\text { (2) }\end{array}$ & $\begin{array}{c}\text { Time to } \mathrm{DD}_{1} \\
\text { (years) } \\
\text { (3) }\end{array}$ & $\begin{array}{c}\mathrm{DD}_{1} \\
\text { (percent) } \\
\text { (4) }\end{array}$ & $\begin{array}{c}\text { Time to } \mathrm{DD}_{2} \\
\text { (years) } \\
\text { (5) }\end{array}$ & $\begin{array}{c}\mathrm{DD}_{2} \\
\text { (percent) } \\
(6)\end{array}$ \\
\hline Cairns & T4E & 10 & 3.09 & 13 & 22.97 \\
\hline Cairns & T9E & 10 & 10.1 & 13 & 22.97 \\
\hline Cairns & T10E & 10 & 4.29 & 13 & 22.97 \\
\hline Cairns & T11E & 10 & 0.06 & 13 & 22.97 \\
\hline Cairns & A11E & 6 & 22.97 & 9 & 30.13 \\
\hline Hood & A19E & 5 & 2.12 & 10 & 22.97 \\
\hline Hood & T3E & 10 & 15.92 & 15 & 22.97 \\
\hline Hood & T5E & 5 & 12.16 & 10 & 22.97 \\
\hline
\end{tabular}

The appropriate distress density values calculated for the distress under consideration are used along with construction history data for fitting the field data to a CDF curve. The construction history data required is the time from the last construction date in years, which may be original construction, an overlay, or a maintenance project which greatly improved the condition of the pavement feature, to the inspection date. The date, in terms of the calendar year, when the condition survey(s) was performed minus the construction date is the time to that data point. Tables F-1, F-2 and F-3 list the time data with the appropriate distress density data.

Once the distress density data and accompanying time data are available, the field data can be fitted to a CDF curve. If there has been more than one survey since the last major construction project, all of the data should be used. Ideally, there should be at least two data points for use in "shaping" the CDF curve. It is convenient for viewing, 
but not required, to set up a chart plotting the field data and the calculated curve as the curve is being fitted to the field data.

Figure F-2 shows the spreadsheet layout with the formulas in the cells for computing the $\mathrm{CDF}$ curve and comparing the field data to the model calculated data. For this example, the Gumbel CDF is used. Column B, rows 7 and greater of Figure F-2, contain the formula for determining the $\mathrm{CDF}$ at various points in time. The time value is taken from column A. The field distress density values are listed in column C. There may only be one or two field data values, and these values should be placed in the appropriate cell corresponding to the time values in column A. Column D lists the difference between the field data and CDF values. The shape and scale parameters in cells $\mathrm{C} 2$ and $\mathrm{C} 3$ are adjusted by hand (increased and decreased) until the difference between the calculated and measured distress density values (column D) are within desired tolerances. 


\begin{tabular}{|c|c|c|c|c|}
\hline & A & B & c & D \\
\hline 1 & & $\begin{array}{l}\text { Gumbel CDF distress density } \\
\text { equation }\end{array}$ & $100\left(\exp \left(-(\rho / t)^{\wedge}(\beta)\right)\right)$ & \\
\hline 2 & & Rho $=$ & $\rho$ & \\
\hline 3 & & Beta $=$ & $\beta$ & \\
\hline \multicolumn{5}{|l|}{4} \\
\hline \multicolumn{5}{|l|}{5} \\
\hline 6 & $\begin{array}{c}\text { Time } \\
\text { in } \\
\text { years }\end{array}$ & Calculated Distress Density & $\begin{array}{c}\text { Field Distress Density } \\
\text { (From Tables F-1, F-2 } \\
\text { and F-3) }\end{array}$ & $\begin{array}{l}\text { Calculated - } \\
\text { Field Distress } \\
\text { Density }\end{array}$ \\
\hline 7 & 1 & $=100\left(\operatorname{EXP}\left(-(C 2 / A 7)^{\wedge}(C 3)\right)\right)$ & $D_{1}$ & B7-C7 \\
\hline 8 & 2 & $=100\left(\operatorname{EXP}\left(-(C 2 / A 8)^{\wedge}(C 3)\right)\right)$ & $\mathrm{D}_{2}$ & B8-C8 \\
\hline 9 & 3 & $=100\left(\operatorname{EXP}\left(-(C 2 / A 9)^{\wedge}(C 3)\right)\right)$ & $D_{3}$ & B9-C9 \\
\hline 10 & 4 & $=100\left(\operatorname{EXP}\left(-(C 2 / A 10)^{\wedge}(C 3)\right)\right)$ & $\mathrm{D}_{4}$ & B10-C10 \\
\hline 11 & 5 & $=100\left(\operatorname{EXP}\left(-(C 2 / A 11)^{\wedge}(C 3)\right)\right)$ & $D_{5}$ & B11-C11 \\
\hline 12 & 6 & $=100\left(\operatorname{EXP}\left(-(C 2 / A 12)^{\wedge}(C 3)\right)\right)$ & $D_{6}$ & B12-C12 \\
\hline 13 & 7 & $=100\left(\operatorname{EXP}\left(-(C 2 / A 13)^{\wedge}(C 3)\right)\right)$ & $D_{7}$ & B13-C13 \\
\hline- & $\ldots$ & $\ldots$ & $\ldots$ & $\ldots$ \\
\hline- & $\ldots$ & $\ldots$ & $\ldots$ & $\ldots$ \\
\hline 24 & 18 & $=100\left(\operatorname{EXP}\left(-(C 2 / A 24)^{\wedge}(C 3)\right)\right)$ & $D_{18}$ & B24-C24 \\
\hline 25 & 19 & $\left.=100\left(\operatorname{EXP}(-C 2 / A 25)^{\wedge}(C 3)\right)\right)$ & $\mathrm{D}_{19}$ & B25-C25 \\
\hline 26 & 20 & $=100\left(\operatorname{EXP}\left(-(\mathrm{C} 2 / \mathrm{A} 26)^{\wedge}(\mathrm{C} 3)\right)\right)$ & $\mathrm{D}_{20}$ & B26-C26 \\
\hline
\end{tabular}

FIG F-2. Spreadsheet Format for Determining Weibull Shape Parameters 
If a plot of the curves is desired, the evaluator should plot the time (column A) as the abscissa versus both the calculated and field distress density values (columns B and C). If the Excel@ Chart Wizard® is used, the selected chart type should be scatter plot. The Chart Wizard $@$ allows for the plot to be viewed with the data and is interactive; as the $\rho$ and $\beta$ are adjusted, the chart is updated. This allows for the evaluator to view the impact of changing the shape and scale parameters so that appropriate values can be determined quickly. The values of $\rho$ and $\beta$ determined for each of the features in Tables F-1, F-2 and F-3 are shown in Tables 11, 12 and 13 (see Chapter V). Figures F-3 through F-14 show examples of the field data plotted against the CDF curve. 


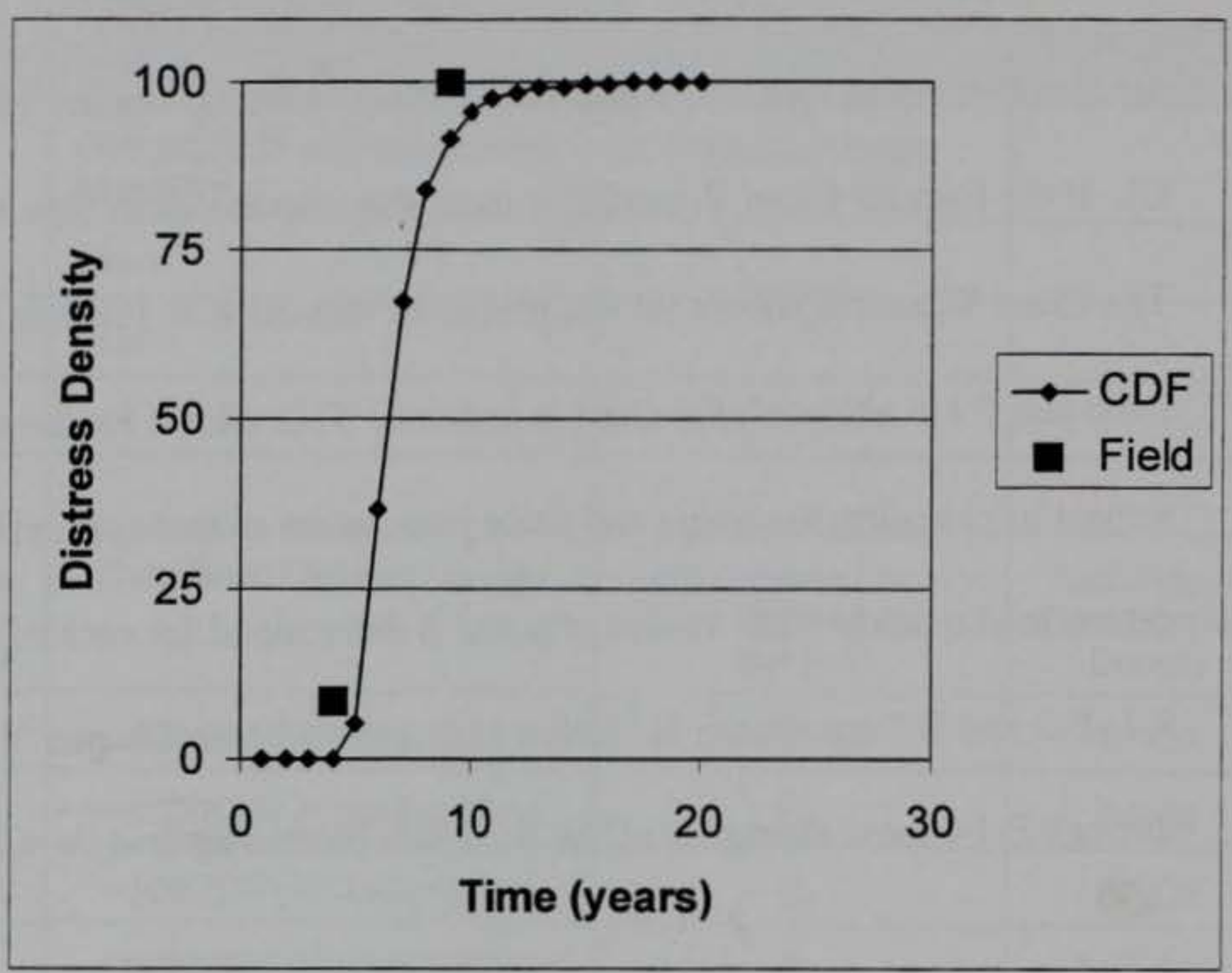

FIG F-3. Biggs AAF, A9E Field Block Cracking Distress Density Data and CDF

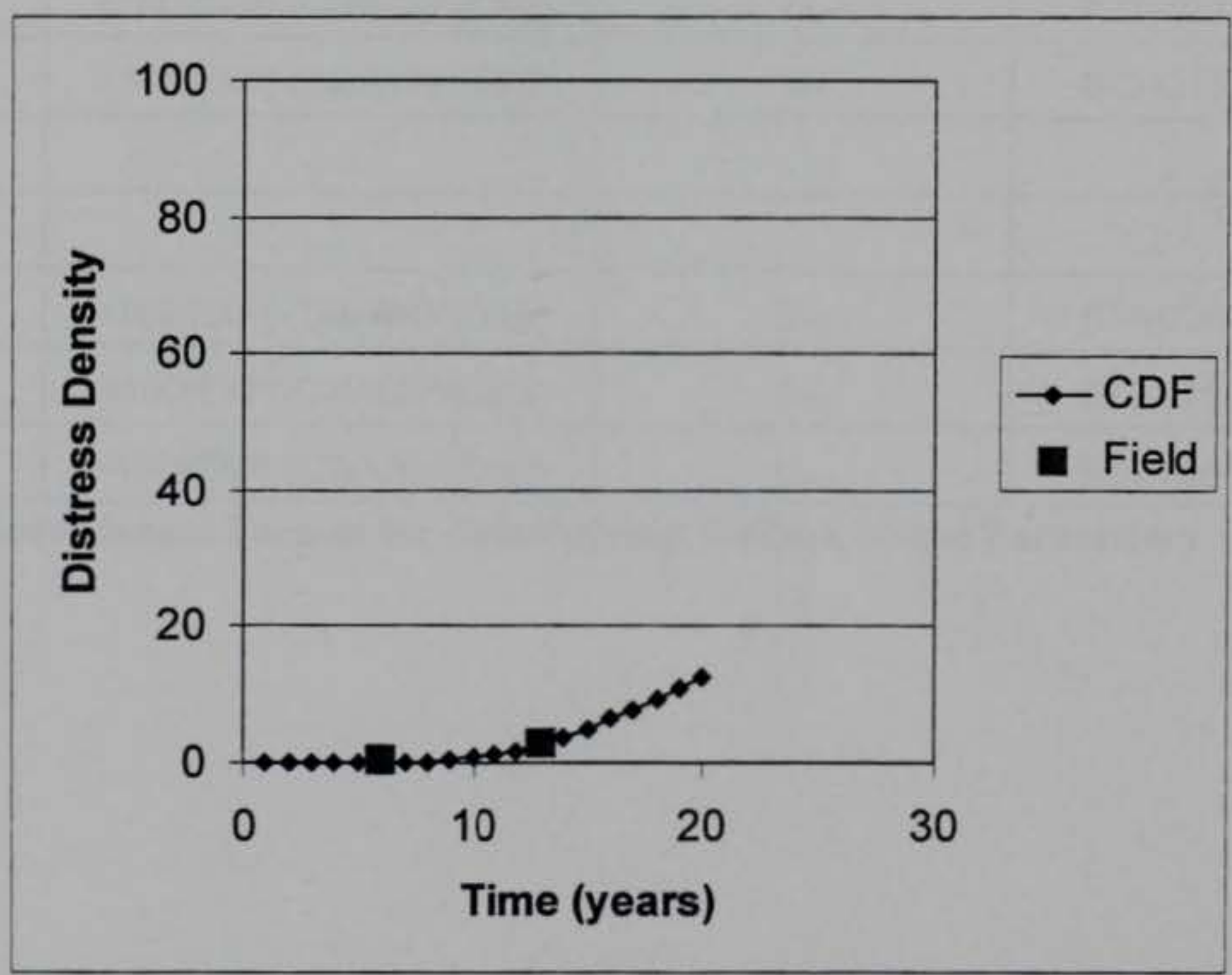

FIG F-4. Cairns AAF, T11E Field Block Cracking Distress Density Data and CDF 


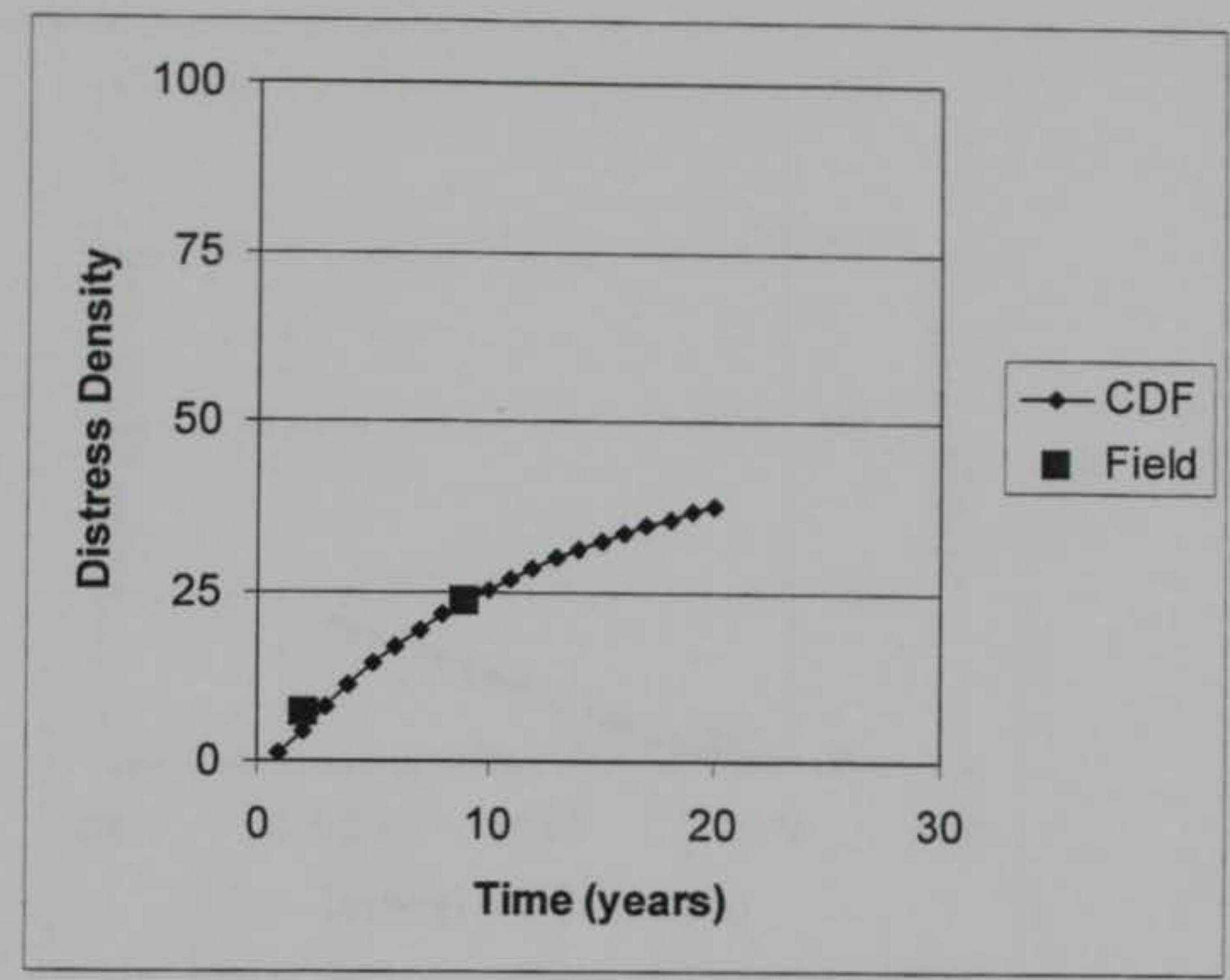

FIG F-5. Hunter AAF, T8E Field Block Cracking Distress Density Data and CDF

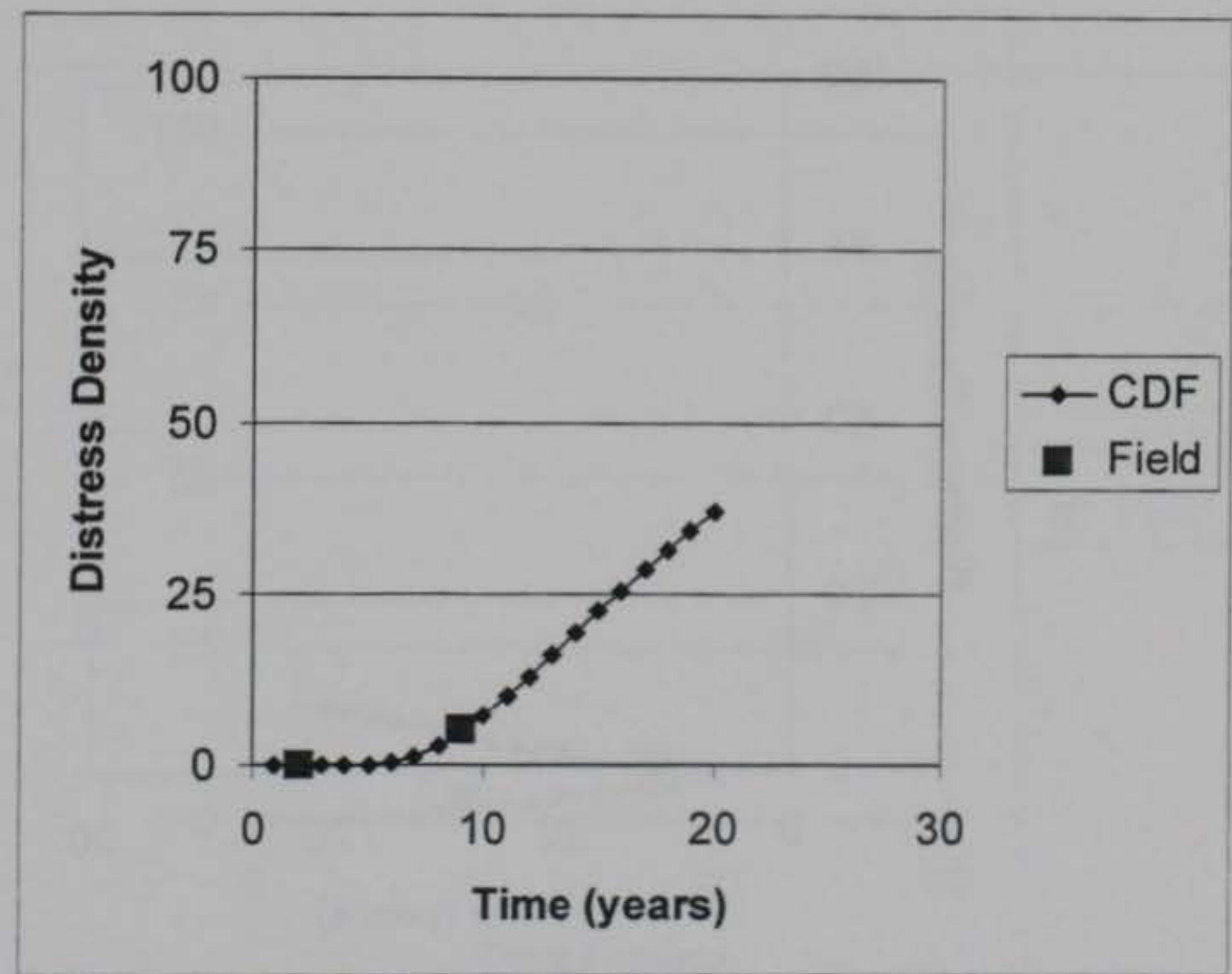

FIG F-6. Hunter AAF, T9E Field Block Cracking Distress Density Data and CDF 


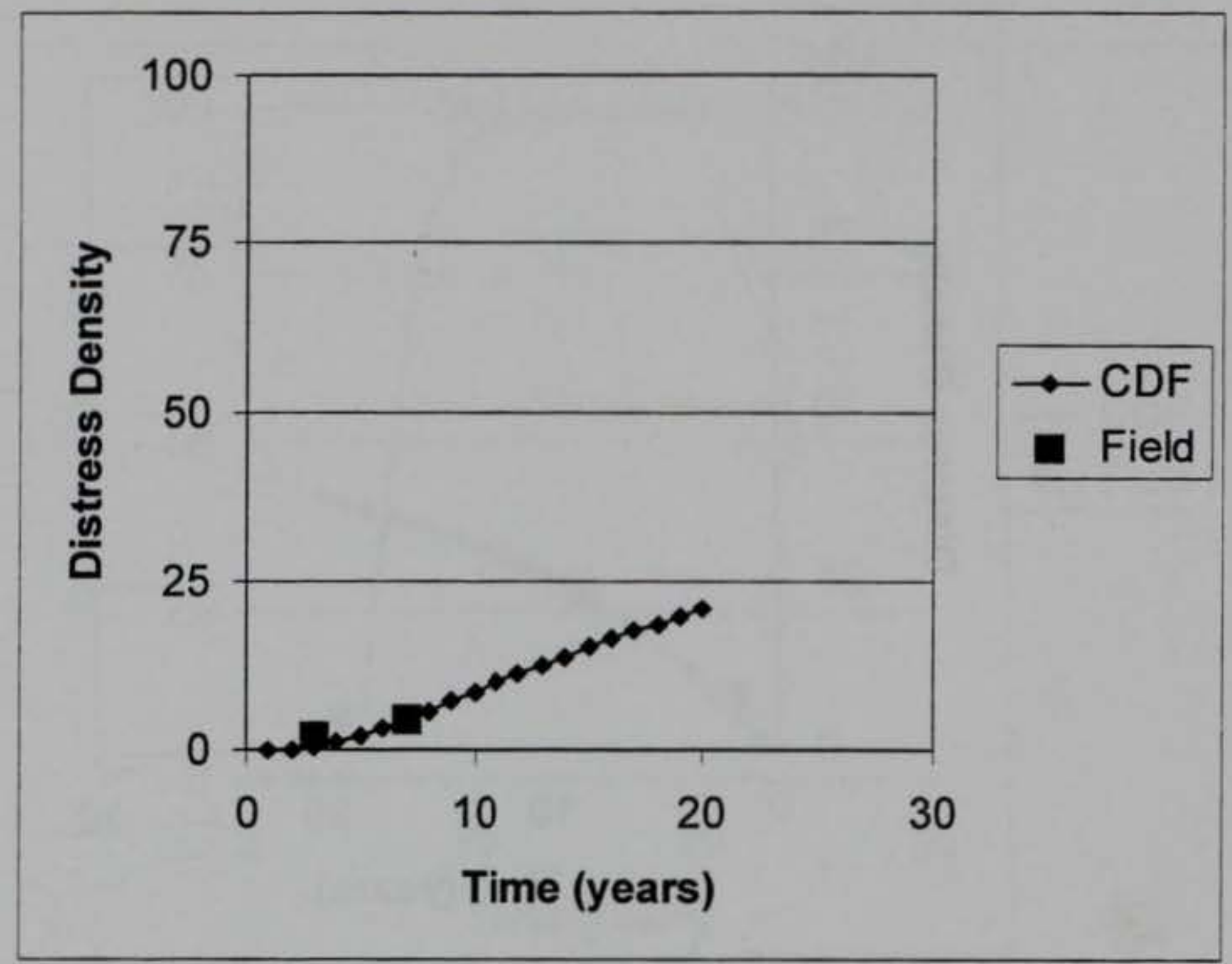

FIG F-7. Butts AAF, R5E Field L/T Cracking Distress Density Data and CDF

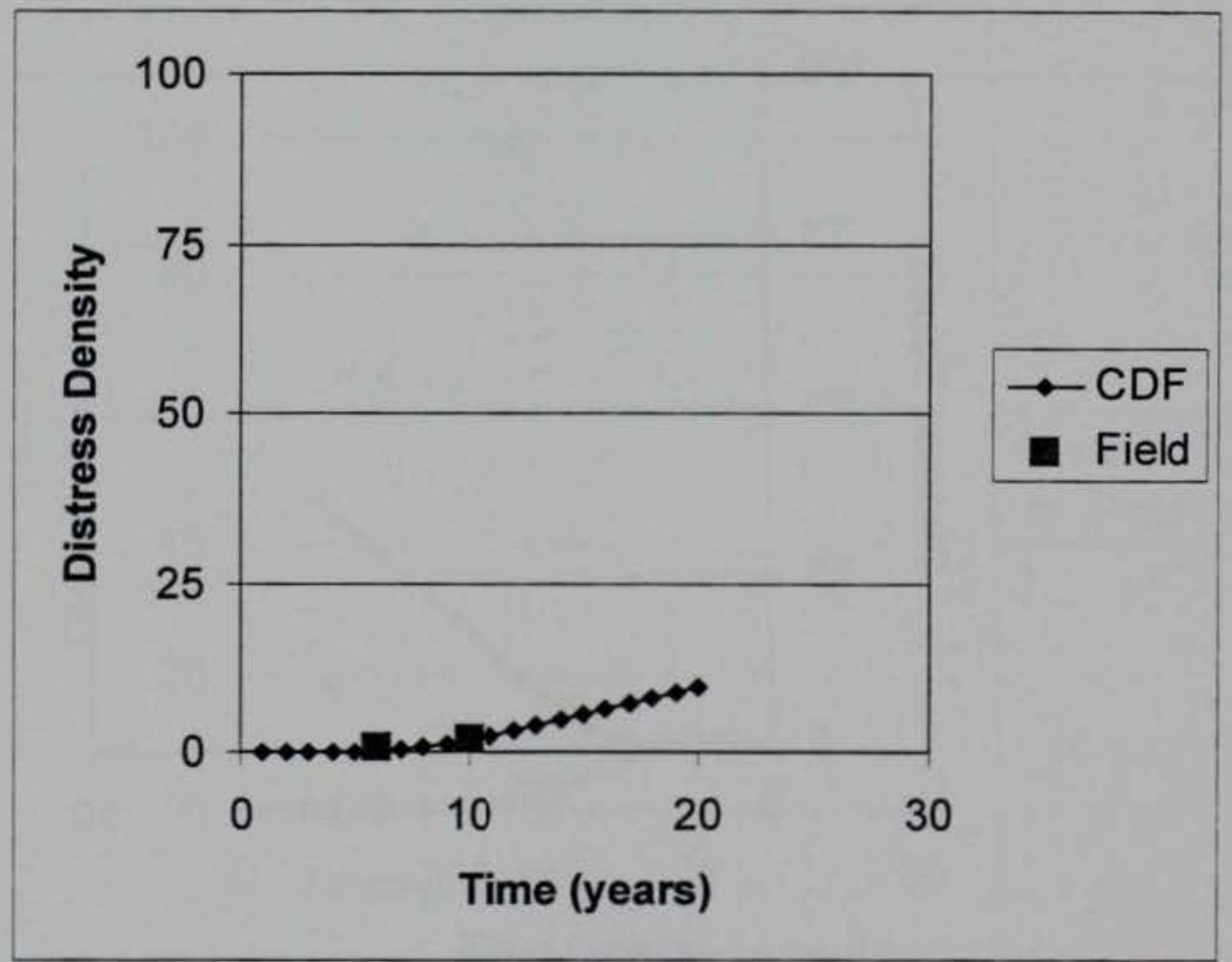

FIG F-8. Cairns AAF, T1E Field L/T Cracking Distress Density and CDF 


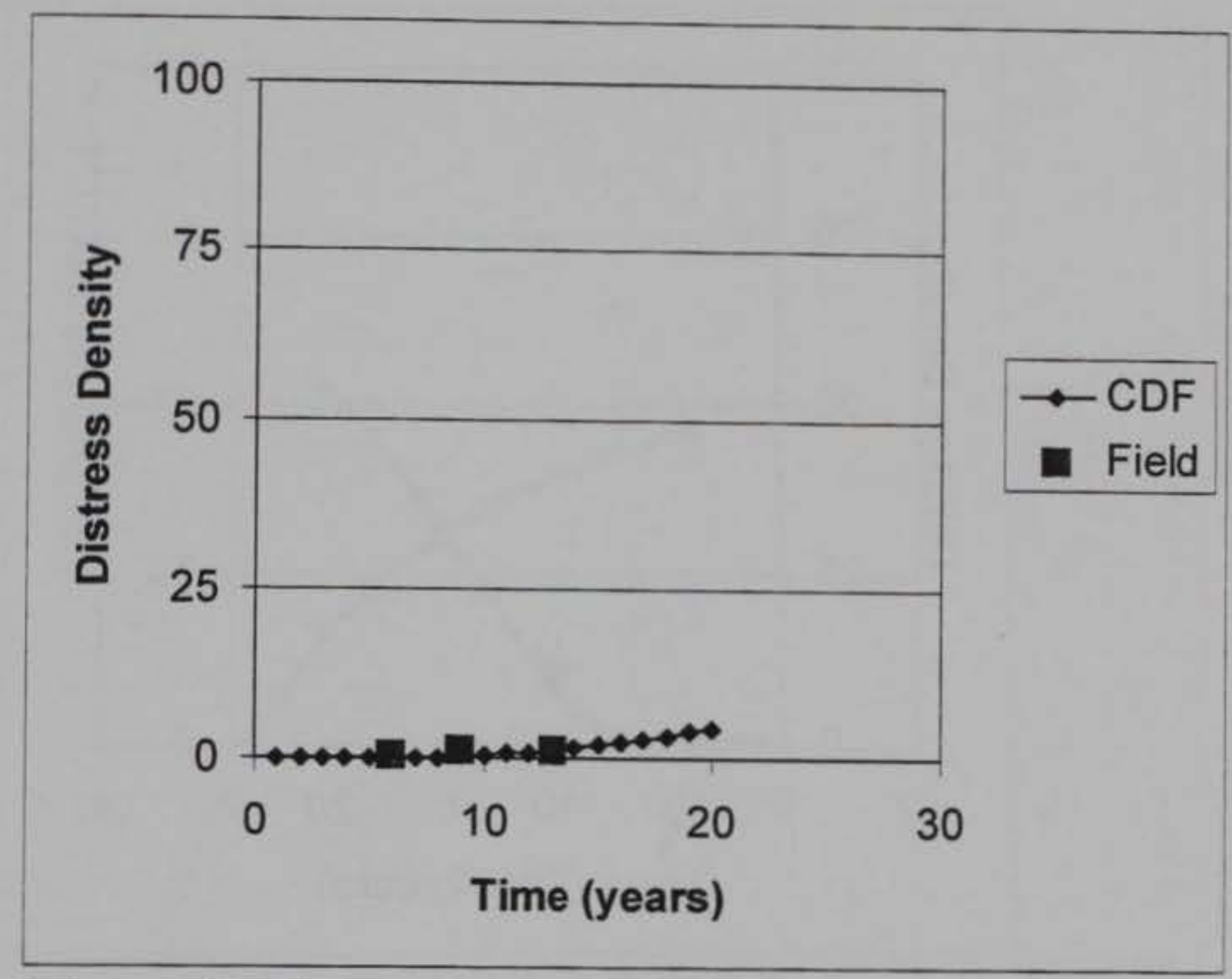

FIG F-9. Cairns AAF, T4E Field L/T Cracking Distress Density and CDF

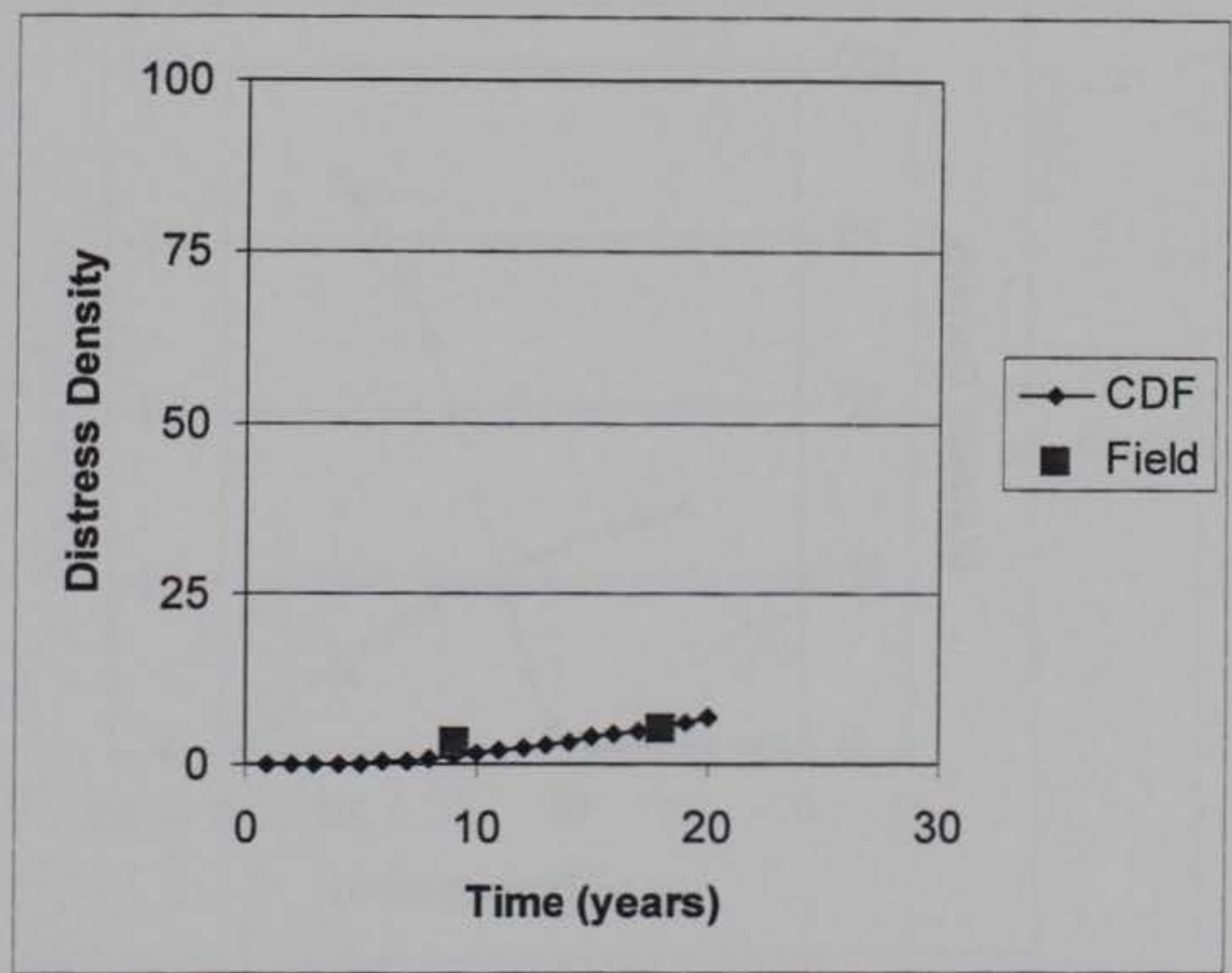

FIG F-10. Selah AAF, A1E Field L/T Cracking Distress Density and CDF 


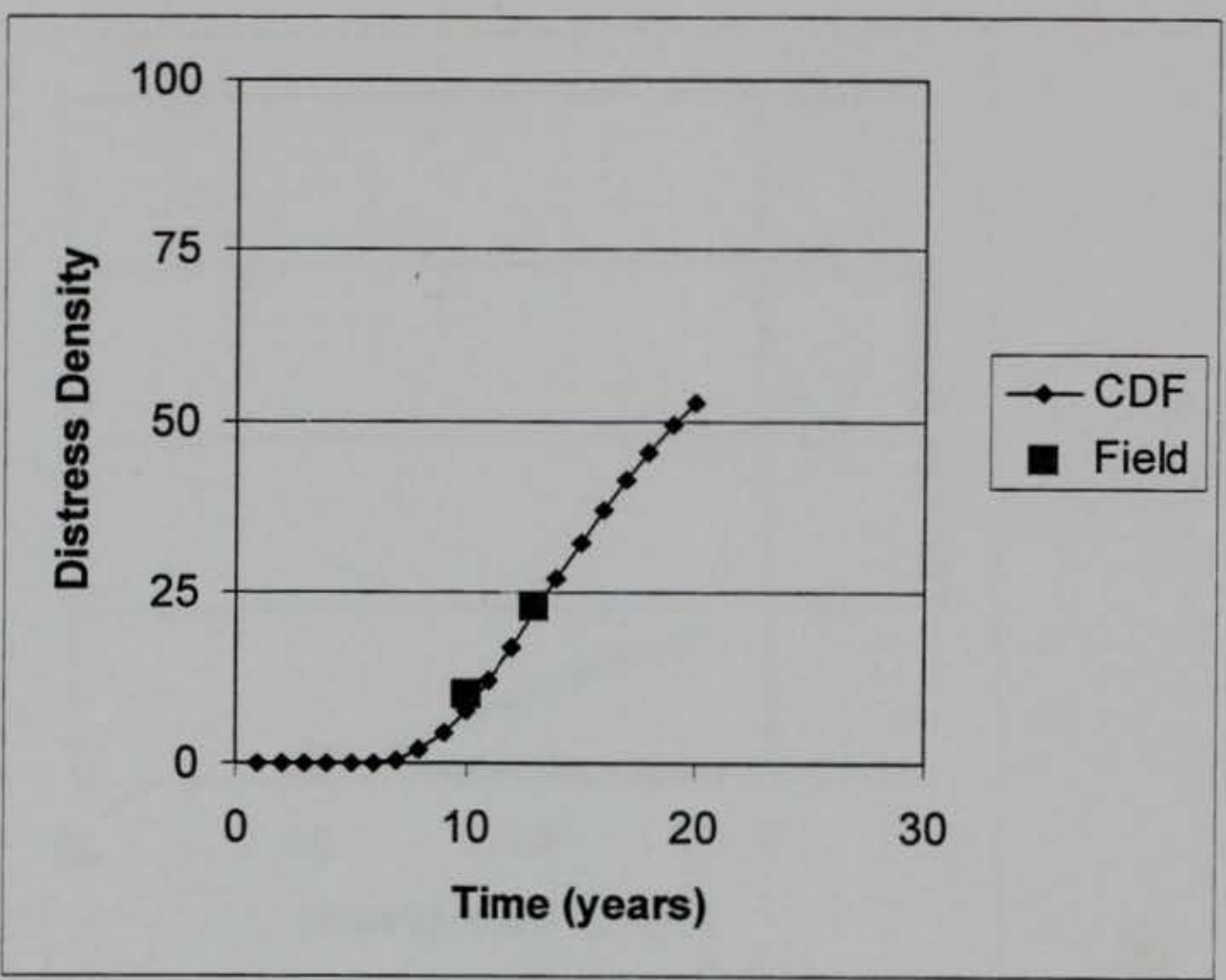

FIG F-11. Cairns AAF, T9E Field R/W Distress Density Data and CDF

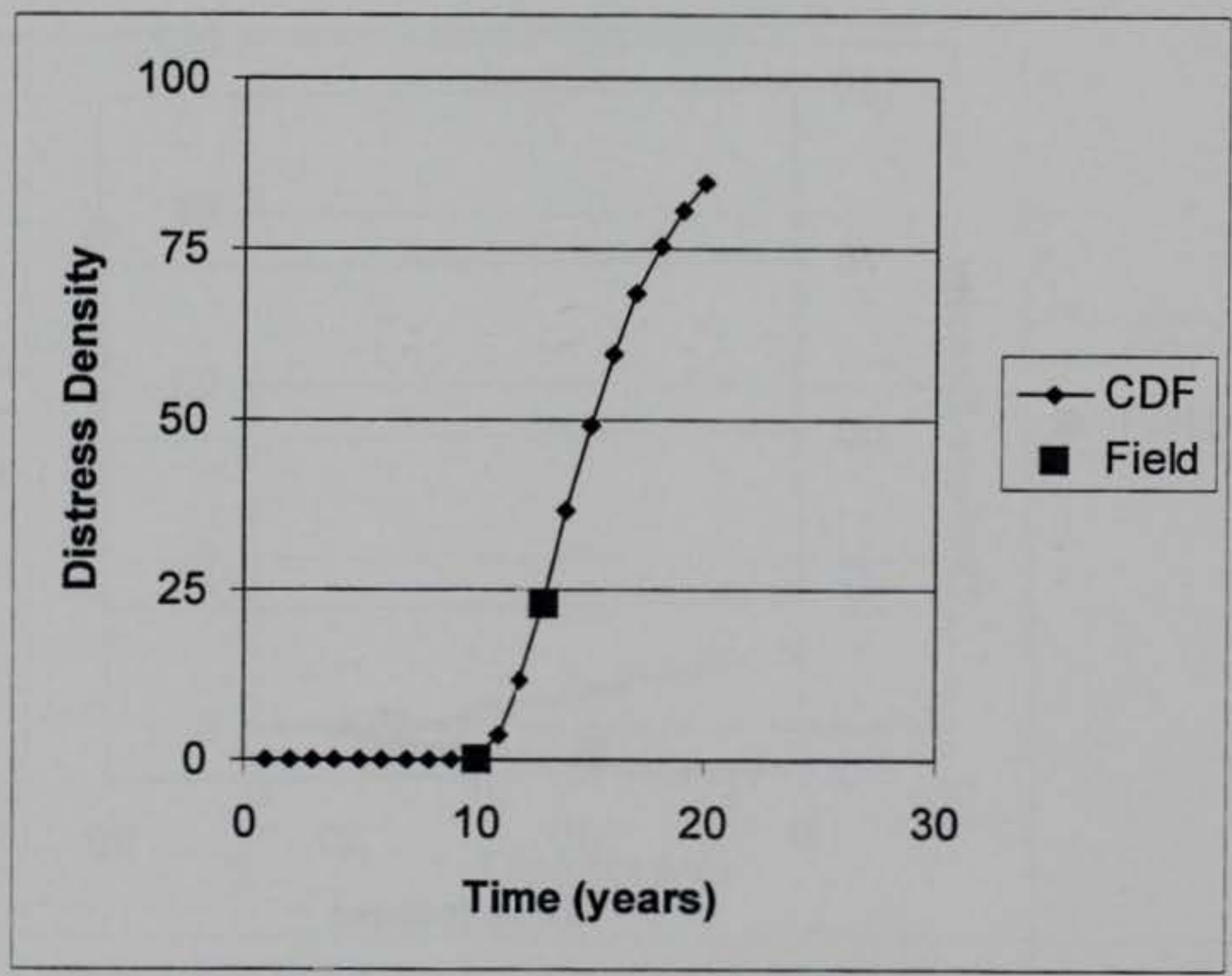

FIG F-12. Cairns AAF, T11E Field R/W Distress Density Data and CDF 


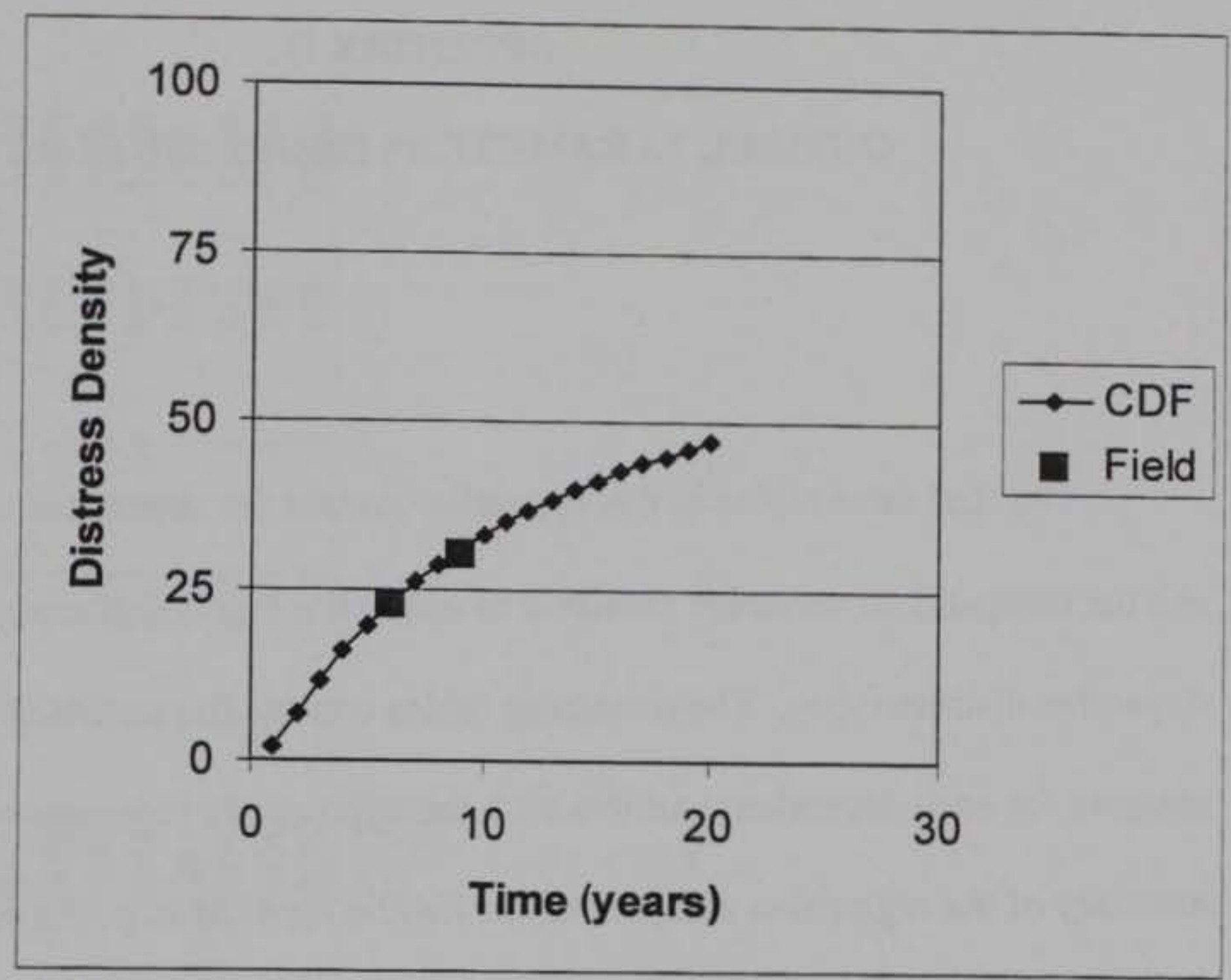

FIG F-13. Cairns AAF, A11E Field R/W Distress Density Data and CDF

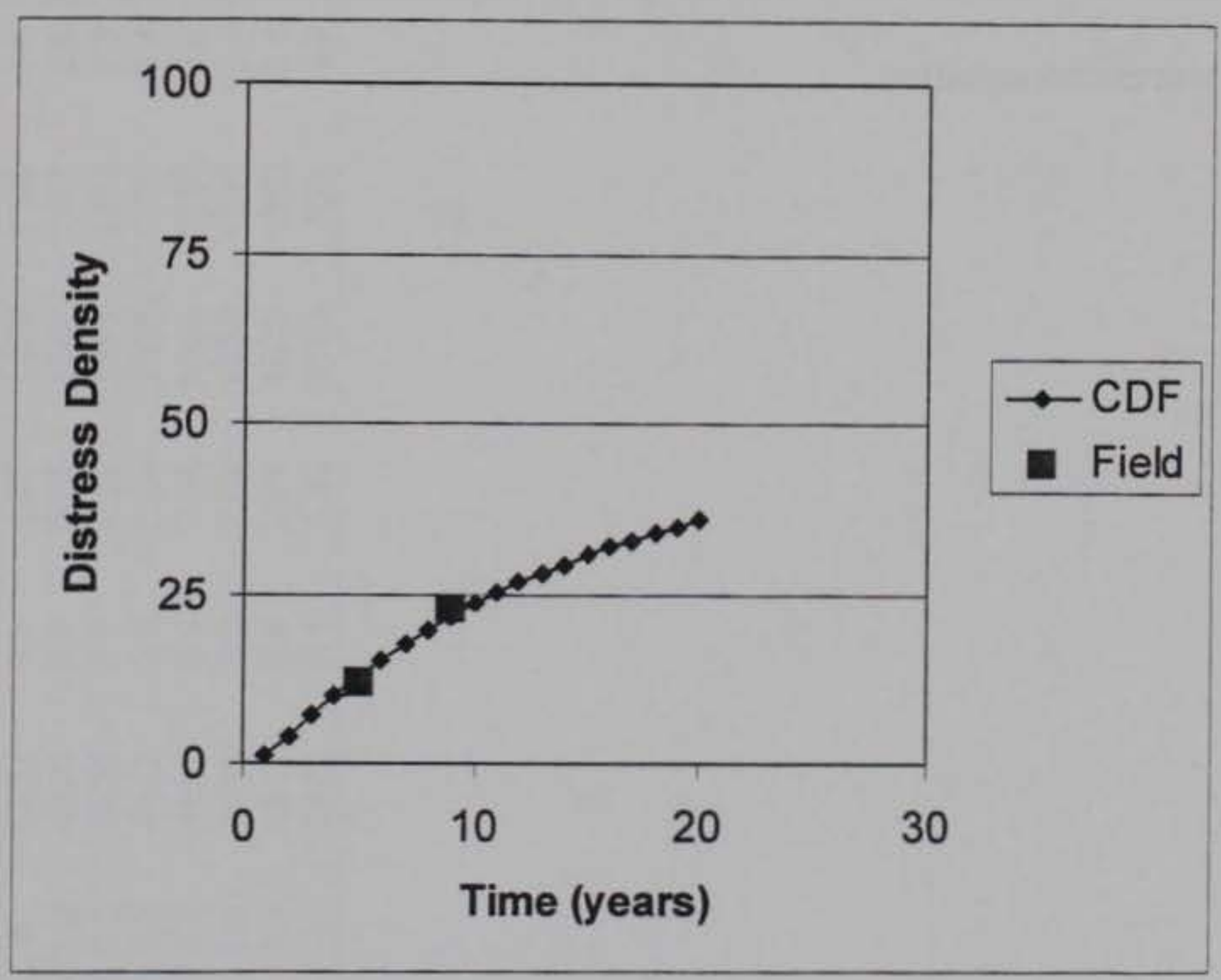

FIG F-14. Hood AAF, T5E Field R/W Distress Density Data and CDF 


\section{APPENDIX G \\ GUMBEL PARAMETERS REGRESSION DATA}

The first three tables in this appendix contain the dependent variables ( $\rho$ and $\beta$ ) and the independent variables available to use in the regression analyses for the respective distress types. The remaining tables contain the results of the regression analyses for each dependent variable with the appropriate independent variables. The summary of the regression analyses tables list the forward step, the independent variables considered, the $\mathrm{P}$-value associated with the independent variable, a recommendation whether to keep the independent variable, and the $\mathrm{R}^{2}$ of the linear regression equation. 
TABLE G-1. Gumbel Parameter Regression Data for Block Cracking

\begin{tabular}{|c|c|c|c|c|c|c|c|c|c|c|c|c|c|c|}
\hline $\begin{array}{c}\rho \\
(1)\end{array}$ & $\begin{array}{c}\beta \\
(2)\end{array}$ & $\begin{array}{l}\text { SR } \\
\text { (3) }\end{array}$ & $\begin{array}{l}\mathrm{SC} \\
\text { (4) }\end{array}$ & $\begin{array}{c}\mathrm{H} 2 \mathrm{O} \\
(5)\end{array}$ & $\begin{array}{l}\text { HDD } \\
\text { (6) }\end{array}$ & $\begin{array}{l}\text { CDD } \\
\text { (7) }\end{array}$ & $\begin{array}{l}\text { WS } \\
\text { (8) }\end{array}$ & $\begin{array}{l}O C \\
\text { (9) }\end{array}$ & $\begin{array}{c}\mathrm{RC} \\
(10)\end{array}$ & $\begin{array}{c}A C \\
\text { (11) }\end{array}$ & $\begin{array}{c}F C \\
\text { (12) }\end{array}$ & $\begin{array}{l}\text { SN } \\
\text { (13) }\end{array}$ & $\begin{array}{c}E L \\
\text { (14) }\end{array}$ & $\begin{array}{c}\text { EP } \\
\text { (15) }\end{array}$ \\
\hline 6 & 6 & 5732 & 3.8 & 1.37 & 1475 & 1180 & 3.4 & 1942 & 1980 & 7.5 & -1 & 1 & 345 & 5700 \\
\hline 25 & 1.2 & 4620 & 5.7 & 2.52 & 1241 & 1273 & 2.9 & 1942 & 1979 & 6 & -1 & -1 & 175 & 1500 \\
\hline 35 & 1.3 & 4620 & 5.7 & 2.52 & 1241 & 1273 & 2.9 & 1942 & 1979 & 6 & -1 & -1 & 175 & 1500 \\
\hline 18 & 1.2 & 4612 & 5.9 & 2.64 & 1038 & 1391 & 3.4 & 1951 & 1984 & 9 & -1 & -1 & 325 & 7000 \\
\hline 20 & 1.2 & 4612 & 5.9 & 2.64 & 1038 & 1391 & 3.4 & 1951 & 1984 & 6 & -1 & -1 & 325 & 7000 \\
\hline 19 & 0.5 & 4612 & 5.9 & 2.64 & 1038 & 1391 & 3.4 & 1951 & 1984 & 6 & -1 & -1 & 325 & 7000 \\
\hline 20 & 1.4 & 4612 & 5.9 & 2.64 & 1038 & 1391 & 3.4 & 1951 & 1984 & 7.5 & -1 & -1 & 325 & 7000 \\
\hline 9 & 6 & 3721 & 7.1 & 1.59 & 3786 & 308 & 4.2 & 1942 & 1976 & 2 & -1 & -1 & 175 & 7200 \\
\hline
\end{tabular}


TABLE G-2. Gumbel Paramter Regression Data for Longitudinal/Transverse Cracking

\begin{tabular}{|c|c|c|c|c|c|c|c|c|c|c|c|c|c|c|}
\hline $\begin{array}{c}\rho \\
(1)\end{array}$ & $\begin{array}{c}\beta \\
(2)\end{array}$ & $\begin{array}{l}\text { SR } \\
\text { (3) }\end{array}$ & $\begin{array}{l}\text { SC } \\
\text { (4) }\end{array}$ & $\begin{array}{c}\mathrm{H} 2 \mathrm{O} \\
(5)\end{array}$ & $\begin{array}{c}\text { HDD } \\
(6)\end{array}$ & $\begin{array}{c}\text { CDD } \\
(7)\end{array}$ & $\begin{array}{l}\text { WS } \\
\text { (8) }\end{array}$ & $\begin{array}{l}\text { OC } \\
(9)\end{array}$ & $\begin{array}{l}\mathrm{RC} \\
(10)\end{array}$ & $\begin{array}{l}\mathrm{AC} \\
(11)\end{array}$ & $\begin{array}{l}\text { FC } \\
(12)\end{array}$ & $\begin{array}{l}\mathrm{SN} \\
(13)\end{array}$ & $\begin{array}{c}E L \\
\text { (14) }\end{array}$ & $\begin{array}{l}\text { EP } \\
(15)\end{array}$ \\
\hline 40 & 0.65 & 4690 & 5.3 & 1.04 & 3524 & 270 & 4.4 & 1959 & 1986 & 8.5 & 1 & -1 & 120 & 12000 \\
\hline 40 & 0.65 & 4690 & 5.3 & 1.04 & 3524 & 270 & 4.4 & 1959 & 1986 & 8.5 & 1 & -1 & 120 & 12000 \\
\hline 40 & 0.65 & 4690 & 5.3 & 1.04 & 3524 & 270 & 4.4 & 1959 & 1986 & 8.5 & 1 & -1 & 120 & 12000 \\
\hline 40 & 0.65 & 4690 & 5.3 & 1.04 & 3524 & 270 & 4.4 & 1959 & 1986 & 8.5 & 1 & -1 & 120 & 12000 \\
\hline 40 & 0.63 & 4690 & 5.3 & 1.04 & 3524 & 270 & 4.4 & 1965 & 1986 & 8.5 & 1 & -1 & 120 & 12000 \\
\hline 60 & 0.77 & 4620 & 5.7 & 2.52 & 1241 & 1273 & 2.9 & 1942 & 1979 & 7.5 & -1 & -1 & 175 & 1500 \\
\hline 60 & 0.77 & 4620 & 5.7 & 2.52 & 1241 & 1273 & 2.9 & 1942 & 1979 & 6 & -1 & -1 & 175 & 1500 \\
\hline 80 & 0.82 & 4620 & 5.7 & 2.52 & 1241 & 1273 & 2.9 & 1942 & 1979 & 6 & -1 & -1 & 175 & 1500 \\
\hline 50 & 0.73 & 4620 & 5.7 & 2.52 & 1241 & 1273 & 2.9 & 1942 & 1979 & 6 & -1 & -1 & 175 & 1500 \\
\hline 50 & 0.82 & 4620 & 5.7 & 2.52 & 1241 & 1273 & 2.9 & 1942 & 1979 & 6 & -1 & -1 & 175 & 1500 \\
\hline 50 & 0.82 & 4620 & 5.7 & 2.52 & 1241 & 1273 & 2.9 & 1942 & 1979 & 6 & -1 & -1 & 175 & 1500 \\
\hline 80 & 0.83 & 4620 & 5.7 & 2.52 & 1241 & 1273 & 2.9 & 1942 & 1979 & 6 & -1 & -1 & 175 & 1500 \\
\hline 60 & 0.76 & 4620 & 5.7 & 2.52 & 1241 & 1273 & 2.9 & 1942 & 1979 & 6 & -1 & -1 & 175 & 1500 \\
\hline 50 & 0.72 & 4620 & 5.7 & 2.52 & 1241 & 1273 & 2.9 & 1942 & 1982 & 7.5 & -1 & -1 & 175 & 1500 \\
\hline 65 & 0.73 & 4620 & 5.7 & 2.52 & 1241 & 1273 & 2.9 & 1942 & 1983 & 3.5 & -1 & 1 & 175 & 1500 \\
\hline 80 & 0.77 & 4620 & 5.7 & 2.52 & 1241 & 1273 & 2.9 & 1982 & 1982 & 2 & -1 & 1 & 175 & 1500 \\
\hline 60 & 0.74 & 4870 & 5.3 & 2.18 & 1193 & 1618 & 5 & 1983 & 1983 & 2 & 1 & 1 & 50 & 28000 \\
\hline 80 & 0.78 & 4870 & 5.3 & 2.18 & 1193 & 1618 & 5 & 1983 & 1983 & 2 & 1 & 1 & 50 & 28000 \\
\hline 60 & 0.74 & 4870 & 5.3 & 2.18 & 1193 & 1618 & 5 & 1984 & 1984 & 4 & 1 & 1 & 50 & 28000 \\
\hline 60 & 0.71 & 4870 & 5.3 & 2.18 & 1193 & 1618 & 5 & 1942 & 1983 & 4 & 1 & 1 & 50 & 28000 \\
\hline 50 & 0.74 & 4612 & 5.9 & 2.64 & 1038 & 1391 & 3.4 & 1951 & 1984 & 7.5 & -1 & -1 & 325 & 7000 \\
\hline 50 & 0.72 & 4612 & 5.9 & 2.64 & 1038 & 1391 & 3.4 & 1941 & 1984 & 10 & -1 & -1 & 325 & 7000 \\
\hline 90 & 0.71 & 4612 & 5.9 & 2.64 & 1038 & 1391 & 3.4 & 1952 & 1984 & 4 & -1 & -1 & 325 & 7000 \\
\hline 60 & 0.73 & 4612 & 5.9 & 2.64 & 1038 & 1391 & 3.4 & 1952 & 1984 & 4 & -1 & -1 & 325 & 7000 \\
\hline 50 & 0.74 & 4612 & 5.9 & 2.64 & 1038 & 1391 & 3.4 & 1952 & 1984 & 4 & -1 & -1 & 325 & 7000 \\
\hline 60 & 0.76 & 4612 & 5.9 & 2.64 & 1038 & 1391 & 3.4 & 1951 & 1984 & 8 & -1 & -1 & 325 & 7000 \\
\hline 55 & 0.75 & 4612 & 5.9 & 2.64 & 1038 & 1391 & 3.4 & 1941 & 1984 & 9 & -1 & -1 & 325 & 7000 \\
\hline 80 & 0.72 & 4048 & 5.9 & 1.87 & 2617 & 696 & 3.9 & 1983 & 1983 & 6 & 1 & -1 & 335 & 8600 \\
\hline 50 & 0.74 & 4048 & 5.9 & 1.87 & 2617 & 696 & 3.9 & 1943 & 1983 & 7 & 1 & -1 & 335 & 8600 \\
\hline 60 & 0.76 & 4048 & 5.9 & 1.87 & 2617 & 696 & 3.9 & 1943 & 1983 & 7 & 1 & -1 & 335 & 8600 \\
\hline 60 & 0.74 & 4048 & 5.9 & 1.87 & 2617 & 696 & 3.9 & 1943 & 1983 & 10.5 & 1 & -1 & 335 & 8600 \\
\hline 80 & 0.75 & 4048 & 5.9 & 1.87 & 2617 & 696 & 3.9 & 1955 & 1983 & 7 & 1 & -1 & 335 & 8600 \\
\hline 100 & 0.6 & 4097 & 5.9 & 1.13 & 3286 & 270 & 3.3 & 1976 & 1976 & 3.5 & -1 & -1 & 155 & 50000 \\
\hline 100 & 0.62 & 4097 & 5.9 & 1.13 & 3286 & 270 & 3.3 & 1976 & 1976 & 2.5 & -1 & -1 & 155 & 50000 \\
\hline 100 & 0.64 & 4395 & 5.8 & 2.13 & 1974 & 839 & 3.5 & 1956 & 1980 & 4.5 & -1 & -1 & 155 & 5500 \\
\hline
\end{tabular}


TABLE G-3. Gumbel Parameter Regression Data for Raveling/Weathering

\begin{tabular}{|c|c|c|c|c|c|c|c|c|c|c|c|c|c|c|}
\hline $\begin{array}{c}\rho \\
(1)\end{array}$ & $\begin{array}{c}\beta \\
(2)\end{array}$ & $\begin{array}{l}\text { SR } \\
\text { (3) }\end{array}$ & $\begin{array}{l}\text { SC } \\
\text { (4) }\end{array}$ & $\begin{array}{c}\mathrm{H} 2 \mathrm{O} \\
(5)\end{array}$ & $\begin{array}{l}\text { HDD } \\
(6)\end{array}$ & $\begin{array}{l}\text { CDD } \\
\text { (7) }\end{array}$ & $\begin{array}{l}\text { WS } \\
\text { (8) }\end{array}$ & $\begin{array}{l}\mathrm{OC} \\
\text { (9) }\end{array}$ & $\begin{array}{l}\text { RC } \\
\text { (10) }\end{array}$ & $\begin{array}{l}\mathrm{AC} \\
(11)\end{array}$ & $\begin{array}{l}\mathrm{FC} \\
\text { (12) }\end{array}$ & $\begin{array}{c}\text { SN } \\
(13)\end{array}$ & $\begin{array}{c}\mathrm{EL} \\
\text { (14) }\end{array}$ & $\begin{array}{c}\text { EP } \\
(15)\end{array}$ \\
\hline 15 & 3 & 4620 & 5.7 & 2.52 & 1241 & 1273 & 2.9 & 1942 & 1979 & 6 & -1 & -1 & 175 & 1500 \\
\hline 16 & 2 & 4620 & 5.7 & 2.52 & 1241 & 1273 & 2.9 & 1942 & 1979 & 6 & -1 & -1 & 175 & 1500 \\
\hline 15 & 3 & 4620 & 5.7 & 2.52 & 1241 & 1273 & 2.9 & 1942 & 1979 & 6 & -1 & -1 & 175 & 1500 \\
\hline 14 & 5 & 4620 & 5.7 & 2.52 & 1241 & 1273 & 2.9 & 1942 & 1979 & 6 & -1 & -1 & 175 & 1500 \\
\hline 12 & 0.55 & 4620 & 5.7 & 2.52 & 1241 & 1273 & 2.9 & 1942 & 1983 & 3.5 & -1 & 1 & 175 & 1500 \\
\hline 13 & 1.5 & 4870 & 5.3 & 2.18 & 1193 & 1618 & 5 & 1983 & 1983 & 2 & 1 & 1 & 50 & 28000 \\
\hline 28 & 0.6 & 4870 & 5.3 & 2.18 & 1193 & 1618 & 5 & 1942 & 1978 & 5 & 1 & 1 & 50 & 28000 \\
\hline 21 & 0.5 & 4870 & 5.3 & 2.18 & 1193 & 1618 & 5 & 1942 & 1983 & 2 & 1 & 1 & 50 & 28000 \\
\hline
\end{tabular}


TABLE G-4. Summary of Stepwise Regression for Gumbel $\rho$, Block Cracking Distress Type

\begin{tabular}{|c|c|c|c|c|}
\hline Step & $\begin{array}{l}\text { Independent } \\
\text { Variable } \\
\text { (2) }\end{array}$ & $\begin{array}{l}\text { P-Value } \\
\text { (3) }\end{array}$ & $\begin{array}{l}\text { Recommended } \\
\text { Action } \\
\text { (4) }\end{array}$ & $R^{2}$ \\
\hline$\frac{11}{1}$ & WS & .0318 & KEEP & 56 \\
\hline 2 & $\begin{array}{l}\text { WS } \\
\text { H2O }\end{array}$ & $\begin{array}{l}.1305 \\
.1461\end{array}$ & $\begin{array}{c}\text { KEEP } \\
\text { REMOVE }\end{array}$ & 73 \\
\hline 3 & $\begin{array}{l}\text { WS } \\
\text { SN }\end{array}$ & $\begin{array}{l}.0047 \\
.0135\end{array}$ & $\begin{array}{l}\text { KEEP } \\
\text { KEEP }\end{array}$ & 88 \\
\hline 4 & $\begin{array}{l}\text { WS } \\
\text { SN } \\
\text { CDD }\end{array}$ & $\begin{array}{l}.0179 \\
.0207 \\
.3912\end{array}$ & $\begin{array}{c}\text { KEEP } \\
\text { KEEP } \\
\text { REMOVE }\end{array}$ & 91 \\
\hline 5 & $\begin{array}{l}\text { WS } \\
\text { SN } \\
\text { SC }\end{array}$ & $\begin{array}{l}.0557 \\
.8682 \\
3912\end{array}$ & $\begin{array}{c}\text { KEEP } \\
\text { REMOVE } \\
\text { KEEP }\end{array}$ & 91 \\
\hline 6 & $\begin{array}{l}\text { WS } \\
\text { SC }\end{array}$ & $\begin{array}{l}.0081 \\
.0080\end{array}$ & $\begin{array}{l}\text { KEEP } \\
\text { KEEP }\end{array}$ & 91 \\
\hline 7 & $\begin{array}{l}\text { WS } \\
\text { SC } \\
\text { AC }\end{array}$ & $\begin{array}{l}.0045 \\
.0310 \\
.7632\end{array}$ & $\begin{array}{c}\text { KEEP } \\
\text { KEEP } \\
\text { REMOVE }\end{array}$ & 91 \\
\hline 8 & $\begin{array}{l}\text { WS } \\
\text { SC } \\
\text { RC }\end{array}$ & $\begin{array}{l}.0038 \\
.0189 \\
8682\end{array}$ & $\begin{array}{c}\text { KEEP } \\
\text { KEEP } \\
\text { RFMOVF }\end{array}$ & 91 \\
\hline 9 & $\begin{array}{l}\text { WS } \\
\text { SC } \\
\text { OC }\end{array}$ & $\begin{array}{l}.0037 \\
.0192 \\
.8682\end{array}$ & $\begin{array}{l}\text { KEEP } \\
\text { KEEP } \\
\text { REMOVE }\end{array}$ & 91 \\
\hline 10 & $\begin{array}{l}\mathrm{H} 2 \mathrm{O} \\
\text { WS } \\
\text { SC }\end{array}$ & $\begin{array}{l}.8682 \\
.0174 \\
.0499 \\
\end{array}$ & $\begin{array}{l}\text { REMOVE } \\
\text { KEEP } \\
\text { KEEP }\end{array}$ & 91 \\
\hline
\end{tabular}

Note: Step 10 used $\mathrm{H} 2 \mathrm{O}$ based on results from the $\beta$ regression. 
TABLE G-5. Summary of Stepwise Regression for Gumbel $\beta$, Block Cracking Distress Type

\begin{tabular}{|c|c|c|c|c|}
\hline $\begin{array}{l}\text { Step } \\
\text { (1) }\end{array}$ & $\begin{array}{l}\text { Independent } \\
\text { Variable } \\
\text { (2) }\end{array}$ & $\begin{array}{c}\text { P-Value } \\
\text { (3) }\end{array}$ & $\begin{array}{l}\text { Recommended } \\
\text { Action } \\
\text { (4) }\end{array}$ & $\mathrm{R}^{2}$ \\
\hline 1 & $\mathrm{H} 2 \mathrm{O}$ & .0000 & KEEP & 97 \\
\hline 2 & $\begin{array}{l}\mathrm{H} 2 \mathrm{O} \\
\mathrm{CDD}\end{array}$ & $\begin{array}{l}.0001 \\
.1480 \\
\end{array}$ & $\begin{array}{c}\text { KEEP } \\
\text { REMOVE }\end{array}$ & 98 \\
\hline 3 & $\begin{array}{l}\mathrm{H} 2 \mathrm{O} \\
\mathrm{RC}\end{array}$ & $\begin{array}{l}.0002 \\
.9374 \\
\end{array}$ & $\begin{array}{c}\text { KEEP } \\
\text { REMOVE }\end{array}$ & 97 \\
\hline 4 & $\begin{array}{l}\mathrm{H} 2 \mathrm{O} \\
\mathrm{SN}\end{array}$ & $\begin{array}{l}.0001 \\
.1517 \\
\end{array}$ & $\begin{array}{c}\text { KEEP } \\
\text { REMOVE }\end{array}$ & 98 \\
\hline 5 & $\begin{array}{l}\mathrm{H} 2 \mathrm{O} \\
\text { WS }\end{array}$ & $\begin{array}{l}.0000 \\
.0655 \\
\end{array}$ & $\begin{array}{l}\text { KEEP } \\
\text { KEEP }\end{array}$ & 99 \\
\hline 6 & $\begin{array}{l}\mathrm{H} 2 \mathrm{O} \\
\mathrm{WS} \\
\mathrm{OC}\end{array}$ & $\begin{array}{l}.0018 \\
.1104 \\
.5974 \\
\end{array}$ & $\begin{array}{c}\text { KEEP } \\
\text { KEEP } \\
\text { REMOVE }\end{array}$ & 99 \\
\hline 7 & $\begin{array}{l}\mathrm{H} 2 \mathrm{O} \\
\text { WS } \\
\mathrm{AC}\end{array}$ & $\begin{array}{l}.0002 \\
.1259 \\
.9365 \\
\end{array}$ & $\begin{array}{c}\text { KEEP } \\
\text { KEEP } \\
\text { REMOVE }\end{array}$ & 99 \\
\hline 8 & $\begin{array}{l}\mathrm{H} 2 \mathrm{O} \\
\text { WS } \\
\mathrm{SC}\end{array}$ & $\begin{array}{l}.0066 \\
.3747 \\
.5974 \\
\end{array}$ & $\begin{array}{c}\text { KEEP } \\
\text { KEEP } \\
\text { REMOVE }\end{array}$ & 99 \\
\hline
\end{tabular}

Note: Step 8 used SC based on results from the $\rho$ regression. 
TABLE G-6. Summary of Stepwise Regression for Gumbel $\rho$, Longitudina//Transverse Cracking Distress Type

\begin{tabular}{|c|c|c|c|c|}
\hline $\begin{array}{l}\text { Step } \\
\text { (1) }\end{array}$ & $\begin{array}{l}\text { Independent } \\
\text { Variable } \\
\text { (2) }\end{array}$ & $\begin{array}{c}\text { P-Value } \\
\text { (3) }\end{array}$ & $\begin{array}{l}\text { Recommended } \\
\text { Action } \\
\text { (4) }\end{array}$ & $\begin{array}{l}\mathrm{R}^{2} \\
(5)\end{array}$ \\
\hline 1 & $A C$ & .0002 & KEEP & 36 \\
\hline 2 & $\begin{array}{l}\mathrm{AC} \\
\mathrm{RC}\end{array}$ & $\begin{array}{l}.0025 \\
.0060\end{array}$ & $\begin{array}{l}\text { KEEP } \\
\text { KEEP }\end{array}$ & 49 \\
\hline 3 & $\begin{array}{l}\mathrm{AC} \\
\mathrm{RC} \\
\mathrm{SC}\end{array}$ & $\begin{array}{l}.0006 \\
.0827 \\
.0140 \\
\end{array}$ & $\begin{array}{l}\text { KEEP } \\
\text { KEEP } \\
\text { KEEP }\end{array}$ & 58 \\
\hline 4 & $\begin{array}{l}\text { AC } \\
\text { RC } \\
\text { SC } \\
\text { EP }\end{array}$ & $\begin{array}{l}.0026 \\
.1122 \\
.0043 \\
.0662\end{array}$ & $\begin{array}{c}\text { KEEP } \\
\text { REMOVE } \\
\text { KEEP } \\
\text { KEEP }\end{array}$ & 63 \\
\hline 5 & $\begin{array}{l}\text { AC } \\
\text { SC } \\
\text { EP }\end{array}$ & $\begin{array}{l}.0003 \\
.0003 \\
.0485\end{array}$ & $\begin{array}{l}\text { KEEP } \\
\text { KEEP } \\
\text { KEEP }\end{array}$ & 60 \\
\hline 6 & $\begin{array}{l}A C \\
\text { SC } \\
\text { EP } \\
\text { OC }\end{array}$ & $\begin{array}{l}.0021 \\
.0002 \\
.2211 \\
.2998 \\
\end{array}$ & $\begin{array}{c}\text { KEEP } \\
\text { KEEP } \\
\text { KEEP } \\
\text { REMOVE }\end{array}$ & 61 \\
\hline 7 & $\begin{array}{l}\text { AC } \\
\text { SC } \\
\text { EP } \\
\text { FC }\end{array}$ & $\begin{array}{l}.0009 \\
.0019 \\
.0726 \\
.9437 \\
\end{array}$ & $\begin{array}{c}\text { KEEP } \\
\text { KEEP } \\
\text { KEEP } \\
\text { REMOVE }\end{array}$ & 60 \\
\hline 8 & $\begin{array}{l}\text { AC } \\
\text { SC } \\
\text { EP } \\
\text { WS }\end{array}$ & $\begin{array}{l}.0009 \\
.0105 \\
.0603 \\
.6743\end{array}$ & $\begin{array}{c}\text { KEEP } \\
\text { KEEP } \\
\text { KEEP } \\
\text { REMOVE }\end{array}$ & 60 \\
\hline 9 & $\begin{array}{l}\text { AC } \\
\text { SC } \\
\text { EP } \\
\text { EN }\end{array}$ & $\begin{array}{l}.0022 \\
.0015 \\
.0570 \\
.6105 \\
\end{array}$ & $\begin{array}{c}\text { KEEP } \\
\text { KEEP } \\
\text { KEEP } \\
\text { REMOVE }\end{array}$ & 60 \\
\hline 10 & $\begin{array}{l}\text { AC } \\
\text { SP } \\
\text { EP } \\
\mathrm{H} 2 \mathrm{O} \\
\end{array}$ & $\begin{array}{l}.0004 \\
.0002 \\
.4741 \\
.2452 \\
\end{array}$ & $\begin{array}{c}\text { KEEP } \\
\text { KEEP } \\
\text { REMOVE } \\
\text { KEEP }\end{array}$ & 61 \\
\hline 11 & $\begin{array}{l}\mathrm{AC} \\
\mathrm{SC} \\
\mathrm{H} 2 \mathrm{O}\end{array}$ & $\begin{array}{l}.0000 \\
.0001 \\
.0292\end{array}$ & $\begin{array}{l}\text { KEEP } \\
\text { KEEP } \\
\text { KEEP }\end{array}$ & 61 \\
\hline 12 & $\begin{array}{l}\mathrm{AC} \\
\mathrm{SC} \\
\mathrm{H} 2 \mathrm{O} \\
\mathrm{CDD}\end{array}$ & $\begin{array}{l}.0000 \\
.0073 \\
.4681 \\
.8789\end{array}$ & $\begin{array}{c}\text { KEEP } \\
\text { KEEP } \\
\text { KEEP } \\
\text { REMOVE }\end{array}$ & 61 \\
\hline 13 & $\begin{array}{c}\mathrm{AC} \\
\mathrm{SC} \\
\mathrm{H} 2 \mathrm{O} \\
\mathrm{EL}\end{array}$ & $\begin{array}{l}.0008 \\
.0002 \\
.0323 \\
.0339 \\
\end{array}$ & $\begin{array}{l}\text { KEEP } \\
\text { KEEP } \\
\text { KEEP } \\
\text { KEEP }\end{array}$ & 66 \\
\hline 14 & $\begin{array}{c}\mathrm{SC} \\
\mathrm{H} 2 \mathrm{O} \\
\mathrm{EL} \\
\mathrm{FC} \\
\mathrm{RC}\end{array}$ & $\begin{array}{l}.0001 \\
.6785 \\
.0003 \\
.0156 \\
.1122 \\
\end{array}$ & $\begin{array}{c}\text { KEEP } \\
\text { REMOVE } \\
\text { KEEP } \\
\text { KEEP } \\
\text { KEEP } \\
\end{array}$ & 62 \\
\hline
\end{tabular}

Note: Step 14 used FC and RC based on results from the $\beta$ regression. 
TABLE G-7. Summary of Stepwise Regression for Gumbel $\beta$, Longitudinal/Transverse Cracking Distress Type

\begin{tabular}{|c|c|c|c|c|}
\hline $\begin{array}{l}\text { Step } \\
\text { (1) }\end{array}$ & $\begin{array}{l}\text { Independent } \\
\text { Variable } \\
\text { (2) }\end{array}$ & $\begin{array}{c}\text { P-Value } \\
\text { (3) }\end{array}$ & $\begin{array}{l}\text { Recommended } \\
\text { Action } \\
\text { (4) }\end{array}$ & $\begin{array}{l}\mathrm{R}^{2} \\
(5)\end{array}$ \\
\hline 1 & $\mathrm{H} 2 \mathrm{O}$ & .0000 & KEEP & 57 \\
\hline 2 & $\begin{array}{l}\mathrm{H} 2 \mathrm{O} \\
\mathrm{CDD}\end{array}$ & $\begin{array}{l}.0143 \\
7995\end{array}$ & $\begin{array}{c}\text { KEEP } \\
\text { RFMOVF }\end{array}$ & 58 \\
\hline 3 & $\begin{array}{l}\mathrm{H} 20 \\
\mathrm{EP}\end{array}$ & $\begin{array}{l}.0000 \\
.1567 \\
\end{array}$ & $\begin{array}{l}\text { KEEP } \\
\text { REMOVE }\end{array}$ & 60 \\
\hline 4 & $\begin{array}{l}\mathrm{H} 2 \mathrm{O} \\
\mathrm{OC}\end{array}$ & $\begin{array}{l}.0000 \\
.6173 \\
\end{array}$ & $\begin{array}{c}\text { KEEP } \\
\text { REMOVE }\end{array}$ & 58 \\
\hline 5 & $\begin{array}{l}\mathrm{H} 2 \mathrm{O} \\
\text { WS }\end{array}$ & $\begin{array}{l}.0000 \\
.7165\end{array}$ & $\begin{array}{c}\text { KEEP } \\
\text { REMOVE }\end{array}$ & 58 \\
\hline 6 & $\begin{array}{l}\mathrm{H} 2 \mathrm{O} \\
\mathrm{FC}\end{array}$ & $\begin{array}{l}.0000 \\
.0157 \\
\end{array}$ & $\begin{array}{l}\text { KEEP } \\
\text { KEEP }\end{array}$ & 65 \\
\hline 7 & $\begin{array}{l}\mathrm{H} 2 \mathrm{O} \\
\mathrm{FC} \\
\mathrm{RC}\end{array}$ & $\begin{array}{l}.0000 \\
.0006 \\
.0114\end{array}$ & $\begin{array}{l}\text { KEEP } \\
\text { KEEP } \\
\text { KEEP }\end{array}$ & 72 \\
\hline 8 & $\begin{array}{l}\mathrm{H} 2 \mathrm{O} \\
\mathrm{FC} \\
\mathrm{RC} \\
\mathrm{SC}\end{array}$ & $\begin{array}{l}.0000 \\
.0016 \\
.0116 \\
.6530\end{array}$ & $\begin{array}{c}\text { KEEP } \\
\text { KEEP } \\
\text { KEEP } \\
\text { REMOVE }\end{array}$ & 72 \\
\hline 9 & $\begin{array}{l}\mathrm{H} 2 \mathrm{O} \\
\mathrm{FC} \\
\mathrm{RC} \\
\mathrm{EL}\end{array}$ & $\begin{array}{l}.0000 \\
.0007 \\
.0131 \\
.7299\end{array}$ & $\begin{array}{c}\text { KEEP } \\
\text { KEEP } \\
\text { KEEP } \\
\text { REMOVE }\end{array}$ & 72 \\
\hline 10 & $\begin{array}{l}\mathrm{H} 2 \mathrm{O} \\
\mathrm{FC} \\
\mathrm{RC} \\
\mathrm{SN}\end{array}$ & $\begin{array}{l}.0000 \\
.0003 \\
.0076 \\
.1800\end{array}$ & $\begin{array}{l}\text { KEEP } \\
\text { KEEP } \\
\text { KEEP } \\
\text { REMOVE }\end{array}$ & 73 \\
\hline 11 & $\begin{array}{l}\mathrm{H} 2 \mathrm{O} \\
\mathrm{FC} \\
\mathrm{RC} \\
\mathrm{AC}\end{array}$ & $\begin{array}{l}.0000 \\
.0002 \\
.0027 \\
.0748 \\
\end{array}$ & $\begin{array}{l}\text { KEEP } \\
\text { KEEP } \\
\text { KEEP } \\
\text { KEEP }\end{array}$ & 75 \\
\hline 12 & $\begin{array}{l}\mathrm{H} 2 \mathrm{O} \\
\mathrm{FC} \\
\mathrm{RC} \\
\mathrm{SC} \\
\mathrm{EL}\end{array}$ & $\begin{array}{l}.0000 \\
.0396 \\
.0000 \\
.0002 \\
.0002\end{array}$ & $\begin{array}{l}\text { KEEP } \\
\text { KEEP } \\
\text { KEEP } \\
\text { KEEP } \\
\text { KEEP }\end{array}$ & 83 \\
\hline
\end{tabular}

Note: Step 12 used SC and EL based on results from the $\rho$ regression. 
264

TABLE G-8. Summary of Stepwise Regression for Gumbel $\rho$, Raveling/Weathering Distress Type

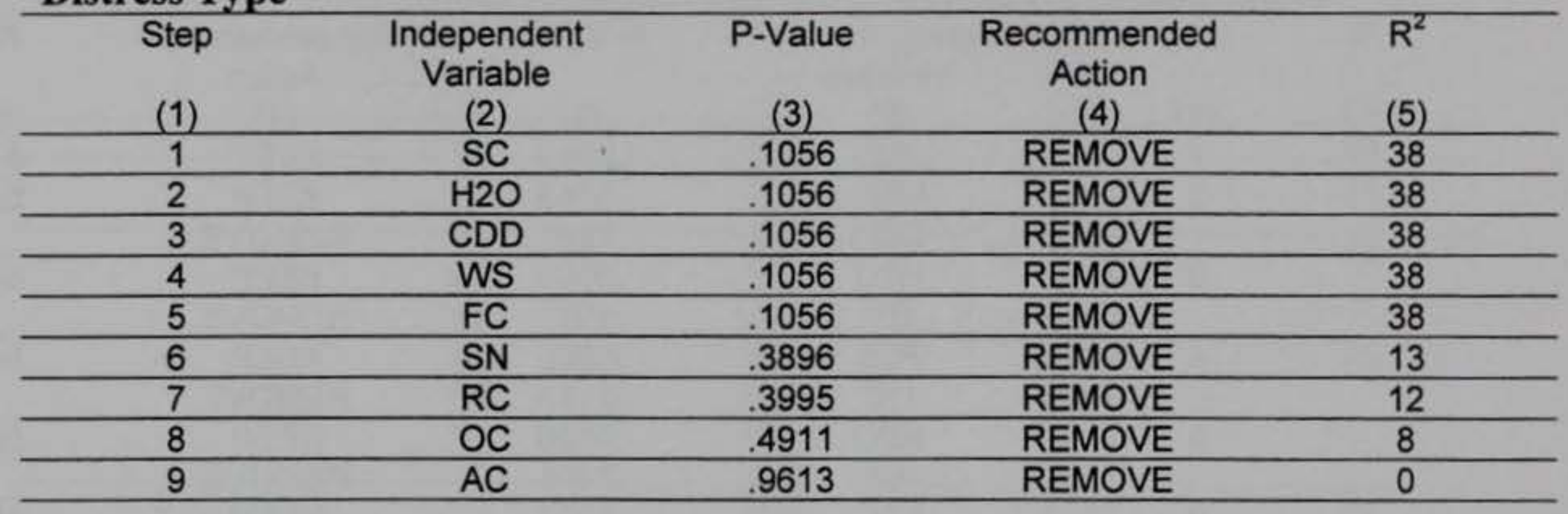

TABLE G-9. Summary of Stepwise Regression for Gumbel $\beta$, Raveling/Weathering Distress Type

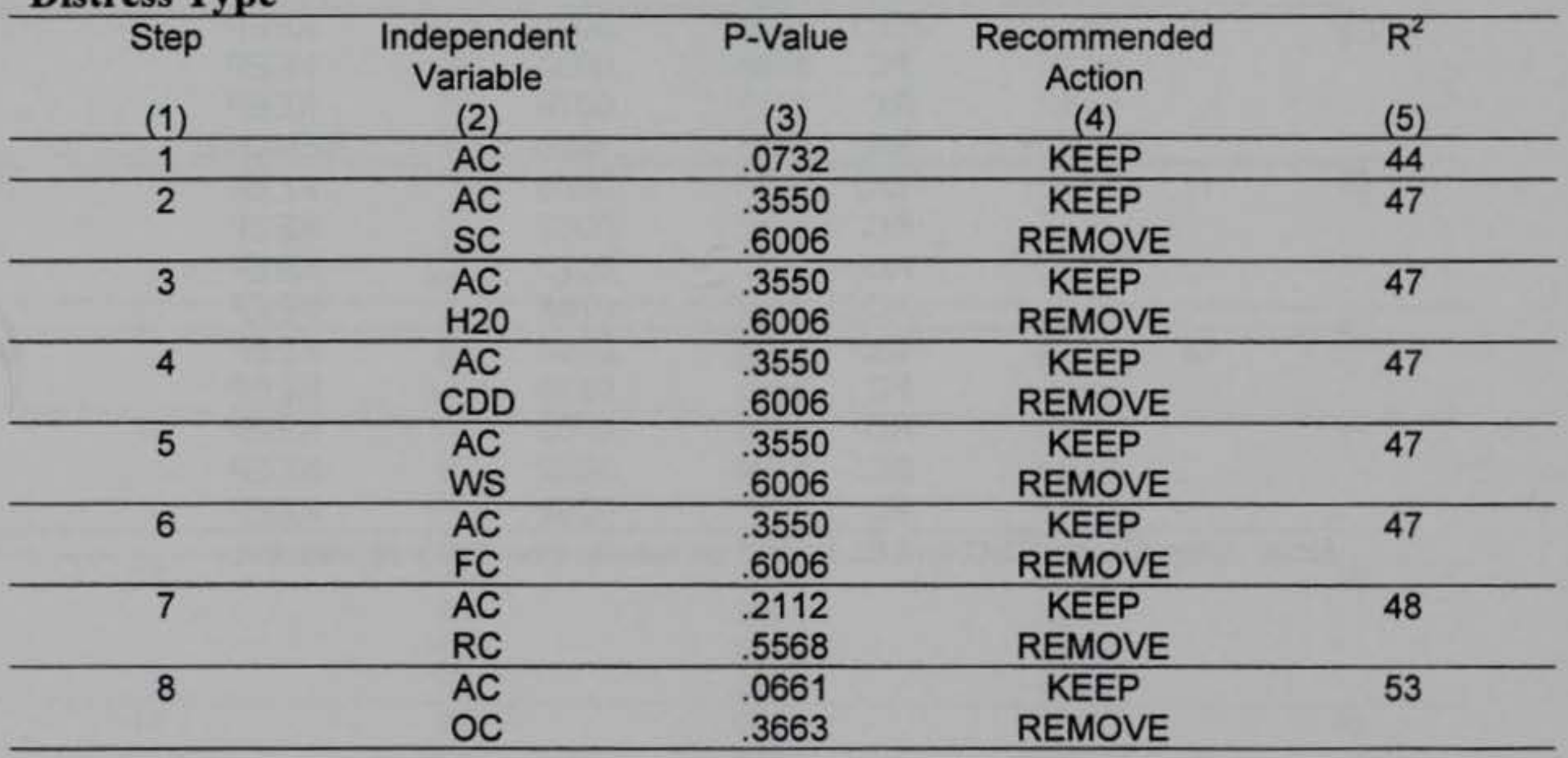




\section{APPENDIX H}

\section{FIELD DATA VERSUS MODEL CURVES}

The figures shown in this appendix display the field data plotted against the model curve for all the data used to create the model. The data is referred to by feature name in the legend of each figure. The associated Army airfield is listed in the title of the respective figure. 


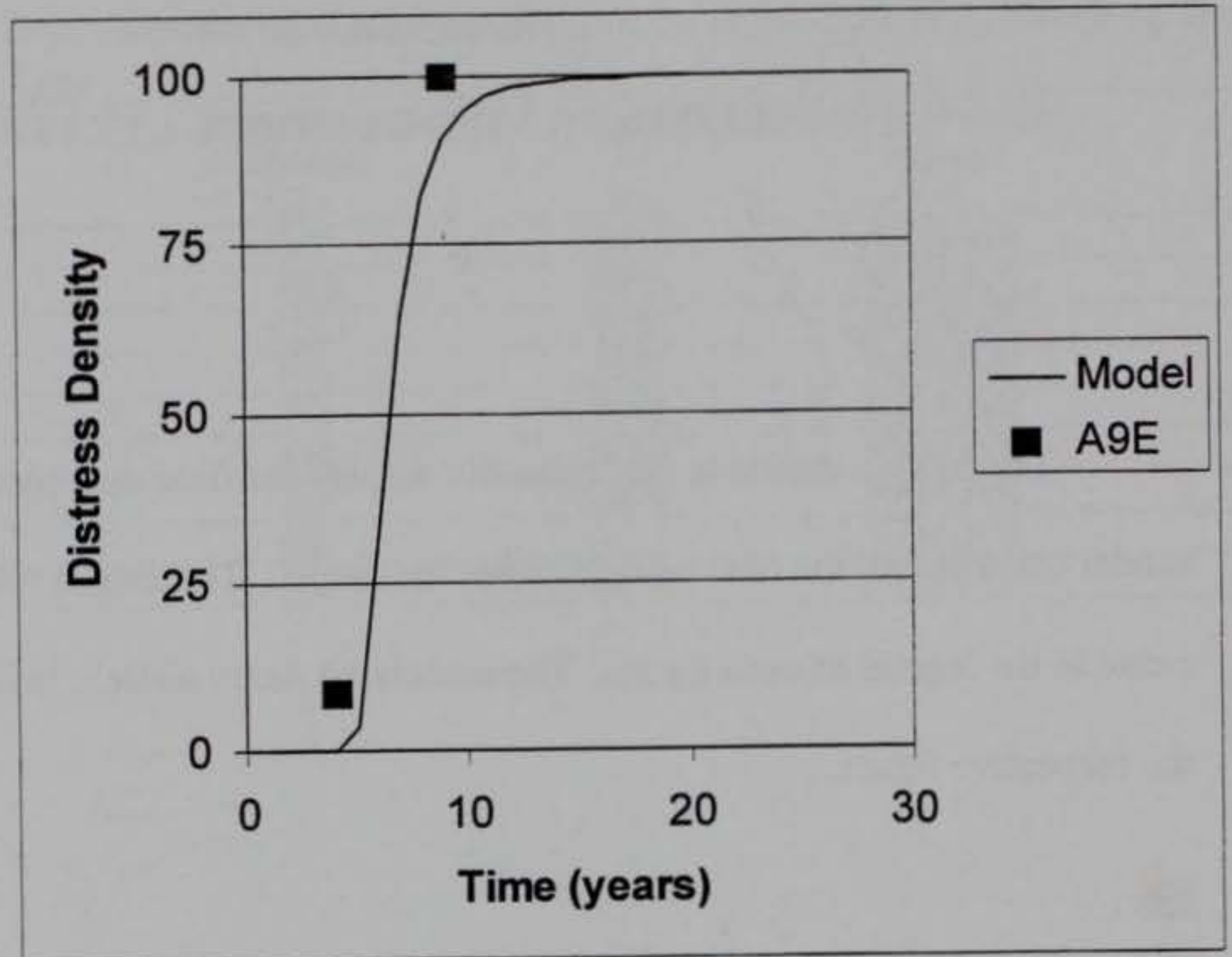

FIG H-1. Block Cracking Model for Biggs AAF

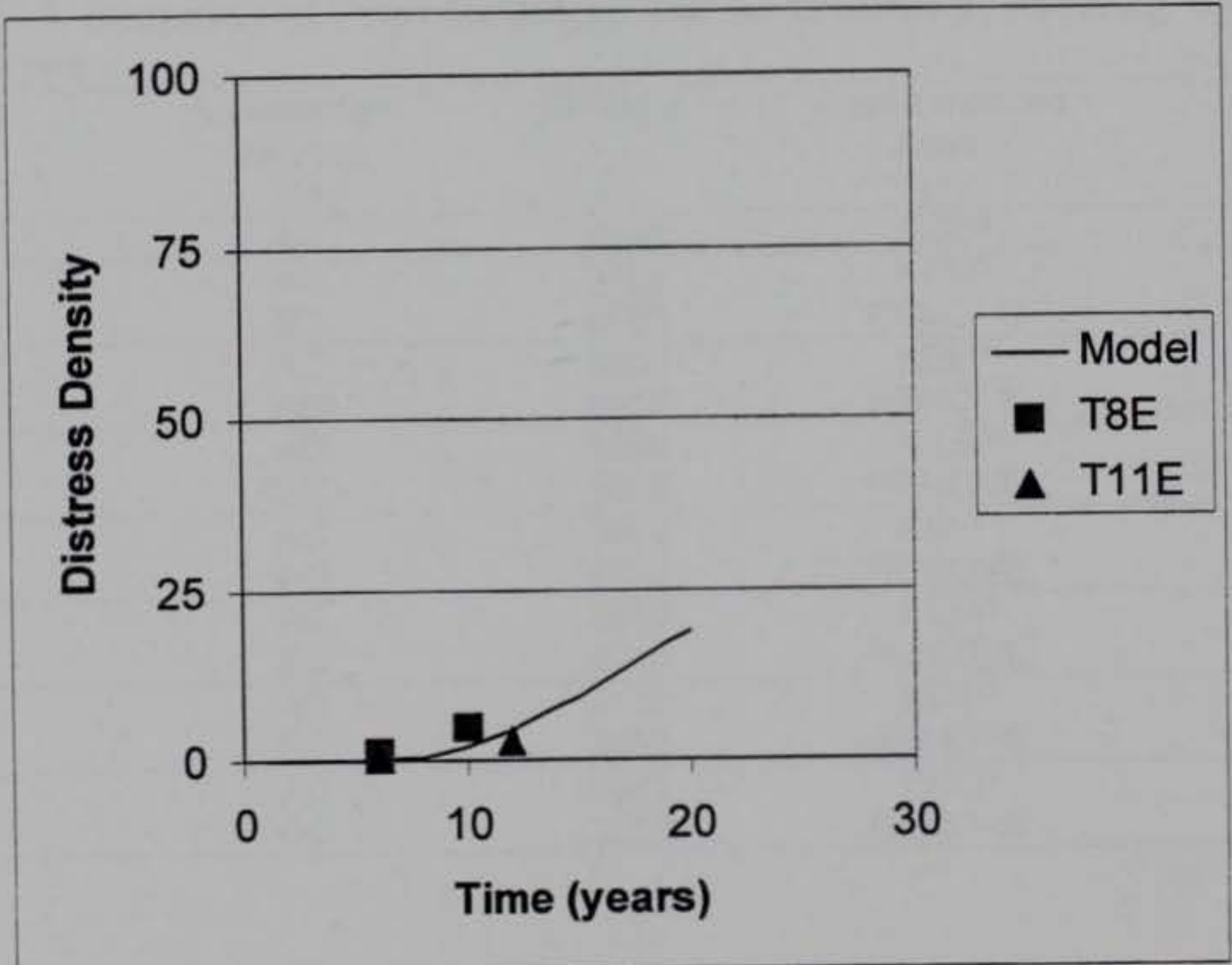

FIG H-2. Block Cracking Model for Cairns AAF 


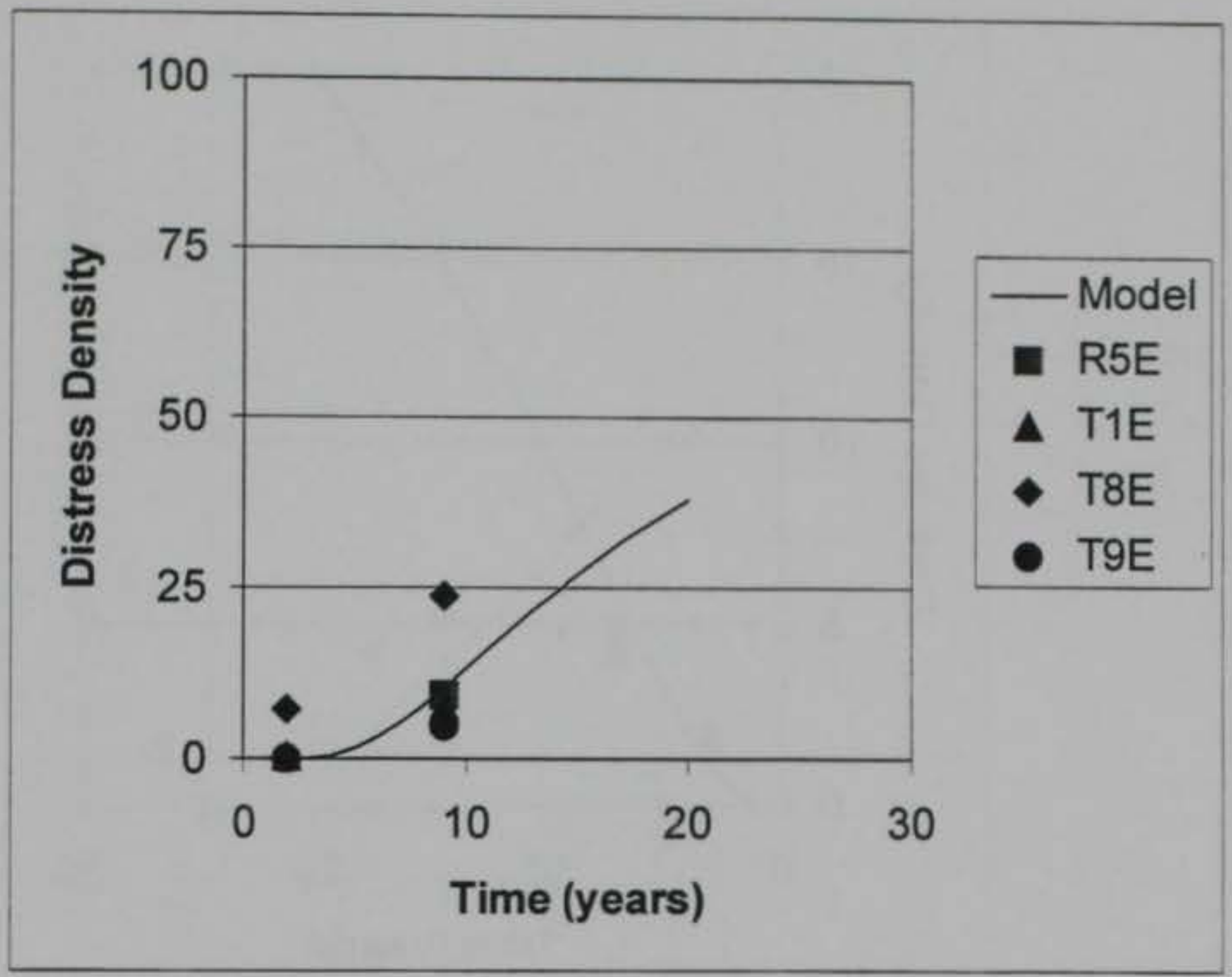

FIG H-3. Block Cracking Model for Hunter AAF

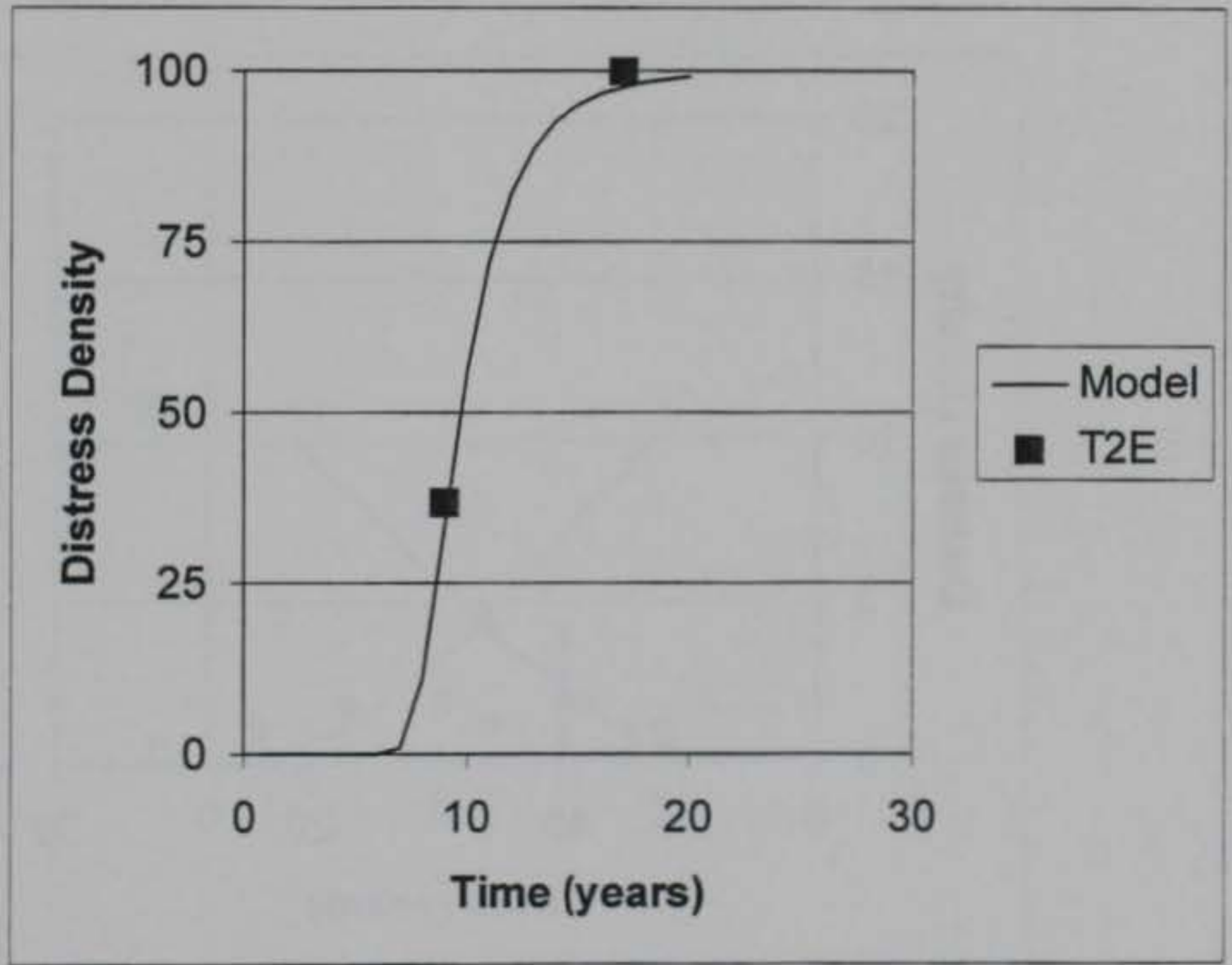

FIG H-4. Block Cracking Model for Wheeler-Sack AAF 


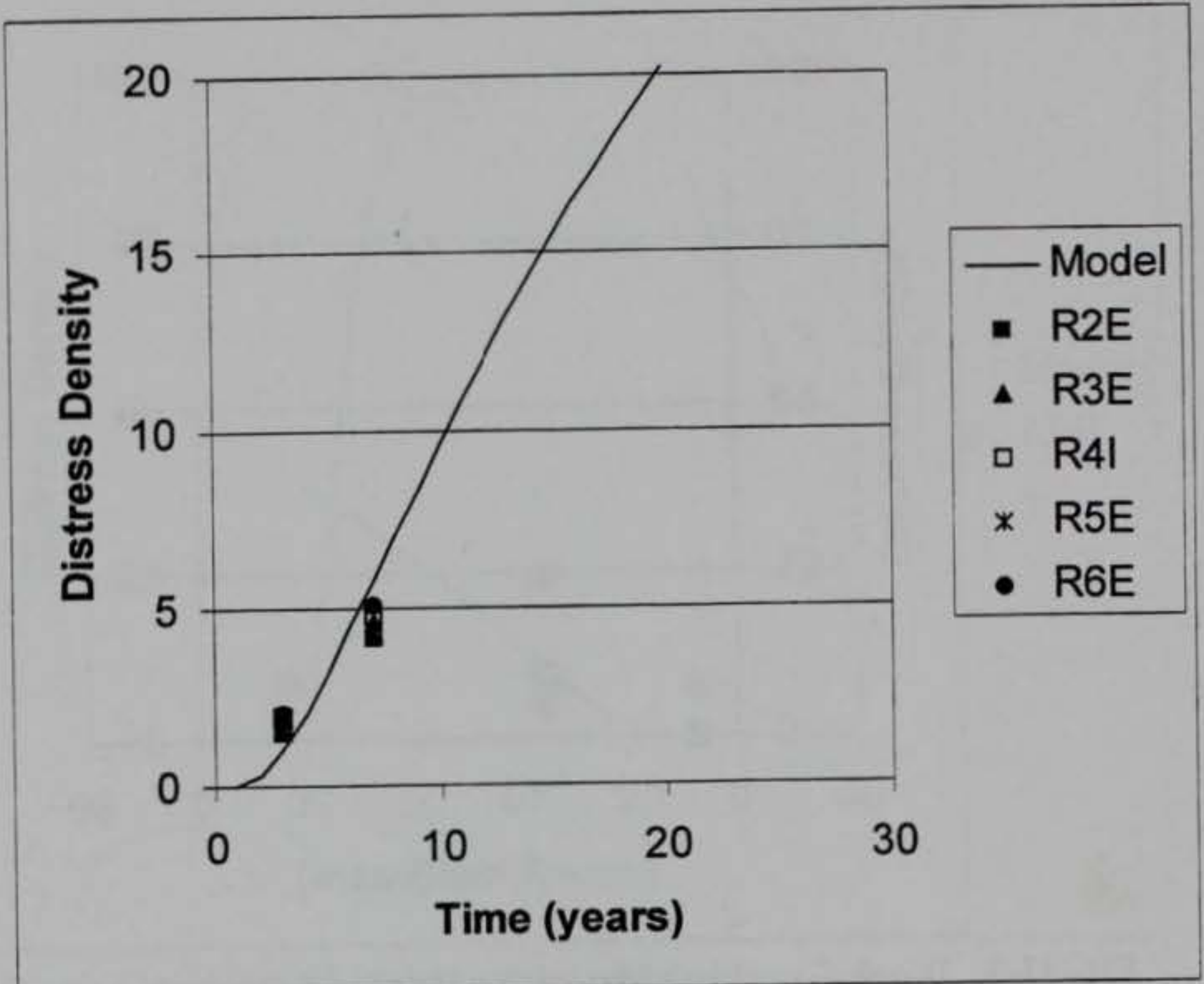

FIG H-5. L/T Cracking Model for Butts AAF

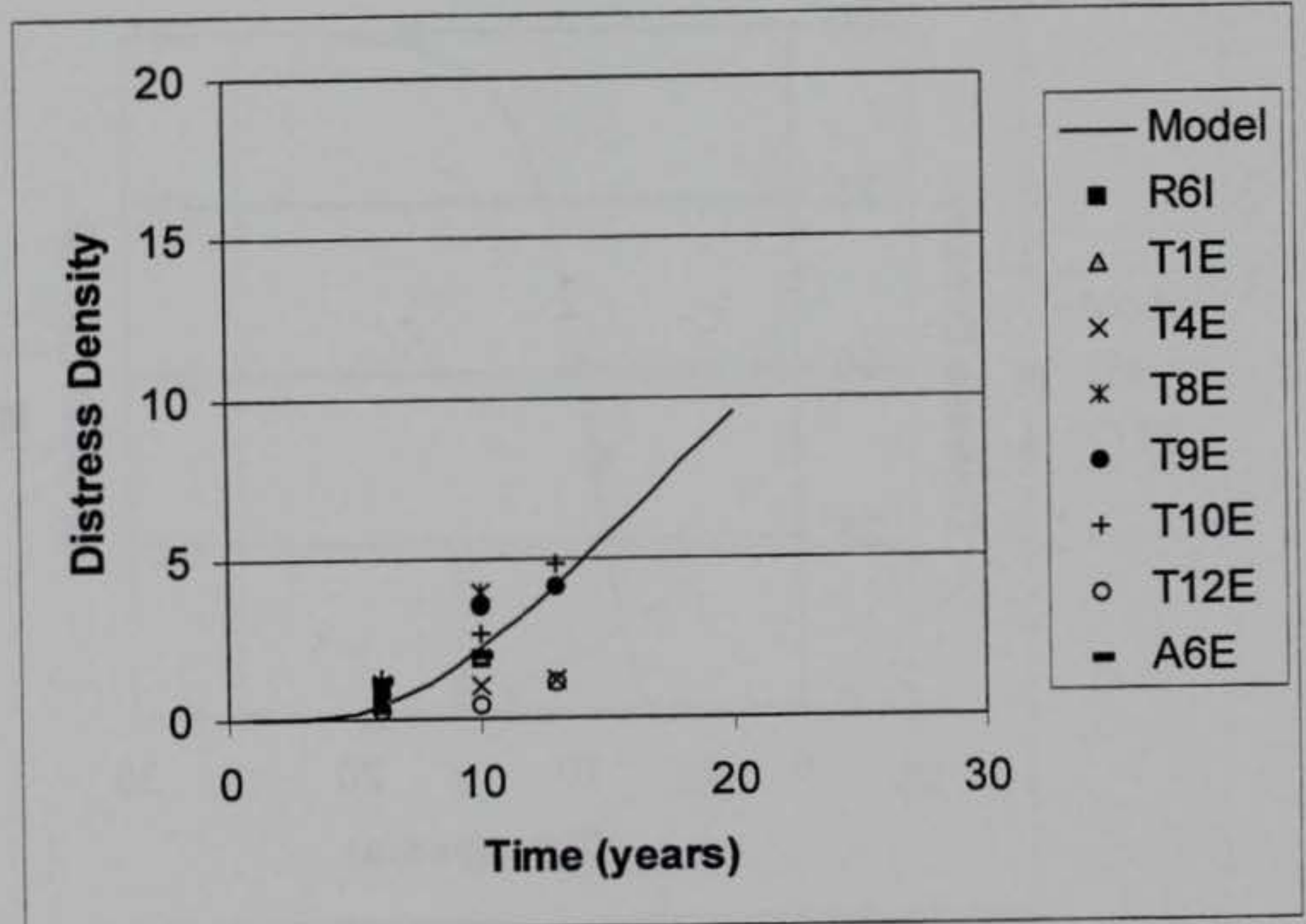

FIG H-6. L/T Cracking Model 1 for Cairns AAF 


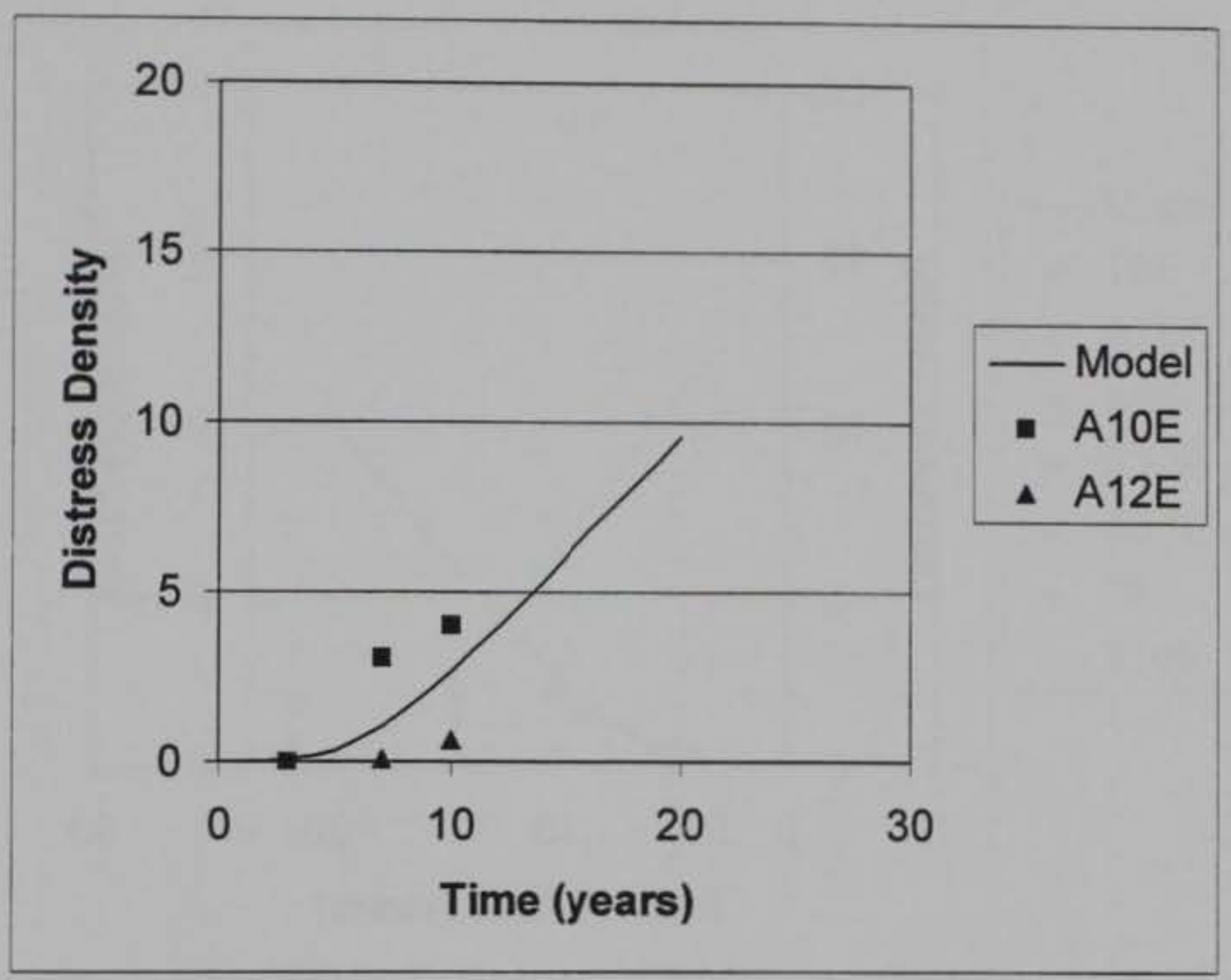

FIG H-7. L/T Cracking Model 2 for Cairns AAF

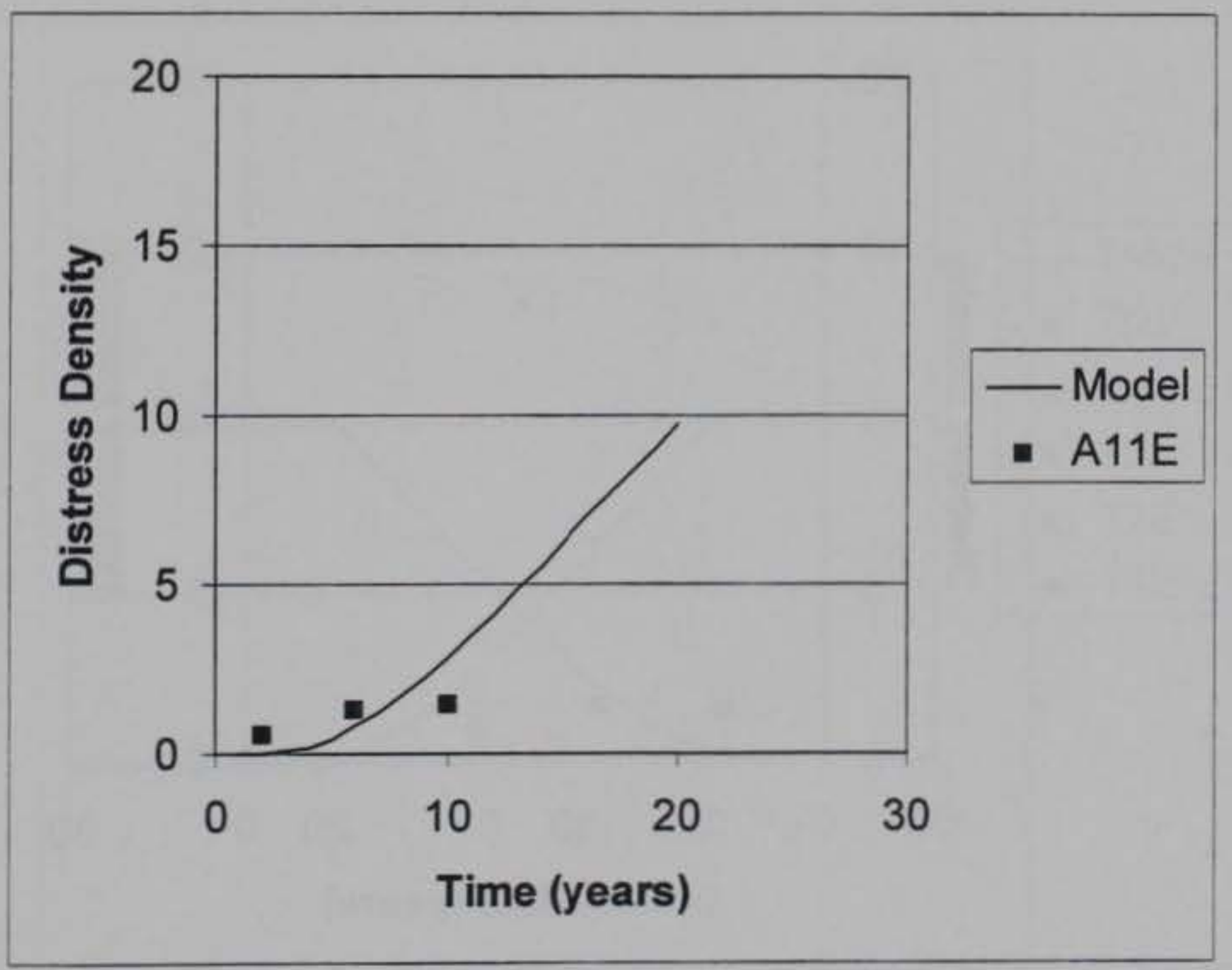

FIG H-8. L/T Cracking Model 3 for Cairns AAF 


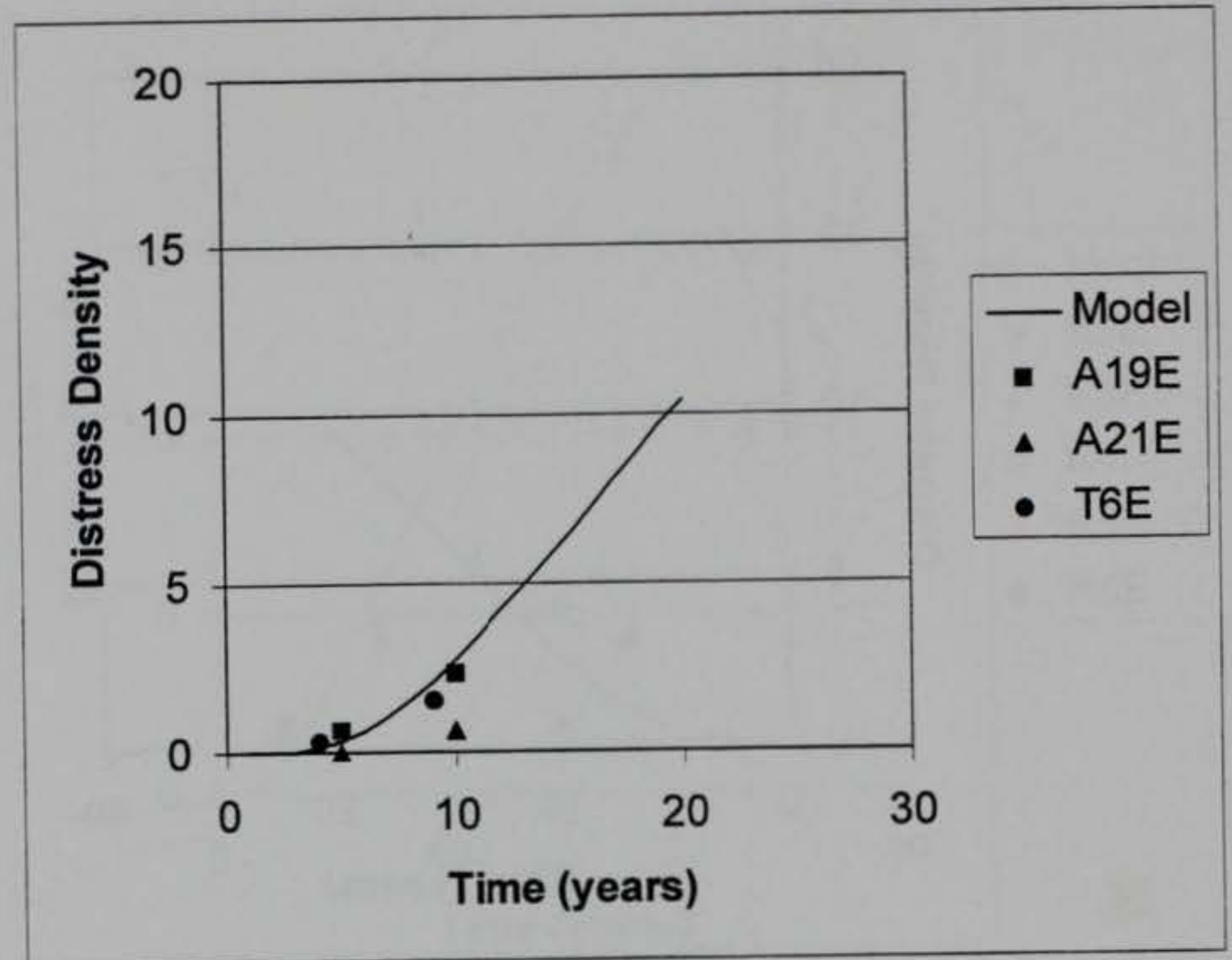

FIG H-9. L/T Cracking Model 1 for Hood AAF

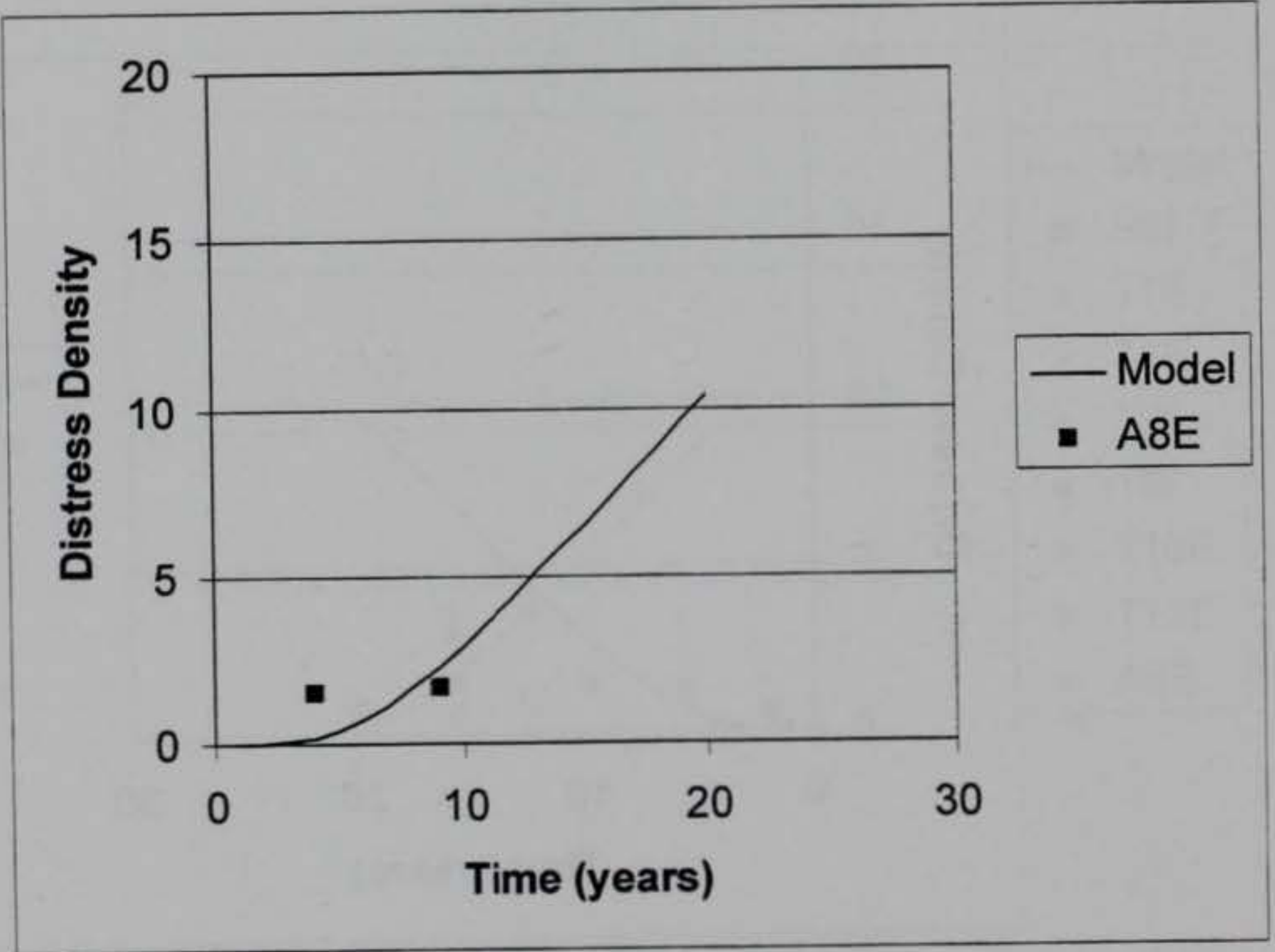

FIG H-10. L/T Cracking Model 2 for Hood AAF 


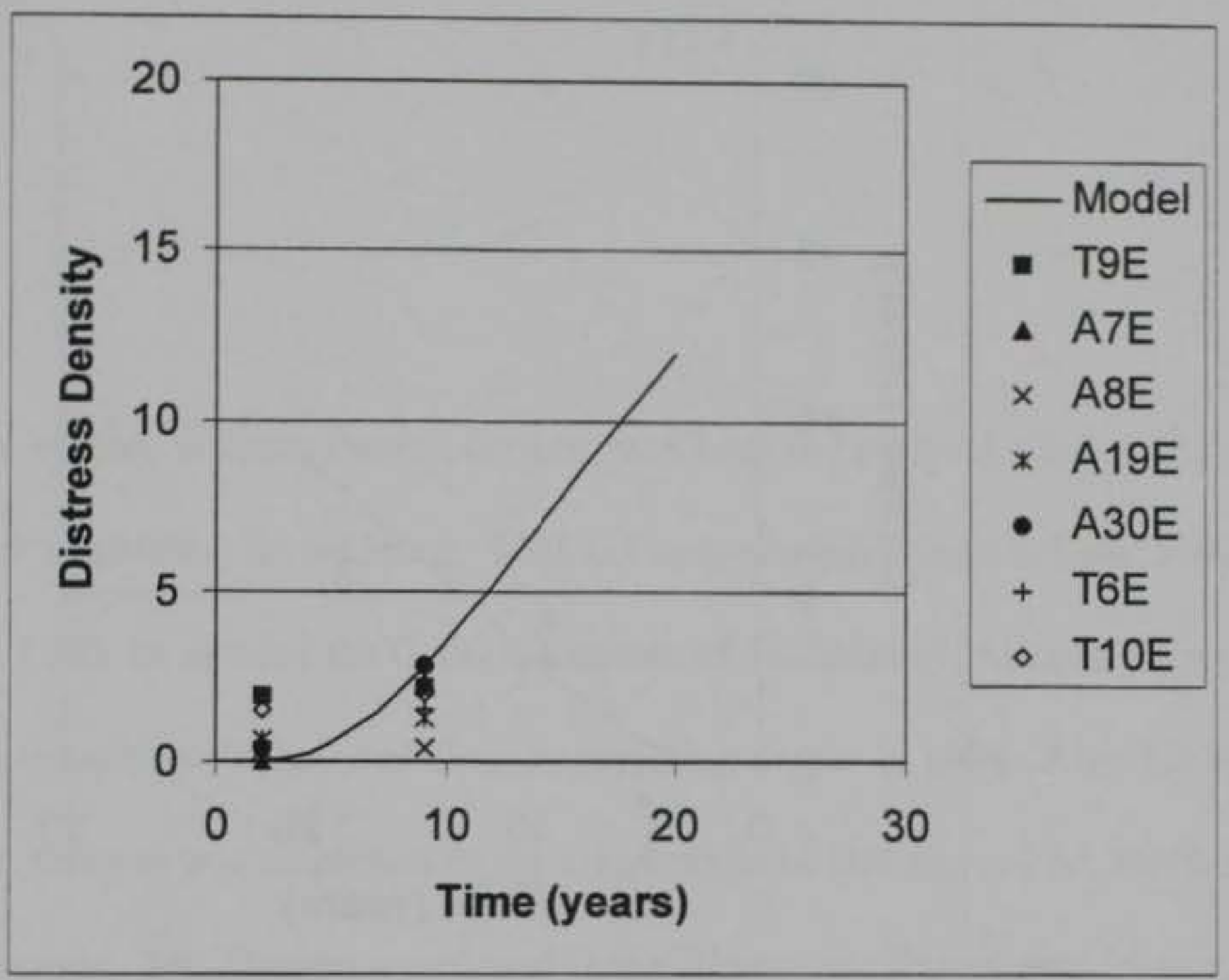

FIG H-11. L/T Cracking Model for Hunter AAF

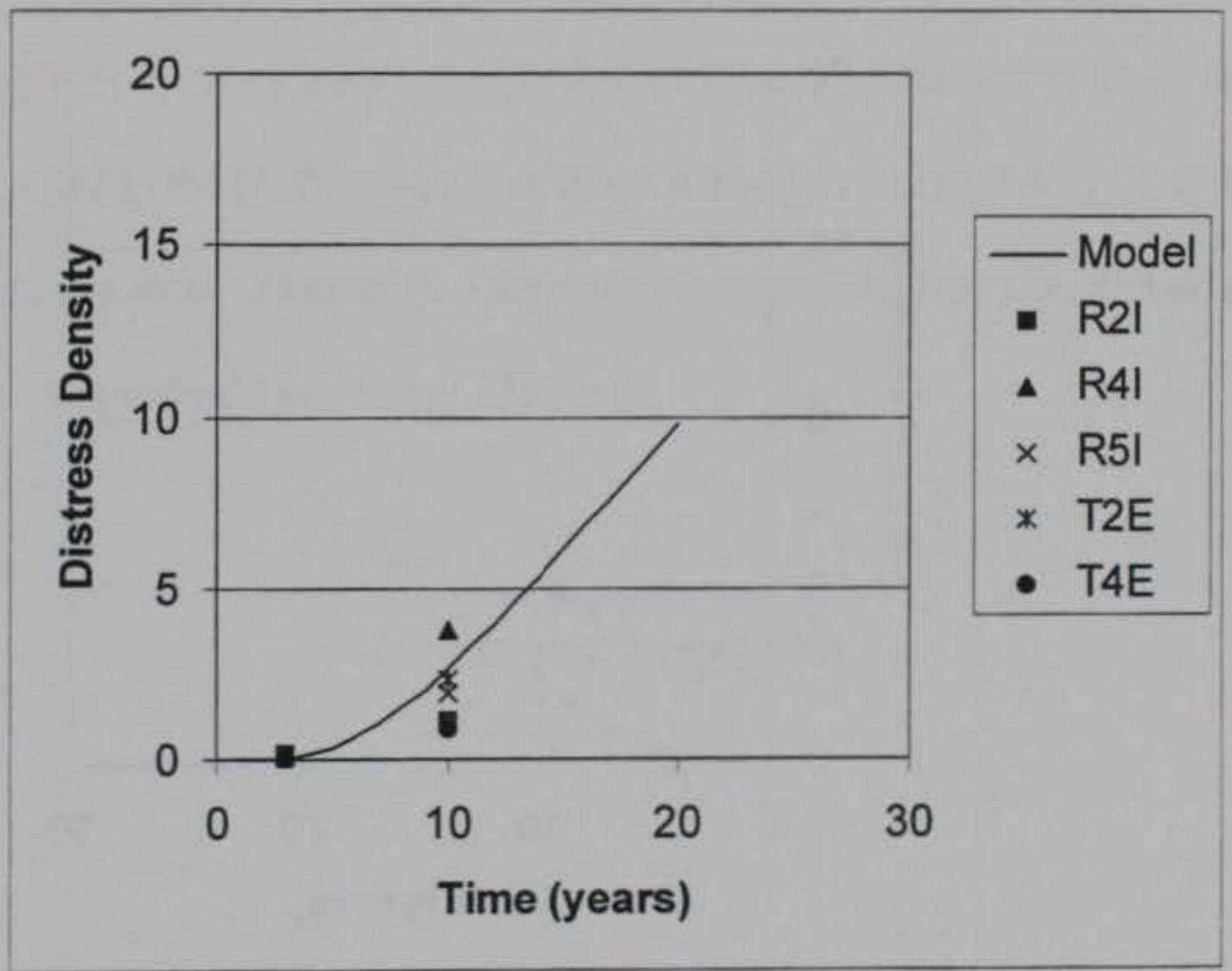

FIG H-12. L/T Cracking Model for Phillips AAF 


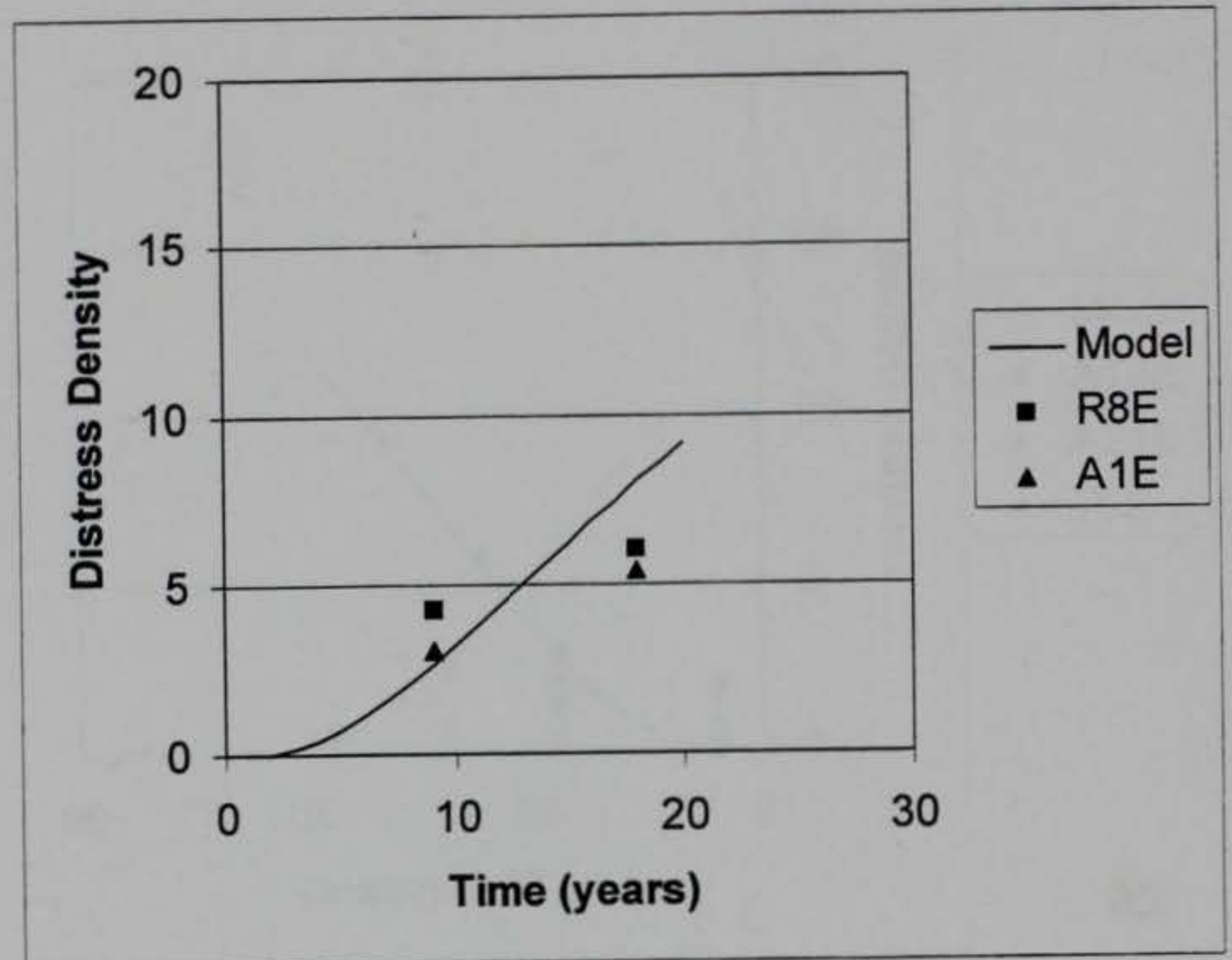

FIG H-13. L/T Cracking Model for Selah AAF

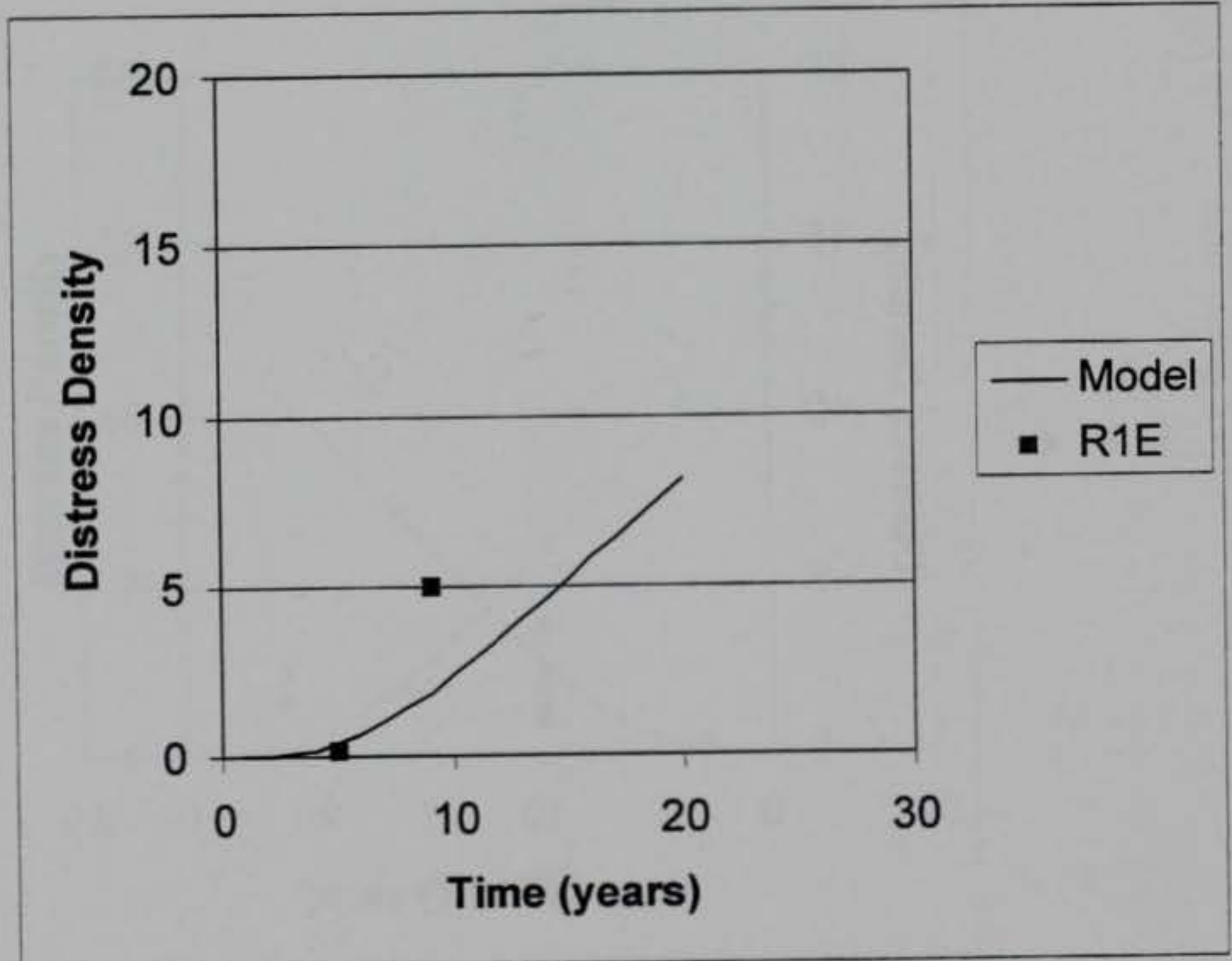

FIG H-14. L/T Cracking Model for Simmons AAF 
VITA

The author, William Patrick Grogan, was born in Loveland, Ohio on July 19, 1962. After graduating from George Walton Comprehensive High School, Marietta Georgia in 1980, he entered the Georgia Institute of Technology, Atlanta, Georgia, and was graduated with a Bachelor of Civil Engineering degree in 1984. After his B.C.E degree, Mr. Grogan was employed by the Department of Defense at Fort McPherson, Atlanta, Georgia. Mr. Grogan transferred to the Waterways Experiment Station, Vicksburg, Mississippi in 1986. In June, 1991 he received his Master of Science degree in Civil Engineering from the Mississippi State University, Mississippi State. Mr. Grogan enrolled in the Ph.D. program at Texas A\&M University in August, 1992. The author's primary areas of interest are pavement management, drainage, design, and evaluation. The author's permanent address is:

100 Concord Drive Clinton, Mississippi 39056

The typist for this dissertation was Mr. William Patrick Grogan 


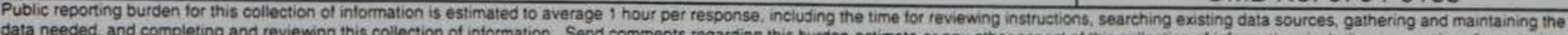

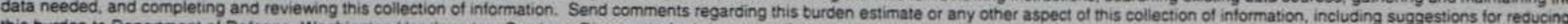

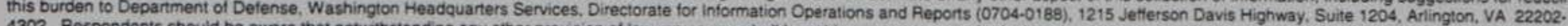

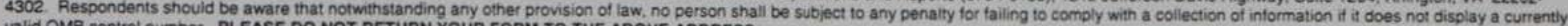
valid OMB control number. PLEASE DO NOT RETURN YOUR FORM TO THE ABOVE ADDRESS.
1. REPORT DATE (DD-MM-YYYY)
August 2000
2. REPORT TYPE
3. DATES COVERED (From - TO)

Final report

4. TITLE AND SUBTITLE

An Environmental Distress Prediction Model for Flexible Army Airfield Pavements

5a. CONTRACT NUMBER

5c. PROGRAM ELEMENT NUMBER

6. AUTHOR(S)

William Patrick Grogan

5d. PROJECT NUMBER

5e. TASK NUMBER

5f. WORK UNIT NUMBER

7. PERFORMING ORGANIZATION NAME(S) AND ADDRESS(ES)

8. PERFORMING ORGANIZATION REPORT NUMBER

U.S. Army Engineer Research and Development Center

Geotechnical Laboratory

ERDC/GL TR-00-6

3909 Halls Ferry Road

Vicksburg, MS 39180-6199

9. SPONSORING / MONITORING AGENCY NAME(S) AND ADDRESS(ES)

U.S. Army Corps of Engineers

Research, Development, Testing, and Evaluation Program

11. SPONSOR/MONITOR'S REPORT NUMBER(S)

\section{DISTRIBUTION / AVAILABILITY STATEMENT}

Approved for public release; distribution is unlimited.

\section{SUPPLEMENTARY NOTES}

\section{ABSTRACT}

The U.S. Army Corps of Engineers supports the U.S. Army through the design, construction, evaluation, and rehabilitation of Army airfield pavements. In terms of evaluation, the Corps of Engineers conducts structural evaluations and performs visual condition surveys to assess the condition of the Army's airfield pavements. Currently, the Corps of Engineers only reports the surveyed condition of the Army airfield pavements, and makes no attempt to predict the future condition of these pavements.

In the research presented herein, a distress density growth model was developed and recommended for use in predicting the performance of Army airfield pavements. This model can be used to help predict when the condition of Army airfield pavements will reach a level that requires the expenditure of funds to improve their condition. The results of this research indicate that environmental distresses are more prevalent than structural distresses on Army airfield pavements.

\section{SUBJECT TERMS}

Environmental distress, Flexible, Pavements, Performance model, PCI

\begin{tabular}{l|l|l|}
\hline 16. SECURITY CLASSIFICATION OF: \\
\hline a. REPORT & b. ABSTRACT & c. THIS PAGE \\
UNCLASSIFIED & UNCLASSIFIED & UNCLASSIFIED \\
\hline
\end{tabular}

17. LIMITATION OF ABSTRACT
18. NUMBER OF PAGES 19a. NAME OF RESPONSIBLE PERSON

19b. TELEPHONE NUMBER (include ares code) 